


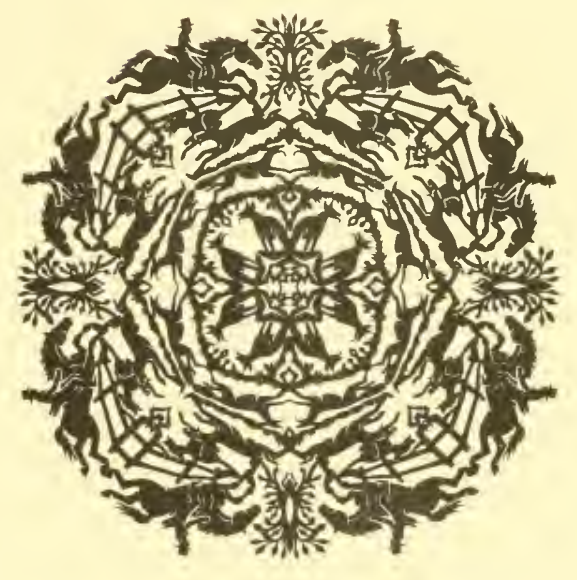

JOHN A. SEAVERNS 
Webster Family Library of Veterinary Medic Cummings sonool of Veterinary Medicine a

Turts University

200 Westboro Road 




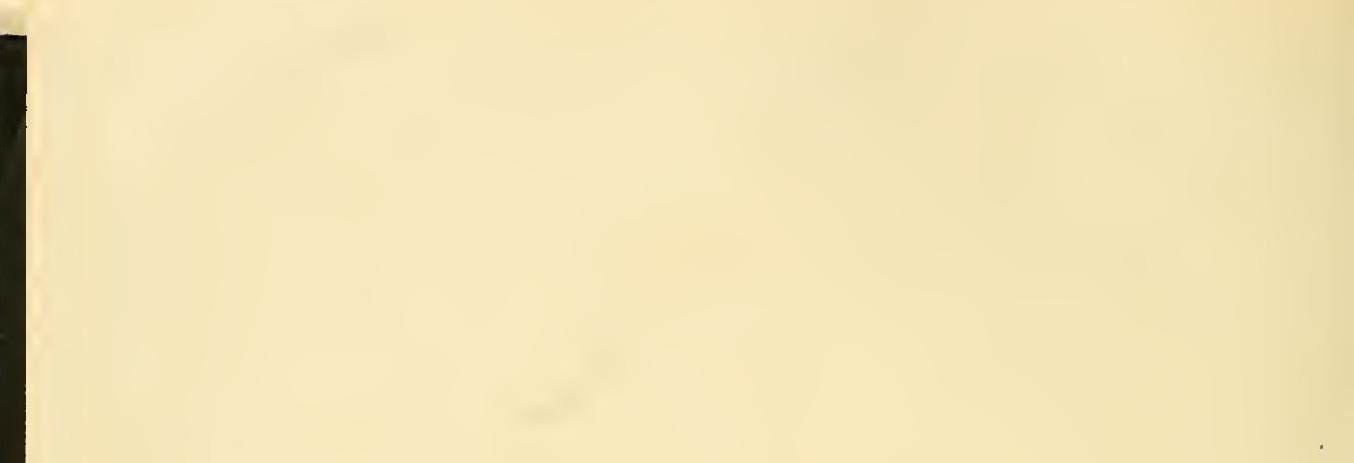


WAR DEPARTMENT, - - - ADJUTANT GENERAL'S OFFICE.

(MILITARY INFORMATION DIVISION.)

\section{No. TXXY}

Major General HenRy C. CORBIN, ADJTANT GENERAL, U. S. ARMY.

Lieut. Cólonel W. A. Simpson, A. A. G., * IN CHARgE OE DIVISION.

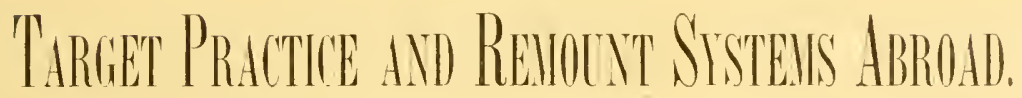

ARRAYGED BY

Captain E. A. EDWARDS, 25Th INFantry,

AND

Captaix J. S. HERRON, 2D Cavalry.

APRIL, 1902.

WASHINGTON :

GOVERNMENT PRINTING OFFICE.

1902. 
WAR DEPARTMENT,

ADJitant General's Office.

Focument No, 159.

II. I. I. 


\section{TABLE OF CONTENTS.}

TARGET PRACTICE.

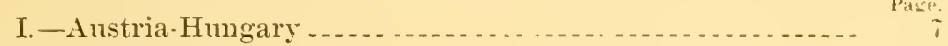

II. - Denmark ...

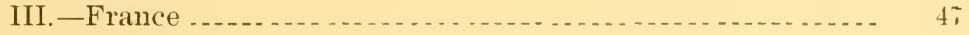

IV.-Germany _............

V.-Great Britain _...

TI.-Russia _... . . .

YII.-Sweden _... $\ldots \ldots \ldots \ldots \ldots \ldots$

VIII._Switzerland _._._.

Japan (see Appendix A) .......................... 343

REMOUNT SYSTEMS.

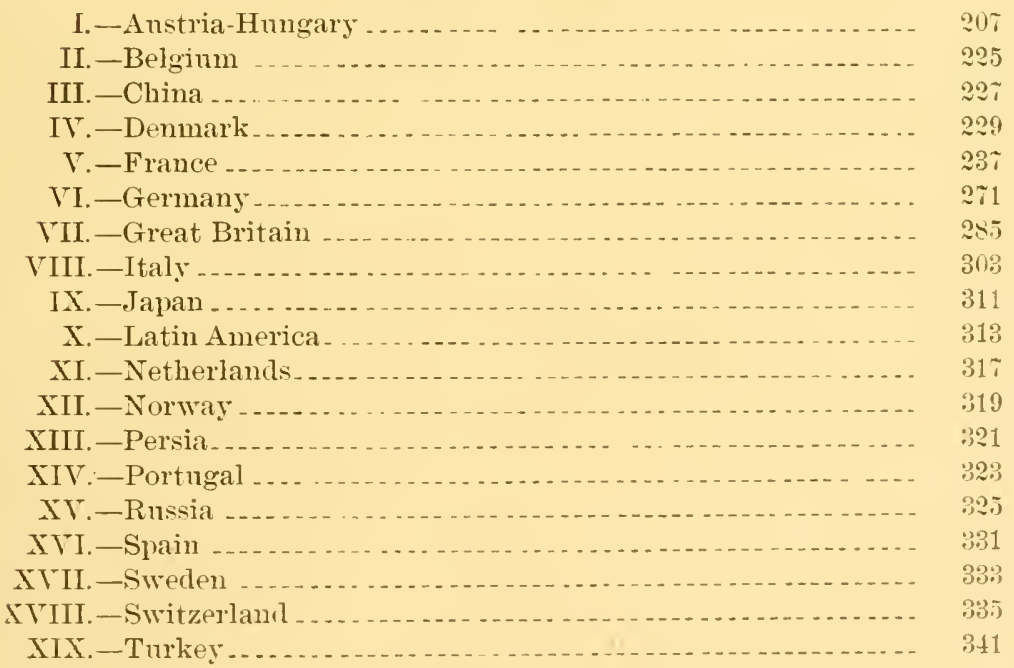

(3) 

TARGET PRACTICE IN FOREIGA COUNTRIES.

(i) 



\section{TARGET PRACTICE IN FOREIGI COUTTRIES.}

Recent events have shown how necessary good marksmanship is to snceess in war. A view of the methods and course of training adopted in several European countries to give their troops the required skill is shown in the following pages.

Working for the same ends, with almost identical tools, of necessity involves much of sameness in methods, but diversities are nevertheless numerous, and valuable hints for adoption into our own service might be gathered from a study of foreign systems.

\section{I.-AUSTRIA-HUNGARY.}

[From translations of official firing regulations furnished by Lieut. Col. Jaures B. Ferr, Ninth cavalry, Cuited states Military Attaché at Berlin, compared and arranged by Capt. E. A. Edwards. Twenty-fifth Iufantry.]

\section{INFANTRY AND RIFLE REGIMENTS.}

GENERAL RULES.

The thorough individual training of every soldier in the fighting use of his rifle is the object of the prescribed conrse of instruction, which is divided into preparatory instruction. firing at known distances, demonstration firing, collective firing at long ranges, and field or combat firing.

The captain is held responsible for the instruction of his men and for the training of his officers. Underofficers and skilled men are assistants in carrying on the instruction of his company. Higher commanders are to foster the fire training and supervise the course of instruction in the units of their command.

The preparatory instruction consists in teaching the recruit the construction, nomenclature, and mechanism of the rifle, the theory of fire, principles of aiming, etc. This is accompanied, or followed, by position, pointing and aiming drills, 
gallery practice, and drill in estimating distances. The instruction is progressive throughout, and each subject or exercise is to be understood before passing to the next.

Men are expected to estimate distances up to 600 paces with reasonable correctness; officers, noncommissioned officer's, ancl skilled privates, distances up to the limit of vision. Men who show special aptitude in estimating distances are trained in the use of the range fincler and in observing the ground with field glasses. The details of the course are very similar to our own, units of length being fixed in the mind by pacing and by frequent exercise and observation in all conditions of light and ground, adrantage being taken of opportunities to note known distances on drill or parade grounds, etc.

FIRING AT KNOWN DISTANCES.

The object of this practice is to enable the soldier to attain as high a degree of skill as possible in the use of the rifle, and to prepare him for field practice.

It is divided into preliminary and regular firing, the preliminary firing being intended to familiarize the man with the principles of firing and the peculiarities of his rifle. The school target is used for this practice. The men are divided into three classes, the first-the lowest-of men in their first year of service, or of longer service who have not fulfilled the conditions of their class; the second class consists of the men who, in the regular practice and authorized repetitions, have made at least 40 per cent of hits; the third class (marksmen) are those who, in the regular practice in the second class, have made 50 per cent of hits.

Soldiers are not to engage in target practice until they have the necessary preparatory instruction. Those who are not armed with rifles should, in their first year, go through the course of the lowest class, and in their second and third years should fire at least 16 shots (four of the excrcises).

Men of more than one year's service begin target practice in Octoler, and continue during the winter in farorable weather. For recruits such weather should always be selected, and their shooting should not be preceded by fatiguing drill or marching, or be conducted at the same time as that of the older soldiers. In very cold or hot weather no practice should be held, and in warm or cool conditions of weather it should not be prolonged beyond two hours. 
As a rule the range practice should be finished by the end of June, and he followed by the long-range and field firing, but if required by local conditions the long-range fire may take place before the spring plowing. In that case young soldiers should have had previous training in gallery practice in firing with raised sights, and have gone throngh their preliminary range firing.

The practice at known distances, instruction practice, and the competitive firings, are held in ordinary field uniform, without knapsack; the individnal field practice, withont the field utensils; and the long-range and field firing, in full marching order.

Men who fail to qualify in one year repeat the same program in the following year. Men in the lowest (first) class who qualify, may, nevertheless, in the discretion of the company commander, be kept in that class, if unsteady or unreliable shots, and such men may be ordered to repeat any exercise in their preliminary shooting if the company commander think it desirable, and if it be not done with ammunition reserved for the regular practice.

During the target year every soldier is required to expend the number of cartridges prescribed; failure to do this on account of detached service, sickness, etc., is noterl on his individual shooting record. At least one exercise should be fired on a practice day, a second only in case that qualification in the first was made in 6 shots. Men who qualify in their class with less than their allowance of ammunition will use the saving at the discretion of the company commander, first repeating exercises in the regnlar practice in which the conditions were not fulfilled.

Men who on account of defective vision are unable to fire at all distances, remain in the lowest class.

TARGETS

The school targets have wooden frames covered with jute cloth, on which the paper targets are pasted; the figure targets and its varieties are of pasteboard, or of papier-maché.

The school target is of the pattern and dimensions shown in the illustration. The center band is white. The two outer vertical bands are light blue or gray. The oval ontlined thereon represents the limit of dispersion of correctly aimed 
shots, aiming, at 200 and 300 paces, at the lower part, and at 400 paces, at the upper part.

The figure target and its variants are shown in fig. 2. The figures are of plain light blue, or colored to show details.

Section targets are made up of figures or variants of the figure target in light blue placed close together. Figure and section targets are used as fixed, moving, and disappearing targets. Their height when used as fixed targets at medium

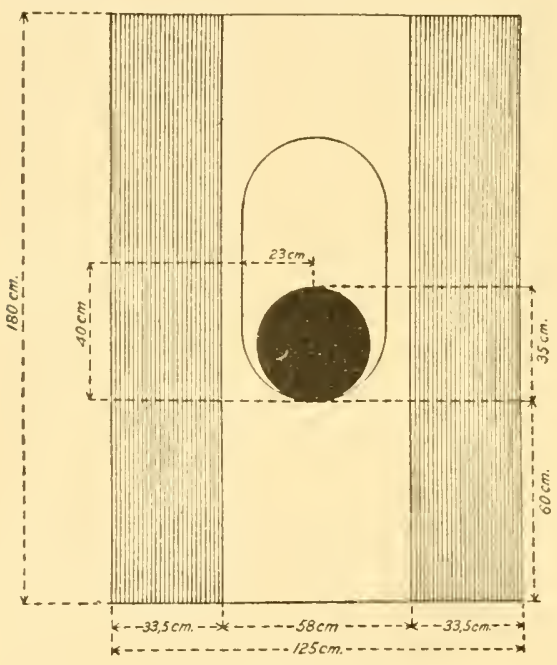

Fig. 1.-School target.

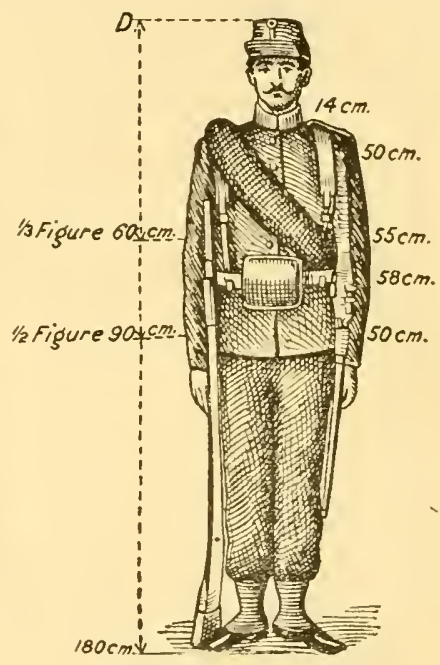

Fig. 2.-Figure target.

ranges is 0.9 meter's, when used as disappearing or moving targets the height is 1.2 meters, the width being in proportion.

In the practice at known distances, when moving targets are used, they are made to move in quick time for a distance of 10 paces; disappearing targets are visible for the period required to march 10 paces in quick time, i. e., 115 paces to the minute.

For firing at long ranges larger groups are used, representing lines and columns in battle formation, and for field firing, targets representing lines and columns of infantry; cavalry, guns, caissons, etc., ar'ranged as in action, are made to move or disappear so as to show different phases of the fight. To ascertain the effect of fire at long ranges on targets representing columns, only one hit by each bullet is counted. This is effected by placing horizontal lines at certain distances from the top edges of the targets, in rear of the first line, counting, on the rear targets, only the hits above the lines. The 
position of the horizontal lines is calculated from the trajectories, allowance being made for the slope of the ground on which the targets are located. For the long-range and field firing the figure and section targets are 1.8 meters high and of corresponding width.

Some targets for infantry field practice recently adopted are described as of coarse-cloth bands 5 meters long and 60

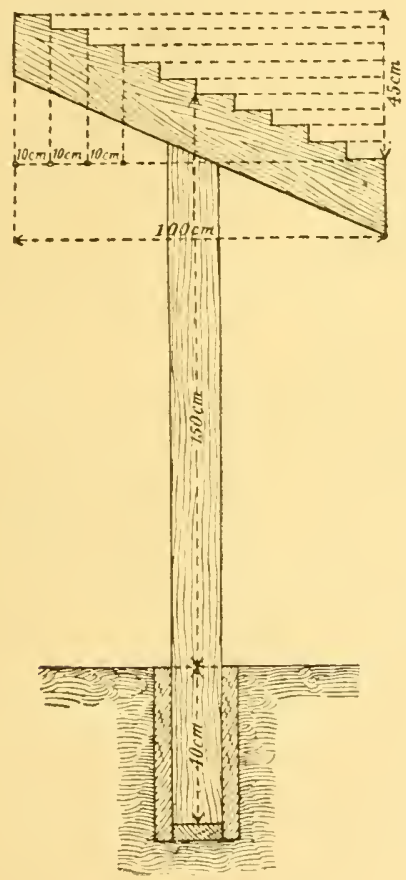

Fig. 3. centimeters high on which are sketched figures of men lying down. From three to fire figures are on each band, to show more or less dense lines. The bands have pickets at the ends, which are driven in the ground, leather borders strengthen the edges of the cloth, and props are used to support them in case of wind. Two or three targets represent a section of sharpshooters.

For transportation they are rolled up, and can be readily carried by a man. They are easily and cheaply made in the company, and by combining all the targets of the battalions, a regiment may represent in position any hostile force likely to be encountered in war, train the men in scouting, in judging distances, developing hostile positions, etc.

A gun rest for fire standing is shown in fig. 3 ; for tirelying down, sand bags are used.

The course of range firing is as follows:

FIRST CLASS.

Preliminary moctice.

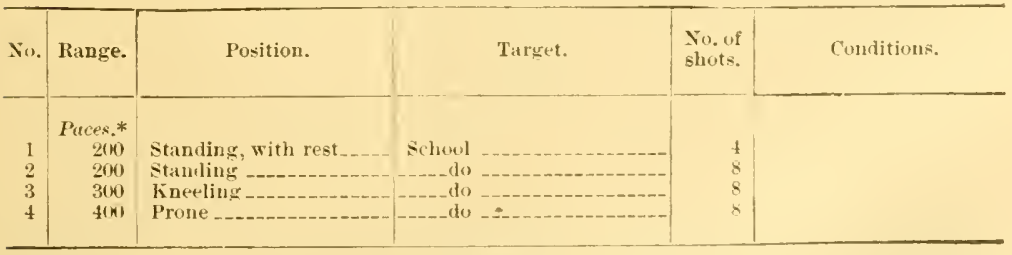

*. A pace is 7 is centinueters $=24.5$ inches. 
Regular practice.

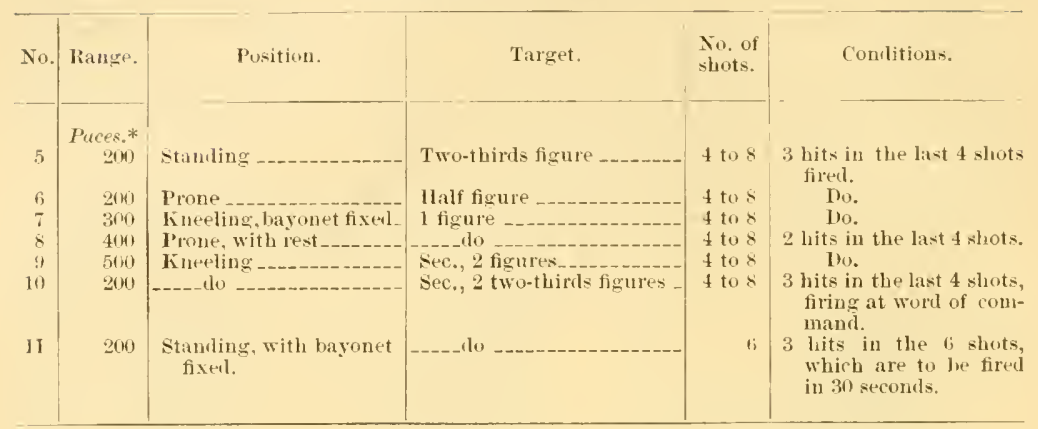

SECOND CLASS.

Preliminary practice.

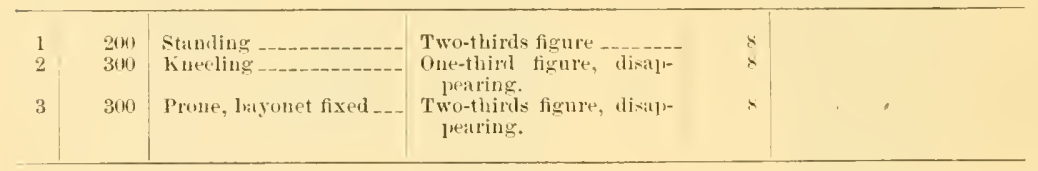

Regular practice.

\begin{tabular}{|c|c|c|c|c|c|}
\hline 4 & 300 & Kineeling -_- & Two-thirls figure & 4 to 8 & 3 hits in the last 4 shots. \\
\hline 5 & 200 & Prosit - & $\begin{array}{l}\text { One-third figure, disil 1- } \\
\text { pearing. }\end{array}$ & 4 to 8 & Tho. \\
\hline 6 & 300 & Pront, bayouet fixed --- & $\begin{array}{l}\text { Two-thirds figure, disay } \\
\text { peariug. }\end{array}$ & 4 to $x$ & Do. \\
\hline 7 & 4010 & Prone, with rest & 10 do & 4108 & Do. \\
\hline$\therefore$ & $5(1)$ & Prone & See., 2 two-thimls figures - & 4 tos & 1wo. \\
\hline 9 & (6) & lineeling _.......-.--- & Sec., 2 figures & 4 to $x$ & Wh. \\
\hline
\end{tabular}

THIRD CLAST.

Preliminury practice.

\begin{tabular}{|c|c|c|c|c|}
\hline 1 & 3011 & Kupeling - & Scliool _................ & $s$ \\
\hline 2 & $4(11)$ & P'rone _- & 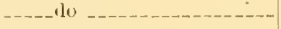 & 8 \\
\hline
\end{tabular}

Regular practice.

\begin{tabular}{|c|c|c|c|c|c|}
\hline 3 & 300 & Kuefling ...... & 1lalf figure ..... & 4 toli & 3 luits in the last 4 shots." \\
\hline 4 & 400 & Stamliug - & 'Two-thirds figute & 4 toti & Du. \\
\hline 5 & $201)$ & P'rone ....... & $\begin{array}{l}\text { Oue-fiftl figure, disal- } \\
\text { jetring. }\end{array}$ & $4 t 08$ & Ino. \\
\hline 6 & 300 & 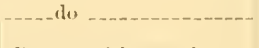 & $\begin{array}{l}\text { Oue-tlired figure, diselp- } \\
\text { pwating. }\end{array}$ & $4 \mathrm{tas}$ & Do. \\
\hline 7 & 400 & $\begin{array}{l}\text { Prone, witls mot, bayo- } \\
\text { net fixerl. }\end{array}$ & llatf figure, disalpuestringr - & $4+108$ & Do. \\
\hline s & 560 & Proule & $\begin{array}{l}\text { Noc., } 2 \text { two-thirds figures, } \\
\text { disit] }\end{array}$ & $4 t+8$ & Wo. \\
\hline 9 & 300 & lineling - new & Two-thirds figure, meving- & $4 t 10 \mathrm{~s}$ & To. \\
\hline
\end{tabular}

* A pace is 13 centincters -29.5 inclues.

Transfers to the second class are made at the end of the target year by company commanders. Transfers to the third 
class (marksmen) are made in each case by the battalion commander on the recommendation of the company commander, as soon as the soldier has made the required scores. Marksmen receive badges of distinction, and may be excused from certain duties, such as room orderly, etc. For men called out for eight weeks' training, for furloughed men, and reservists, special courses of instruction are prescribed. The marksman's badge is a line of red worsted, with red-worsted ball tassels, worn on the left sleeve of the tunic.

RANGES, HARKING, SCORING, ETC.

Ranges are established at convenient points and are arranged according to prescribed directions in official manuals for the different kinds of shooting-known-distance, long-range, and field firing. The range practice is managed by the company commander.

The service of marking is done by trained men under the direction of an officer, who before the practice inspects all the arrangements, and sees that everything is in order; he regulates the details of the service.

Hits in the oval on the school target are signaled by placing a red disk over the shot hole; in the center band ontside the oval by a black disk; in the side bands of the school target and in figure targets by a white disk. Ricochets on the school targets are signaled by waving the white disk; on figure targets that are raised and lowered from covers, by exposing the uncolored back of the target.

Intentional false marking is severely punished.

Communication between the targets and firing points is maintained by a system of electro-magnetic bell signals for showing when fire is to begin or cease, calling for repeated marking of shots, etc. The table of signals is posted nu at firing points and targets. Where the system is not installed trumpet signals may be used. When a hit is made on a fixed target, a danger Hag (red) is immediately displayed at the butt and the markers leave the cover, find, paste up, and signal the hit, and return to the cover, withdrawing the danger flag. When the firing is to be interrupted the danger flag is displayed, but men must not leave the cover" nntil the signal "rest" is heard from the firing stand. With targets that may be withdrawn behind cover, the red disk is shown when fire is to be interrupted; for marking, the target is 
withdrawn, hole pasted up, and the location of the hit signaled when the target is again exposed.

The service of marking the target at long-range, and in field firing, is always under the supervision of an officer, who receives the necessary instructions from the leader of the practice. The number of hits is signaled by swinging a flag to the right for tens, to the left for units. The flags are also used to show whether the shots are too high or low, or going to the right or left.

\section{AT THE FIRING STANDS.}

To each target five or six men are assigned for practice under an instructor, who sees that each man fires in the proper position of body, rifle, etc. A noncommissioned officer or soldier acts as scorer. Men are called in succession to the firing point and deliver their fire. Before each shot the man announces the target he is to fire at, the distance and point of aim, and after firing states, or indicates on a small target, where the gun was held when the shot was fired. This point is insisted on, carelessness in this regard not being permitted; if the soldier does not know where the gun was held at the moment of firing, he must so state.

When the shot has been signaled the soldier calls out the result and it is recorded by the scorer, who notes the hit as correct or incorrect with regard to the point of aim. When the soldier has gained skill in shooting he may fire an entire score of the regular practice withont interruption, announcing the result after each shot.

When firing at moving and disappearing targets, the gun is not raised until the target appears.

RECORDS, REPORTS, ETC.

A complete record of every shot fired at known distances, and in the indixidual field firing by each officer, noncommissioned officer and soldier during the target year is kept on separate shot sheets for each person. It is closed at the end of the target year and signed by the company commander. These sheets go to make up a man's record, and if the man be transferred, the sheet for the last complete year is sent with his descriptive list to his new company.

In the school target only hits in the center band are counted; they are marked 1 , if within the oval $1+$. Shots that fail to hit the target or hit in the outer bands are comnted 
misses and marlied 0 , but those shots that fall in the onter bands are marked $0+$.

All hits in the figure targets are counted and marked 1. Misses are marlied by a cipher.

With disappearing and moving targots, shots prescribed but not fired are counted as misses.

A record is made at the end of each practice of the ammunition expended. Mimntes are also made and record kept of the lind and effect of firing at long range, and of the regular practice of the company in field firing for each subdivision. Similar minntes are made and kept by commanders of battalions and regiments. The field and long-range fire is executed by units at approximately the war strength.

AMMUNition.

The yearly allowance of ammunition for target practice is:

1. For every officer, cadet officer, and sergeant major of infantry and rifle battalions, 60 cartridges.

2. For every soldier of the normal peace strength, including one-year rolunteers, 150 cartridges.

Of the 150 cartridges allowed there are used for range firing: 80 for men of the first class, and 80 for men of the second and third classes.

For field-firing practice of men of the first class, $\% 0$, and for the men of the second and third classes, 80 cartridges.

In the field firing, men of the first class fire 10 cartridges in the individual preparatory exercises, those of the second and third classes, 20 cartridges, and all classes fire 25 cartridges in skirmish line and platoon fire, 25 in the regular field firing, and 10 cartridges in the long-range firing.

When individual preparatory field practice can be carried out only in part, or not at all, the ammunition sared will be expended in repeating the fire of skirmishers and platoons and in extra range practice.

3. For every man called out for a training course of eight weeks, 60 cartridges. Of these 40 are used for range practice and 20 for field firing.

4. For officers, carlet officers, furloughed men, and reserrists, 15 cartridges.

Of these the officers and callet officers use 15 in range firing, the furloughed men and reservists, 5 for range practice and 10 for field practice. If there be no suitable grom ds for field 
firing, the men called out for eight weeks, furloughers and reservists, use the ammunition in range practice.

For instruction practice, trial shots on the range, and for testing rifles, ammunition saved from other firing is to be used.

DEMONSTRATION FIRING.

This firing is intended to illustrate the accuracy of the rifle, and the effect of fire under different conditions. The firing is done by good shots in the presence of all the members of the company, and takes place as early as possible during the target-practice season.

The extent of the practice depends on the amount of saved ammunition that can be devoted to it.

The following are some of the exercises: To show the center of impact of different rifles; the effect on the fire of having the bayonet fixed; the trajectory of the bullet; the accuracy of the rifle at 200, 300, 400, and 500 paces; firing from cover at targets also concealed behind cover, and night firing, or firing in a heavy fog.

The simpler exercises are commanded by the company commander; those requiring considerable care and preparation are supervised by the battalion commander. Some may be carried on during the field practice for which the ground oflers facilities not available on ordinary ranges.

LONG-RANGE FIRING.

The object of this practice is to show the effect of volley firing and to illustrate its tactical importance, and the best method of utilizing it in action. Appropriate targets, representing lines and columns of troops, are used. The firing is participated in by all classes in the company.

Two positions are taken exceeding 1,200 paces, and five volleys fired from each position, the first firing being from the shorter distance. After the firing at each distance the result of the fire is ascertained and signaled by the marking party. At the conclusion of the exercise the company is marched to the targets and the leader gives a lecture on the subject of the firing.

FIELD OR COMBAT FIRING.

This firing is esteemed the most important part of the course, being intender for the instruction of leaders of all 
grades, as well as the individual soldier. It takes place after the range practice, and if possible after the long-range firing. All classes of firers take part.

The exercises are based on simple offensive tactical suppositions. The total front of the targets must not be greater than the front of the firing detachment in extended. order, and the figure targets used are of natural size.

The leader determines what targets are to be used, in what order, how long visible, and the signals on which they are to appear or disappear. The exercise should be arranged to permit of all kinds of fire. At distances less than 800 paces, section targets 0.9 meter high must be used, and at less than 600 paces no section targets are shown.

At the end of the exercise the men are marched to the targrets and the leader gives a short dissertation on the firing.

The field firing is divided into preparatory and regular practice for individual soldiers, groups, and platoons.

The individual preparatory practice may be held, if necessary, on the ordinary ranges, the man at first using dummy cartridges and afterwards ball cartridges. The course is arranged by the instructor; for example, the man is shown suddenly a target which remains visible during the time necessary to march 15 paces in quick time (about eight seconds). The target may, at 600 paces, be a section target of two whole figures, at 300 paces a half figure, or at 400 paces a twothird figure. Within the time during which the target is visible the man must estimate the distance, adjust his sight, aim, and fire. The shots are delivered from the prone position.

The preparatory practice of groups and platoons is carried on similarly. During the practice the leater's are not to be interfered with, comment or criticism being reserved till the end of the exercise. In the individual exercise, the result of each shot is ascertained, and if there be time in the group and platoon practice, the hits at each range, and for the different kinds of fire, should be marked.

REGULAR PRACTICE.

This takes place, as a rule, in companies or battalions of approximately war strength. The leader is the battalion or regimental commander; higher commanders do not interfere with the course of the exercise, unless gross faults are observed, and comment is not made until the exercise is over. 
The closest resemblance to war conditions is sought, reenforcements and reserves may be represented by other troops than those going through the exercise; these may use blank cartridges to simulate the assumed conditions. The commander and men of the detachment going through the exercise do not know the distances, or the targets to be shown, and previous discussion of the practice is not permitted.

Fire must not be opened until within the zone of mediumrange infantry fire, 1,000-500 paces, and is not delivered at distances less than 300 paces. Markers should not belong to the company practicing, and the results of fire are not ascertained until the close of the practice. While the company is going through the field practice, the system of ammunition supply in battle is also rehearsed.

FIRING PRIZES.

No general competitions are held for prizes, but company, squadron, and battery commanders should, as far as practicable, encourage emulation in firing among their men of all practice classes who show skill in shooting.

Money prizes are provided from an allowance made annually as follows:

Infantry companies:

Florins.

Minimum strength

Normal strength _....

Maximum strength.... . . .

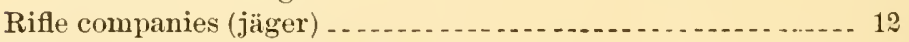

Engineer and pioneer companies....................... 8

Railroad and telegraph companies . . . . . . . . . . . . . . . . . 6

Cavalry squadrons _ . . .

Batteries of light, heavy, horse, and mountain artillery_..... 9

Companies of fortress artillery, for battery practice _....... 9

Companies of fortress artillery, for rifle practice ............ 4

Allowances are also given to depot troops, to landwehr called ont for eight weeks' training, to reservists, and to furloughed men.

The allowances are distributed in January of each year. Three prizes of 20 kreutzers for each exercise are given to the men of the lowest class in the company in their first year of service who make the best scores in the second, third, and fourth preparatory exercises of that class. Scores made in repetitions of those exercises are not considered.

Half of the amount remaining is used for prizes of 10 and 20 kreutzers to men of all classes for special progress made, 
and skill shown in target practice. These sums are handed to the men on the range during the firing season.

The rest of the money is distributed at the end of the target practice to the men of all classes who have the largest percentage of hits in their regular practice and authorized repetitions. For the first and second classes one prize only is given, of not less than half a gulden (jo kreutzers) for men of the first class; the second class prize may be a little more, and the rest is divided in higher sums for prizes for the best shots in the company.

The award of prizes is noted on the shot sheets of the winners.

\section{REVOLTER PRACTICE.}

This practice is nearly the same for all officers and men of infantry and technical troops, and for caralry and train troops, armed with that weapon. The annual allowance for infantry and technical troops is 20 rounds, for caralry and troops of the train 30 rounds.

The targets used are the school and figure targets, and the distances from 15 to 50 paces. No practice is held at distances greater than 50 paces.

The following is the program for practice of infantry and technical troops:

\begin{tabular}{|c|c|c|c|c|}
\hline $\begin{array}{c}\text { No. of } \\
\text { practice. }\end{array}$ & Distance. & Position. & Target. & Remarks. \\
\hline $\begin{array}{l}1 \\
2 \\
3 \\
4\end{array}$ & $\begin{array}{r}\text { Puces. } \\
25 \\
50 \\
25 \\
50\end{array}$ & 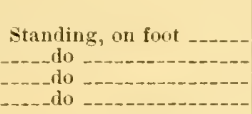 & $\begin{array}{l}\text { School } \\
\text { Figure }\end{array}$ & $\begin{array}{l}5 \text { shots. } \\
\text { Do. } \\
\text { Do. } \\
\text { Do. }\end{array}$ \\
\hline
\end{tabular}

Noncommissioned officers who have shown skill in previous years may omit Nos. 1 and 2, and ammunition so sared may be used in other firing. When momnted, as are regimental and battalion buglers of rifle troops, exercises Nos. 1 and 2 should be fired from horseback. Adrancing on a line parallel to the target and 15 paces from it, with revolver raised, the rider halts opposite the target, turns his body to the right. aims, and fires.

\section{CATALRT AND TRAIN TROOPS.}

In addition to the firing on foot, the cavalry has two exercises firing from horseback, one at a halt, and one while in 
motion riding past the target, at 15 paces. The train troops fire from horseback at a halt, approaching the firing stand first at a walk, and then at a gallop.

Officers and cadet officers of all troops practice separately.

\section{CA TALRY.}

GENERAL RULES.

The method and course of instruction is the same as for infantry, except that demonstration firing is omitted. The men are classed as in infantry, and similar targets are used for the known-distance, long-range, and field firing. When possible the infantry ranges are nserl and the service of mark. ing, signaling, scoring, and recording is carried on as prescribed for infantry.

No soldier is to fire with hall cartridges on the range until he has gone throngh the course of preparatory instruction. The practice for recruits should be during the months of April, May, and June, and only in favorable weather'; trained soldiers should frequently practice in bad weather.

The time for long-range and field firing is fixed by regimental commanders, unless otherwise specially ordered, as might be the case in large garrisons. The long-range firing and the individual preparatory field firing are confined to men in their first year of service, and to such men of higher classes as may hare missed the practice in their first year.

The practice at known distances is in ordinary drill uniform, the long-range and field practice in full field equipment.

ALLOWANCE OF AMILNITION.

The yearly allowance of carbine ammunition for target practice is as follows: For every officer and cadet officer, 30 rounds; for every soldier of the authorized strength armed with the carbine, 50 rounds; and for every noncommissioned officer armed with a revolver, 30 rounds of revolver ammunition.

Of the 50 rounds of carbine ammunition, 35 rounds per man are reserved for range firing; and from the total allowance of the squadron, 10 rounds per man are allotted for each man required to go through the individual preparatory field firing, and 9 rounds per man for those who are to take part in the long-range firing. 
FIRING AT KNOWX DISTANCES.

The course for all clisses consists of seren scores of five shots each, of which two are preliminary, and five regular practice. The ranges are from 200 to 600 paces, and the difficulties are increased for the higher classes by the use of smaller targets for the same ranges, or by disappearing or moving targets visible only for a limited periorl, during which the shots must be delivered.

LONG-DISTANCE FIRING.

For long-distance firing the men of each squadron taking part are formed in a detachment. Three positions, at distances greater than 1,000 paces, are taken, if prossible one to be from 1,800 to 2,400 paces. At each position three volleys are fired, and the results ascertained for each range.

Firing commences at the longest range. At the end of the firing the detachment is marched to the targets and the leader gives an instructive talk on the practice.

FIELD FIRING.

The field firing is conducted as in the infantry, except that section targets 1.8 meters high are used at distances of not less than 400 paces.

The preparatory practice is managed by the squadron commander. An officer or noncommissioned officer commands the men, who are combined in one or two platoons. Noncommissioned officers promoted within the year act as groul leaders. While the conditions of actual service are to be copied as far as possible, the exercise is to be interrupted as often as the leader deems proper for the instruction of those taking part, and to ascertain the effect of the firing. Of the 10 cartridges allowed for this practice, 4 are used for volley firing and 6 for indiridual firing. The practice should be held in good weather and be finished in one day.

REGULAR PRACTICE.

This, as a rule, is carried on in the ordinary formation of the squadron. The leader is the divisional commanter. In order to show the action of mounted troops in a fight, a mounted detachment from another syuadron may take part in the exercise. 
The problem is made known to those engaged only just before it is to take place; distances, targets, etc., depending on the conditions of the fight. As with cavalry the main object is to delay the advance of an enemy, special attention is to be given to firing at medium ranges. The most important feature is to represent the advance of an enemy by means of targets. For this purpose disappearing and moving targets are used, the latter being carried on sleds; if necessary, targets showing the enemy in position further alvanced may be kept in readiness on the ground, and set up during a pause ordered for the purpose, while at the same time more distant targets-lines and columns-may be removed. The exercise may also be made to represent an offensive action.

This practice may be held in any kind of weather and should be preceded by a march.

\section{TARGET PRACTICE FOR OFFICERS.}

Officers and cadet officers, of infantry and cavalry, practice with the rifle or carbine, and revolver, separate from the men, under the direction of a field officer or captain. The practice is generally similar to that of the men, but no classification is made. To maintain interest in shooting, practices or competitions are held among them.

\section{TECHNICAL TROOPS.}

For the technical troops, practicing with the short rifle, the course of instruction, targets, classification, and records are the same as for infantry.

\section{ALLOWANCE OF AMMUNITION.}

For officers, cadet officers, and sergeants major, 60 rounds; for each man of the authorized strength, equipped with the short rifle, including one-year volunteers, 85 rounds.

Of these there are used in range firing by men of the first class, 45 ; by the second class, 40 ; and by the third class, 35 rounds. Fifteen rounds are expended in preparatory field firing, 10 rounds in long-range firing, and the remainder for regular field, firing.

Men called out for eight weeks' training have a smaller allowance and have special programs of firing. 
RANGE FIRING.

The practice is in scores of 5 shots each, as follows: For the first class, 9 ; second class, 8 ; third class, $\%$, at distances from 200 to 600 paces, the conditions being more difficult for the higher classes.

Two prizes of 20 kreutzer's for each of the exercises 1 and 2 of the first class are given to men of that class, the remainder is distributed as in the infantry.

\section{TRAIN TROOPS.}

The train troops practice with the carbine. For every officer, cadet officer, and every man of the authorized strength, including one-year volunteers, equipped with the carbine, 25 rounds are allowed annually.

The practice of the several classes is in five scores of five shots each at distances from 200 to 600 paces, the principle of increasing difficulties for better shots being observed.

A prize of 10 kreutzers for each of the exercises 1 and 2 of the first class is given, one-half of the remainder is given, in prizes of $10 \mathrm{kreutzers}$ each, to men of all classes. for special progress, and the rest is divided in larger amounts among the best shots of the company. 



\section{II.-DENMARK.}

[Reported by Lient, Col. William R, Livermore, Corps of Enuineers, [nited states Military Itrachw Coprenhagen and stockinolm.]

\section{INFANTRY.}

The preparatory drills should be completed before the firing commences. They should not be practiced more than half an hour at a time, but may be practiced several times each day. To keep the men in constant practice, it is advisable to give them five or ten minutes of these drills whenever there is an opportunity thronghout the course of instruction.

Sighting.-A rifle is laid on an aiming stand at such a height that the man who is aiming can sit down.

The teacher first directs the sight against a sharply defined point on the target, and then makes the men look at the line of sight, one after another, with the right eye, while they close the left eye.

The sights are then directed against another point on or off the target, and the men again look one by one, and tell the teacher again at which point it is directed. This drill is repeated several times.

The teacher finally makes the men direct the aim against a given point.

Amixg. - The men are next instructed in aiming in different positions, stanting, kneeling, lying, behind trees, rocks, ete.

To test the aiming the mirror may be used, or the men may be told to point at the eye of the instructor or of other men. In this case, the man against whom the gun is directed must satisfy himself that the gun is moloaded.

As preparation for firing at a movable target, the men are taught to follow a horizontal line with the aim with a slow and uniform motion to the right or left, then to move the aim past a slowly moring object until the proper deriation has been reached, and then follow it for a while at this distance. 
Grunastic Exercises. - In order to strengthen the muscles brought into play in shooting, the men are practiced in gymnastic exercises with the rifle, viz:

1. The man takes in succession the positions of ready, aim, ready, etc., holding the rifle for a few seconds in each position.

2. He takes the position of aiming, standing; holds the piece with the left hand while the right hand with the arm extended describes as large a circle as possible, and again grasps the rifle.

3. He takes the position of aiming high, and then drops the left hand, holding the rifle in the right pressing the butt against the shoulder, and gradually letting the rifle fall to the horizontal position, etc.

4. He takes the position of aim; drops the left hand, turns the rifle with the right until the muzzle is vertical, extends the right arm horizontally forward, contracts it, etc.

5. In exercises in squads the men are taught to maintain the position of aim for two minutes.

These, and similar exercises, are repeated when kneeling, and in all the positions of aiming.

Pulding: the Trigger.--The men are then taught to pull the trigger without disturbing the aim, both against a fixed target, and against all kinds of objects moving forward, backward, and in all directions, and at all distances.

RAPID FIRE with DUumes. - They are then practiced with dummy cartridges in loading and firing rapidly under all circumstances.

Blank Cartridges. - They fire blank cartridges to become accustomed to the report.

Practice for Field Shooting. - Finally, as a preparation for field shooting, they are practiced with blank or dummy cartridges in the motions of firing asainst targets made to appear and disappear mexpectedly and at unknown distances, moving in all directions, etc. The man must first estimate the distance, then he decides whether the object is near enough for him to fire at it. In the latter case he must specify the elevation, deviation, etc., fix his sights, decide what point to aim at, and commence firing. Sometimes two or more targets are made to appear at once, and then he must decide which to fire at.

In some cases he may be allowed to choose his moment for firing when he thinks that by waiting he will have a better 
chance of hitting. At first he is allowed plenty of time to consider what should be done, but in the final exercises rapidity should be taken into consideration as well as accuracy. He is then practiced in all these exercises while he himself is in movement when the targets appear.

Then the men are practiced in squads, platoons, companies, etc.

GALLERY PRACTICE.

Gallery practice begins after the recruits have received the elementary instruction in aiming and pulling the trigger, and firing blank cartridges.

It is conducted with reduced charges and reduced targets, at very short range either indoors or in the open air, as explained in the following tables:

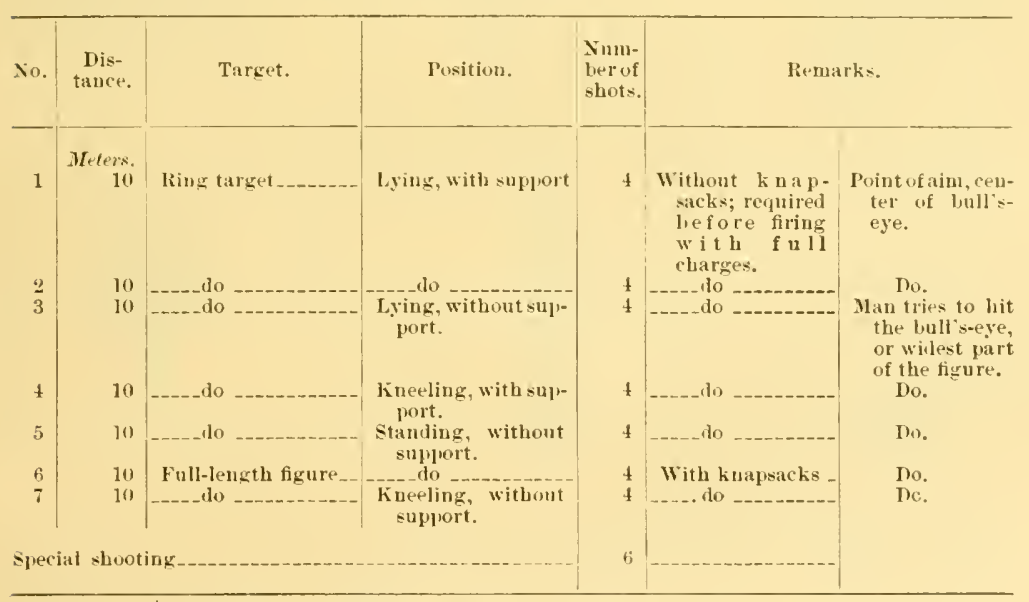

Apportionment of excreises.

\begin{tabular}{|c|c|c|c|}
\hline Classitication. & $\begin{array}{c}\text { Carry out } \\
\text { exercises } \\
\text { No. - }\end{array}$ & $\begin{array}{l}\text { Number of } \\
\text { cartridges } \\
\text { per mith. }\end{array}$ & lienarks. \\
\hline $\begin{array}{l}\text { Recruits } \\
\text { Men in continued service } \\
\text { Men callerl in for continuous } \\
\text { practice; } \\
\text { Sergeants' school } \\
\text { Second lientenants' school.-. } \\
\text { Shooting for officers, young } \\
\text { officers, and nusleroficers, } \\
\text { on temporary duty with } \\
\text { recruit battalions. }\end{array}$ & $\begin{array}{l}1-7 \\
2-7 \\
6,7 \\
1-7 \\
1-7 \\
1-7\end{array}$ & $\begin{array}{l}34 \\
31 \\
14 \\
30 \\
34 \\
34\end{array}$ & $\begin{array}{l}\text { Special shooting with gallery ammunition } \\
\text { is unt whligatory, but may be practiced by or } \\
\text { der of the company commanter, ete. } \\
\text { shooting Nos. tiand } 7 \text { with gallery ammu- } \\
\text { nition, for men called in for continuous prac- } \\
\text { tice, alle not obligatory hut may he jracticed } \\
\text { hy order of the company comuander. }\end{array}$ \\
\hline
\end{tabular}

The targets for gallery practice are, first, the ring target, 30 centimeters square with a black bull's-eye of 6 -centimeter 
diameter, and a black ring of 18-centimeter inner and 24centimeter outer diameter; and second, a figure target, 30 centimeters square with a black figure-a man 17 centimeters high and 5 centimeters wide.

ESTIMATING AND MEASURING DISTANCES.

Estimating. -Officers and men shonld hare practice in estimating distances in all positions, standing, kneeling, lying, etc.

At first the men are taught to judge with the eye distances of 100, 200, and 400 meters, and the size of a man at these distances. This preparatory practice is repeated also during the later exercises. They are made in all kinds of terrain and under all possible circumstances, especially on ground with which the men are not familiar'; at first slowly and then in a time not to exceed 10 seconds.

Corporals, undercorporals, and men should be able to estimate distances not over 600 meters, and have some practice with greater distances. There should be at least 50 problems in estimating distances at the recruit school, 80 in the candidates' school, and 60 for the men in continuous service.

Officers and permanent underofficers should accuire facility in estimating listances up to 1,200 meters and have some practice in estimating greater distances.

All these exercises are repeated after the regular course of instruction has ceased.

In the second lientenants' school there are at least 100 problems and in the sergeants' school 80.

Measuring.-Distances are measured by means of a chart, by pacing, by distance measurers, and by observation of the effect of shooting.

Exercises in estimating distances by help of a chart are practiced by officers, underofficers, and pupils in the second lieutenants' school in commection with other methods.

Exercises in pacing are practiced by officers and men.

Use of the distance measurer is practiced by officers, permanent underofficers, pupils in second lieutenants' school, and in the sergeants' school, in connection with estimating distances with the eye.

In shooting, attention is paid to the falling of the shots, and to the effect upon the target. 
TEST ()F PIUHICIENCY.

Regimental officers report the proficiency of the most skillful of the corporals, undercorporals, and men.

The minister of war issues special order's every year ahout tests, usually in August, for the ability of the officer's and permanent underofficers in estimating distances.

\section{TARGETS.}

The targets used atre shown in the figures below:

1.
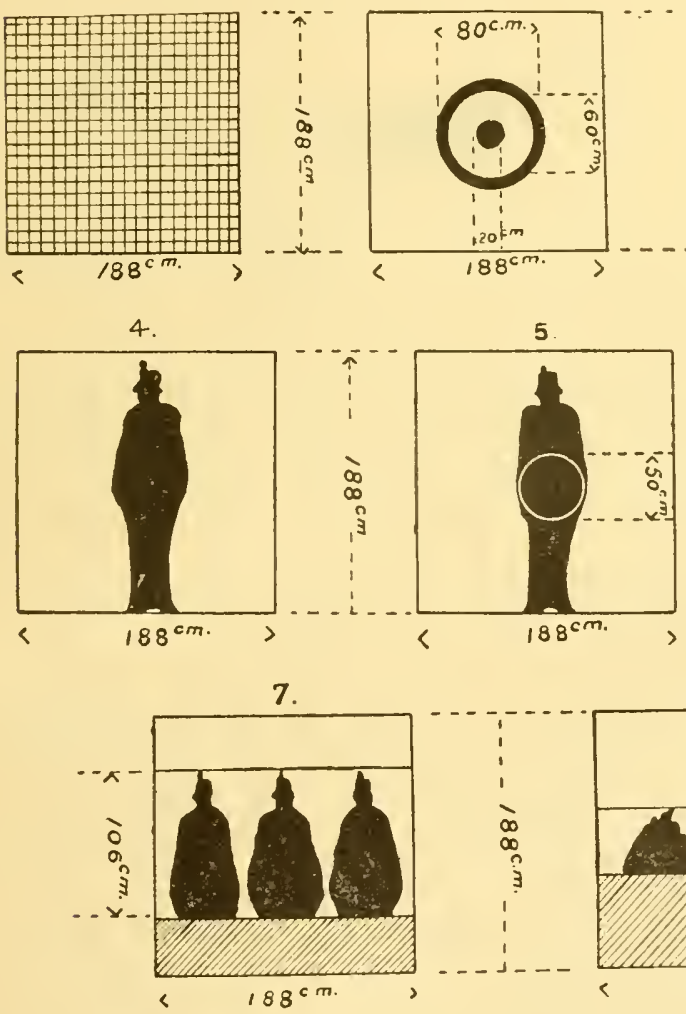

8.
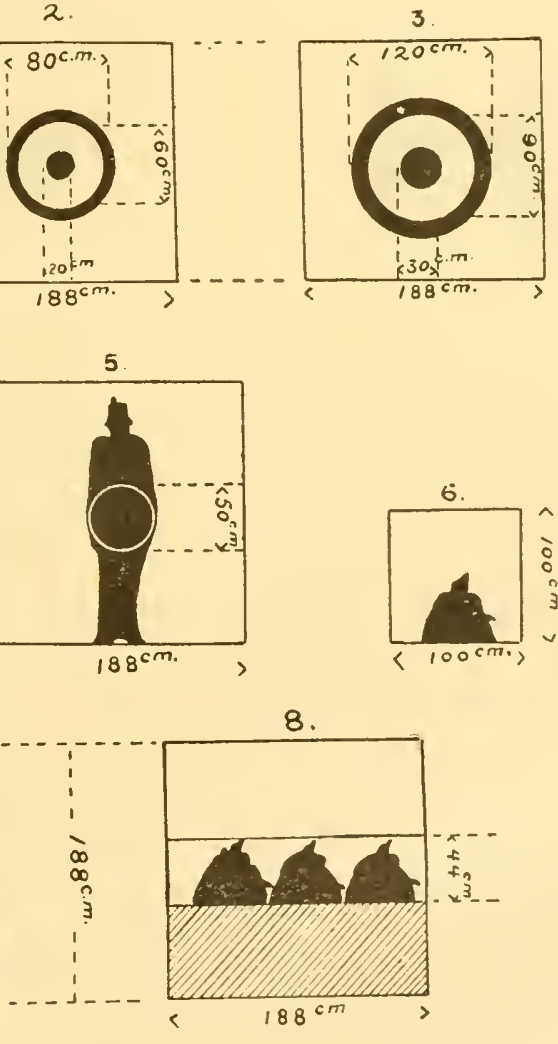

9.
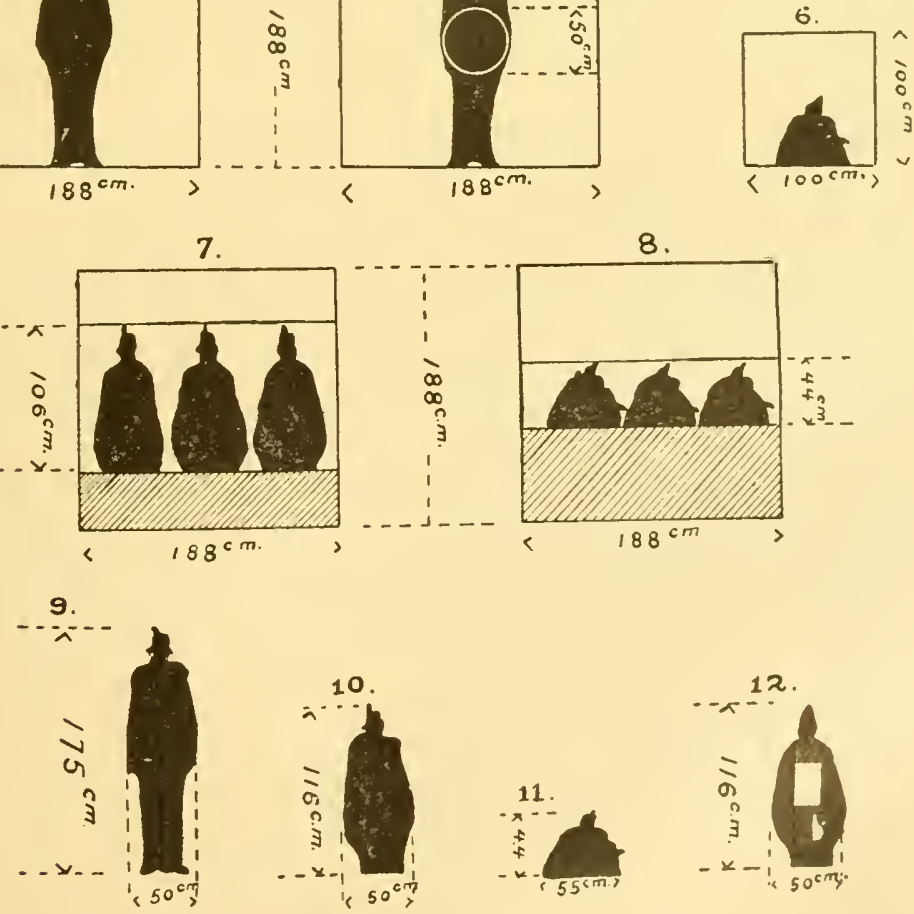
13.

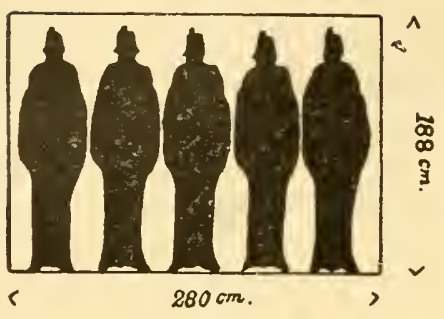

15.

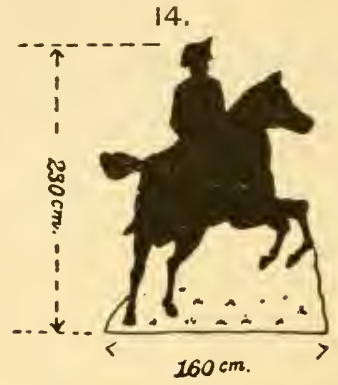

16.
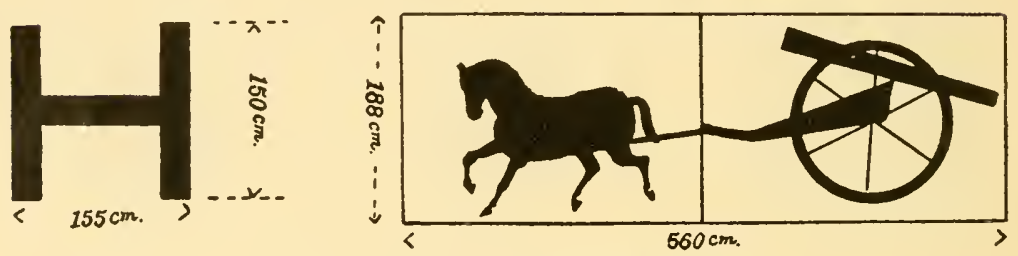

FIRING WITH LOADED AMMINITION.

In all the practice with loaded ammunition, as soon as a man has fired his rifle he calls out where he thinks the shot went. The following table gives a synopsis of the practice:

Apportionment of exercises, range and field.

\begin{tabular}{|c|c|c|c|c|c|c|c|c|}
\hline \multirow{2}{*}{ No. } & \multirow{2}{*}{$\begin{array}{l}\text { Dis- } \\
\text { tance in } \\
\text { meters. }\end{array}$} & \multicolumn{2}{|r|}{ Turget. } & \multirow{2}{*}{ Position. } & \multicolumn{2}{|c|}{ Number of shots. } & \multirow{2}{*}{ Sight. } & \multirow{2}{*}{ Renurks. } \\
\hline & & No. & Hescription. & & Blank. & Loarleal. & & \\
\hline 1 & {$[1,6$} & l & $\begin{array}{l}\text { Range-fimliug tat- } \\
\text { get. }\end{array}$ & & 2 & 4 & 250 & $\begin{array}{l}\text { Withont packs } \\
\text { aim takeu at } \\
\text { bull's-eye. }\end{array}$ \\
\hline 2 & & 2 & Ring target & Lying ....... & -... & 4 & 250 & Without packs. \\
\hline 3 & 250 & 3 & (l) & $\ldots$ do & & 4 & 250 & Do. \\
\hline 4 & I01 & 4 & Full-length figure.. & $\begin{array}{l}\text { Eneeling, w it h } \\
\text { support. }\end{array}$ & & 4 & 250 & Do. \\
\hline 6 & $2(k)^{-}$ & 4 & do & Lying & & $\begin{array}{l}4 \\
4\end{array}$ & $\begin{array}{l}250 \\
250\end{array}$ & $\begin{array}{l}\text { Do. } \\
\text { Do. }\end{array}$ \\
\hline 7 & 100 & 1 & Range finding - & $\begin{array}{l}\text { Lying, with sup- } \\
\text { port. }\end{array}$ & & 4 & $2=11$ & Do. \\
\hline 8 & 150 & 6 & One-fourth fignre & - div - & & 4 & 250 & Do. \\
\hline $9 q$ & 200 & 7 & 3 half figures & Lying & 6 & 6 & 250 & Do. \\
\hline 10 & 200 & 8 & 3 one-fourth figures & 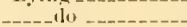 & & 5 & 250 & With pracks. \\
\hline $11 a$ & 200 & 7 & 3 half figures & do & & 5 & 250 & Do. \\
\hline 12 & & 7 & - do & Kineeling & & 5 & 250 & Do. \\
\hline 13 & 300 & 8 & 3 onde-fourth tigures. & Jying - & & 5 & 250 & Do. \\
\hline $14 a$ & 250 & 7 & 3 half figures & $\log ^{2}$ & 10 & 10 & 250 & Do. \\
\hline 15 & & 8 & 3 one-fourth figures & Inteling, witb & & 5 & 250 & Do. \\
\hline ]6 & 100 & 5 & Fult figure, 1 ring & St:mpling - & & 5 & 250 & Do. \\
\hline $17 a$ & 200 & 7 & 3 half tigures & $d_{10}-d_{1}$ & 8 & 8 & 250 & Do. \\
\hline 18 & 300 & 8 & 3 one-fonth figures- & $\begin{array}{l}\text { lineeling, with } \\
\text { sujuort. }\end{array}$ & & 5 & $400 i$ & Do. \\
\hline 19 & 400 & 7 & 3 hulf figures & bying & & 5 & $I(x)$ & Do. \\
\hline 20 & 500 & 13 & 5 full figures & Lying, with snp- & & 5 & 400 & Do. \\
\hline $21 a_{1}$ & 200 & 7 & 3 lialf figures & $\begin{array}{l}\text { According to the } \\
\text { groumd. }\end{array}$ & & 6 & 250 & Do. \\
\hline
\end{tabular}


In series 1 the aim is taken at the bull's-eye wery time.

In series 2 to 6 and 8 , the instructor, hefore the firing legins, gives instructions about the point of aim.

Series No. ` for trial.

Magazine Fire.-In series 9 and 11, the time is limited to twenty-five seconds for each 6 shots; in series 14, to forty-five seconds for 10 shots; in series $1 \%$, to thirty-fire seconds for $S$ shots; in series 21 , to fifteen seconds for 3 shot.

Firing at unknown ranges.

\begin{tabular}{|c|c|c|c|c|c|c|c|}
\hline \multirow{2}{*}{ No. } & \multirow{2}{*}{$\begin{array}{l}\text { Distance } \\
\text { in meters. }\end{array}$} & \multicolumn{2}{|r|}{ Tirget. } & \multirow{2}{*}{ Position. } & \multirow{2}{*}{$\begin{array}{l}\text { Numbers } \\
\text { of shots. }\end{array}$} & \multirow{2}{*}{ sight. } & \multirow{2}{*}{ Remarks. } \\
\hline & & No. & leserijtion. & & & & \\
\hline 22 & $350-100)$ & 9 & $\begin{array}{l}\text { Fublength figure } \\
\text { sudienly aplear- } \\
\text { ing. }\end{array}$ & $\begin{array}{l}\text { Aceoriding } \\
\text { to ground. }\end{array}$ & 4 & $\begin{array}{l}\text { Accoriling to mats's } \\
\text { judgment. }\end{array}$ & $\begin{array}{c}\text { Field yack } \\
\text { curriesl. }\end{array}$ \\
\hline 23 & $\begin{array}{r}\text { Between } \\
150-250\end{array}$ & 11 & One-fourth figure--- & 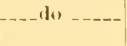 & 3 & $\ldots$ do $\ldots$ & Iro. \\
\hline 24 & $\begin{array}{r}\text { Between } \\
250-350\end{array}$ & 12 & Two-thiril figure.--- & $\ldots$ & - - - & -..-do & Do. \\
\hline
\end{tabular}

Score No. 22 is conducted on the target ground. The man firing advances from a distance of 350 meters to 100 meters from the target, and then retreats. - Whenever the target is shown he halts and fires a shot. The target is visible each time for 10 seconds. Each shot is marked.

Two men can fire at the same time each agrainst his own figure.

Scores Nos. 23 and 24 are conducted outside the regular target range and usually by a firing line of the same extent of front as that of the targets. Each man has a separate target to fire upon. The figures, one for each man, are placed in groups of two to five figures in each group. The distance between the groups is about 4 meters, and between the figures of the same group, about 2 meters from center to center. The firing is slow fire by file by command. After firing 3 rounds the firing ceases and all go to the target to see the effect. Each man only notes whether he has hit his own figure or not. 
Firing in open and close order (all available men take part in this practice).

\begin{tabular}{|c|c|c|c|c|c|c|c|}
\hline No. & $\begin{array}{l}\text { Distance in } \\
\text { meters. }\end{array}$ & Target. & Position. & $\begin{array}{l}\text { Nirm. } \\
\text { ber of } \\
\text { shots. }\end{array}$ & Sight. & $\begin{array}{l}\text { liind } \\
\text { of } \\
\text { fire. }\end{array}$ & Rewarks. \\
\hline 25 & $\begin{array}{l}\text { Unknown, bre- } \\
\text { tween } 7(0) \\
\text { and } 1,200 . \\
\text { about } 7(0)\end{array}$ & $\begin{array}{l}\text { Liue of f ull- } \\
\text { length figures. }\end{array}$ & $\begin{array}{l}\text { According to } \\
\text { grount. }\end{array}$ & 5 & $\begin{array}{l}\text { As specified by } \\
\text { the commander. }\end{array}$ & & $\begin{array}{l}\text { With knap- } \\
\text { sacks, etc. }\end{array}$ \\
\hline 26 & Abont 704 & $\begin{array}{l}2 \text { section targets, } \\
\text { sille by sidts. }\end{array}$ & -... do - & 3 & $\ldots$ d $b_{0}$ & & Po. \\
\hline 27 & $\begin{array}{l}\text { Unknown; lee- } \\
\text { tween } 350 \\
\text { and } 550 .\end{array}$ & $\begin{array}{l}\text { Line of two- } \\
\text { third figures. }\end{array}$ & --_do & 3 & __do & & Do. \\
\hline $2 m$ & About 300 & Line of one- & - d do - & 3 & $\ldots d o$ & & tho. \\
\hline 29 & About 200 & $\begin{array}{l}\text { line of two- } \\
\text { thirit figures. }\end{array}$ & __do _ & 6 & 250 & $\begin{array}{l}\text { llag- } \\
\text { azine. }\end{array}$ & Iro. \\
\hline
\end{tabular}

This shooting is made by 1 section to 1 company at a time. About as many figures are set up as the number of men firing; about one to a pace.

Witl recruits the firing is continued for two days.

Synopsis of firing in close order (with blank cartridges).

\begin{tabular}{|c|c|c|c|c|c|c|c|}
\hline $\begin{array}{l}\text { No. of } \\
\text { score. }\end{array}$ & $\begin{array}{l}\text { Distance in } \\
\text { meters. }\end{array}$ & Target. & Position. & $\begin{array}{l}\text { Number } \\
\text { of blank } \\
\text { car- } \\
\text { tridges. }\end{array}$ & sight. & $\begin{array}{l}\text { lipid } \\
\text { of } \\
\text { fire. }\end{array}$ & Remarks. \\
\hline 30 & $\left\{\begin{array}{l}\text { About } 600 \\
\text { Abont } 450-- \\
\text { About } 300\end{array}\right\}$ & $\begin{array}{l}3 \text { figures of horse- } \\
\text { men at each dis- } \\
\text { tance. }\end{array}$ & $\begin{array}{l}\text { Kneeling, } \\
\text { with sul- } \\
\text { port. }\end{array}$ & Up to 8 & 400 & $\begin{array}{l}\text { skir- } \\
\text { mish. }\end{array}$ & $\begin{array}{c}\text { Kn apsacks } \\
\text { and field out- } \\
\text { fits; targets } \\
\text { shown at in- } \\
\text { tervals of I5 } \\
\text { seconds at } \\
\text { each dis - } \\
\text { tance. } \\
\text { Do. }\end{array}$ \\
\hline 32 & 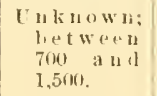 & $\begin{array}{l}2 \text { section targets } \\
\text { ville ly side. }\end{array}$ & $\ldots$ do & 3 & $\begin{array}{l}\text { Specified by } \\
\text { commander. }\end{array}$ & $\begin{array}{l}\text { Yol- } \\
\text { ley. }\end{array}$ & $\begin{array}{l}\text { Iin a psacks } \\
\text { and fiekl out- } \\
\text { fits. }\end{array}$ \\
\hline
\end{tabular}

Immediately before fire is opened in score 31 the detachment runs forward 100 meters and executes "To fire-Halt."

In firing volleys there shonld be a uniforın pause between the volleys.

SPECIAL SHOOTING.

With the ammunition which may be left over, special shooting will be ordered by the company commander or director of the course.

FIELD SHOOTING,

which follows the individual and collective shooting, is made to conform as nearly as possible to actual warfare. 
It should be based upon a tactical problem which should be clear and simple. For defense, time is given to estimat. distances, ete.

The targets are, as far as possible, ar'anged to rise and fall, alvance and retreat, move sidewise, and fall when struck, as may be required to carry out the problem.

Figures 9, 10, and 12 represent videttes, skirmishers, single men, or small patrols in motion.

Single figures, like 11, represent videttes lying down, or skirmishers, or small patrols that have halted.

A line of figures like 9 represents a firing line in motion, etc.

Cavalry targets are made by combining figures like 14; artillery by combining figures like 15 and 16 .

Reserves can be represented with targets without figures.

The effect of fire can be shown by a prolonged movement of some of the pieces forming the target.

The hostile fire can be shown by igniting cartridges, or by the markers firing blank cartridges.

The manner of working the targets is shown in Plate I. The targets are brought to the ground on a beam with wheels. Fig. A represents a series of one-fourth figures raised. By means of the levers, cords, and pulleys they can be turned horizontally and raised again at will, for example:

\begin{tabular}{|c|c|c|c|}
\hline At at signal froni- & $0 \mathrm{f}-$ & Narkers in- & \\
\hline 1 & 1 balloon up .... & a & Raise one-fourth figures. \\
\hline 1 & 1 balloon down & b & Ratise one-fourth figures. \\
\hline I & 2 ballowns up..... & $a$ and $\mathrm{b}$ & $\begin{array}{l}\text { Lower one-fourth figures, and raise two- } \\
\text { third figure one minute. }\end{array}$ \\
\hline II & 1 balloon up ..... & c & liaise one-fourth figures. \\
\hline II & 1 b;alloou down & c & $\begin{array}{l}\text { Lay one-fourth figures, and raise two- } \\
\text { thiml figure three-fourth minute. }\end{array}$ \\
\hline II & 2 halloons up ---- & d & $\begin{array}{l}\text { Raise one-fourth fignres, and laise two- } \\
\text { thiril figure three-fourth minute. }\end{array}$ \\
\hline
\end{tabular}

Plate II shows the arrangement for marking.

The markers and the frame of the target are protected by an iron screen, "a," and the markers also by a covering of earth, "b," and a wooden screen, "c," to keep off. fragments from the earthen bank behind the target. After each shot, or after a signal on an electric bell, the target is rolled in and marked and the result is signaled by the wings of the semaphores. 


\section{Plate I.}

II

mmmrm

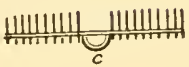

$$
\text { I }
$$

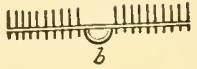

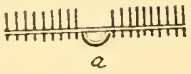

$$
\bigcup_{\mathrm{H}}
$$

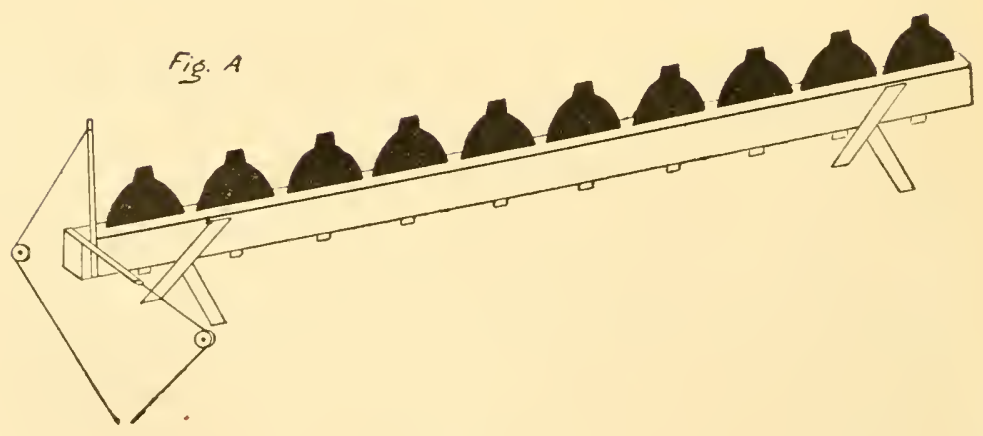


Plate II.
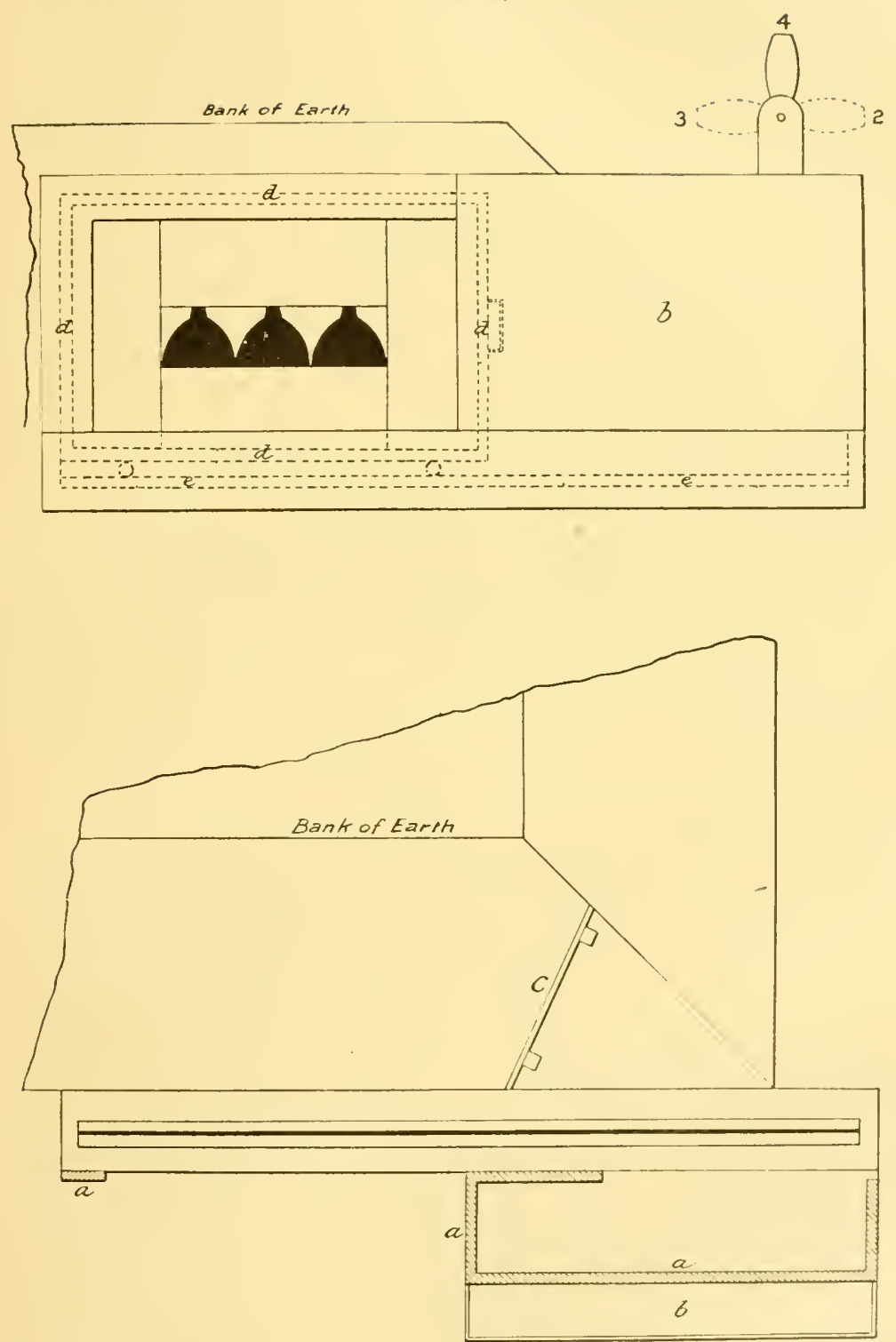


\section{TEST SHOOTING.}

To test the proficiency in firing in the detachments, etc., firings are held annually by special orders from the war department.

No special practice must be held for preparation.

The chief of the detachment is responsible for carrying out the test in accordance with the orders of the war department and reporting upon the result.

\section{PRIZE SHOOTING.}

The chief of the regiment, or some one detailed by him, superintends the prize shooting ordered by the war department.

The ranges are selected so as to afford as equal chances for the competition as possible.

Immediately before the shooting the competitors draw lots for targets, and for the order of shooting.

The results of the company competitions are reported to the chief of the regiment, or to the man delegated by him.

The prizes are distributed according to the number of points. In case of a tie the last shot, or the next to the last, etc., determines the precedence.

Prizes are distributed in the presence of all those who compete for them.

Number of scores, time of proctice, number of cartridges.

\begin{tabular}{|c|c|c|c|c|c|c|c|c|c|c|c|c|}
\hline \multirow{4}{*}{ Clans. } & \multirow{3}{*}{\multicolumn{5}{|c|}{ Course. }} & \multicolumn{5}{|c|}{$\begin{array}{c}\text { Number of cartrilges } \\
\text { per man for- }\end{array}$} & \multirow{3}{*}{\multicolumn{2}{|c|}{$\begin{array}{l}\text { Total } \\
\text { number } \\
\text { of car- } \\
\text { tridges } \\
\text { per man. }\end{array}$}} \\
\hline & & & & & & \multirow{3}{*}{ 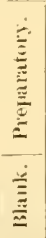 } & \multirow{2}{*}{\multicolumn{2}{|c|}{ 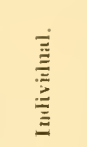 }} & \multirow{2}{*}{\multicolumn{2}{|c|}{ 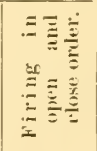 }} & & \\
\hline & & & & & & & & & & & & \\
\hline & Srore $\mathrm{Nu}$. & $\doteq$ & $\cong$ & $\begin{array}{l}\stackrel{\varrho}{E} \\
\vdots\end{array}$ & $\stackrel{-}{=}$ & & 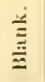 & $\bar{\equiv}$ & $\stackrel{\dot{\Xi}}{\underline{\underline{\Sigma}}}$ & $\stackrel{\bar{\Xi}}{\cong}$ & 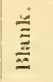 & 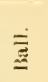 \\
\hline \multicolumn{13}{|l|}{ Regimentul recruits: } \\
\hline $\begin{array}{l}\text { For instruction in two } \\
\text { months. }\end{array}$ & \multicolumn{5}{|c|}{$\begin{array}{l}\text { In the companies loefore they } \\
\text { are sent honle. }\end{array}$} & 12 & 26 & 122 & & & 55 & 142 \\
\hline Body-guard recruits & $1-32 \ldots \ldots$ & 61 & 161 & 9 & 9 & 12 & $26 i$ & 122 & 17 & 20 & 55 & 142 \\
\hline $\begin{array}{l}\text { Men for continuous service: } \\
\text { With regiments }\end{array}$ & $1(1-19$ & 10 & 16 & 5 & 24 & & Ix & 59 & & & 18 & \\
\hline With borly guard & $10-19-\ldots$ & 10 & 16 & 3 & 29 & - & is & 59 & & & 18 & 59 \\
\hline $\begin{array}{l}\text { Men called for in continuous } \\
\text { practice. }\end{array}$ & $24.27,28 \ldots$ & 9 & 14 & 9 & 24 & 5 & - & 3 & -- & 6 & 5 & \\
\hline Caudidlates' school _. & $\begin{array}{l}11,12-15,23 \\
24,27\end{array}$ & 10 & 21 & 3 & 24 & 5 & 10 & 36 & & 3 & 15 & 39 \\
\hline Sergeants' school & $7,9,14,17-19$ & 10 & 21 & 3 & 24 & 5 & 21 & $4 s$ & $\ldots$ & 12 & 29 & 60 \\
\hline Second lientenants school & 10.12-14,23, & 3 & 2 & 5 & 14 & 5 & 10 & 31 & & & 15 & 31 \\
\hline Officers' rourse in slowting --_-- & $7-24,24 ;-29 \ldots$ & & 26 & : & 6 & 5 & 21 & 98 & ---- & 15 & $2 ?$ & 113 \\
\hline $\begin{array}{l}\text { Younger officers and underothers } \\
\text { on temporary duty with reeruit } \\
\text { lattahion. }\end{array}$ & $7-24 \ldots \ldots+\ldots$ & $\begin{array}{ll}\text { Situr } \\
\text { (1) }\end{array}$ & $\begin{array}{l}\text { ue tim } \\
\text { vits. }\end{array}$ & He' as & & 5 & 24 & sin & $\ldots$ & $1 \overline{5}$ & 29 & 113 \\
\hline
\end{tabular}


The officers of the battalion staff and the company officers take part in the officers' course, but captains only (in whole or in part), if they so desire, and battalion adjutants and staff sergeants can be excused by the chief of the battalion when their duties make it advisable.

SHOOTIXG-BADGES.

Of those of the regimental recruits who before the 31st of August have completed the individual shooting at known distances, the six who have made the most points in scores 10-21 receive a badge "for shooting." In case of tie, scores $17-21$ decide, or if there is a tie here also, scores 1:-16.

\section{CATALRY.}

The regulations for carbine shooting are similar to those for the infantry but have not been revised since 1899 , whereas the infantry regulations were revised in 1901.

The regulations for revolver shooting, and for the practice of engineer troops, have been declared obsolete and are in process of revision.

For cavalry the preparatory exercises are similar to those for infantry.

$$
\text { PROGRAM FOR SHOOTING. }
$$

In the Regmental School. - In the second class of the school; drill with carbine; preparatory drills in aiming; position of firing, and pulling the trigger.

Gallery Shooting.-Five shots lying, with support, 5 shots kneeling, and 5 shots standing.

In the Squadrox. - First or second year.

DRILLS WITH CARBINE.-The drills in the regimental school (preparatory) are repeated in connection with the target practice. Preparatory drills in rapid fire and in squad fire.

Ten shots per man can be fired with gallery carbine; '2 shots lying, 3 kneeling, and 5 standing.

Shooting with blank cartridges, on the average 2 shots per man.

Shooting with loaded ammunition: At 100 meters, 3 shots kneeling, 2 shots standing; 200 meters, 3 shots lying, 2 shots standing; 300 meters, 3 shots lying, 2 shots kneeling; 400 meters, 3 shots lying, 2 shots kneeling; 500 meters, 5 shots lying, with support. 
Combined Shooting. - When advancing in loose order from 450 meters, two positions are taken between 400 and $: 50$ meters and there are fired - from the first position 2 blank and 5 ball cartridges; from the second position 1 blank and 5 ball cartridges.

The fire is skirmishing fire with pauses. Target-skirmish line with half figures.

Advancing from 550 meters, two positions are taken between 500 and 400 neters, and there are fired-in the first position ? blank, 5 ball cartridges; in the second position 1 blank and 5 ball cartridges.

The fire is given with first 1 or 2 shots as volleys in each position, the remainder as skirmish fire. Target-Target C.

Shooting at unmeasured distances, individual shooting; five shots with or without support (at choice of the marksman himself) against full-length figures at distances of 100-300 meters.

Drills with revolver.

Judgment of distances.

Drills with carbine.

Repetition of preparatory drills.

Combined shooting, as for the men of the first and second year.

IN THE SCHOOLS.

Drills with carbine: Repetition of the preparatory drills. Fifteen shots are fired by each pupil with gallery carbine, 5 shots lying, 5 kneeling, and 5 standing.

Individual shooting with loaded ammunition, and combined shooting the same as the first and second years.

Drills with revolver.

Judgment of distances: With officers (lieutenants) and underofficers.

Drills with carbine: The preparatory drills.

Each man fires 30 shots with gallery carbine, of which 10 are against a movable target; of the remainder, 5 are fired lying, 5 kneeling, and 10 standing.

Individual shooting with loaded ammunition: At 200 meter's, 1 shot kneeling, 4 shots standing; 300 meters, 3 shots kneeling, 2 shots standing; 400 meters, 3 shots lying, 2 shots kneeling; 500 meters, 5 shots lying.

Drills with revolver: Judgment of distances in the first and second class. 
SPECIAL SHOOTING.

Competition.-After the shooting for the first and second years has been completed, competitions are held.

The shooting is conducted by the regimental commander according to rules given by the minister of war, and the inspector general for the cavalry.

The marksmen are selected from the records of firing in accordance with rules specified for each competition.

No special practice for the competitions is permitted.

The regimental commander reports to the war office the results of the competitions.

\section{OTHER COMPETITIONS.}

If the time allows, and there is sufficient ammunition available, further competitions are held: Against movable targets (gallery shooting, 10-meter distance); rapid firing (with blank cartridges) and shooting at unmeasured distances (ball cartridges).

\section{AMMUNition.}

The supply of ammunition in the field is regulated as follows :

For each man with carbine, 40 ball cartridges, of which 30 are in Bretton holders in the ammunition bags, and 10 in the magazine.

For each man with revolver, 24 ball cartridges, in 4 boxes with 6 in each, which are kept in the cartridge-bag.

\begin{tabular}{|c|c|c|c|}
\hline & $\begin{array}{c}\text { Gallery } \\
\text { cartridges. }\end{array}$ & $\begin{array}{l}\text { Ball car- } \\
\text { tridges for } \\
\text { carbine. }\end{array}$ & $\begin{array}{l}\text { Ball car- } \\
\text { tridges for } \\
\text { revolver. }\end{array}$ \\
\hline Regimental school & 3 & & . \\
\hline First year with the siuadron & 2 & 2 & \\
\hline Second year with the squaridron & 2 & 2 & 1 \\
\hline Thiril and fourth year with the squadrou & & I & \\
\hline Practice school & 5 & 2 & 2 \\
\hline (ifticers aul uuderofficers & & 5 & 5 \\
\hline
\end{tabular}

In drilling the horses to stand fire, and in field maneuvers, the following number of blank cartridges can be nsed for the carbine:

Regimental school...................... 20 cartridges per man.

Ien of the first year....................40 cartridges per man.

Men of the second year .................. 40 cartridges per man.

Nen of the third and fourth year -........30 cartridges per man.

Second lieutenants, sergeants, and corporals' school ........................ 40 cartridges per man.

Undercorporals' school .................... . 30 cartridges per man. 
The following supply of cartridges is fixed for the garrisons outside Copenlagen:

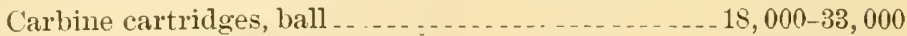

Carbine cartridges, blank ................... 4,000-22,000

Carbine cartridges, gallery _..._........... 4,000-10,000

Revolver cartridges ...................... 3,600-5,500

The lowest number shows the quantity of ammunition to be on hand in case of mobilization; the highest number, this amount plus the quantity which will probably be used in the course of the year.

Number of cartridges authorized for each man during his instructions.

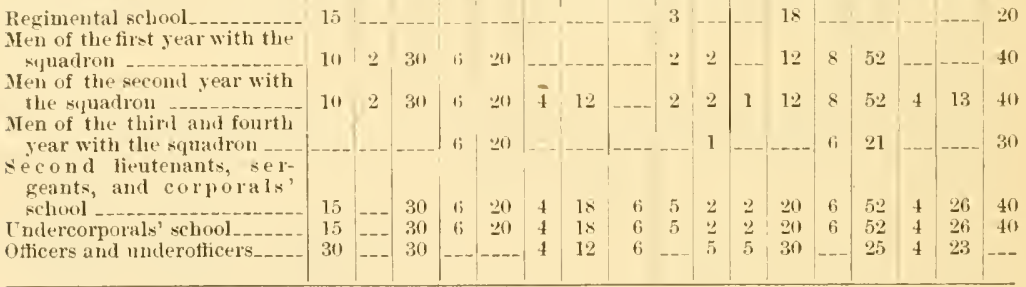

The targets which are used at the drills are the divided Targets $\mathrm{A}$ and $\mathrm{B}$, Target $\mathrm{C}$, figure target, pistol target, gallery target, and aiming targets.

Targets A and B have a square bull's-eye with rectangular spaces around it; Target $\mathrm{C}$ has no divisions.

The figure targets are pasted on cardboard.

The targets have the following dimensions in centimeters:

\begin{tabular}{|c|c|c|c|c|}
\hline Target. & Width. & lleight. & ('inter sipuare. & Division outside center. \\
\hline $\begin{array}{l}\text { Target } \Lambda \text { (inf. 2) } \\
\text { Target } B \text { (inf. 4) } \\
\text { Target } \\
\text { Tar. }\end{array}$ & $\begin{array}{l}160 \\
2 \times 0 \\
320\end{array}$ & $\begin{array}{l}18 \mathrm{x} \\
18 \mathrm{~s} \\
188\end{array}$ & $\begin{array}{l}40 \\
70\end{array}$ & $\begin{array}{l}\text { Al wide, } 100 \text { high. } \\
140 \text { wide, } 188 \text { high. }\end{array}$ \\
\hline Pistol target_..... & 62 & $18+\{$ & $\left.\begin{array}{r}8 \text { wide } \\
24 \text { high }\end{array}\right\}$ & $\begin{array}{l}\text { Inner rectangle, } 48 \text { ligh, } 1 \text { is wide; center } \\
\text { rectangle, } 94 \text { high, } 31 \text { wide. }\end{array}$ \\
\hline $\begin{array}{l}\text { Salon target } \\
\text { Figure target_....- } \\
\text { Half-figure target_ }\end{array}$ & $\begin{array}{l}30 \\
50 \\
50\end{array}$ & $\left.\begin{array}{r}30 \\
172 \\
87\end{array}\right\}$ & $\begin{array}{l}5 \\
\text { Pastell on carib } \\
\text { figure. }\end{array}$ & $\begin{array}{l}10 \text { wide, } 15 \text { high. } \\
\text { board and cut out along the outline of the }\end{array}$ \\
\hline
\end{tabular}


ARTILLERY PRACTICE.

Denmark has, for many years, been troubled by lack of sufficient appropriation to carry out the improvements in its artillery matériel that its officers have desired. Recently extensive trials have been made of all the most improved systems of rapid-fire field guns, and, as a result of the reports of these trials, large sums have been appropriated for new matériel which will probably soon result in a revision of its system of target practice.

After the usual preliminary drills and instructions in the theory of ballistics, and in the use of the sights against targets of different kinds, the field-artillery practices at the range nearest to the garrison, in firing with loaded ammunition, and when these exercises are completed, each battery in turn is sent for several days to one of the target grounds for field practice. One of these grounds, situated at a day's march from Copenhagen, covers several square miles of rolling country with a surface varied by forests, pastures, cultivated, sandy, and swampy land, with some fences and stone walls and a few buildings; but generally open and affording admirable positions for imaginary warfare.

The exercises here are based upon a tactical supposition which is so contrived as to give practice in the work that would be required of a battery in action. The targets are mare to represent as nearly as possible the appearance of the enemy against whom the fire is to be directed, and the battery and its commander have no more knowledge of the nature or position of this target than in actnal warfare they would have about the enemy. For instance, a battery commander is told to take up a position on a certain little hill and fire against another battery in position on the right of the red farmhouse with two chimneys, or against a line of skirmishers in the cornfield to the left of a certain forest, or to take up a position to prevent hostile caval'y from crossing a certain point, etc. In any event the target is not usually seen by the battery commancler until he arrives on the spot. He must then find the target, select the ground for the guns, estimate the distance, decide upon the ammunition, fuse, etc., and take such measures that in coming into battery his men and horses are not too much exposed to hostile fire. In the latter case he may be obliged to fire with only a few of his guns and even then with reduced effect. 
Great attention is paid to the time required to find the target, and to the number of trial shots necessary to get the range. As soon as practicable a field observatory is set up to watch the shots. This is simply an extensible ladder with a hinged prop to support it and a rest for a spyglass near the top. It is so placed that the observer can see without being himself too conspicuous.

The amount of ammunition for all the artillery firing depends upon the annual appropriations.

TARGETS.

For Field Artillery.-The targets, representing infantry in line standing up, are rectangles measuring 30 and 15 feet wide by 5 feet high; infantry kneeling or partly covered, 30 feet wide by 3 feet high; infantry in column, 10 feet wide and 15 feet high; for the pieces and limbers of artillery, $\mathrm{H}$-shaped figures 5 feet wide and 5 feet high; for skirmishers standing, figures about 20 or 21 inches wide and $5 \frac{1}{2}$ feet high; for skirmishers kneeling, 21 inches wide and 33 inches high; for skirmishers lying, 22 inches wide and 19 inches high. Sometimes the targets are set up in rifle pits. Disappearing targets are 30 feet long and 6 feet high with two pivots at the center of each end, which rest on supports which are driven into the ground wherever the target is required.

Movable targets, 12 to 20 feet long and 6 feet high, are moved on sleds with corrugated-iron runners. The wooden framework is covered with canvas or linen. The sled is dragged by a line attached to a wagon or limber.

The targets for fortification artillery consist of real objects, viz, old cannon, magazines, bombproofs, gum pits, lifle pits, sapheads, batteries made of old cannon; and representations of objects, such as siege batteries traced on the ground and with the exterior slopes, etc., marked by colored cloth. Infantry targets 60 and 30 feet long and 5 feet high. Standing figures 5 feet high and 2 feet wide, kneeling figures $2 \frac{1}{2}$ feet high and 2 feet wide, lying figures $1 \frac{1}{2}$ feet high and 2 feet wide. Artillery pieces or limbers, 5 feet high and 5 feet wide. All kinds of objects against which the fire of position artillery may be directed are represented by combinations of flags, etc.

Targets falling automatically when struck are made as follows: A figure representing a kneeling skirmisher is cut out of a board, $\frac{3}{3}$ or $\frac{1}{2}$ inch in thickness, and set up with a 
slight inclination from the rertical, supported by a hook which is hinged to a stake and caught in a staple on the target. A little hammer turning on a pivot is supporterl in a horizontal position by a little pin so that when the target is struck it falls and knocks the hook out of the staple and the target falls to the ground. Another figure, representing a skirmisher lying down, is supported by a copper wire with an eye in the end, instead of by the hook. The eye is passed orer a pin on the top of the target so that when the hammer falls the wire is knocked off and the target drops.

To represent field artillery, a standing figme is set up on each side of the target representing the piece, and is held up by a hook which is loosened in the same manner as with the kneeling and lying figures.

For Seacoast Artillerr, moving targets, made to be drawn by torpedo boats or tugs, are constructed on the plan of a catamaran as shown by the sketches.

A for mitrailleuse.

B for guns of small caliber.

C for guns of medium and large caliber.

The dimensions are given in feet. 


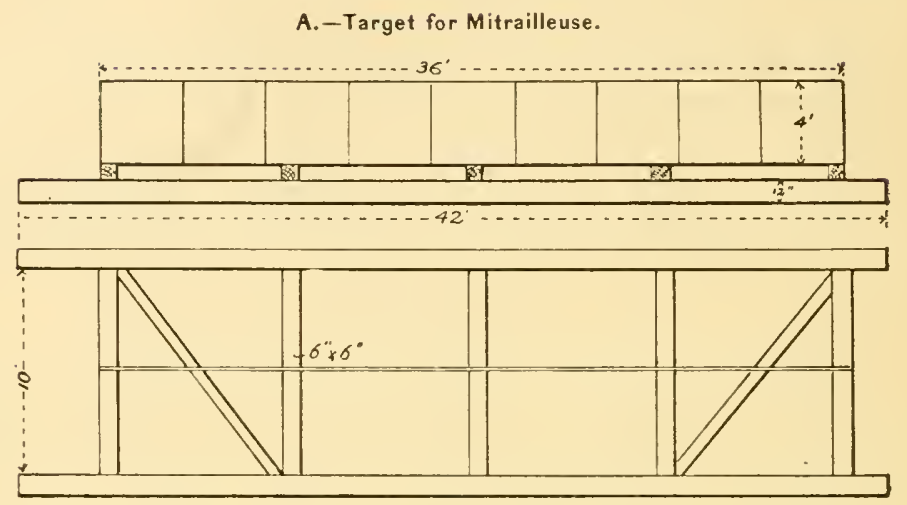

B.-Target for çuns of sma I calijer. drawn by torpedo boat (10 miles" sfeed).

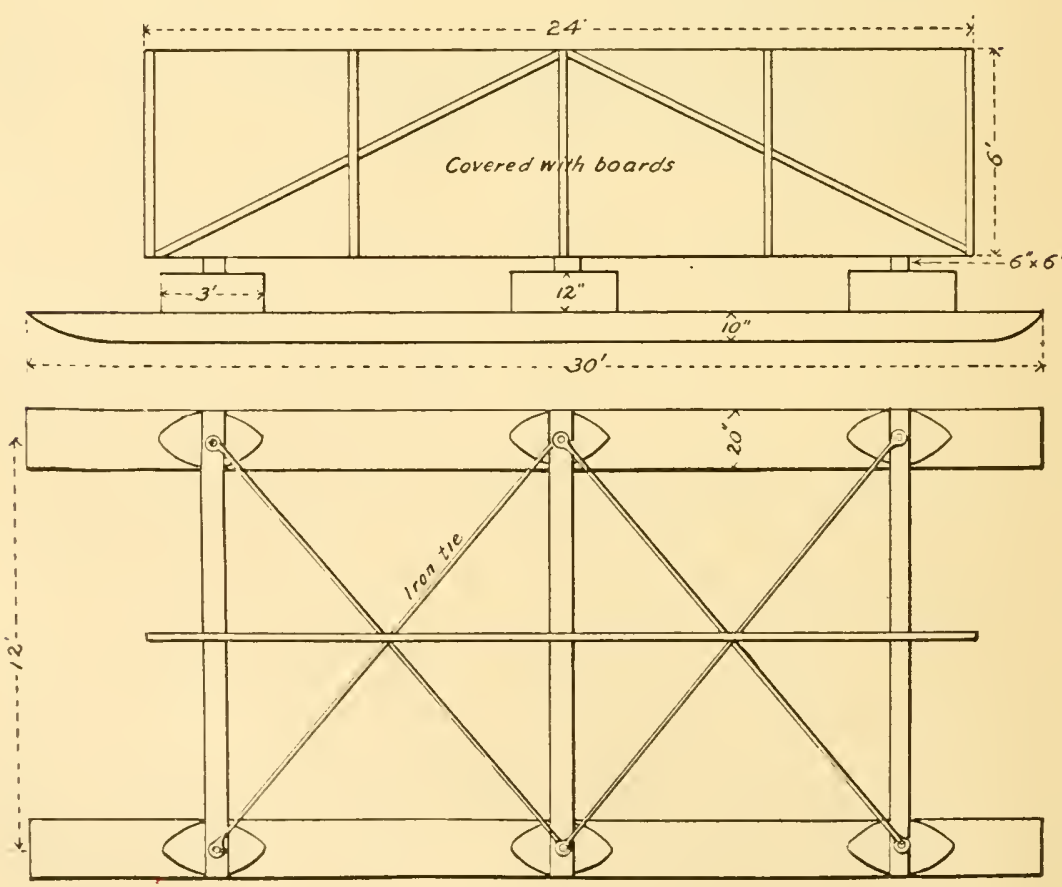




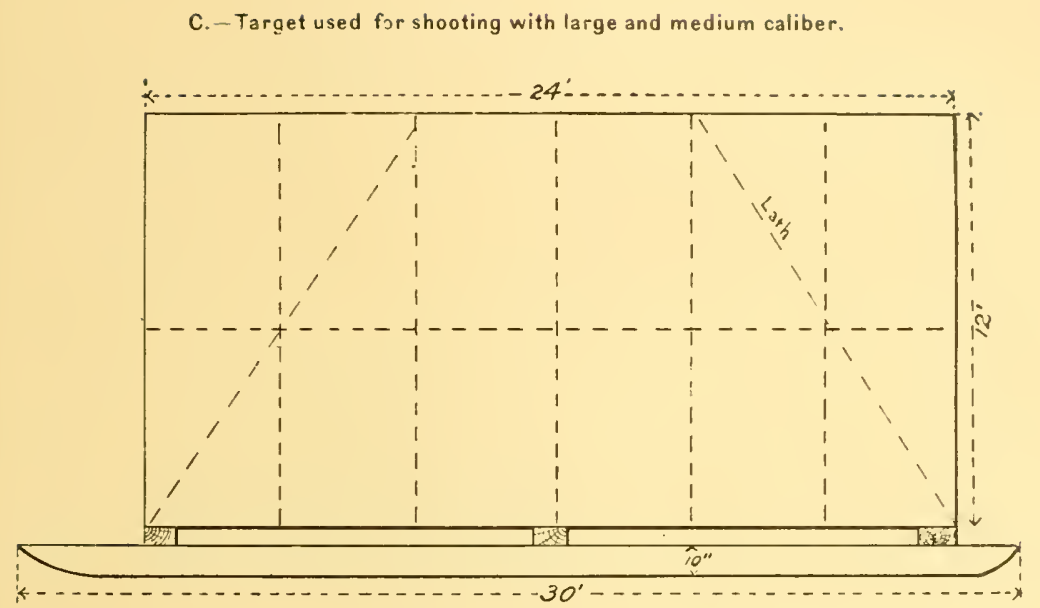

Covered with battens or hoards.

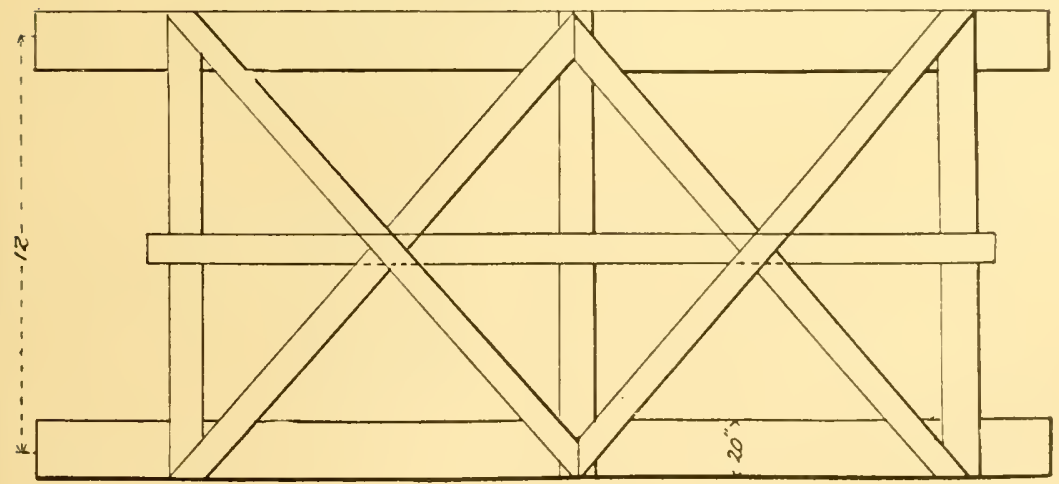





\section{III.-FR ANCE.}

[Reported by Cajt, 'F. Bentley Mlott, Artillery ("orlw, Lnited states Military Attache, Paris.]

Target practice to be executed cach year.

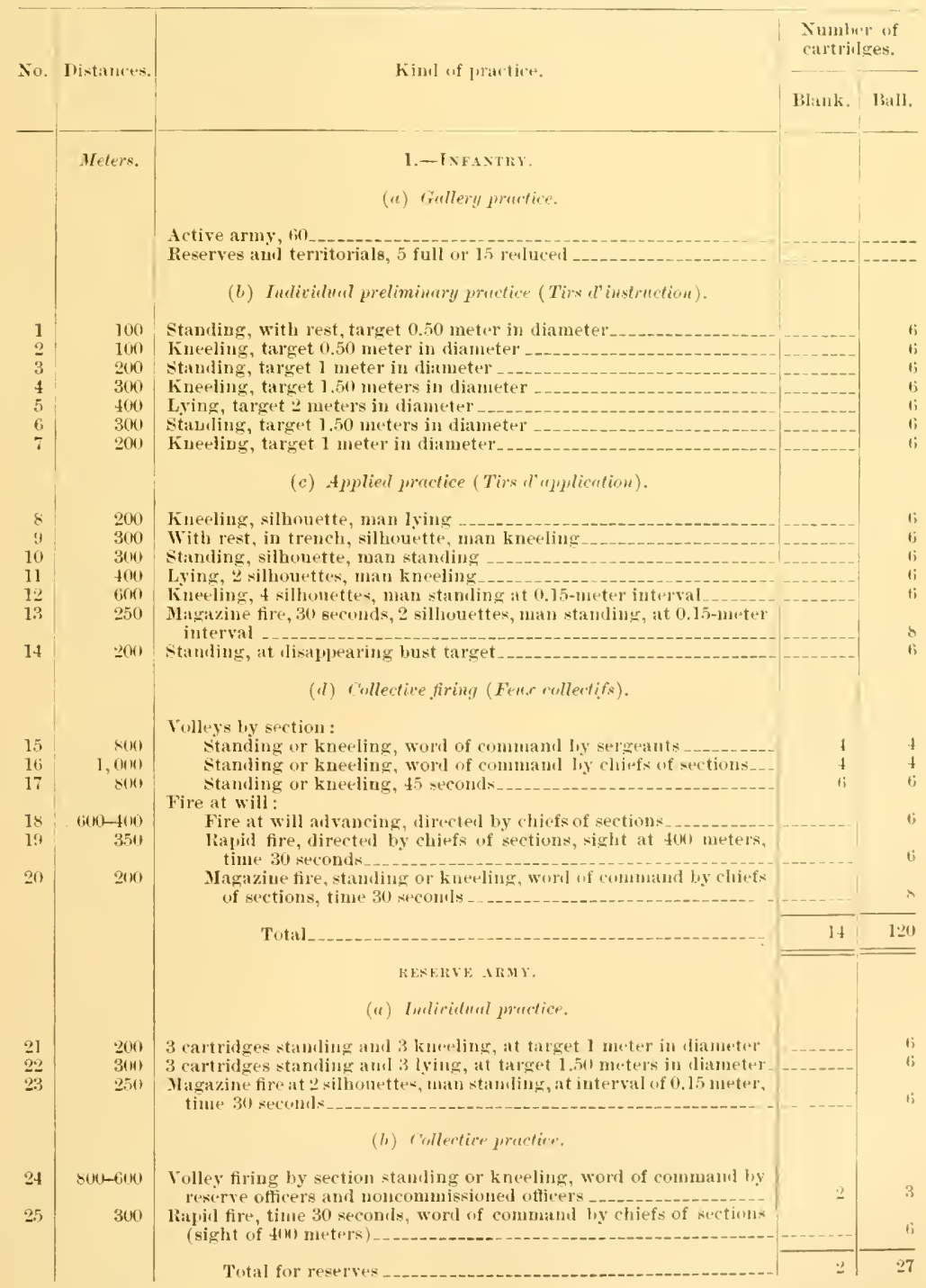


Target practice to be executed each year-Continued.

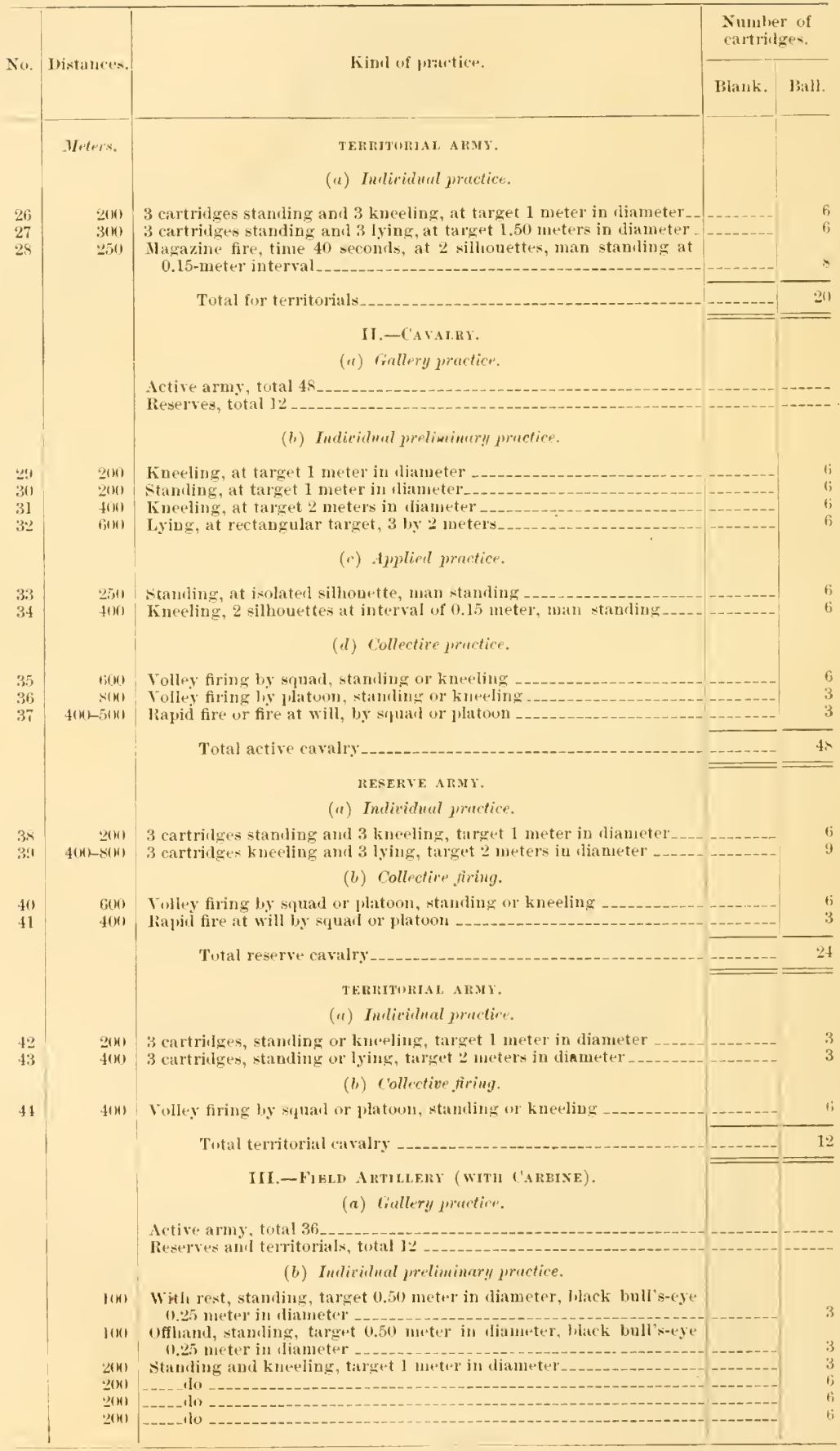


Revolver practice.

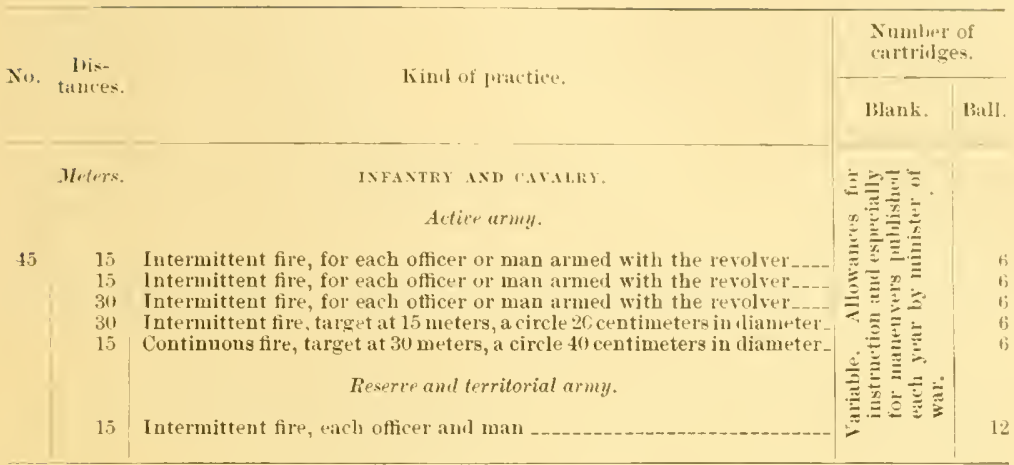

Ammunition allowance.

\begin{tabular}{|c|c|c|c|c|c|}
\hline \multirow{2}{*}{ (1!ganizatiuns. } & \multicolumn{2}{|c|}{$\begin{array}{l}\text { Ball car- } \\
\text { tridges, rithe } \\
\text { or carbiute. }\end{array}$} & \multirow{2}{*}{$\begin{array}{l}\text { Re- } \\
\text { volver, } \\
\text { in- } \\
\text { fantry } \\
\text { anil } \\
\text { cav- } \\
\text { alry. }\end{array}$} & \multicolumn{2}{|c|}{$\begin{array}{c}\text { Blank car- } \\
\text { trilges. }\end{array}$} \\
\hline & $\begin{array}{c}\text { ln- } \\
\text { fatutry. }\end{array}$ & $\begin{array}{l}\text { Car- } \\
\text { alry. }\end{array}$ & & $\begin{array}{c}\text { In- } \\
\text { fantry. }\end{array}$ & $\begin{array}{l}\text { Car: } \\
\text { alry. }\end{array}$ \\
\hline \multicolumn{6}{|l|}{ Active army: } \\
\hline Men armed with ritle or carbine & 120 & $\begin{array}{l}70 \\
48\end{array}$ & & 50 & 18 \\
\hline Men armed with revolver & 120 & 48 & 36 & & \\
\hline \multicolumn{6}{|l|}{ Reserves: } \\
\hline Men armed with rifle or carbine & 27 & 24 & n-con & 20 & 6 \\
\hline \multirow{2}{*}{\multicolumn{6}{|c|}{ Teritorial army: }} \\
\hline & & & & & \\
\hline $\begin{array}{l}\text { Officers } \\
\text { Men armed with ritte or carbine }\end{array}$ & 20 & 12 & 12 & & i; \\
\hline Men armed with revolver & 211 & 12 & 12 & & $\ldots$ \\
\hline \multirow{2}{*}{\multicolumn{6}{|c|}{$\begin{array}{lc} & \text { Blank } \\
\text { Gallery practice, full or reductel charges: } & \text { cartrinlges. } \\
\text { Infantry- } & \end{array}$}} \\
\hline & & & & & \\
\hline \multicolumn{6}{|c|}{$\begin{array}{l}\text { Active army } \\
\text { Reserves or territorials, } 15 \text { reducerl, } 5 \text { full }\end{array}$} \\
\hline \multirow{2}{*}{\multicolumn{6}{|c|}{ Cavalry- }} \\
\hline & & & & & \\
\hline \multirow{2}{*}{\multicolumn{6}{|c|}{ Field artillery (carbine)- }} \\
\hline & & & & & \\
\hline Reserves or territorials & & & & & 12 \\
\hline
\end{tabular}

\section{INFANTRI.}

The education of the soldier in shooting is divided into two distinct phases: First, the preparatory exercises, gallery practice and firing at known distances, conducted under favorable conditions and individually; second, the practice at silhonettes at known and unknown distances, individual or collective skirmish firing, and rolley practice under every variety of conditions, exactly as the soldier would find them in war. 
The men are divided into two classes according to their proficiency.

The ammunition for the year is turned over to the captains, who are allowed a large initiative in its use for the instruction of their men. Each captain selects a lieutenant to supervise the instruction of the noncommissioned officers, and a sergeant, who is especially charged with the details of the practice, teaching the awkward and helping the lieutenant in developing instructors among the men. This sergeant is called the "target-practice sergeant."

An officer is selected by the regimental commander to lecture on the suhjects treated of in the documents furnished by the "École Normale de Tir." Each year this school furnishes the various regiments with copies of lectures delivered there, and with information as to recent progress in matters of target practice.

The old way of establishing a man's ability as a shooter by the percentage he had made in individual practice has been mostly abandoned. At present practical examinations are used to determine the comparative skill.

The prizes given for shooting are equally divided among the various companies.

The colonels, with the approval of the general commanding the brigade, arrange the programs of the collective service practice.

It is recognized that the responsibility for producing good shots rests chiefly with the captain and he is given great latitude to this end.

In each regiment a captain is designated as instructor and range officer. He has a lieutenant as assistant; he is required to be present at all collective skirmish firings, though he may send his assistant to others; he keeps the regimental target book and has the usual functions of a range officer.

Officers are required to learn to shoot and are practiced in using the range-finder and in estimating distances.

Allowance of Amunition.-Each officer and man is allowed the cartridges indicated in the tables on page $4 \%$ Cartridges for competition and examinations are furnished from this allowance. For the collective service practice, 50 cartridges per man are allowed in addition, for each man taking part. The whole allowance is required to be consumed in the course of the year. 
In individual practice the targets, silhonettes or groups, are placed at least $t$ meters apart.

A noncommissioned officer is charged with supervising the markers in the pits.

In the practice at known distances the range officer places on the line of targets a frame 2 meters square covered with ruled paper. He then, before the men arrive, fires 12 shots from a rest, with a rifle whose shooting he is familiar with, aiming each time at the lower edge of a circle traced with a diameter equal to the range divided by 1,000. The center of impact is then determined, and the resulting point at which to aim is marked on a regulation target which is placed to the right or left of the line of targets. This serves as an indication to the men of corrections to make in their aiming. If during the day's shooting the atmospheric conditions change decidedly, the range officer redetermines the point.

There are two markers for each target, one who pastes, and one who signals the score of each shot with a flag.

\section{PREPARATORY EXERCISES.}

These are in general similar to those prescribed in our regulations. The men are first taught to place the piece in the correct position of aim, to do so rapidly and accurately, then the instruction proceeds in the use of the sights, aiming with the different elevations, action of the finger on the trigger, pulling the trigger without deranging the aim, etc.

Instruction with the gun on a rest to induce regularity in aiming, in the amount of front sight to take, etc., proceeds on lines with which we are familiar.

The instructions for the positions standing, kneeling, and lying down are almost exactly the same as in our regulations except that in the position of the "order kneeling" the butt of the piece is held on the right thigh, the left hand grasping the stock.

\section{GALLERY PRACTICE.}

After thorough instruction in the preparatory exercises the recruits are given a course in gallery practice before going on the range. The allowance of ammunition will be found in the table. This practice is executed in the three positions, first at targets, and then at silhouettes. They begin with individual practice at fixed targets, then at moving and disappearing targets, then practice for rapidity, individual practice at word of command, and volley firing. 
The practice with reduced charge is now being largely replaced by practice with the service cartridge at reduced distance (30,50, 60, 100 meters) and gallery practice with reduced charge is maintained only at those posts where no safe range for gallery practice with the service cartridge exists. The latter is considered much more useful to the soldier in preparing him at once for the range and prevents his acquiring the bad habits which come with shooting reduced charges.

Whenever it is impossible to get a safe range within 2 or 3 miles of the post, gallery practice is used with reduced charges. Gallery practice with full charges is given not only to recruits, but to all soldiers, each being allowed 60 cartridges a year. The captain regulates the kind of instruction to be given to each, and he may direct men who have been prevented from practicing on the range, to shoot their allowances in the gallery.

The range preferred is 30 meters, but ranges of 50,60 , or 100 meters may be used if necessary.

The targets used in this practice, i. e., full charges at retuced distances, are of white paper traced with two concentric circles whose dimensions are given in the table. These sheets are pasted on the regulation target frame 2 meters square.

\begin{tabular}{|c|c|c|c|c|}
\hline & Fitugrs. & $\begin{array}{l}\text { Radius of } \\
\text { inner circle. }\end{array}$ & $\begin{array}{l}\text { Padius of } \\
\text { outer circle. }\end{array}$ & $\begin{array}{c}\text { Diameter of } \\
\text { disks. }\end{array}$ \\
\hline $\begin{array}{l}30 \text { meters - } \\
50 \text { meters } \\
60 \text { meters - } \\
100 \text { meters }\end{array}$ & 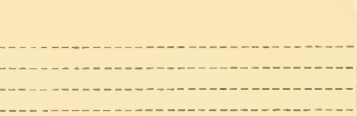 & $\begin{array}{c}\text { 'entimeters. } \\
5 \\
7.5 \\
9 \\
12.5\end{array}$ & \begin{tabular}{|l} 
Pentimeters. \\
10 \\
15 \\
18 \\
25
\end{tabular} & $\begin{array}{c}\text { Centimeters. } \\
3 \\
5 \\
6 \\
10\end{array}$ \\
\hline
\end{tabular}

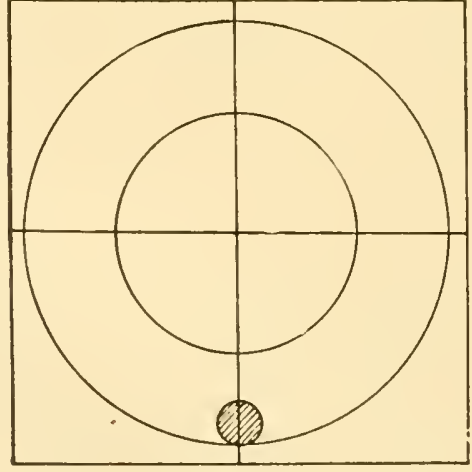

Fig. 1.-Target.

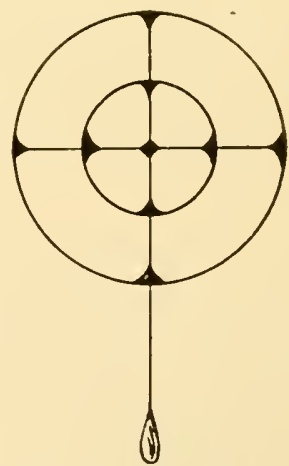

Fig. 2.-Shot grouper.

Figures 1 and 2 show the ordinary target and the skeleton shot grouper; the table gires the dimensions of the target for various ranges. 
The points of impact can be seen from the firing point by the instructor (using a glass if need be), who coaches the man accordingly. The holes are not pasted until after each series of 6 shots. Whatever the kind of practice, it is considerert satisfactory when all the 6 shots of any suries have been put in the outer circle. Generally no conditions are imposed for passing from one practice to another, the instruetor alone judging when the man has done well enough. No record is made of this shooting, though in order to stimulate interest each shot may be counted as in ordinary practice, i. e., 2 points for the inner circle and 1 for the outer.

The practice progresses as follows:

1. The target is a black paster on a white sheet of paper. The man fires one series of 6 shots and the grouping of the holes is remarked. The "shot grouper," as shown in the sketch, is placed over the holes so as to contain in its onter circle the greatest possible number of hits. This practice shows the man how his gun shoots, and enables the instructor to teach uniformity of shooting.

2. When a series of six shots are all contained in the "grouper," the man proceeds to fire at the target as sketched above. The point aimed at is a paster of the dimensions given in the table placed generally as shown in the sketch, though, following the peculiarities of the man and the gun as determined in the first practice, it may be placed in another position whose relation to the center of the target is such as would canse that center to be hit when the paster is aimerl at.

3. The two practices as above being satisfactory, shooting at will and at the word of command, rapid and magazine fire, are next taught in succession. For this practice the men are placed in line, elbows touching, and each shoots at his own target.

The firing at will is at first slow and then proceeds pro gressively to "rapid fire" ( 6 shots in thirty-five seconds). Sometimes a dozen cartridges are given each man and he is allowed to fire as fast as he can during one minute, and the results established. Some of the firings at will, etc, are performed from the magazine.

Noncommissioned officers and men who have qualified as marksmen may be excused from gallery practice if the captain chooses. 
The men pass to the practice at silhouettes only after they have shown proficiency at the ordinary targets.

The shooting at moving and disappearing targets, and the firing for rapidity, are intended to teach the man to load and aim rapidzy without quitting the target with his eye.

In preparation for volley firing, the men are given individual practice at the word of command, then they pass to volleys by squad.

Commanding officers arrange the exercises so as to give as much variety as possible and make the work interesting.

With Reduced Charges. - This practice is the same in principle as that with the regulation cartridge, except that magazine and rapid fire are not allowed. The range is always 15 meters, the sight being at 250 . The target is of white paper, 15 centimeters square, on which are drawn two concentric circles with radii of 5 and 10 centimeters, horizontal and vertical diameters as in the sketch above given. A black disk, 1.5 centimeters in diameter, is pasted at the center so that its lower edge is tangent to the horizontal diameter. The point to aim at is this disk. Metal plates for targets are prohibited, a suitable stop butt of wood, etc., being required.

\section{RANGE PRACTICE.}

The actual firing on the range is divided into five courses.

1. "Tirs d'instruction," at known distances (100 to 400 meters), against circular targets.

2. "Tirs d'application," at known distances (200 to 600 meters), against silhouettes drawn on rectangular paper targets, representing men in three positions.

3. "Tirs de combat individuels," individual combat practice at unknown distances, generally up to 600 meters, ntilizing cover, against fixed or moring silhouette targets, or manikins.

4. "Feux collectifs," volley firing, or firing at will at known distances, or arlvancing, against silhouettes painted in rows, to teach fire discipline and to prepare for 5 ; executed at from 200 to 1,000 meter's.

5. "Tirs de combat collectifs," collective combat practice, under service conditions; the company or battalion advancing to attack, targets being silhouettes, manikins, etc., fixed and moving; volleys, counted cartridges, and fire at will. 
The dimensions and arrangement of the various targets mentioned above will be given with the description of each kind of practice now to follow.

1. Tirs D'Trstruction.--For this preliminary individual practice, the target is a wooden frame 2 meters square, corered with paper traced with two concentric circles of dimensions, according to the range, as follows:

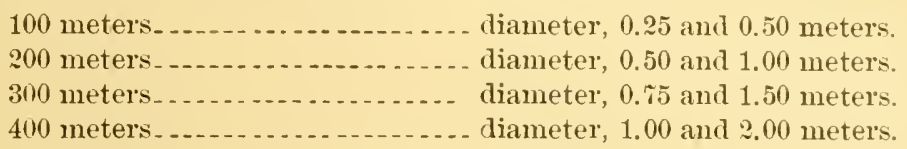

Horizontal and rertical axes, intersecting at the centers, $s$ centimeters wide, complete the target.

A hit in the inner circle counts 2 points; in the outer circle, 1 point; outside of this, zero; ricochet hits, zero.

Each man fires 42 shots during the season at these targets as shown in the tables on page 4\%. He must make, out of a possible 84, a score of 25 before he is passed on to applied practice (No. 2). To this end he may be obliged to fire some of his applied allowance at preliminary practice.

2. Tirs D'APplication. - For this applied practice the targets are all silhouettes of men 5 feet 6 inches tall, lying, kneeling, or standing. The silhonettes are traced in black on a target frame covered with white paper. The progress of this practice is given in the tables page 4\%. For practices numbered $s, 9$, and 10 , the silhonettes are drawn on the lower part of a panel 1 meter wide and 2 meters high. A horizontal line passing througl the top of the silhonette limits the part of the panel to be struck. Every hit in the silhouette connts 2 points; if below the horizontal line and outsicle the silhouette, 1 point.

For practice at Nos. 11 and 13 , two silhonettes are traced on the panel 2 meters square. The silhouettes are framed in a rectangle of the height of the figure and 1.50 meters wide. A hit in the rectangle counts 2 points.

For practice at No. 12, the 4 silhonettes are traced on a panel 3 meters wide by 2 high. A horizontal line across the top of the figures limits the space in which a hit counts. A hit in the rectangle counts 2 points.

In practice No. 14, the bust silhouette on the end of a pole is moved up and down by a marker in the target pit. The targets for the different men shooting are marked distinctly; 
each target is raised and lowered always at the same point. It appears for three seconds and disappears for three seconds.

When the range is not long enough for the distances prescribed, the applied practice is held at such ranges as are possible.

In applied practice a ricochet hit counts 1.

3. Tirs de Combat Individuels.-Executed by all men who have qualified for the "tirs d'application." In the gallery practice a preparation for this practice is made; the various exercises of campaign service are utilized to teach the positions, and blank cartridges used as the instruction progresses. The captain has great latitude in teaching this shooting, in choice of targets, etc. Of course he is limited by the nature of the ground and the range which is at his disposal.

The targets are nsually silhouettes, bust silhouettes, and manikins, fixed and movable. The practice is held after being fatigued with drills and marches, and after double timing.

When there is no maneuver ground near the garrison suitable for this practice, advantage is taken of any presence of the regiment at a suitable range.

Cartridges for this practice come from savings effected from the other practices.

4. Feux Collectifs.-Executed by all the men without distinction as to marksmanship, at a target consisting of panels placed side by side, making a target 2 meters high by 20 meters long. Profiles of 28 silhouettes, men standing with 0.15 -meter interval, are painted in black on this target. The officer commanding the section orders the sight to be used and gives the commands for the fire and the point to be aimed at. Ricochets count as hits. When the garrison range is not suitable for this collective practice it is held at the time and place prescribed for the collective combat firing.

5. Tirs de Combat Collectifs. - The program for this practice is mapped out by the commanding officer according to the material and ground at his disposal and submitted to the generals commanding the brigade, division, etc.

The targets are panels, silhouettes, moving targets, etc., representing the different arms. They are placed beforehand in natural positions and as much under cover as possible. The fire is opened against them and progresses as much as possible as in actual combat. The distances being unknown, 
the ranges are determined by the methods describer. The company is on a war footing, and all officers and men must be present if possible. Before this practice begins the troops must have had a long march or maneuver, so as to simulate actual conditions.

TARGETS. - Revolving and sliding targets, commonly used in our service, are rarely found. Each regiment or commani, as a rule, makes and maintains its own range and targets so that considerable variety will be found within the limits laid down in the regulations, and following the skill, ingenuity, and resources of the command. An annual credit is allowed each organization for material (wood) out of which to make targets for their practice.

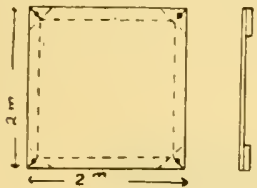

Fig. 3.-Square target.

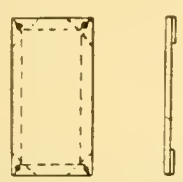

Fig. 4.- Rectangular target.

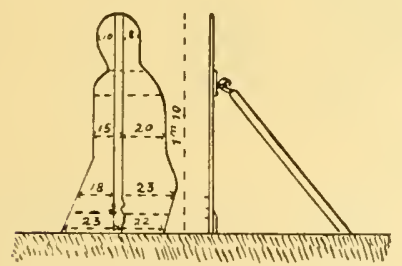

Fig. 6.-Silhouette, man kneeling.

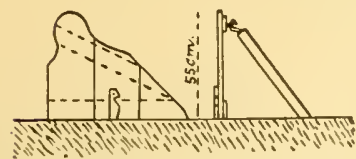

Fig. 7.-Silhouette, man lying down.

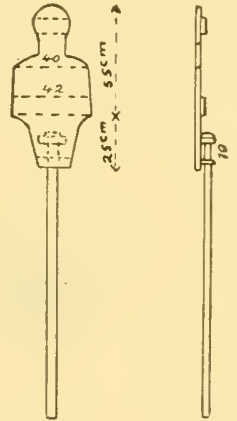

Fig 5.-Bust silhouette target.

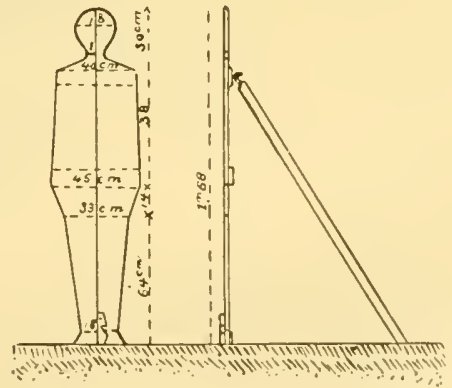

Fig. 8.- Silhouette, man standing.

The amount varies with the necessities of each as set forth in a report, generally 55 francs per regiment and 15 francs per isolated company.

The mirror is of colored or lightly ground glass and is set at an angle of 45 degrees with the line of sight. The man 
sees the rear and front sights and the target through the mirror; the instructor standing on the man's left, opposite

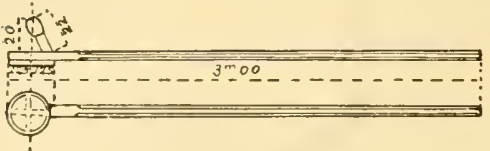

Fig. 9.-Marking disk and shot-hole tamper.

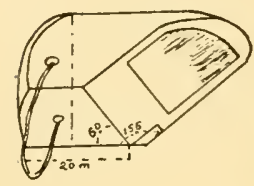

Reflector in normal position.

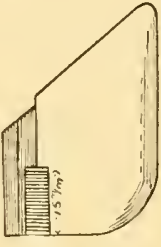

Pieflector seen from below.

Fig 10.-Reflector for examining the bore of infantry rifle from the breech.

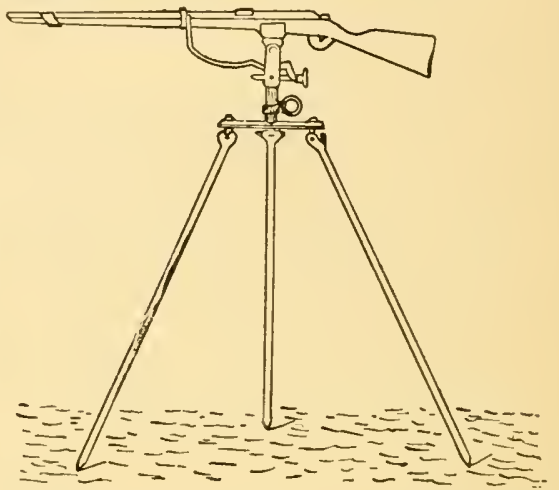

Fig 11.-Tripod for use in the aiming drills and in shooting to determine accuracy of the rifle.

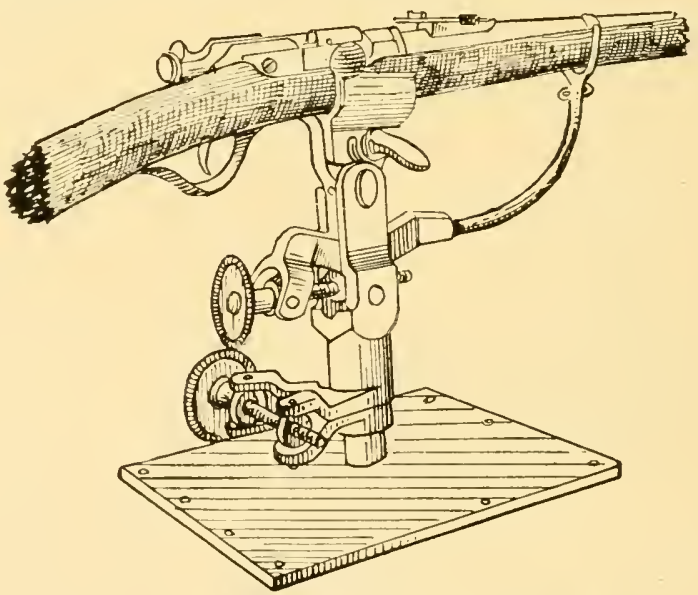

Fig. 12.-Tripod.
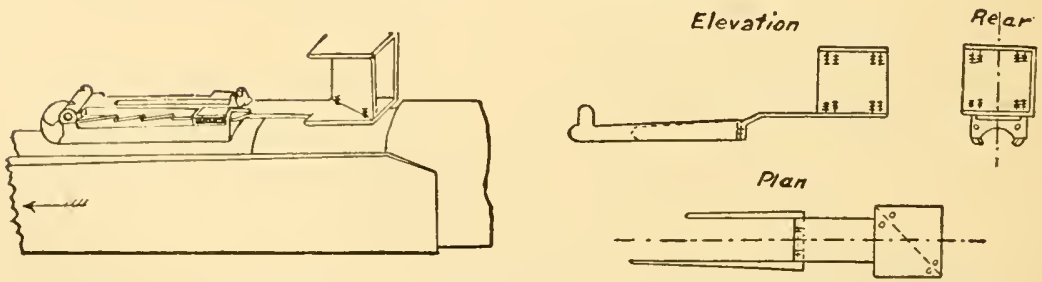

Fig. 13.-Instructor's mirror for verifying the accuracy and correcting the faults of a recruit's aiming.

the mirror, sees in it (reversed) the rear and front sights and the target, and can appreciate at once the mistakes the man is making in his aim. 
The above sketches give the shape and dimensions of the various targets referred to in the tables, of the marker's disk and shot-hole tamper, of the mirror for examining the bore, of the tripod for aiming drills, and of the mirror for teaching aiming.

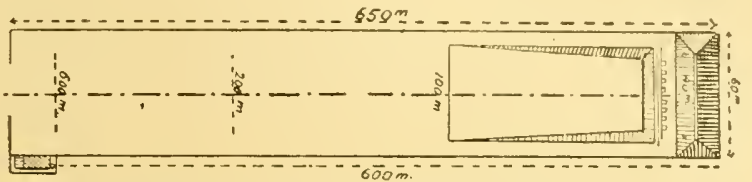

Fig. 14. - Type of a 600-meter range plan.

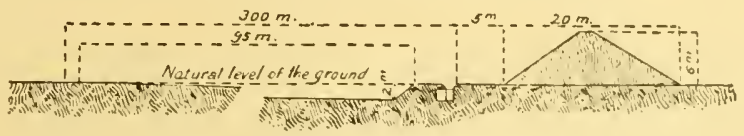

Fig. 15.-Profile, pits entirely sunk below the natural level of the ground.

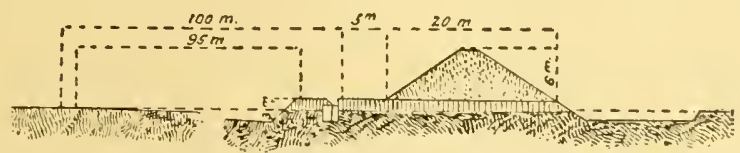

Fig. 16. - Pits half sunk below natural level.

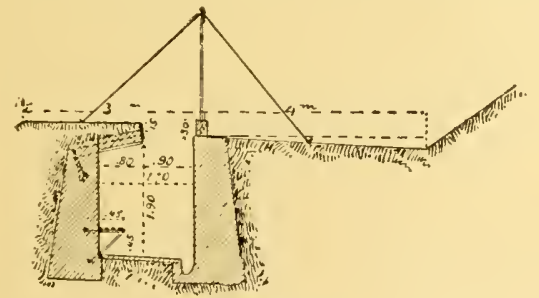

one method.

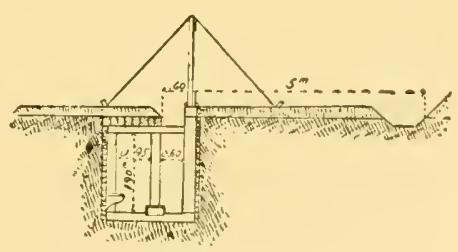

Another method.

Fig. 17.-Section.

RANGES.

The above plan and section of a typical range, butt, and pit need little further explanation. It will be noticed that the earth in front of the target is remored to a depth of about 6 feet, and from there slopes to the natural level at about 100 meters' distance. This is to prevent ricochets.

The targets, of whatever nature, are erected on slides on a heavy wooden sill in front of the markers' pits, steadied by guy-ropes. The hits are signaled and the holes pasted by means of a disk, with a long handle, having a plug on the back for holding the pasters. 
The material and the methods at these garrison ranges are, from our point of view, rather crude, though it is to be said that at the great permanent camps where the infantry, as well as the artillery, get their best exercises in shooting, the arrangements are much better. The work there done, in the matter of actual combat practice on varied ground, with whole companies and battalions moving forward and shooting as in battle, is much greater than we have ever seen in America.

As a rule each garrisoned town has its permanent target range, used throughout the year not only by the infantry and other troops stationed there, but by the gendarmery, the customs and forest guards (donaniers and forestiers), the territorial regiments, and shooting clubs. The latter are generally organized among territorial regiments and consist wholly of territorials, or partly of these and partly of civilians; these clubs are encouraged by the military authorities in every way, ranges lent them, arms and ammmition furnished or sold at cost, prizes awarled, etc.

These ranges are rarely more than 600 meters long, and collective practice on them is generally out of the question. A range is not considered a good one that is less than 1,000 meters long by 100 wide, and permitting of all the firings. except the combat exercises. When a garrison has no permanent range, or it is too small, or circumstances render an additional one advantageous and obtainable, use is made of the occasional or temporary range. This is simply a large tract of land safe for shooting, and placed temporarily at the disposition of the troops (generally in the fall, after the crops are in) by the commune, or hired from the owners. No butts or shelters are ever constructed on such land, and the few trenches that may be dug are filled in at the close of the practice. Such a range is required to be 2,000 by 500 meters for the actual maneuvers of the troops using it, and it must, of course, besides this, present the necessary features of security. On these ranges all the combat practices, even for a battalion in action, can often be held, and at very small, or no expense to the govermment.

\section{CAMPS OF INSTRUCTION AND SHOOTING.}

A short account of these camps would seem to be of interest here. They are primarily intended for the target practice of 
field and siege artillery, but infantry troops also use them for their collective-combat and long-distance practice. The principle of their existence contemplates one for each army corps or equivalent; actually there are seventeen such camps in France and one in Algeria. The army corps which have none use the camps nearest to their region.

By far the best and most important of these camps is the one at Chalons. This is the only place in France where field artillery can maneuver a fire as on the field of battle, and where combat practice of masses of artillery can be had. At this camp is situated also the normal scliool of target practice, which furnishes instructors to the infantry.

The camp at Fontainebleau is also used by the artillery school of application situated there; the one at Bourges as a proving ground for the government foundry of Bourges; the one at Poitiers by the commission of practical study of artillery target practice which has its seat there.

The brigades of field artillery (each of two regiments) use their respective camps in turn, but in order that they may not get to know the ground too well, they are sent every two or three years to a different camp. When the camp is orer 7 or 8 miles from the garrison, the troops go into camp on the ground, and to this end temporary and even permanent shelter has been erected at some of them.

The artillery regiments pass from twenty to twenty-five days each year at these camps.

Infantry collective-combat practice demands a range 500 by 4,000 or 5,000 meters; a range for all arms must be 9,000 or 10,000 by 6,000 or $\%, 000$ meter's.

\section{CAVALRY.}

What has thus far been written applies in its entirety to infantry target practice. The cavalry allowance of ammunition and the ranges at which it is shot can be seen in the tables, p. 48 .

The cavalry troops generally have no special target ranges; they use whatever ones the region affords. The targets are the same for both arms, except that the cavalry does not use silhouette targets of men lying and men kneeling; the bust and standing silhoinettes are the same.

The revolver practice (with ball cartridge) is executed only on foot. 


\section{MACHINE-GUN PRACTICE.}

This matter is now being studied, but as no type of gun has yet been definitely adopted for infantry battalions, nothing has been put in practice concerning target practice for them.

SCHOOLS AND INSTRUCTORS OF INFANTRY TARGET PRACTICE.

There exists at the great camp of Chalons the École Normale de Tir, a thoroughly equipped and most efficient school of infantry target practice.

The object of the school is:

1. To form a body of technical specialists for the school itself, for the military schools of Saint $\mathrm{Cyr}$ and Saint Maixent, and for the technical section of infantry at the ministry of war.

2. To form for each infantry regiment a number of target practice instructors (capitaines de tir) having a thorough knowledge of everything concerning target practice and small arms.

3. To determine upon models of arms and munitions intended for the infantry; to test all modifications proposed; to seek modifications or improvements by research and experiment; to examine all matters submitted to it by the minister of war concerning the rifle, ammunition, or target practice; to experiment with, and test all rifles used in foreign services.

4. To test all rifles coming from the government factories (trimonthly) and all ammunition being issued (monthly).

5. To lay down the rules for infantry fire; to indicate modifications of the drill book made necessary by changes in the arm or ammunition; to propose means for keeping the army informed of all foreign progress in rifles or target practice.

The instructors of the school consist of 15 infantry officers; there is a polygon reserved solely for the use of the school, a complete workshop of arms and ammunition, $\%$ enlisted men and 7 civilian employees.

The students are all captains of infantry who have been recommended by their superiors; each regiment or battalion of chasseurs sends an officer every other year to follow either course No. 1 or No. 2; this makes the number of student, officers in all about 140 .

Course No. 1 lasts five months, from February 1 to June 30. It includes ballistics (a complete study thereof), the effects of fire, construction and fabrication of arms and ammunition, 
and range finders. This course is especially intended to produce instructors for the schools, etc., mentioned above.

Course No. : lasts one month, from October 1 to October 31. It is confined to instruction in the care and preservation of the service rifle. This course is especially intended to give to the regimental range ofticers (capitaines de tir) the necessary technical mechanical instruction.

\section{REGIMENTAL SCHOOLS OF TARGET PRACTICE.}

In each regiment or separate command these schools are organized to teach the officers and noncommissioned officers by lectures, exercises, and questions what each should know. The lecturers and instructors are generally captains who have come from the École Normale de Tir. The officers are taught by regiment or (more frequently) by battalion; the noncommissioned officers and men, by company; the lieutenant. colonel is charged with supervision of these schools.

The course embraces armament and ammunition, estimating distances, range finders, and the various prescribed drills and practices.

CLASSIFICATION OF MARKSMEN, COMPETITIONS, RECOMPENSES.

IxFANTRY. - At the close of the applied practice, on a day fixed by the colonel, the annual classification takes place. Enlisted men who have made a total of 36 points or more in the applied practice form the first class; those who have made less than this, the second class; those who, in preliminary practice, have not qualified for applied practice, the third class.

At the end of the season a practical examination, ordered by the colonels or generals, is held to see what may be the results of the season's work in each company.

The examination consists of applied or individual combat practice for the first and second classes united; preliminary practice for the third class, and, finally, collective practice for the whole company.

All the men not in hospital must be present. No classification is made as a result of this examination; indeed, there is no classification whatever of companies in the regiment, or of regiments, etc., according to skill in shooting; the only classification is that of the men given above. 
The recompenses for shooting consist, for each company, of one silver pin, three hunting-horns embroidered in bullion, and a number of horns made of cloth, equal to one-fifth the effective of corporals and men in the company. These are given to the best shots in order of classification, and are worn on the left sleeve of the coat.

The sergeants of each regiment, armed with the rifle, have a competition for the regimental prizes consisting of nine gold, silver, or embroidered horns; those armed with the revolver also compete for a silver and bronze medal, given to the best shots.

These competitions are not exhaustive; they are finished in one séance; the commanding officer regulates the whole matter.

A regimental order announces the names of the best shots, and this is posted on the bulletin boards at headquarters and in the companies. Commanding officers are directed to allow to the good shots of their commands all the privileges compatible with the interest of the service.

There are no competitions other than those just described.

Cavalry.-The classification, made after the close of the individual practice, is as follows: Men who have made 30 points out of 36 shots with the carbine and put 24 hits out of 36 shots in the target (see table p. 48), using the revolver, constitute. the first class; those who have made 15 points with the carbine and put 12 hits in the target with the revolver, constitute the second class; the others form the third class. The recompenses are the same, and are awarded under essentially similar conditions as for the infantry.

Field Artilleri (carbine and revolver practice).-The classification, made after the "tirs d'instruction," is as follows :

First class: All men who have made 1 point for each shot fired with the carbine and $\frac{1}{2}$ point for each shot fired with the revolver;

Second class: All men who have made one-half the number of points required for the first class;

Third class: The rest of the men.

There aré no recompenses for small-arm shooting in the artillery.

The latest regulations (1902) regarding revolver practice in the field artillery prescribe one range only, 20 meters. The 
target consists of a bull's-eye 5 centimeters in diameter, and two circles of 25 and 40 centimeters diameter. A hit in the inner (25-centimeter) circle counts 2 points; in the outer circle 1 point.

It is to be remembered that in the field artillery, all men not mounted are armed with the carbine and bayonet; all mounted men with the revolver.

\section{UNIFORII WORN AT TARGET PRACTICE.}

Gallery practice is held in drill dress without knapsack or equipment.

The "tirs d'instruction" (preliminary individual practice) take place in drill uniform with equipments and knapsack on, but the latter empty.

The "tirs d'application" (applied practice) are in drill uniform with the knapsack fully packed.

The individual and collective combat practices, and all the volley practice, take place in regular campaign uniform with the full campaign kit packed in place-in other words, heary marching order.

(The drill uniform spoken of above is something like our stable dress and is worn over whatever clothes the season may demand.)

ESTIMATING Distances.

A great deal of attention is given to teaching the men to estimate distances, and officers are thoroughly practiced.

Practice in estimating by sight and comparison is given by the various means used in all services and familiar to our own. This instruction is pursued in connection with other drills at all seasons and in all weather throughout the year. Privates are taught to estimate up to 600 meters, officers and noncommissioned officers up to 1,200 meters by sight, and beyond that by using instruments and the map. The latter work is especially given to officers, but sergeants who show aptitude are also instructed.

At present each infantry battalion has a telemeter, but a movement is on foot to provide one for each company. The telemeters are thus distributed by regiment: One Souchier field-glass stadiometer, and three Labbez, or more recently, Goulier range finders. 
However, most infantry officers have a range-finder field glass of either the regulation or other make, which is their private property, and with this they practice.

Experiments in certain infantry regiments on unknown ground have given the following results in estimating distances by the eye: Officers, skillful in estimating, make a mean error of 12 per cent of the distance; officers not very skillful, 20 per cent; privates of the active army and noncommissioned officers of the reserve army, 30 per cent.

With the Labbez and Goulier instruments, using a tapeline or wire for measuring the base, the mean error is from 2.5 to 3.5 per cent of the distance.

With the field-glass range finder, the mean errors are 7 or 8 per cent of the distance.

It is considered that, to be useful, a telemeter should give the range to within 50 meters.

\section{FIELD-ARTILLERY TARGET PRACTICE.}

The program of instruction in target practice for the field artillery is compreheusive and minute. It comprises-

1. Exercises preparatory to actual practice, riz:

(a) Indoor work for officers only.

(b) Outdoor work for the whole battery.

(c) Simulated fire.

(d) Practice in designating objectives.

2. Actual practice at targets:

(a) Preparatory firing.

(b) War practice.

3. War practice of masses of artillery.

1. (a) The object of this indoor instruction is to teach officers how to conduct target practice under all conditions. The instructor announces whatever conditions he may choose, as to target, weather, estimated listance, etc.; the officer being questioned must then give immediately the resulting commands for the fire; the instructor announces the observed strike of the shot, the pupil continues with his orders as to range, fuse, etc., as though conducting actual practice with his battery. The instructor's oral indications are sometimes replaced by pictorial representation of the hits on a blackboard sketch of the terrain.

The pupils in this exercise are the captains and lieutenants; the field officer is the instructor. This work is continued 
every year to keep the ofticer's in practice and enable them to solve withont hesitation any problem in fire direction.

(b) Following on this work indoors comes its application, using the guns and men in the barrack court, stable corral, or on the drill ground. These drills continue the exercise of the officers in giving commands appropriate for any conditions under more real surroundings, and habituate the men to their work, so that all, especially the noncommissioned officers, absorb the icleas governing the selection of the various kinds of fire and their application.

The captain thus gets his battery in hand and knows what he can expect of the intelligence, quickness, and coolness of his subordinates. He is the instructor. He begins with the simplest conditions, as "fixed target, range so and so," and proceeds to the most complex. He takes the case of changing objective, moving target, rapid fire, distribution of fire, etc., until his directions are translated into correct action almost mechanically. When this is well done he takes his battery to the drill ground for a continuation of the iame work.

When the separate batteries have been sufficiently practiced in this way, the group (three batteries) is similarly exercised by the major in the various group problems. This is always done on the drill field or, better, on varied ground.

(c) The preceding practices have been chiefly mental exercises. In the simulated fire they are continued, but made more real by the use of dummy cartridges and projectiles, and of petards of stont pasteboald holding about 4 ounces of black powder. The latter are caused to explode along the positions supposed to be held by the enemy and give an imitation of his fire, and of the striking projectiles of the battery being instructed.

This work is first done by battery and then by group. It is usually preceded by practice in observation of fire, using petards so as to show the chiefs of platoon how to estimate overs and unders, rights and lefts, as well as the height of the burst. When they are fairly skillful in this, the progress of fire, the whole battery working together, can go ahear as though actual projectiles had been used.

(d) The practice in designating objectives by the officers, sergeants, and pointers, is continued throughont the year in all weather and conditions of the atmosphere. The idea is so 
to exercise these men that there shall be no confusion, misunderstanding, or loss of time at the moment of opening fire upon an objective chosen by the group or battery chief. It is also to develop skill in making rapid changes of objective, concentrating the fire of several batteries or groups on a point, or again distributing it. They commence first with the officers, then with the sergeants and pointers. Especial attention is given to teaching the staff officers (or noncommissioned officers), who would be the bearers of messages from one battery, group, or brigade to another, to carry in the eye the objective which it is desired to shoot at, so that they may unfailingly indicate it to the officer to whom the order is sent. To this end, also, they teach the use of a little deflection scale, held at arm's length and enabling the aid to fix the relation of an obscure target to some conspicuous landmark.

2. Actual Practice at Targets. - This is held on the ranges or camps of instruction spoken of on page 60 .

(a) The preparatory firings are executed under simple conditions, slowly and in such manner as to show up every mistake. This practice is preferably interpolated with the outdoor instruction above described in $1(b)$ and $(c)$.

When the battery is already well instructed, these firings may be omitted and all the ammunition used for-

(b) The war practice.-Besides the captain, each lieutenant must command one of the war practices. The exercise is made by every possible means to resemble actual service. The simplest work of course comes first, but instruction being the object and not hits, commanding officers do not hesitate later in the practice to place the batteries in difficult positions, select indistinct objectives, use indirect fire (pointing on an auxiliary target), and come into battery and open fire with the utmost rapidity. The whole of the preceding and rather tedious work having been a preparation for this practice, the desire is to prove just how effective the artillery would be in actual battle, using the methods taught it, while at the same time receiving excellent training in using these methods. The targets and ranges for the various exercises are arranged with great care and at considerable expense. They consist of panels or canvas-covered frames, silhouettes, single and in rows, dummies, etc., of the shape and dimensions of the different arms of the service and formations in battle. Only small use is made of disappearing, moving, and mechanical 
targets, though some are so arranged as to fall down when hit. Petards are used to disclose a hidden enemy's position, and trenches are dug and walls built to give every sort of useful target.

Each year, for certain days of this practice, the battery is mobilized on a regular war footing to combine campaign service with shooting, drill being had in bringing up and replacing men, horses, and ammunition mnder fire.

3. IV AR PRACTICE of MAsses.-Every year groups of horse batteries and regiments of field artillery are sent to the camp of Chalons to constitute, on almost a war footing, the whole artillery and ammunition train of an army corps. These troops begin work together with the instruction described under $1(b)$ and $(c)$ and proceed up to actual firing, following every phase of battle in which the artillery takes part. Separate exercises are had for divisional artillery, corps artillery, horse artillery, and then all working together. Some of these are in combination with infantry and cavalry troops.

The orders for the target practice of field and siege artillery for the summer of 190\% direct the following series of practice for the troops named at the camp of Chalons:

Series 1.-From April 30 to 1 Lay 25, directed by General Feldmann, commanding the artillery of the sixth region: Six field batteries of the twenty-fifth regiment; 7 of the fortieth; 9 of the eighth; 2 horse batteries of the fifth division of cavalry; 4 batteries of the fifth battalion of foot artillery; 1 battery of the fourth battalion of foot; total, 29 batteries.

Series 2.-From May 30 to June 25, directed by General Groth, commanding the artillery of the twentieth region: Six field batteries of the twenty-fifth regiment; 6 of the fortieth; 9 of the thirty-ninth; 2 horse batteries of the fourth dirision of cavalry ; total, 2:3 batteries.

Series 3.-From June 30 to July 31 : Four field batteries of the second battalion of foot artillery ; 6 batteries of the fourth battalion; 5 of the fifth; 5 of the sixth; 6 of the seventh; 6 of the eighth; 7 of the ninth; 6 of the sixteenth; total, 45 batteries.

WORK AT THE CAMPS OF INSTRUCTION.

As kefore stated, all the target practice using real projectiles takes place on the polygon, or camp of instruction, at the disposal of the regiment concerned. The general commanding the artillery of each army corps has the direction 
of the practice of the troops of his corps at the camps as well as in their garrisons. The minister of war designates each year the camp at which each regiment will perform its target practice. A regiment of field artillery puts in twenty-five days at its camp.

Generals whose commands comprise artillery, brigadier generals who in all likelihood will reach such commands, and certain staff officers, are permitted to attend and be instructed at these exercises.

It may be said in general that the instruction of the field artillery in target practice is most businesslike and thorough, and that one object alone is kept in view, viz, to get quickly into action after thoughtful and exact preparation, and then to reach the target immediately. The education to this end is minute, but not a projectile is fired in practice until the theoretical instruction and the fire drills $(1 a, b, c, d)$ have taught every grade what he is to do and how to do it with calmness and confidence. From the very start of the preparatory instruction to the war practice of masses of artillery, one guiding principle is evident: to teach the artillery how to quickly select and suddenly reach its proper target; all work, however pretty or interesting, which does not point directly to this end is omitted or minimized.

If practically the whole time of the artillery is taken up in teaching it to shoot, the government does not spare expense in material or ammunition. Besides the cost of maintaining the camps and sending the regiments to them, there is a large bill for ammunition fired each year. Every gun is allowed about 100 rounds per annum of war ammunition for target practice ( $2 a$ and $b$ ); in addition to this there is allowed a considerable extra expenditure for (1) the instruction of officers who would become captains of reserve batteries upon mobilization; (2) for reservists and territorials, and (3) for the war practice of masses at Chalons.

Each gun is allowed about 75 petards and 8 blank cartridges per year for instruction purposes, as well as an ample supply of dummy cartridges and projectiles.

SCHOOLS AND BOARDS OF ARTILLERY TARGET PRACTICE.

From what has preceded, it will be evident that all the camps of instruction, and especially the one at Chalons, are practical schools for studying and teaching artillery target 
practice; moreover, at the Artillery School of Application at Fontainebleau this subject naturally receives considerable attention both theoretically and practically (the school has its own polygon); but besides these establishments there sits at Poitiers a board for testing artillery, which is charged with examining the best methods to employ in the fire of field, siege, and seacoast artillery. At the same place, and using in part the personnel of this board, is established the practical course in artillery fire whose object is to exercise captains of artillery (chiefly seniors) in the rigid application of the accepted methods of fire of their arm, and also to give them, as far as is possible, on the polygon of Bourges, instruction in the methods in use for siege and seacoast artillery fire.

There are three courses during the year, each two months in length, as follows: From February 15 to April 15, from April 16 to June 16, and from September 15 to November 15. The student officers are sent in classes of 20 or 30 , and remain for two months. For the second month of each course a certain number of field officers are sent to the school to be exercised in organizing, directing, and criticising the conduct of target practice of several batteries united.

The instructors of these courses consist of a director (colonel or lieutenant colonel) and three field officers or captains; there is permanently attached to the institution one foot battery; a field battery from the garrison of Poitiers is available when needed.

\section{CLASSIFICATION OF GUNNERS. RECOMPENSES.}

At the conclusion of the preparatory exercises, and before the actual target practice begins, the captain holds a competition, first, among men already qualified as first-class gunners (maîtres pointeurs); second, among the rest of the men for the class of gunner (pointeur).*

* Since the above was written a new regulation has been published on the subject of classification and recompenses for gumners in the field artillery. It prescribes that each year, when the instruction has been completed, and before or during the ammual target practice, according to circumstances, the colonel will appoint a board to hold a competition in aiming among the batteries of the regiment.

Each captain selects a gun detachment commanded by a sergeant. Men who are already first-class gumers are not selected.

The same piece is used by all detachments.

Three tests are given to each detachment. Time and accuracy form the basis of the marks. The tests are prescribed with great detail, but 
The competition is wholly practical and consists of aiming the piece six separate times at an inclistinct target at 2,000 yards; the accuracy of each laying is determined by an instrument. Each trial is given a mark according to accuracy and time taken; to this is added the captain's appreciation of the man's ability. The results establish the provisional list of gunners.

After the target practice season, when the captain has been able to judge of the gunners' abilities, he makes an additional note to the list before made, and establishes the annual classification of gumners (first and second class) in the battery.

In each regiment there is a competition at the close of the target season among the first-class gunners chosen, one from each battery. There are money prizes awarded, and also the first three are allowed to wear a grenade embroidered in gold on the left sleeve. All first-class gunner's wear a grenade in red cloth on the left sleeve. The names and grading of gunners are published as in the infantry.

ARTILLERY SHOOTING CLUBS.

Another evidence of the fostering care of the French gorernment in the matter of artillery shooting is found in the "sociétés de tir an canon" which have been formed of reserve or territorial officers and even civilians. These clubs are encouraged in every way; cannon and ranges lent them, ammunition given or sold at nominal rates, prizes and honors conferred, etc. It can not be said with any accuracy what the practical results may be, but these clubs keep up an interest in artillery shooting, and are an evidence of the feeling on the subject.

they can not be understood withont a thorough knowledge of the sight and the aiming mechanism of the rij-centimeter gun, and are therefore not reproduced here.

The detachments are classified in order of merit. For every regiment there are accorded 4 grenades embroidered in gold, which are giren to the pointers of the batteries standing $1,2,3$, and 4 on the merit roll.

Shooting-Competition.-At the close of the target season there is held in each regiment a shooting-competition among the batteries. Each captain designates a detachment commanded by a sergeant to represent the battery. The conditions are minntely prescribed, and the value to be given to each result. Each detachment fires 3 shots, and the classification ensues from the results obtained. The prizes are in money: first prize about $\$ 6$, second $\$ 4$, third $\$ 2$. The prize is divided among the men of the detachunent winning it. 
SIEGE AND SEACOAST ARTILLERY.

The method of procedure in teaching target practice to the personnel of the siege and seacoast artillery is the same as that ontlined above for field artillery, taking into account the differences in the material and the problems of fire.

The instruction begins at the garrison with indoor work for officers and sergeants in the use of instruments, and the solving of fire problems.

The instructor proceeds with practical exercises and mental drills on the lines already explained until fictitious fire problems can be solved on sight; then work of the whole personnel at the guns with all the instruments and combat elements, simulated fire and the observation of fire, bring the instruction up to the time for actual practice at targets. This target practice for the battalions of foot artillery manning siege and land-fort guns takes place at the polygons or camps already described. All the problems of attack and defense of siege and fortress artillery are there worked out and illustrated; direct and indirect fire, attack by night with elements of fire obtained in the day, etc. The men not serving the guns are required to be present and observe the conduct and effects of the fire. Each battalion (6 companies) passes about three weeks of every year at its camp and expends about 450 rounds of war ammunition, besides the petards, blank rounds, ete., used in instruction in its garrison.

The battalions stationed at coast forts receive the preparatory instruction outlined above, and when money and other considerations make it possible, are also sent for the practical firing at a polygon. Their target practice with great guns takes place in the harbor they garrison. The preparatory firings by piece at fixed targets teach the men the drill of the piece under service conditions, and illustrate the problems of fire they have been theoretically solving. The rest of the firing, the whole battery or group of batteries in action, progresses to conditions as near those of actual war as the locality and equipment make possible. Every post is occupied, the complete range-finder service assured, the mine lefense manned, and communication established with the coast torperloboat defense. The target is towed in the field of fire whereever an enemy would be likely to go. This target generally consists of two catamarans of about the shape and dimensions given in the sketch, joined by a towline about 300 feet long. 
Each catamaran consists of three timbers about 40 feet long and 12 by 12 inches in section, braced together by iron rods as shown.

The center log supports a light wooden frame on which is stretched canvas painted in black and white blocks as indicated.
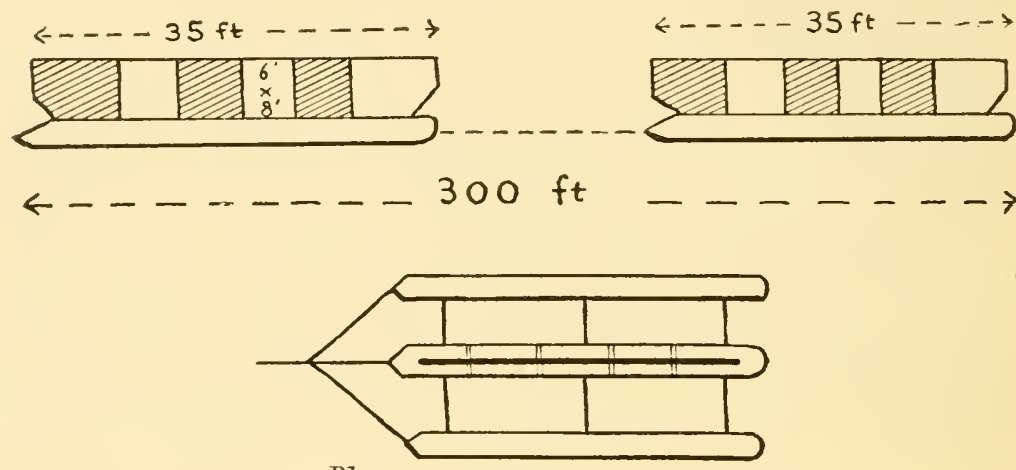

Fig. 18.

The observation of the fall of the shot with this target is very easily made.

On page 71 reference was made to the courses in artillery fire at Poitiers; the instruction at that place also includes siege and fortress artillery. A course for coast artillery is established for three weeks every year under similar conditions in one of the great fortified harbors, generally at Toulon. The officers designated to take this course are generally those who would have a coast command in case of mobilization. The battalion of foot artillery at Toulon furnishes the men for this work.

It is not believed that the instruction in target practice of the French coast artillery is as efficient and up to date as that of the field and (perhaps) garrison artillery. In the first place, since 1871, the French have been ardently occupied in perfecting their field and frontier fortress artillery, and the coast artillery has generally come in for second place. The events of 1898 directed more attention to the coast works, and the completion of the new armament for the field artillery has withdrawn a serious burden from the war budget; therefore it is to be expected that the activity in construction of the last three years is not to be dropped and other improvements in the coast artillery will doubtless follow. 
Also, as a matter of fact, a great many of the coast forts are garrisoned wholly or in part by infantry, who perform the service of the guns in addition to their other work; hence, target practice at these works is not what it should be. Of the 108 batteries of foot artillery only 42 man the coast defenses. The colonial (formerly marine) artillery furnishes $2 \mathrm{~S}$ more batteries and 6 companies of workmen for this service; in other words, on a peace footing there are hardly 500 officers and 10,000 trained artillerymen to man the coast defenses of the whole country. When it is remembered that it would probably require 5,000 men to furnish one relief for the guns of Brest or' Toulon alone, the lack of technical personnel is evident. These reasons seem sufficient to account for the fact that target practice in the coast artillery is not so thor. ough as it is in the field artillery; and yet the allowance of ammunition for practice with the great guns is, from our standpoint, enormously liberal. 



\section{IV.-GERMANY.}

[From translations of official firing regulations furnisherl by Lient. Col. Janes B, Kerr, Nintl Cavalry, luited states Mlilitary Attache at berlin, and from other official somres, compared and arranged by Capt. E. A. Edwards, Twenty-fifth Infantry.]

\section{INFANTRY.}

The conrse of instruction for the German infantry soldier comprises preparatory instruction and exercises, range firing, and field (combat) firing. To these may be added instruction or demonstration firing, and examination firing.

The course is desigued to train the infantry soldier in the efficient use of the rifle in battle, and the importance of the subject requires that the exercises be conducted with great exactness, and so directed that at the end of his first year of service the soldier shall be trained to use his rifle in actual warfare. In subsequent years the knowledge acquired is completed and strengthened.

The captain is primarily responsible for the instruction of his company; he is assisted by the officers and noncommissioned officers, who are expected to have a thorough acquaintance with the theory of fire and practical skill sufficient to regulate defective rifles, besides having a theoretical and practical knowledge of the duties of their grades in the direction of fire in action. If convenient, the captain may direct special practice for the noncommissioned officers.

The battalion and regimental commanders, while respecting the initiative of company commanders, supervise the instruction, more particularly the field and instruction firing. They may direct special practice for officers, and generally sisonld keep themselves informed of the aptitude and efficiency of the various instructors.

Higher officers in their inspections see that the instruction has been properly conducted, and by directing special exercises can compare the firing efficiency of the various troop units. The results are not published.

PREPARATORY INSTRUCTION.

The instructor first explains to the recruit in simple language how the shot is fired, the use of the sights, principles of aiming, the different kinds of targets, etc. The recruit is 
drilled in a variety of movements of the arms and bocly, with and without the rifle, designed to give strength and ease of movement to the joints and muscles used in aiming, care being taken to avoid undue fatigue or weariness. This is followed by position, pointing and aiming drills, at first with rests, afterwards offhand, standing, kneeling, and lying, behind entrenchments, rifle pits, or trees, aiming at targets.

During this period the recruit is also practiced in estimating distances, the course concluding with the firing of blank cartridges aiming at targets, and with gallery practice.

\section{GALLERY PRACTICE.}

This may be conducted in rooms, halls, barrack yards, or on open drill grounds, and is usually directed by an experienced noncommissioned officer. The rifle or carbine used resembles the ordinary service weapon, into which is inserted a smaller barrel of aluminum bronze of a caliber of 5 millimeters. Reduced targets are used, so that at 5 meters the

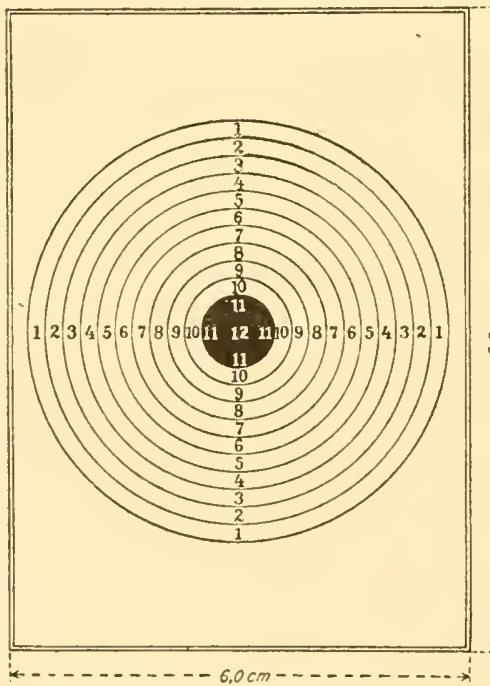

Fig. 1.

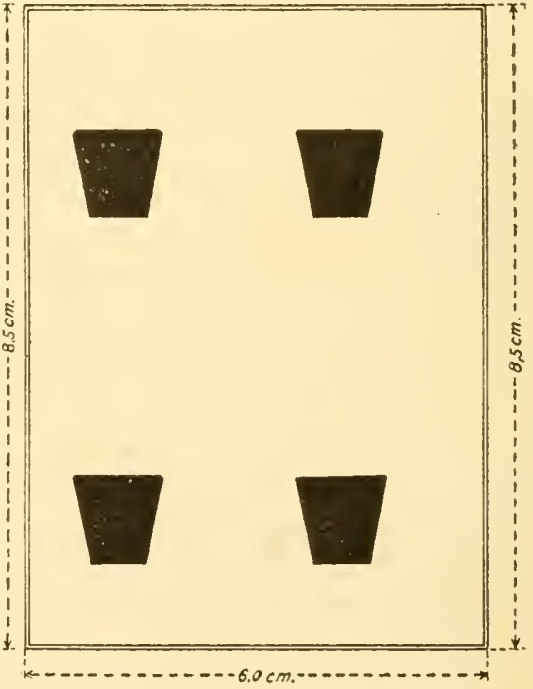

Fig. 2.

appearance of the target and the probability of a hit are about the same as with the regular target and rifle at 1.00 meters. The bullet used in the gallery-practice target will, at 5 meters, penetrate from 2 to $2 \frac{1}{2}$ inches into soft wood, and has an extreme range of 80 meters.

Targets for gallery practice are shown in figs. 1 and 2. 
For the first instruction a target of white ground, marked as shown in tig. ?, is recommended.

Until the recruit has attained proficiency in the preparatory course he is not allowed to fire with ball cartridges. Special attention is paid to the eyesight and visual defects are to be promptly reported, so that if necessary the surgeon may prescribe the glasses to be worn.

The judicious choice of positions, use of cover, correct estimate of distances, rapid loading, proper adjustment of sights, rapid and correct aiming, are qualities that require to be frequently exercised and are indispensable to the efficient use of the rifle in action. The pointing and aiming exercises are therefore to be continued during the whole service of the soldier, but they must never be too long continued, and are to be executed strictly with a view to maintaining efficiency.

ESTIMATING DISTANCES.

Instruction in estimating clistances is carried on during the same time as that of the preparatory instruction in the use of the rifle. Men are expected to be able to estimate correctly distances up to 600 meters; officers, noncommissioned officer's, and skilled privates up to 1,000 meters, and are exercised in estimating even greater distances. Officers are required to be able to read, correctly and readily, distances on large-scale maps.

The training is progressive, units of distance being fixed in the mind by pacing and observation, and the eye trained by frequent practice in different conditions of surface, light, etc.

RANGE FIRING.

In these exercises officers and men are expected to acquire and maintain the highest degree of efficiency, so as to be skilled in the use of the rifle in all positions, but this, while important, is to be regarded only as a preparation for field firing. Firing at known distances being necessary for thorough instruction, relatively more time and ammunition are properly devoted to those exercises.

The progressive development of the course necessitates the division of those firing into classes. The second class consists of all men in their first year: of service, and men of longer service who have not qualified for the first class. The first class includes the men who have marle the scores required in 
the second class. A special class is formed, consisting of offcers, noncommissioner officers, and reenlisted men, who have twice qualified in the first class. The classification is made at the end of the practice year by the battalion commander on the recommendation of the company commander.

Poor shots must be sent back to the preparatory exercises, and the company commander must personally see that they are sufficiently instructed before allowing them to resume firing with ball cartridges, but turning back is to be aroided with men in the higher classes, who should have special attention when they have difficulty in making the scores required in their class.

The target year is from October 1 to September 30 following, and is named after the year in which it terminates. All officers and men of the company join in the practice unless prevented by absence. As a rule, in all firings men fire with their own rifles and are required to go through all the exercises prescribed for their class during the year. This mar necessitate advancing to higher ranges men who have repeatedly failed in the preceding exercises. The firings at 300, 400 , 500 , and 600 meters may take place out of their order if the conditions of the range require it, but if possible this must be avoided with men of the second class, who should also qualify in their preliminary firing before commencing their regular practice.

The preliminary practice must be conducted with the greatest exactness and attention to detail. The instructor corrects faults as they occur. Frequently this must be done while the rifle is in position, and the correction must be made briefly and calmly so as not to tire the recruit or make him nerrous.

Men whose sight, even with the aid of glasses, is less than three-fourths of the normal, may be authorized by the battalion commander to go throngh the firings at reduced distances. These men are to be examined each year before the firing exercises commence, and are debarred from promotion to a higher class. Fine weather should be selected for practice, especially for recruits.

Not more than two qualifying scores should be fired on one practice day, nor less than the number of shots prescribed for one exercise. A qualifying score will be considered as made, when the last 3 or 5 shots have the required value. 
When the required score is made in less than 3 or 5 shots, the other shots in the score will be fired nevertheless.

An immoderate number of cartridges must not be allowed to poor shots to enable them to make the required scores. Except in special cases, the supplementary allowance will not exceed the number prescribed for the preliminary or regular practice in which engaged.

\section{TARGETS.}

The frames are of wood covered with pasteboard or cloth.

The following patterns are used in range firing:

The ring target (fig. 3). The dimensions are shown in the illustration. The diameter of the inner circle No. 12 is 10 centimeters; the diameters of the rings from the center outward increase by 10 centimeters. Rings 10 and 11 are

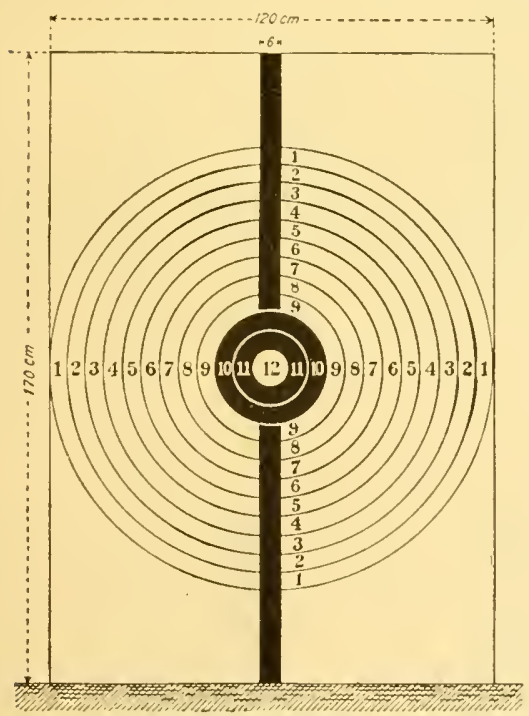

Fig. 3.-Ring target.

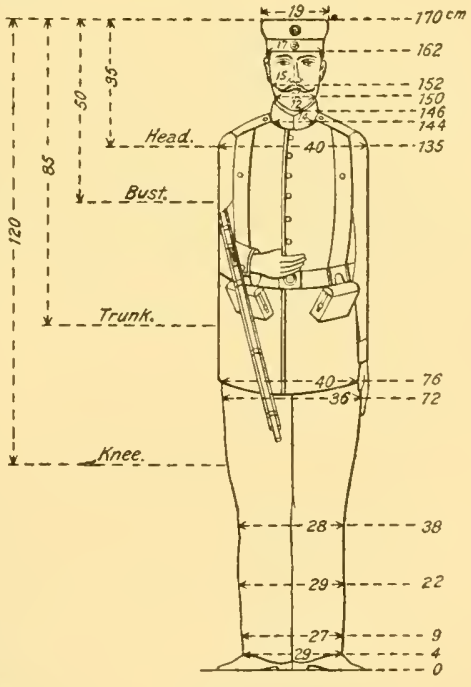

Fig. 4.

black and with 12 constitute the bull's-eye. A vertical black band 6 centimeters wide runs through the middle, interrupted at the bull's-eye. The division between rings 10 and 11 is marked in red, the line of the rings from 1 to 9 may be marked in pencil where they pass through the vertical band.

The figure target (fig. 4) and its varieties, the head, bust, trunk, and knee targets of the dimensions shown in the illustration. The figure is a colored representation of an infantry 
soldier, the equipments and trousers of dark shade. The details of the face, dress and equipment need not he shown.

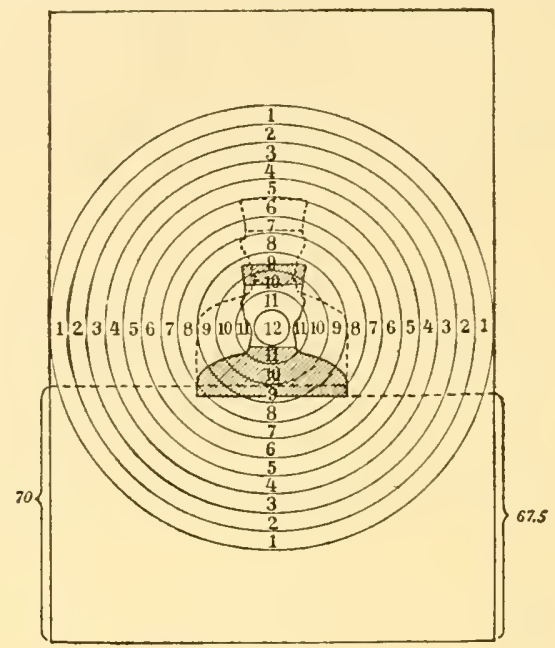

Fig. 5 .

Combined ring and figure targets, ring-head and ring-bust, (fig. 5). The head or bust target is pasted on a ring target of gray pasteboard so that the middle vertical line of the

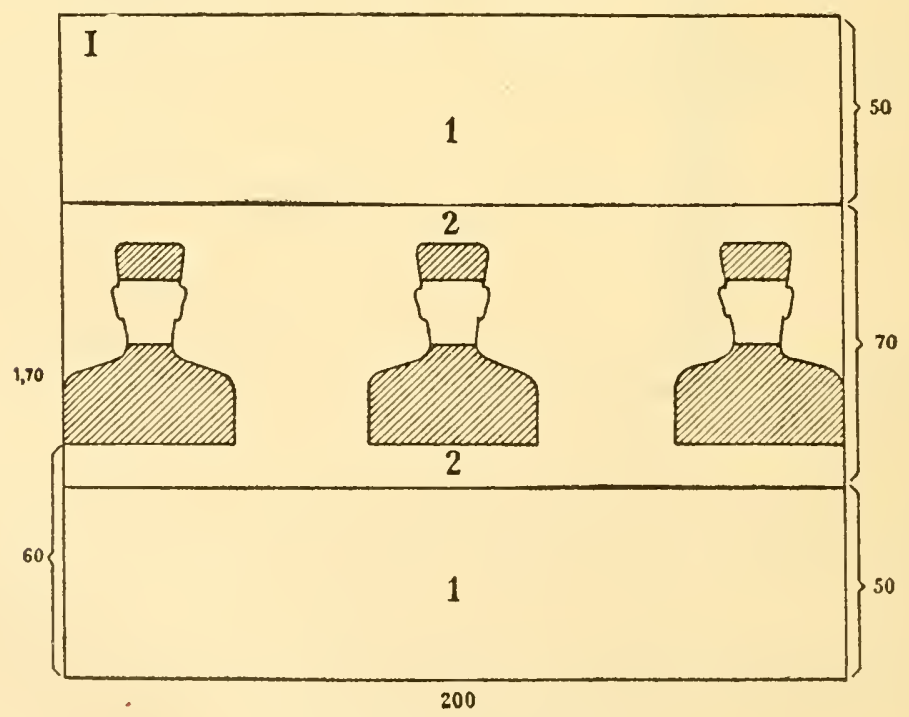

Fig. 6.-Section 400-meter targets.

figure coincides with that of the ring target. The lower edge of the head target is $6 \% .5$ centimeters and that of the bust 
target 00 centimeters from the bottom of the ring target. The lines of the rings are marked in red, where they pass through the figure. Rings 10 and 11 are not blacked and the vertical band is omitted.

Section 400-meter targets (fig. 6). Three bust targets are pasted on a target of gray pasteboard or cloth covered with gray paper as indicated. The horizontal lines diriding the target into three bands marked in red are not visible at the firing point.

The section 500-meter and 600-meter targets are the same as that for 400 meters, except that the widths of the bands vary. The central band for 500 meters is 102 centimeters, for

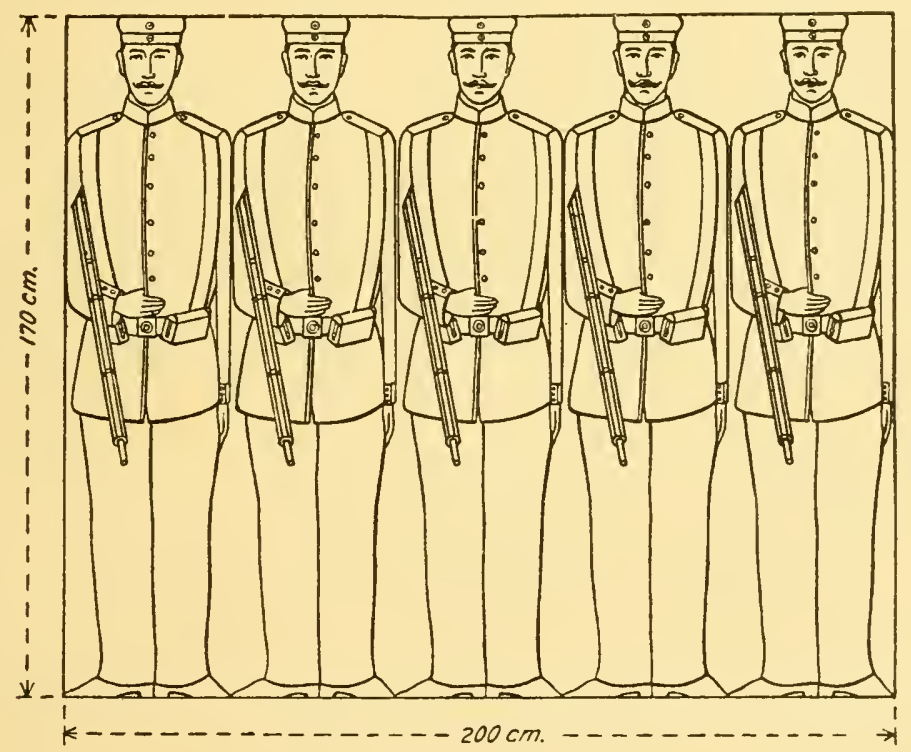

Fig. 7.-Section-figure target.

600 meters 130 centimeters; the outer bands are $3+$ centimeters and 20 centimeters, respectively. The central band

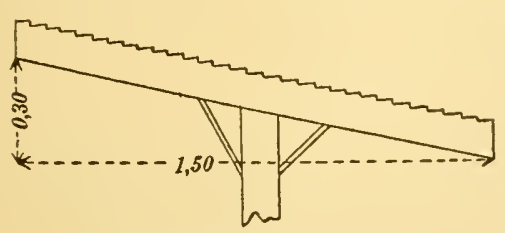

Fig. 8.-Gun rest. is known as No. 2, the outer bands as No. 1 .

Section-figure target (fig. \%).

The figures are the full height of the target.

For fire, standing with rest, a support shown in fig. 8 is used. The notches, of which there are 30, are numbered for convenience in finding each man's position of rest. 
Each battalion receives a money allowance for targetpractice material allotted under this head in the annual estimates.

VALUE OF HITS.

On the ring, ring-head, and ring-bust targets, from 1 to 12 , according to the number of the ring struck.

On the section targets $(400,500$, and 600 meters $)$ all direct hits in the center band, either in the figures or in the intervals, count 2 , hits in the outer bands count 1 .

On the section-figure target all direct hits either in the figures or in the intervals are comnted 1.

The location of ricochet shots is first shown by placing the disk over them, and they are then signaled as misses by waving the disk in front of the target.

The value of the hits is shown by rectangular tablets on which the figures from 1 to 6 are in black on white ground, the Roman character $\mathrm{V}$ being used instead of the figure 5; from 7 to 12 the figures are in white on a black ground, 10 being indicated by a white circle, 11 by a vertical white band, and 12 by two white squares placed diagonally on the tablet. A white cross indicates a hit in the target ontsicle the rings.

Grooves are arranged in the marker's shelters, in which the signals are made to slide in and out of view. They are manipulated under the direction of the noncommissioned officer at the butt.

ALLOWANCE OF AMMUNITION.

Of the ammunition allowed to each company there are reserved:

1. For field firing, 60 rounds per man of the effective strength on which the allowance is based.

2. For special practice of officers, 500 rounds.

3. For instruction firing, at least $\$ 00$ rounds.

4. For competitive firing, 15 rounds for each officer and noncommissioned officer.

5. For special practice prescribed by higher authorities, 12 rounds for each noncommissioned officer and private. This number must not be exceeded.

Cartridges are allowed for testing and regulating rifles. At the beginning of the target year a general testing and regulating of all arms issued to recruits is recommended. The remainder of the allowance is used for range firing. No savings should be made in the allowance for field firing, for 
special practice of officers, or for instruction firing. If, however, there should be any, the eartridges will be used for field firing in the following year.

Savings made in the allowance for testing and regulating, and under heads 4 and 5 supra, will be used for supplementary target practice, special exercises for noncommissioned officers, field firing, and lastly for competitive firing by privates.

RANGE FIRING.

The firing is divided into preliminary and regular practice for each class, as follows:

\section{Second class.}

PREIMINARY PRACTICE, THREE SHOTS AT FACII RANGE.

\begin{tabular}{|c|c|c|c|c|}
\hline No. & Range. & Position. & Target. & Qualifying score. \\
\hline $\begin{array}{l}1 \\
2 \\
3 \\
4 \\
5 \\
6\end{array}$ & $\begin{array}{r}\text { Heters. } \\
150 \\
150 \\
150 \\
200 \\
2(1) \\
200\end{array}$ & $\begin{array}{l}\text { Standing, with rest } \\
\text { Standing } \\
\text { Prone, with rest } \\
\text { Prone } \\
\text { kneeling } \\
\text { Standing }\end{array}$ & $\begin{array}{l}\text { King } \\
\text { Ring-beatl } \\
\text { King-bust } \\
\text { Riug }\end{array}$ & $\begin{array}{l}\text { All shots to be above } 7 \text {. } \\
\text { All shots to be above } 4 \text {. } \\
\text { All shots to be above } 7 \text {. } \\
\text { All shots to be above } 4 \text {. } \\
\text { Do. } \\
\text { Do. }\end{array}$ \\
\hline
\end{tabular}

REGLLAR PRACTICE, FIVE SHOTS AT EACH RASGF.

\begin{tabular}{|c|c|c|c|c|}
\hline 1 & 150 & Prove, with lest & Bust _._. & 3 hits in figure. \\
\hline 2 & 200 & Plone - & Truuk & Do. \\
\hline 3 & 300 & Prone, with rest & Ring-head ___-_... & 5 lits, 25 points. \\
\hline 4 & 300 & Kneeling _. & Ring-bust _ & 5 hits, 20 piuts. \\
\hline 5 & 400 & Prove _. & Section, 400 ueters & $t$ lits, 6 points. \\
\hline 6 & 400 & Kneeling _... & Section figure & 4 hits. \\
\hline 7 & 500 & Plone & Section, 500 meters & 3 hits, 4 points. \\
\hline 8 & 600 & Ḱneeling _. & Section, 600 meters. & 2 hits, 3 points. \\
\hline 9 & 300 & Standing _. & Section figure & 3 hits. \\
\hline
\end{tabular}

In the sixth practice 5 shots are fired in one minute, and in the ninth practice the shots are fired in thirty seconds, in each case commencing with two cartridges in the clip or magazine, according to model of rifle used.

First class.

PREIJMINARY PIRACTICE, TIIREE SHOTS AT EACH RANGE.

\begin{tabular}{|c|c|c|c|c|}
\hline No. & Range. & Position. & Target. & Qualifying scote. \\
\hline $\begin{array}{l}1 \\
3 \\
2 \\
4\end{array}$ & $\begin{array}{r}\text { Heters. } \\
150 \\
150 \\
200 \\
200\end{array}$ & $\begin{array}{l}\text { Standing, with rest } \\
\text { Standing }\end{array}$ & $\begin{array}{l}\text { liing } \\
\text { Fing-head }\end{array}$ & $\begin{array}{l}3 \text { hits all above } 8 . \\
3 \text { hits all above } 6 . \\
3 \text { hits all above } 5 \text {. } \\
\text { Do. }\end{array}$ \\
\hline
\end{tabular}


First class-Continued.

REGLLAR PRACIICE, FIVE SHOTS AT FACH RANGE.

\begin{tabular}{|c|c|c|c|c|}
\hline No. & Range. & Position. & Target. & Qualifying score. \\
\hline $\begin{array}{l}1 \\
2 \\
3 \\
4 \\
5 \\
6 \\
7 \\
8\end{array}$ & $\begin{array}{r}\text { Meters. } \\
150 \\
200 \\
300 \\
300 \\
4100 \\
5100 \\
600 \\
3100\end{array}$ & $\begin{array}{l}\text { Prone, with rest } \\
\text { P'rone } \\
\text { Prone, with rest } \\
\text { Kneeling } \\
\text { Prone } \\
\text { Kneeling } \\
\text { Prome } \\
\text { Fineeling }\end{array}$ & $\begin{array}{l}\text { lle:ul } \\
\text { Bust } \\
\text { Ring-head } \\
\text { Ring-hust } \\
\text { Section, } 400 \text { meters } \\
\text { Section, } 500 \text { mettrs } \\
\text { Section, } 600 \text { neters } \\
\text { Siection figure }\end{array}$ & $\begin{array}{l}3 \text { hits in tigure. } \\
\text { Do. } \\
5 \text { hits, } 30 \text { points. } \\
5 \text { hits, } 25 \text { points. } \\
5 \text { hits, } 7 \text { wints. } \\
4 \text { hits, } 5 \text { points. } \\
\text { 1). } \\
4 \text { hits. }\end{array}$ \\
\hline
\end{tabular}

Practice No. 8 is the same as the ninth practice in the second class.

Special class.

PREIIMIXARY PLATTLE, THREE SHUTS AT EACH RASHE.

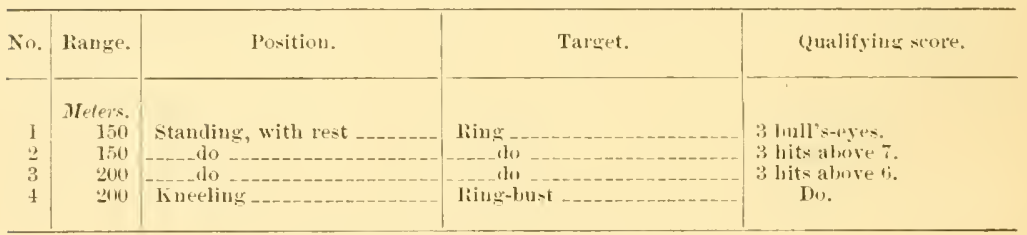

REGLIAL PRATITE, FIVE SHOTS AT FACH RASG

\begin{tabular}{|c|c|c|c|c|}
\hline 1 & 150 & Prone, with rest & $\mathrm{Heal}$ & 4 bits in figure. \\
\hline 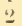 & 200 & Prone & Bust. & I). \\
\hline 3 & 300 & Proue, with $\mathrm{r}+\mathrm{at}$ & limu-burl _... & 5 hits, 35 points. \\
\hline 4 & 300 & Kneeling - & 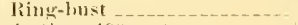 & 5 lits, 31) juints. \\
\hline 5 & $4(10)$ & Promet & Seetion, 4 (n) meter & 5 hits, 8 puints. \\
\hline (j) & $514)$ & linetling .....- & Sectimu, 5111 nueters......... & thit-, li juints. \\
\hline 7 & (i) & $P^{\prime} r_{1}+$ He & Seetion, fitho netr.ls:- & In. \\
\hline 8 & 3010 & $\ldots+-\infty 10 \ldots$ & Sertien figm»........ & 5 hitu. \\
\hline
\end{tabular}

The eighth practice is the same as the ninth practice in the second class.

SERVICE ON THE RANGE.

Signaling, Marking, AND Scoring.-A noncommissioned officer and three men from the firing company are at each target. The noncommissioned officer is responsible for the correct signaling and marking of each shot, severe penalties being prescribed by the military penal corle for intentional falsification.

When a shot is fired the target is withdrawn, the shot hole marked with a pencil, and the value signaled to the firing point by exposing the proper signal at the side, or on top. of the marker's shelter, according as the shelter is on the side of or below the target. The location of the hit on the target 
is shown by placing the disk over the shot hole for a moment after the target is returned to position. This proceeding is repeated after each shot, the last hit being marked in pencil, and the preceding one then pasted up. The marking party is relieved every two hour's. At the firing point a noncommissioned officer is charged with the arrangements necessary for the practice. He sees that the ammunition, targets, and other material are provided, assigns markers, scorers, etc. A noncommissioned officer or competent private may be detailed to keep the scores.

Before firing commences the officer in charge sees that everything is in order, he inspects the targets, noting the number of shot holes already pasted np; he directs the practice, oversees the work of the markers and scorers, and at the conclusion of the firing he examines the targets, connts the number of hits, comparing them with the scores, and certifies over his signature to the correctness of the record, and to the amount of ammunition expended. The officer is assisted by one or more noncommissioned officers, and all are reliever every two hours.

The men are marched to the range under arms, wearing for preliminary practice, cap, belt, and cartridge-pouches; during the regular practice, the helmet, belt, and cartridge-boxes are worn, the knapsack packed or empty as may be prescribed, cooking utensils, and overcont carried as on the march. Arms are inspected before and after all firings. The bayonet is not fixed during the practice.

The firing detachment, as a rule not more than five men to each target, forms in rear of the firing point, and each man steps in turn to the firing point, delivers his shot, and returns to his place in ranks. The scorer observes the signal from the target and calls out the name of the firer and the result of the shot, which is immediately entered in ink on the company record and in the small target-record book carried by each soldier.

BADGES.

To the best shots badges are distributed annually as follows: To the noneommissioned officers and reenlisted men of each company, 3 ; to the men of each company in battalions of higher strength, 8 for the first class and 5 for the seconch class; in the battalions of lower strength, 7 and 5 , respectively; to noncommissioned officers and reenlisted men of the 
instruction battalion, 3 ; and to the men of the first class, 20 .

Badges are also allowed to noncommissioned officers and reenlisted men serving at recruiting depots.

In the competitions for these insignia only men who have fully qualified in their respective classes are considered. The badges are assigned to those who qualified with the least number of shots; if these be equal, to those making the most bull's-eyes and hits in the figure, and, lastly, to the highest number of points.

Men who obtain badges receive with them a certificate from the company commander, and notation of the same is male on descriptive books and discharge papers. The badge is forfeited by reduction to a lower class, but is restored when standing is reestablished. It may be retained by the winner when transferred to the reserve.

HONOR PRIZES.

Separate annual competitions are instituted for officers and noncommissioned officers. The wimner, if an officer, receives a sword or saber, and if a noncommissioned officer, a watch, presented in the name of the emperor. The prizes are inscribed with the name of the winner and year of the competition. To each army corps three prizes are allotted, one for the best shot among the officers, and two for the best shots of the noncommissioned officers of the infantry.

The competitions are held on the various ranges in July or August of each year. All officers and noncommissioned officers who are required to take part in the firing at known distances, present at the time and not prevented by sickness or other duty, take part. Field officers are permitted to compete in the officers' match. Detacher officers and noncommissioned officers take part in the competitions at the place where they are serving, if they have not joined in that of their own corps in the same year. Those who have won prizes are debarred from further competitions.

The target used is the ring target with 24 rings, instead of 12 as in the ordinary target. The service arm and ammunition are used.

The range is 150 meters, number of shots $r, 3$ standing, with rest, 4 standing offhand; one sighting shot, previonsly announced, is permitted. The prize can not be won with a score of less than 140 points. The highest score wins, ties being decided by counting the value of the shots backward. 
The names of the officers who win prizes are borne on the anmual reports of the corps and are made known to the emperor. The honor prizes obtained by noncommissioned officers are entered in their descriptive registers and noted on their discharge papers.

OTHER PRIZES.

To each battalion the sum of 80 marks is allowed annually for the purchase of prizes, having the character of souvenirs, for noncommissioned officers and privates in the higher classes. Money must not be given as prizes. The range and target is the same as already described. Three shots are fired standing, offhand; the highest score wins, ties being decided by counting the shots backward; if all the shots are equal, they are decided by additional shots. Men in the second class are not permitted to compete.

\section{RIFLE BATTALIONS (JÄGERTRUPPEN).}

The rifle battalions (jägertruppen) have a higher standard of markmanship, more extended range practice, and a larger allowance of ammunition than the infantry of the line. The course of instruction is in general the same, with a few modifications. Men who on account of prolonged absence, etc., are deficient in skill, have additional practice to enable them to keep up with their class.

The range firing must be carried out in the order prescribed, the omission of any of the series being forbidden, nor must regular practice be commenced until the preliminary firing is finished. The firings at 400,500 , and 600 meters may, however, take place ont of their turn in the series if the conditions of the range require this to be done.

The classification is the same as for infantry of the line, except that having once qualified in the first class, officers, noncommissioned officers, and reenlisted men pass into the special class, and, if of superior skill, into a higher class, "A," at the discretion of the company commander.

The course of range firing for the second and first classes is conducted in scores of 3 shots at each of 10 exercises of preliminary practice, and in scores of 5 shots at each of 16 exercises in regular practice. The exercises for each class are nearly the same, the main distinction being in requiring a greater number of hits or points to qualify in the first class. 
BADGES, PIRIZES, ETC.

Each year after the firing is completed badges are given to the best shots, six to the special class, five to the first class, and four to the second class. The competitions for badges, honor, and other prizes are conducted as in the infantry, 75 marks being allowed to each battalion for the purchase of prizes-15 marks to each company and 15 marks for the battalion noncommissioned officers.

\section{CASH GRATUITIES.}

In addition to the badges and prizes mentioned, a inonthly allowance of 360 marks is made to the battalion of the guards and 180 marks to the other rifle battahions for distribution in equal parts to the 30 best shots of each company.

The right to receive this gratuity is determined at the end of the target year by competition among those men who have qualified in their class in the regular practice at full distances. Men who have been tried and convicted by court-martial forfeit the right. In special cases, on the recommendation of the company commander, approved by the battalion commander, their right may be restored. Noncommissioned officers and one-year volunteer's are excluded. Men of class A who receive the gratuity while serving with the colors lose their right to it when transferred to the reserve.

The gratuity is awarded to the 30 men in each company who have qualified in the regular practice in the least number of shots; when the number of shots is equal, to the greatest number of hits in figmre targets, and, lastly, to the highest number of hits and points. A board, composed of a lientenant, a noncommissioned officer, and a private selected by the men of the company, the selection approved by the battalion commander, makes out the lists from the records of the companies which are submitted to them. The names are published in orders.

ALLOWANCE OF AMMUNITION.

Of the ammunition allowed to each company, 90 rounds per man are reserved for field firing, 1,000 rounds for special practice for officers; for instruction fire, a minimum of 200 rounds; for competitions, 15 rounds for each officer and noncommissioned officer and 3 rounds for noncommissioned officers and privates; for special exercises directed by company 
commanders, 15 rounds for each noncommissioned officer and private, and the same number for exercises prescribed by the higher authorities.

\section{CYCLISTS.}

Cyclists take part in the course of instruction like other soldiers with the arm of their corjes and have a little additional practice, using the carbine model 1891. The practice is for all classes, the firing is done in the dress prescribed for regular practice, and is without qualifying conditions.

TECHNICAL TROOPS.

The classification is the same as for infantry, but the amount of range practice prescribed is much less, being for the second class of engineer troops, 3 preliminary scores of 3 shots, and 5 scores of 5 shots each in regular practice, at ranges from 150 to 500 meters; for the first and special classes, 2 preliminary and 5 regular scores at from 150 to 600 meters. The railroad and telegraph troops, for the second class, 3 preliminary and $t$ regular-practice scores, and for the other classes, 2 preliminary and 4 regular scores at from 150 to 300 meters; the number of shots in each score of preliminary and regular practice being the same as for engineers-3 and 5, respectively.

Competitions for badges are held annually, there being allowed to each company of engineer and railroad troops, 7 for the first slass and 5 for the second class. Of honor prizes one is allowed for officers and two for noncommissioned officers of the engineer and technical troops in common. For the purchase of prizes for the annual competitions among the noncommissioned officers and privates, 50 marks are allotted to each battalion of engineer's and railroad troops; $3 \% .50$ marks to the telegraph troops; 12.50 marks to the balloon detachment, and 9 marks to the operating' detachment of railroad troops. The competitions are conducter as in the infantry.

\section{AMMUNITION}

From the company allowance of the engineer troops 15 rounds per man are reserved for field firing, 5 for individual fire, and 10 for collective fire; for competitive firing 15 rounds for each officer and noncommissioned officer, and 3 rounds for each private. Some cartridges are also set apart for testing 
and regulating arms. In the railroad and telegraph troops 10 rounds are reserved for field firing, 5 for individual fire, and 5 for collective fire; the other reservations are the same as for engineers.

\section{INSTRUCTION FIRING.}

This firing is intended to demonstrate the ballistic properties of the rifle, and serves not only to form a well-trained staff of instructors, but to instruct the men as to their conduct in battle when direction of fire fails. The more elementary exercises are directed by the company commander, for the benefit of the noncommissioned officers and men at the beginning of the firing instruction season; important ones are conducted by battalion commanders. All are carried on under the most favorable conditions, sources of error being as far as possible eliminated. Some examples are:

TO SHOW THE ERROR OF DIFFERENT RIFLES.

A grood shot seated behind a table fires, from a rest at a ring target at 350 meters with the same point of aim, ! shots from an accurate rifle, 9 from one shooting high, and 9 from another shooting low. The center of impact of each group of shots will measure the error of the weapon, and show what point of aim should be taken with each rifle.

DEMONSTRATION OF THE ACCURACY OF RIFLES AT IIFFERENT RANGES.

Good shots, seated, the rifle at a rest, fire 2. shots at each of the distances :350, 500, and 600 meters, at a ring target or at a white target of the same dimensions, having marks to serve as points of aim.

A comparison of the extent of the several shot gromps with the size of varions objectives in war, illustrates the reason for fixing the distance, determined by the accuracy of the weapon itself, at which a hit may be expected.

Other exercises are arranged to exhibit the trajectory of the bullet; the effect on fire when the bayonet is fixerl; penetration of the bullet into various substances-earth, wood, iron plates, ete.

FIRING UNDER SPECIAL CONDITIONS.

Single men in shelter trenches fire at 200 meters at targets placed behind cover, screens, sandbags, etc., through openings about 4 by $\approx$ inches (100 by 50 millimeters), or targets 
representing the supposed cover, with the opening or embrasure in darker shade, may be used. This familiarizes men with the different kinds of cover used in war and their influence on fire, and shows the importance of watching shots and correcting aim in firing at small objectives. The exercise may be extended when practicable to detachments firing at from 400 to 700 meters at low, wide targets, fixed or disappearing.

The principles of indirect fire, night firing in attack or defense in siege warfare using rests, etc., are also illustrated by appropriate exercises.

\section{EXAMINATION FIRING.}

Every year examination firing is held in the field. This affords the higher anthorities means to observe the training of the men in firing under conditions resembling those of actual war, and the aptitude and efficiency of the officers and instructors.

The firing is directed by brigade or division commanders, or by the commander in chief, and the exercise, partaking of the nature of an inspection, is prescribed by the inspecting officer.

A special allowance of ammunition is made for this firing.

\section{TARGETS FOR FIELD FIRING.}

The authorities responsible for the instruction in firing are also responsible for the adequate use of appropriate targets.

In addition to the figure target and its varieties used in range practice, other targets are provided to simulate war conditions in the various field-firing exercises. They are constructed of light wood frames covered with cotton cloth, or, in case of figures and silhouettes, of papier-maché, the object being lightness and ease of management. Fixed targets representing men, horses, guns, and caissons of full size have legs to be driven into the ground, or they may be attached by wooden pins to base-pieces permanently placed in position.

Infantry is represented by figures or silhouettes of men lying down, front and side views, and others showing them advancing, retiring, and walking or running to the right or left. Cavalry is shown by figures of mounted men in motion and at a halt, front, side, and rear views artillery by varie- 
ties of the figure target, showing men of the gun detachment facing to the front, and by silhouettes showing them facing the gun, rear view of horse without rider, and by side, front, and rear views of horse and rider; by targets showing front views of guns and caissons of full size, and others showing the upper half of these objects. The half-target guns and caissons, when posed, have the appearance of being on a rererse slope. Men figures are grouped with the gun and caisson targets as they would appear in actual service. See figures 9 to $1 \%$.

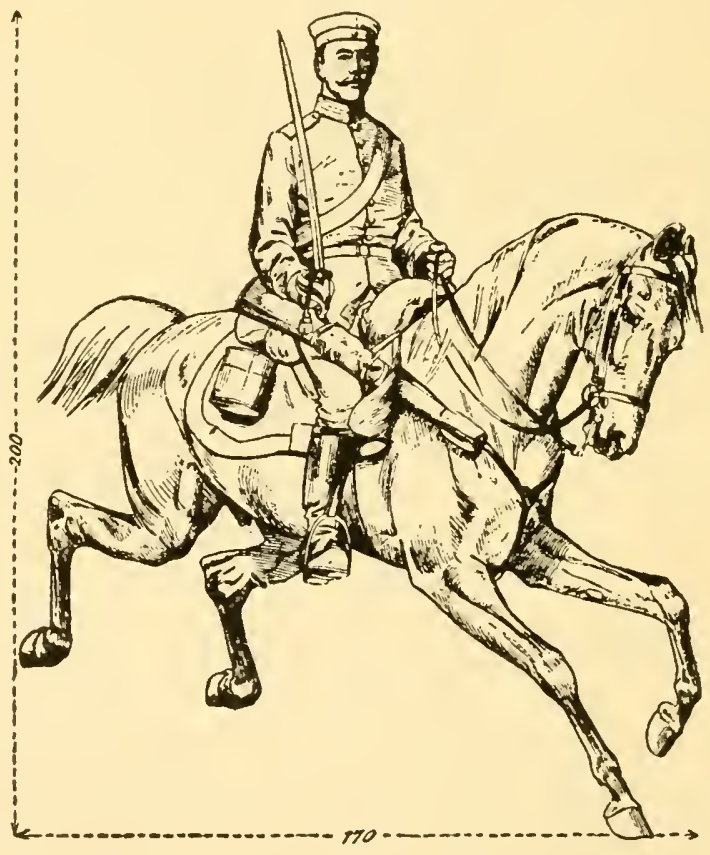

Fig. 9.

Lines of skirmishers lying down are represented by rows of balloon targets or head figures; advancing and retiring lines in close or open formation by variants of the figure targets, cavalry by rows of targets, and artillery by a combination of figure and profile targets with guns and caissons, horses, etc. As a rule, artillery must be shown as though behind cover, by the half battery targets. When full targets are used they must be placed, as in actual service, in rear of elevations, so that only the upper part shows above cover. 


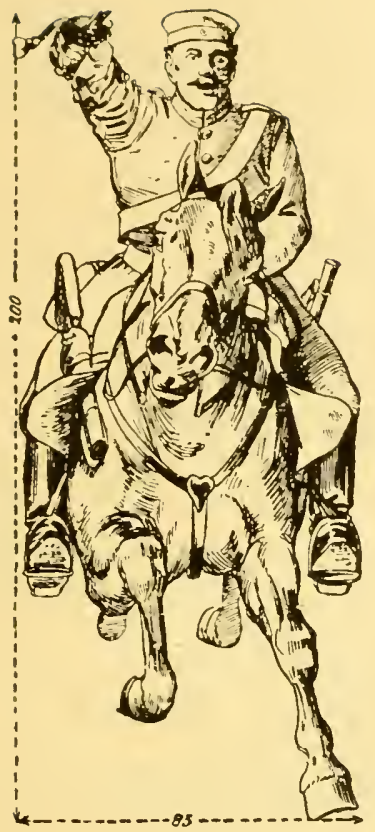

Fig. 10.

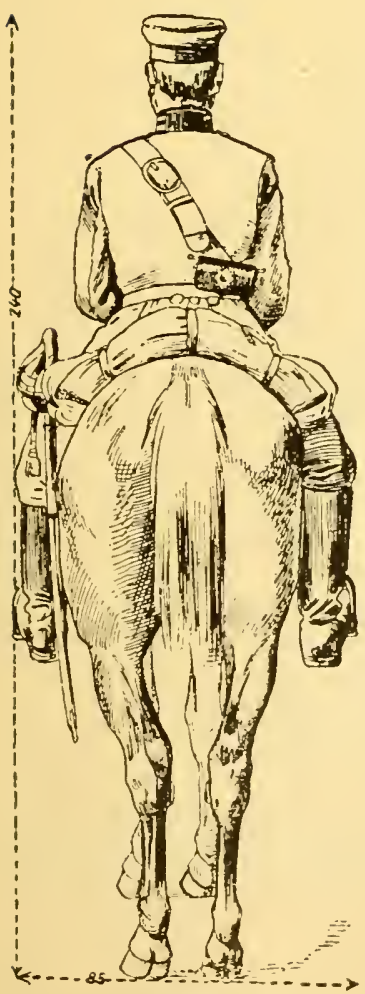

Fig.

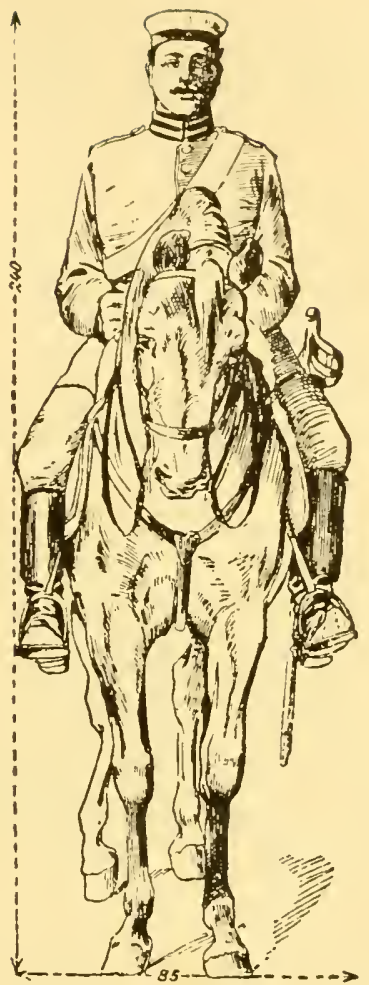

Fig. 11.
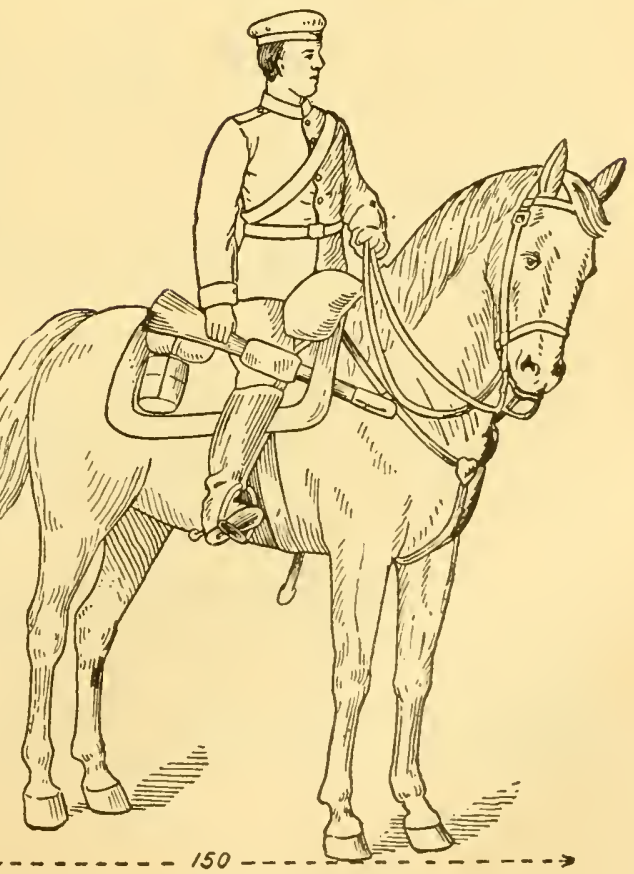
In all cases the appearance of reality must be copied. In the line targets the figures should be placed at irregular

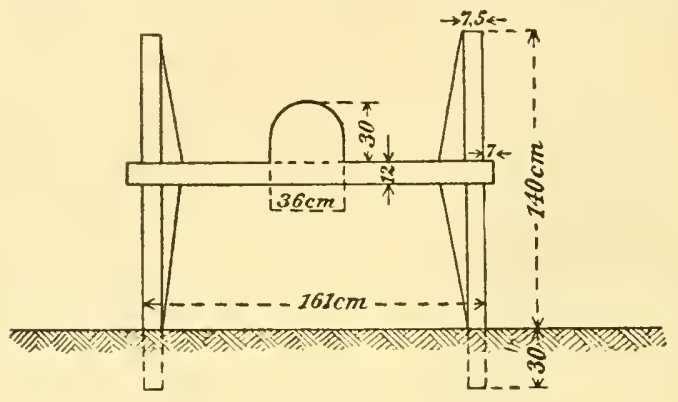

Fig. 14 .

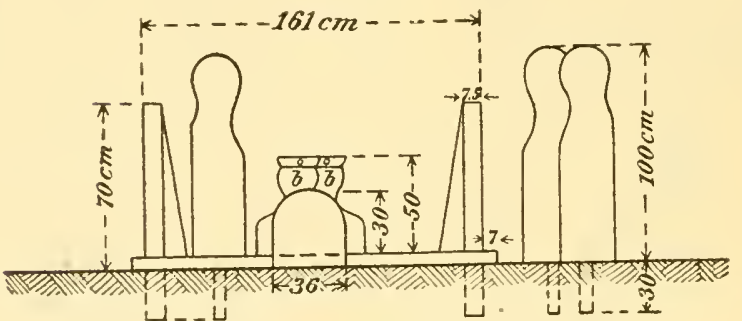

Fig. 15.-Gun, full and half view.

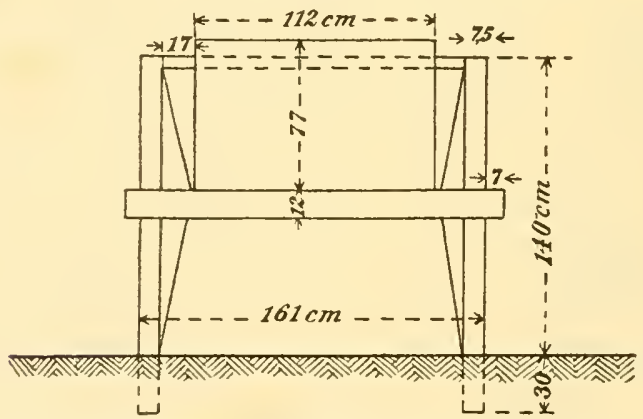

Fig. 16.-Caisson, full and half view.

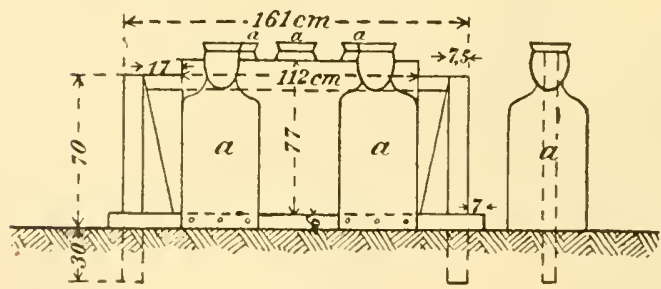

Fig. 17.

intervals, and the upper line of the figures representing advancing or retiring men should not be of uniform height. 
Advantage is to be taken of rolling ground by placing fixed targets so that they may become suddenly visible to the attacking line.

\section{DISAPPEARING ANI MOVING TARGIETS.}

On permanent ranges various figures are arranged as disappearing or moving targets, and are manipulated from covers not noticeable from the front. A target representing a line of infantry 100 meters long may be erected in ten minutes by eight men and be worked by one man. Its construction is simple, pieces of dimension stuff about 18 feet long, $2 \frac{1}{2}$ inches thick, and 3 inches wide are pinned together at the ends to make the continuous base required. These rest at the joinings on wooden sills and are kept in position by small stakes driven in the ground. To the front edge of the base are fastened the targets (head, bust, etc.); the end of the base projects into the shelter and is provided with a handle by turning which the targets can be turned over on the ground, or turned up into view, as may be required. Similar targets can be constructed on both sides of the cover, which might then be the center of a target 200 meters long. 'To represent the reenforcement or thinning of a line, two or more of such lines of targets are placed close to each other. In such cases the figures in the rear must show through intervals in those in front. The lines of targets are turned up or down to show reenforcement or losses, the first line turned forward and the rear targets backward, so as to allow the lines to be placed close together. In a final charge, to facilitate the counting of hits, each line has the figures placed close together and the line which has been fired on is turned down and a fresh one turned up. The same object may be attained in the use of one line of timbers by nailing figures to three of the faces. In this case a trench must run under the target to allow the revolving of the figures. The advance of a line or groups of men may be shown with this arrangement by having the head figures on one face, bust or trunk figures on the second, and knee or full figures on the third, each appearing in succession, as the targets are turned.

Balloon targets used to represent lines of sharpshooters lying in a trench are made of air-tight cloth cylinder's about 10 inches high and 8 inches in diameter. They are attached at intervals to the base timbers. The target is arranged about as described for the line targets, the base being laid in 
a shallow ditch, with pits under each balloon, so as to be able by a turn of 180 degrees to throw the balloon entirely below the surface of the gromd. To prepare them for service they are inflated by means of a bellows or air-pump; the inflation is more or less complete, depending upon whether colder or warmer temperature is to be looked for during the time they will be in use. Inflation lieeps them erect, and when punctured by a bullet they soon collapse, thus showing to the firers the effect of their fire. Shot holes or other injuries are repaired by covering then with patches of rubber cloth fastened on with rubber cement; temporary repairs may be made with gummed-paper patches. The balloons are provided with a valve for deflation when not in use, and detailed directions are given for their proper care and repair, which is intrusted only to skillful, careful men.

The arlvantage of seeing at once the effect of fire and the illusion of reality they present at long ranges, render the nse of this style of target very desirable, but they are expensive and troublesome. Recent military publications state that a new style of target, having the advantages of the balloon target with the adled one of cheapness, has been experimented with at the Döberitz camp and adopted for use in Germany. The targets are thin pottery vessels shaped to show the outlines of the head or bust figures. When in position they are filled with water, and on being struck by a bullet from a modern rifle they are shattered by the explosive effect, which allows immediate observation of the efficacy of the fire. At the long ranges at which they would be used hits are infrequent and the cost to replace trifling.

The figure target and its varieties are also nsed as a disappearing target by providing a pit into which it may be revolved out of sight. It is provided with holes for pins to fasten the target to the base so as to permit such parts of the figure to show as correspond to the head, bust, trunk, and knee targets. When hit, or after a certain time, or at a given signal, it is withdrawn from view. As it requires time to install, and one man to work each target, this kind is used only in exceptional cases on permanent ranges, for individual and group firing. A less expensive and more easily operated system of disappearing targets is arranged by sinking a post in the ground, the top slightly above the level of the surface, and having a rertical pin on which is piroted a wooden piece 
forming the base of the target, which may be from $t$ to 10 meters long. The figure or figures composing the target, stiffened by light strips of wood at the back, are fastened to the base piece, regard being had to equalizing the weight on each side of the central pirot. It may be operated from a shelter by means of ropes attached to the ends of the base and led into the shelter. When in position for firing, the target faces the range and it is made to disappear by being revolved on the vertical axis so that the edge of the target is presented to the firing point. Stakes driven into the ground limit the motion to the proper extent. Several targets may be operated simultaneously from one cover (see fig. 18).

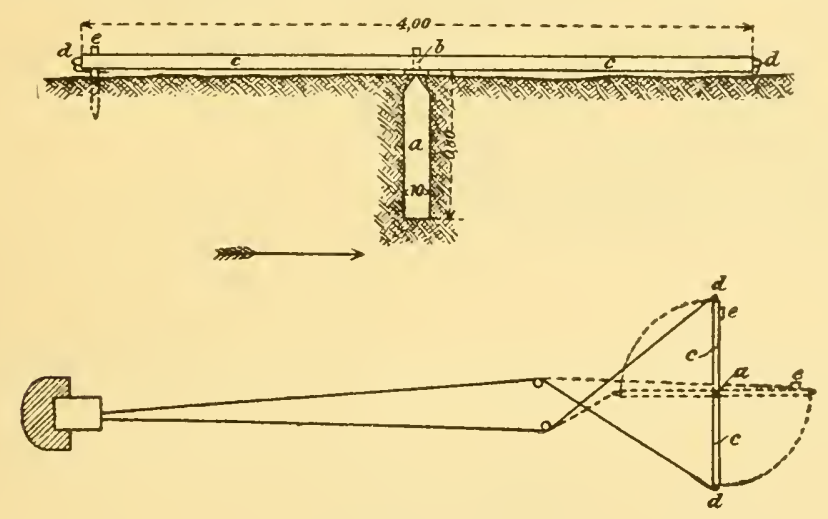

Fig. 18.

The system has the objection that the figures are on one line. To show guns, caissons, and men in proper perspective a rectangular frame ( $:$ by $1 \frac{3}{4}$ meters) is used. Crosspieces are piroted to the sides of the frame; the crosspieces serve as bases to which the proper figures are fastened. The frame lies on the ground, the crosspieces at right angles to the line of fire, so that the targets face the range. By means of a cord attached to the targets and led back to the shelter over a pulley suitably placed, the figures are made to drop backward out of view, or are raised ant held up as may be desired (see fig. 19).

\section{MOVING TARGETS.}

Targets are attached to sleds and moved in the required direction over the surface of the ground by means of wire ropes to which the sleds are fastened. On the larger permanent firing grounds machinery operated by steam or other 
power is employed; on small ranges man or horse power can be used to operate the windlasses or capstans on which the wire rope is wound when the targets are moved. The targets represent infantry, cavalry, and artillery advancing, retiring, moving to the right or left, according to the situation it

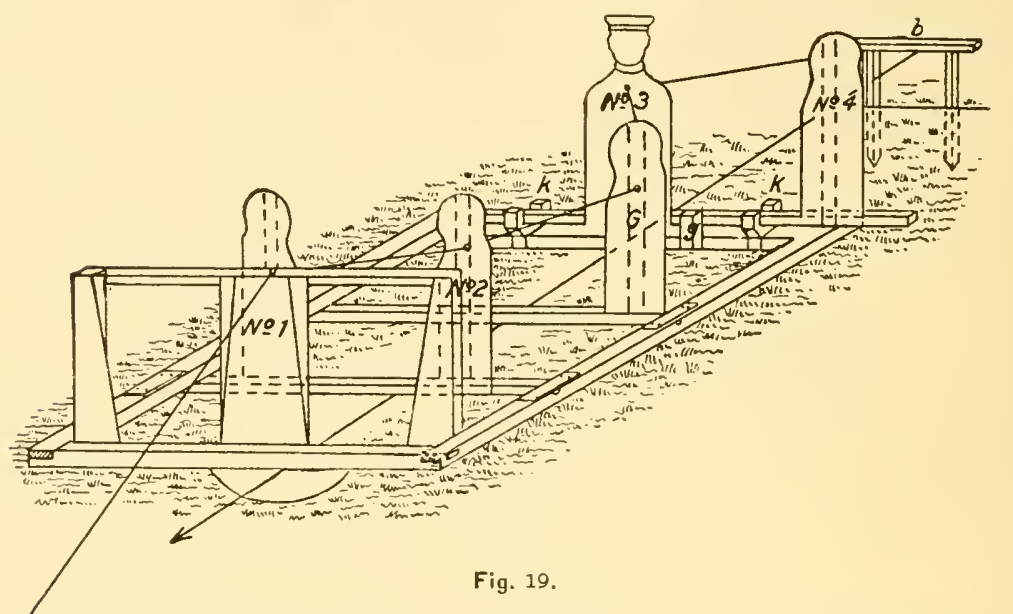

is desired to depict. They are fastened to permanent bases bolted to the sleds, at right angles to the rumners to show advancing or retiring troops, and parallel to the rumners for targets moving to the riglit and left. When in position ready for use, the sleds are placed so that the edges of the targets are turned to the firing point, and at the pull on the rope when first put in motion the sled swings around, bringing the target into view; at the end of the rum the sled is again turned, causing the target to disappear. Another plan is to have the targets folded down on the sled, raising them when it begins to move. The sled rumners are curved at the ends to facilitate movement over uneven ground, and two sizes of sleds are used, depending on the size of the target to be carried. The targets are constructed of light frames suitably braced, covered with cloth, and they can be enlarged laterally by extension pieces. The small sled can be used to carry targets showing skirmish lines of 8 figures, a close line of $1 \%$ figures, and 7 figures of mounted men; the large sled carries targets of 11,23, and 11 figures, respectively. A target showing a side view of gun and horses is carried on two small sleds joined together, the first carrying the figures of the two foremost horses and riders, the second the third horse and rider, 
limber, and piece. The number of targets to be fastened on a sled depends on the ground, the weight of the targets, strength

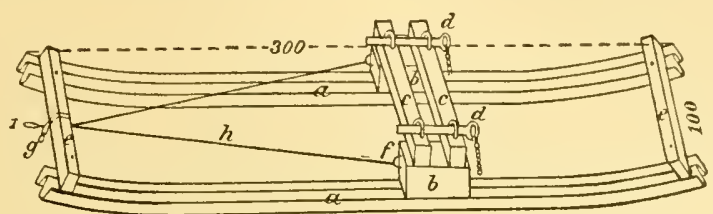

Fig. 20. - Sled for moving target.

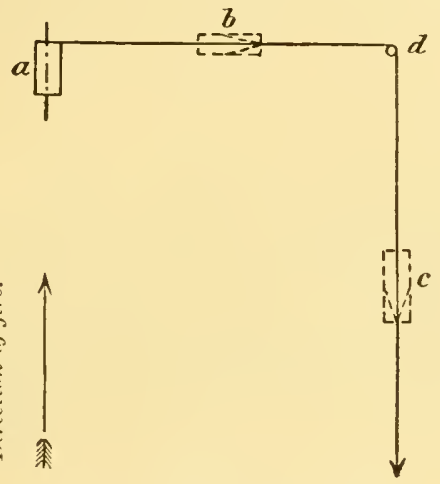

Fig. 21.-How sled is operated.

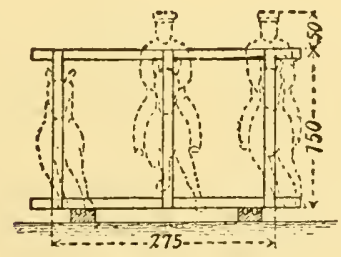

Fig. 22.

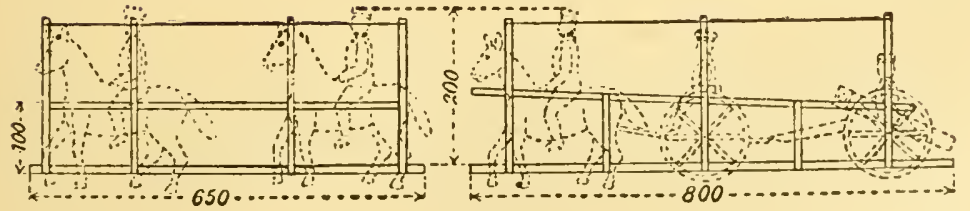

Fig. 23.

and clirection of the wind, as well as the pulling power. When a number of targets are operated at the same time, a power of from four to eight horses is required. 
When the nature of the ground will not permit the use of moving targets, fixed targets showing the objects as they would actually appear may be used.

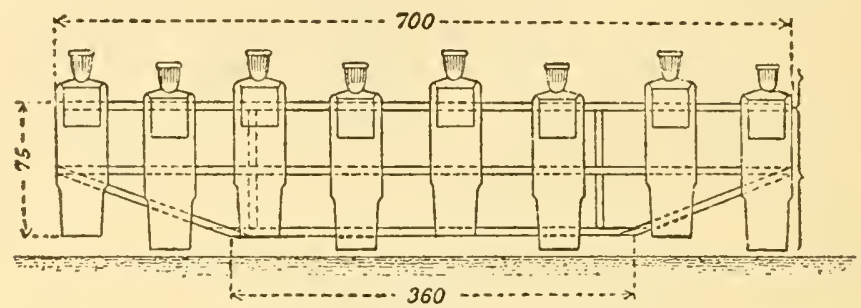

Fig. 24.

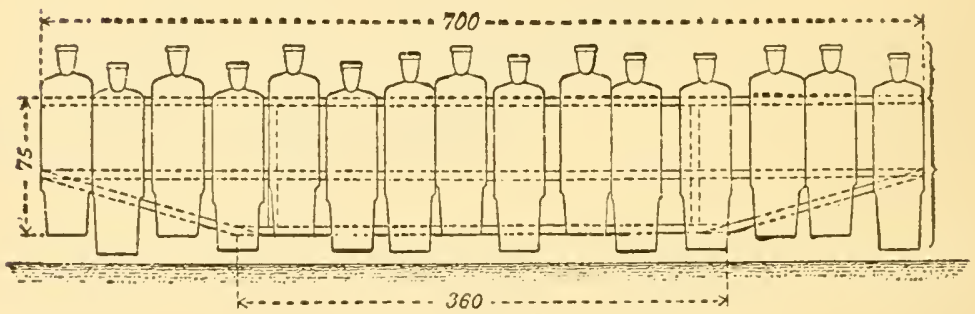

Fig. 25 .

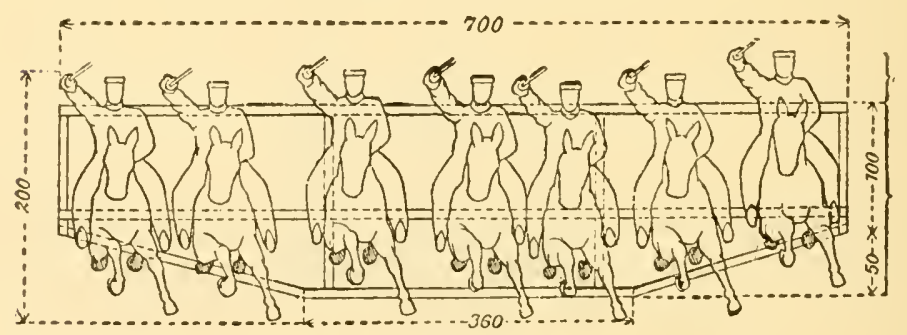

Fig. 26 .

SIMUIATTED FIRE.

As the sound would be drowned by the real firing of groups or larger bodies of infantry, it is used for individual fire only, or for squads when their attention is to be drawn to targets which they would not otherwise detect. It is produced by the explosion of crackers behind the covers.

The fire of artillery is simulated by the explosion of bombs or petards of different kinds, gaged to give the desired sound and appearance. They are exploded by means of fuses, 
friction tubes, or by electricity. Their arrangement on the ground, and the manipulation during the practice, is managed by well-trained noncommissioned oflicers, and every precantion is taken to prevent accidents from their use.

\section{MARKERS' SHELTERS.}

These, whenever practicable, are to be sunken covers, and so arranged as to preclude injury from shots or the explosion of crackers or bombs, to the men in the pits. With raised shelters every means is to be used to prevent the locations being known, by making them look like the surrounding ground. To aroirl unnecessary digging, shelters are definitely located on permanent firing grounds, and when not in use are fenced around to prevent accidents when the ground is used for drill purposes. Each cover is equipped with a contrivance holding two mirrors, which, when arljusted and in position, enables the men in the cover to see the range and observe the different signals; reserve mirrors are provided to meet accidents. At least one noncommissioned officel and one private are in each shelter, the one to observe the firing party and the signals, and the other to manipulate the targets; additional men may be required, depending on the nature of the practice. If gun crackers or bombs are to be exploded from the cover, a noncommissioned officer is assigned for that duty.

In the covers are signal flags and material for pasting up targets and shot holes.

Flags are used for communication between the director and men manipulating the targets. The director whenever practicable occupies a cover overlooking the others, from which signals are given to the men operating the targets. The signals should not be visible to the firing party, nor must flags be waved from any cover that would betray its location. When this can not be avoided, the necessary directions must be given before the firing party comes on the ground. Appropriate signals are arranged to show when firing may commence, or must cease, for signaling hits, etc., by flags and bugle calls, and these signals, as well as those which designate the targets that are to appear or disappear and any special directions for the conduct of the exercises, must be well understood by ail concerned in the several operations. 
FIELD FIRING, GENERAL RULES.

The course for infantry comprises individual and collective firing, and each is preceded by preparatory exercises with dummy and blauk cartridges.

The lieutenants, noncommissioned officers, and men of each company take part in the individnal fire; noncommissioned officers and men in the collective firing-the former may compose a special detachment for collective fire.

Individual fire with ball cartridges may be conducted by a sworl-knot noncommissioned officer; collective fire must be directed by an officer. Individual fire and collective fire of groups, sections, and platoons is managed by company commanders. Collective fire of larger units is directed by battalion or regimental commanders. The company officers are present at collective firing conducted therein; all the battalion officers are present at that of larger units. The dress is the same as for regular practice at known distances, with the addition of the canteen, haversack, and intrenching tools.

For siege firing the dress is forage cap, cartridge-boxes, overcoat carried like a blanket roll, canteen, haversack, cooking utensils, and intrenching tools. Bayonets are not fixed.

Field firing is conducted in the field or on such suitable ranges as may be available, special regard being paid in every case to safety from accidents, which must be insured by every possible precautionary measure, in accordance with general rules prescribed on this subject.

INDDIVIDUAL FIELD FIRING.

Instruction in this is based on the consideration that the accuracy of the rifle is such that a good shot may expect to hit a man lying down at 250 meters, one kneeling at 350 meters, a file (two men side by side) kneeling at 500, and a file standing or a single horseman, at 600 meters. Firing at the various targets must, therefore, be within the limits of probable liits, with which the instructor must be weil acquainterl.

I'REPARATORY EXERCISES.

The preparatory exercises are arranged by the instructor so that the man sees various targets at different distances, and is instructed how to take cover, to estimate the distances and decide upon the elevation required, point of aim, 
etc.; later he may do all these things by himself, the instructor afterwards correcting errors.

The course demands ligh qualifications on the part of the instructor, and such time and care is to be given to the instruction of the recruit, including practice with dummy and blank cartridges, as will supplement that already received in the theory of rifle fire, demonstration of the capabilities of the rifle, and handling of the piece, so that the only real novelty in the field firing with ball cartridges will be the effect produced by the bullets.

\section{FIRING WITH BALL CARTRIDGES.}

These exercises are carried on against figure targets with its modifications and targets representing horsemen, in the same manner as in the preparatory exercises.

For skillful men more difficult exercises are arranged. To insure thoroughness men pursue the course separately, under the surveillance of the instructor. Without moving the man may fire at targets appearing in succession at different ranges, or he may himself advance or retire. To encourage the observation of shots he may be accompanied by another man, who watches the shots and tells him where they strike, and they may alternate in firing and watching for each other, provided that they go through their course independently, firing at their own targets. At first, before firing, the man announces to the instructor his estimate of the distance, elevation required, etc.; these are corrected if necessary. After the man has gained assurance he operates alone, and may state these details after firing the shot. On the company target record the days of practice by the man are entered on the memorandum made at the range, the name of the man, and the number of cartridges fired. The company commander decides whether, and how, the result of the fire is to be recorded.

Men of the lowest class take up the firing as soon as sufficiently instructed, others as early as possible after the beginning of the target year. If convenient ground for the individual fire be lacking, the commander in chief may authorize it to be omitted, but the omission of such fire for two years in succession in the same unit is to be aroided. The omission must be specially noted in the annual report of firing. 
COLLECTINE FIRE.

In the preparatory exercises, dummy and blank cartridges are used. Targets may be represented by detachments, which appear or disappear according to the signals or instructions agreed on, and in pursuance of a prearranged scheme of the instructor. Artillery and cavalry may be shown by men carrying flags of certain colors, or by targets. To develop promptness and decision in leaders and quickness in the men, different targets are presented at unknown distances, and these may appear, or be supposed to be visible for varying periods, and a certain time be allowed to deploy the men to deliver the appropriate fire.

The first exercises are by a file of men, then by a group. The men are instructed how to act in attack or defense, in the use of sights, in rising quickly for a rush, and getting into position for firing, catching the aim promptly, etc. This is succeeded by progressive exercises for platoons and larger detachments. Conditions requiring independent action on the part of the men are also to be represented.

FIRING WITH BALL CARTRIDGES

The exercises are on similar lines to the preparatory ones, using appropriate targets, among which should be, if possible, disappearing and moving targets. The exercises should be based on simple tactical suppositions, represent some phase of an action, rather than a continuous conflict, and in general the detachment is assumed to be acting in concert with or as a part of a larger body. The training is to be addressed more particularly to infantry opposed to infantry, by frequent fire at short and medium ranges at low targets representing skirmish lines, but firing at longer ranges is not to be neglected.

During pauses, or at the end of the exercise, results of fire are ascertained and compared with the expenditure of ammunition, on the available supply of which the extent of the exercises will, to a great extent, depend.

The results of the fire are not recorded, but the days on which collective fire has been held are noted, and if a superior desires information regarding exercises at which he was not present, it, is furnisherl in a simple, brief report.

The development of the exercises depends on the allotment of ammunition by the higher authorities, in addition to the 
ordinary allowance of the unit. The additional supply is meant to allow the different units in turn to have exercises on a large scale, rather than to be equally divided between them each year. If extensive exercises in siege warfare and indirect fire can not be carried on, the principles of these kinds of fire will be illustrated in the instruction or demonstration firing.

In field firing the course of an action is usually swifter, the fire more rapid, and the consumption of ammunition much greater than it would be in reality. To prevent peace habits from having a bad effect in actual service, leaders and men must be thoroughly instructed on this point.

From experiments in, and study of, the effect of collective small-arm firing, the Germans have derived the rule that for ranges up to 800 meter's one sight should be used; for greater distances, two sights, differing by 100 meters, one 50 meters more, the other 50 meters less than the estimated distance. 'The front rank fires with the lower, and the rear rank with the higher sight. There is thought to be no advantage in the use of more than one sight for bodies of less strength than a section of infantry or a platoon of cavalry.

Sufficient results may be obtained from collective fire on low targets (infantry) up to 600 meters; beyond that distance the expenditure of ammunition would be too great, though high targets (representing cavalry) can be hit up to 1,000 meters. At greater distances fire should not be opened except on objects that by reason of height, breadth, and depth present a favorable target.

CAVALRY.

The men are trained in the use of the carbine, officers and noncommissioned officers in the use of the carbine and revolver, trumpeters in the use of the revolver only.

GENERAL RULES.

The course of instruction for the cavalry is the same as for infantry. The same targets are used, the section targets 400 , 500 , and 600 meters being designater as section targets I, II, and III, respectively. The rules for range practice and field firing, competitions, etc., are in general, as far as applicable, the same as prescribed for infantry. 
CLASSIFICATION.

The third class consists of men in their first year of service, and poor shots of longer service; the second class of the men who have qualified in the first year's course, the first class of the men who have qualified in the second class. Officers are classed by the regimental commander, and those officers and noncommissioned officers who have twice fulfilled the conditions of the first class form a special class to which special fire problems are assigned by the regimental commander.

The preliminary and regular practice of all classes is held in seven scores of 3 shots each, three of preliminary, and four of regular practice. The third class fires at ranges from 150 to 500 meters; the second and first classes at from 150 to 600 . meters. The qualifying scores for all classes are less than those of the corresponding infantry classes.

One badge for each of the special, first, second, and third classes in every company is given anmually to the best shots among the noncommissioned officers and privates.

HONOR PRIZES.

For the cavalry there are allowed three for officers and four for noncommissioned officers.

REGIMENTAL COMPETITIONS.

An annual allowance of 50 marks for the purchase of prizes is made to each regiment, 10 marks for the noncommissioned officers, and 8 marks for the men of each squadron. The winner among the noncommissioned officers is the one who makes the best score in revolver practice. The competition among the men is joined in by as many men of all classes as the supply of ammunition for the purpose permits. They fire three shots, using the carbine, at 150 meters, standing, offhand, at a target similar to that used in the honor-prize competition. The one getting the highest number of rings wins; ties are decided by counting shots backward, etc. For the noncommissioned officers of detached squadrons of mounted orderlies, 6 marks are allowed for prizes, and 1 mark more for each additional squadron in the same garrison; for the men of each squadron 8 marks.

TROOPS OF THE TRAIX.

The men are armerl with the carbine, and are instructed in its nse at short ranges. They are divided into two classes and 
the preliminary and regular practice for each class is held in five scores of 5 shots each, two of preliminary and three of regular practice, at ranges from 150 to $: 00$ meters.

\section{REVOLYER PRACTICE.}

In the cavalry, all officers and men; in the infantry and foot artillery, company officers, sergeants major, vice-sergeants major, sword-knot noncommissioned officers, colorbearers, regimental and battalion drum-majors, and such noncommissioned officers and men as are trained as litterbearers and for service in the sanitary detachments, and officers of the train troops, are instructed in revolver firing.

The course of instruction is the same for all branches of the service; it is designed to teach the proper use of the weapon in battle, and includes a knowledge of its construction and manipulation, the principles of pointing and aiming, with and without a rest, and firing with dummy and blank cartridges.

Each firing practice is preceded by instruction in handling the revolver and by practice with dummy or blank cartridges elsewhere than on the range, and strict rules are enforced for the purpose of preventing accidents. For practice with ball cartridge the ring and figure targets are used.

The firing exercise for infantry and foot artillery is as follows:

Five shots, using a rest, at 20 meters, at the figure target, aiming at the body, each shot being marked after firing.

Five shots, offhand, same range, target, and point of aim, each shot marked as before.

The accuracy of the weapon is such that a good shot can hit the target every time.

The company commander may direct special exercises for such officers and noncommissioned officers as show superior skill.

For cavairy :

Five shots, with rest, at 20 meters, at the ring target, aiming at ring 5 below the bull's-eye, each shot being marked.

Five shots, offhand, at 20 meters, at the figure target, each shot marked.

Five shots, offhand, at 30 meters, at figure target, each shot marked.

Five shots, at same range and target, shots marked at the end of the score. 
A good shot is expected to hit the bull's-eye in the first exercise, and the figure target in the other shooting, at every shot.

Officers of the train fire 5 shots at 20 meters, using a rest, at the ring target, and 5 shots, offhand, at the figure target.

Revolver practice is always under the rlirection of a commissioned officer; no exception to this rule is permitted.

FIEID ARTTLLEPY.

The target practice for field artillery is divided into firing at known distances (school practice), and the field or combat firing. The school practice is carried on in the battery; the field firing in the battery, battalion, or regiment, on troop. exercise grounds, artillery practice grounds, and in the open country, which latter gives opportunity for the use of unknown ground offering difficulties differing according to the season.

The practice period is in summer, the time for which is fixed by the corps commander. The duration of the practice is from twenty-one to twenty-three days, when two regiments are present, and from twenty-seven to thirty days, when three or four regiments are on the gromnd at the same time. Practice in the open country is carried on after the field firing, and before the autumn maneuvers.

As soon as the higher authorities issue the orders for target practice, the regimental commander makes general arrangements for the program to be carried out, assigning days, time, and place for the different firings, directs the division of the ammunition among the batteries, assigns officers temporarily attached for instruction, and gives general instructions for the batteries and battalions in carrying ont the program. He also arranges the exercises that seem to him most useful. For this purpose he calls for suggestions and recommendations from battery and battalion commanders as to nature and place of targets, positions of batteries, etc. Fatigue parties are sent ahead by each regiment to make preparations for its practice and get the targets ready.

The various targets used have already been referred to. The batteries report for practice with six guns and, if possible, three caissons.

SCHOOL PRACTICE.

The school practice is regarded simply as preparation for the combat firing, and is limited to the amount considered to 
be absolutely necessary, determined for every battery by the regimental commander according to the degree of training shown and the number of officers to be instructed. The battery chief conducts the school practice. As he knows the problems to be solved he prepares the battery by instruction and practice, the lieutenants commanding in turn. Usually the first practice day is devoted to finding the range by trial shots; to firing at different targets at known distances, and to observing the accuracy and effect of the fire. On succeeding days, according to proficiency of the men and officers, instruction in the use of fuses, firing with time shells, deliberate fire at targets up to 1,500 meters, curved fire, etc., is given, if necessary repeating the exercises of the first day. Observation is extended to noting grazing shots, bursting points in front of and beyond the targets, which should be the effect of design. Instruction in the service of the piece and in laying and pointing is included in the school practice, but is not to interfere with the firing instruction. Deployments are in all cases made as in actual serrice. Fieldhowitzer batteries use "exercise shells" against targets that would in actual service be fired at with percussion or fuse shells. This is because the danger from the use of highexplosive shells can not be sufficiently guarded against if fired in practice.

\section{FIELD PRACTICE.}

This is the most important part of the course and the greater part of the time is devoted to it.

The exercises are based on simple tactical suppositions, and leaders and troops must not know in advance the problem to be solved. It is given ont just before the exercise is to take place. Leaders have the utmost latitude in selecting their positions, new problems are presented by the disappearance of some targets and the appearance of new ones, the changing conditions of a fight being shown by these means and by causing men and officers to fall ont as though disabled, etc.

Most of the field practice is deroted to the battery practice, which is directed by the battalion commander, the batteries are commanded, as prescribed in regimental orders, by their chiefs, or by one of the lieutenants, and the problem given usually assumes their connection or cooperation with other troops. Individual batteries may have more extended practice, for which an increased supply of ammunition is given. 
In the practice by battalion, the chief or one of the senior captains may command; in the latter case the regimental commander may charge the battalion commander with the management of the practice, and the batteries be commanded by their chiefs or one of their lieutenants.

The ordinary ammunition allowance is sufficient for only a few days' practice for each battalion, the battery practice being favored in this respect. Leaders are expected to select problems that will give instructive phases of an action, such as carrying out an artillery attack in different conditions; opposing an infantry attack; preparing for an attack by friendly infantry; the use of shells against fortified positions, etc. The course of the action is always to be varied by the battalion conmander directing a change of targets, combining the fire of several batteries, etc. By causing the unexpected appearance of horse artillery or other targets at close range, cases are presented where the battery commander has himself to order a change of target.

The fire of one battery or group of batteries may serve for the instruction of others, and exercises are arranged so that all the officers of a group may assist at the fire of one of its batteries, and all the officers of a regiment at the fire of a group or specially instructive fire of one battery. Similarly, the gunners of a battery are present at all the firings of their own battery, being relieved from all other duty for this purpose.

Regimental field practice may take place if the supply of ammunition and other conditions permit.

The allowance of ammunition and the money credits necessary to carry on the practice are fixed by the military authorities and depend on the sum appropriated in the amnual budget. This usually permits only a limited supply of ammunition, so that only the more important kinds of firing can be executed, and the expenditure of ammunition has to be carefully watched to prevent waste. Details of the allowance and cost of ammunition for the various units are not published except for the information of those concerned in carrying on the practice. The "Armed Strength of the German Empire," published by the British intelligence division in 1888 , states that a sum of money which for Prussia alone amounts to about seven millions of marks (over $\$ 1,600,000$ ) is set apart every year for artillery practice, divided up 
among the various ranges. The same source gives the annual allowance of ammunition for battery practice as 244 shell, 100 shrapnel, and 12 case. The recent changes in armament of the German artillery, and the great development of this arm, would warrant the belief that these figures are at present increased rather than diminished.

\section{REPORTS OF FIRING.}

These furnish a means of determining comparative efticiency, and for collecting instructive data regarding the guns and ammunition. The careful preparation of these reports, which should be absolutely reliable, is supervised in the battalions and regiment. The firing list is prepared in each battery by an officer specially detailed for the purpose, from notes of the firing of the battery made by two noncommissioned officers, one of whom records the commands and directions of the battery commander, and the other the time and order of fire, number and kind of projectile, etc. The report of the effect of the fire on the targets made by the observing detachment charged with this duty is attached to the firing list, which is made up immediately after each firing, and sent to the leader for completion by adding thereto any memoranda of the conditions of the action, orders or directions of the battalion commander, etc., necessary to the proper understanding of the practice.

The duty of observing and recording the effect of fire is performed by detachments commanded by an officer, assisted by underofficers and soldiers, all carefully chosen, and well instructed in their duties. Observation stations are located at convenient points on the ground, connected by wire with the position occupied by the officer directing the fire. Every shot fired is observed, and record made at the time, of the striking or bursting points, effect on the target, etc., so that the report made by the observers can be compared, shot by shot, with the record kept at the firing points. Togrether they give the data for the "critique" which is made at the conclusion of the exercises. The observation posts may serve for one or more targets, and are provided with necessary blanks for recording shots, sketches of the ground, material for repair of damaged targets, etc.

After the close of the exercises, regimental commanders make up a review of the firing, to which may be actded any 
special remarks on the effect or result of any particular firing, or explanations regarding any departures from prescribed rules. If exercises take place in the open country, only the expenditure of ammunition, approximate cost of the same, and occurrences calling for special mention are reported. These reports, with the remarks thereon of brigade and division commanders, are sent to corps headquarters, from which they are forwarded by the 1 st of November of each year to the "inspection of field artillery," and are sent from there to the war minister on or before Norember 15.

To enable the inspector of field artillery to judge of the arrangement of the practices and the firing capacity of the troops, he is furnished with copies of the regimental programs and the firing lists of any one or all the regiments in the corps.

COMPETITIONS, PRIZES, AND BADGES.

Two competitions are held annually among the gunners of each battery, in which prizes are awarded to the successful ones. One-year volunteers are allowed to compete, but may not receive money prizes. The first competition is held in April of each year, all gunners appointed within the year being eligible.

The exercises consist of pointing at targets at supposed ranges, with different kinds of fire and projectiles. Rectangular targets about 67 inches ( $1 \% 0$ centimeters) high and 20 inches (50 centimeters) wide, upper half black and lower half white, are placed at distances from 500 to 1,000 meters, to determine the correctness of direction of the piece. Only competitor's who attain a fixed standard receive prizes. Of these the first gets 6 marks, the second 5 marks, and the third 4 marks.

The second competition is also held in the batteries on their retur'n from the field exercises among the six best gunners who have not already received prizes. In addition to the pointing exercises at targets, guns are aimed at a supposed hostile battery, represented by guns located at such a distance as to be barely visible. The competitor on seeing the flash and smoke of the shot from the hostile gun trains his piece thereon with the elevation corresponding to his estimate of the distance. As soon as the pieces are pointed, and at a given signal, a man with a flag places himself at the muzzle of the piece just fired and an officer verifies the correctness of 
the pointing. Three such exercises are given to each competitor, and the final classification is based on standing in both competitions, ties, if any, being decided by superiority in the pointing at hostile guns.

Insignia are given to privates in their first year of service, including one-year volunteers, who have shown skill in pointing, and to noncommissioned officers and reenlisted men who are distinguished for slitll and intelligence in the field firing. The latter are in eight classes, being promoted to a superior class every year. Soldiers who receive their insignia discharge the functions of gumner while in service and are candidates for appointment as noncommissioned officers. The badge for skill in field firing is a silver grenade and is the highest class of badge worn. Men who win badges as pointers or gunners receive certificates to that effect, and the fact is noted in their records and on their discharge papers.

\section{FOOT ARTILLERY.}

The foot artillery manning land fortresses has annual target practice on the artillery practice grounds, conducted on the same principle as that of the field artillery. The objects fired at are permanent works, masonry revetments or targets representing such works, siege batteries, etc. Competitions for gunners' prizes are held as in the field artillery.

FIRING SCHOOLS, RANGES, ETC.

The infantry firing school at Spandau (northwest of Berlin) is under the supervision of the inspection of infantry schools, and is designed especially for the training of infantry in combat firing, though for the last few years cavalry has also received training here. Spandau is a large fortress, and, in addition to its instructional uses, is a great center of army supplies, an experimental and testing station for all kinds of small arms and machine-guns, and is designed for a refuge for the archives, treasure, and court. The imperial war treasure is kept here, which is intended to meet the first expenses of mobilization in case of war.

The school staff consists of 1 colonel or lieutenant colonel in command; he has a lieutenant as aid, a field officer, 4 captains, and 8 lieutenants, and an instruction company of noncommissioned officers of Prussian, Saxon, and Wurttemberg infantry. Among the instruction courses carried on here 
each year are two of fourteen days each for lieutenant colonels of dismounted troops, including foot artillery; one of fuurteen days for 36 captains of cavalry, one of fourteen clays for commanders of infantry regiments, and four courses of five weeks each for 60 captains and 30 first lieutenants of infantry.

Practice courses for noncommissioned officers of infantry and cavalry are held at Spandau, Hagenau in Alsace, Gruppe, near Graudenz on the Vistula, and Munster in Hanover; and at Spandan (for the first time in 1900) a training course in the use of machine-guns for officers and noncommissioned officers of the rifle battalions. Infantry practice on a large scale, not practicable in the limited space at Spandau, is held at Tegel, north of Berlin, and, in connection with field artillery, on the extensive firing grounds at Jüterbog.

The royal Bararian military firing school is at the range and drill grounds of Lechfeld, 16 miles south of Augsburg. It is intended solely for Bavarian troops, and courses of instructions are held annually for field officers, captains, and lieutenants of infantry, and for officers and noncommissioned officers of cavalry and foot artillery.

The field-artillery firing school at Jïterbog, in Brandenburg, is under the supervision of the inspector of field artillery. The school staff consists of 1 major general, 2 field officers, and an aid. Four field officer's and 12 captains are detailed as instructors, and an instruction regiment is stationed there, made up of three detachments of three field batteries each. Courses for senior officers, in classes of 12 field officers, 72 captains, and 46 first lieutenants, are held yearly; two courses for lientenants in classes of $100 \mathrm{each}$, and four spring courses for furloughed officers, 35 in each class. Bavarian, Wurttemberg, and Saxon field-artillery officers are also detailed to these courses.

The foot-artillery firing school is also located at Jüterbog. Its personnel consists of 1 field officer commanding, with a lieutenant as aid, and 3 field officers and 2 eaptains as instructors. There is, in addition, an instruction battalion of three companies. There are held here yearly two conrses for junior officers, one for officers of the furloughed class, and two for noncommissioned oflicers.

Since 1899 there have been detailed for instruction to the infantry firing school at Spandau from each army corps, one division commander, who were originally in the cavalry or 
artillery; and to the artillery firing school at Jïterbog, one division commander and one senior brigade commanter, who were originally in the cavalry or infantry.

Ranges are established at convenient points thronghout the empire for instruction of the troops in firing. Those for artillery practice are at Tegel (near Berlin), Jüterbog, Gruppe, Falkenburg, Wesel, Wahn (Rhineland), Lockstedt (Holstein), Darmstadt, Hagenan, Zithain (near Riesa), and Lechfeld (near Augsburg). These are all large ranges, as much as 5,500 yards long, sitnated on heaths or surrounded by forests. Accommodations for troops, oflicer's' quarters, barracks, stables, etc., of a permanent character, are provided for a brigade of field artillery. These ranges are also used by the cavalry for their regimental drills, by infantry for their field firing, and by the landwehr when called out for training, so that they are occupied during a great part of the year. Each range is administered by a staff of artillery officers, who attend to necessary construction, repairs, and general supplies. Material for their own practice and ammunition is brought by the troops assigned to the range for target practice. 



\section{V.-GREAT BRITALN.}

The musketry regulations of 1898 hare already been found to need revision on account of the experience gained in Sonth Africa, and the military anthorities are still engaged in preparing an edition to bear date 1901. The revision not being completed in December, 1901, a "prorisional course of musketry for the year 1902" was issned.

Targets for individual range practice are rectangular with bull's-eyes surrounded by one ring: First class 6 by 8 feet, bull's-eye 3 feet, ring 5 feet in diameter; second class 6 by 6 feet, bull's-eye 2 feet, ring 4 feet in cliameter, and third class 4 by 6 feet, bull's-eye 1 foot, ring 2 feet in diameter. For collective firing a sectional target ( $t$ by $\&$ feet), haring on a white ground four rudely outlined silhonettes of men in line kneeling, is used.

In the musketry regnlations a soldier is a "recruit" until he has gone through his recruit course. Table A, when he is called a "trained man." A trained man is said to be "exercised" when he has been through the conrse in Table B.

A military correspondent in the Times of December 20, 1901, gives the following synopsis of the provisional course for 190 ?:

"Table A, recruits, cavalry, and infantry," consists of four parts, of which the first three count for classification. Part I includes eleren practices at 200, 300, and 400 yards, r rounds, "independent," in each practice. The targets for the various distances are as laid down in the 1898 regulations, but in practices Nos. 5 and 8 , at 200 and 300 yards, respectively, the position is "sitting," and thronghout the eleven practices any kind of natural or artificial rest may be nsed by a recruit if found necessary. Parts II and III remain unchanged except for the substitntion of the terms "independent" and "magazine independent" for "deliberate" and "rapid individual," and the reduction of the time allowed in "magazine independent" from a minute to forty-fire seconds from the command "Commence." Part IV consists of four "independent" practices, the first three at 100, the fourth at 150 yards, one at a vanishing target, one at a fixed head and shoulders, and two at a moving figure. In the practice at the fixed head and shonlders the firer, crouching behind cover, momentarily exposes himself sufficiently to fire a rapid shot, recruits being allowed four seconds for exposure, fire, and complete return to cover from "Commence" or signal. In the above-mentioned practices 168 rounds are expended, leaving 32 for three fieid practices to he directed by the assistant adjutant and carried out under conditions as practical as possible. The points required for classification as a first-class shot are, as at present, 300 for cavalry and 330 for infantry: 
"Table B, trained infantry," now consists of three parts-independent, miscellaneons practices, and practices for which rounds are allotted to commanding officers and company commanders. Part I includes twelve practices, of which the first six are in the 1898 regulations, with the exception that the position in $\mathrm{N}$. 4 at 500 yards is "sitting." instead of "kneeling." No. 7 is "any position," 100 yards at a vanishing head and shonlders exposed four seconds; No. 8 at a fixed head and shonlders, 100 yards, the firer crouching behind cover and momentarily exposing hinself as in the similar practice in Table A. Trained men, however, are allowed only three seconds for exposme, fire, and complete return to cover. Nos. 9, 10, and 11 are at vanishing head and shonlders, fixed head and shonlders, and vanishing second-class targets respectively, the distances being in the first two cases 200 and in the third 500 yards. No. 12 practice is any position, magazine independent, 600 yards, at a second-class vanishing target exposed forty-five seconds. Part II embraces three practices, No. 13, independent, abont 150 yards at a moving figure; No. 14, magazine independent, abont 200 yards, any position, behind cover, two shots at each backward and forward rum of a moving figure, 8 rounds in all; No. 15, magazine independent, abont 200 yards, any position, behind cover, at a ranishing figure. A target to appear at intervals of five seconds, each time at a different place, and to remain exposed four seconds. Horizontal space for each man's target not less than 28 feet. In the first two parts 106 rommds are expended, leaving 94 for Part III, of which 41 are allotted to the commanding officer and 5:3 to the captain, who formerly had only 40 ronnds per man at his disposal. In addition to these 94 rounds per man, general officers are anthorized to draw 4,000 rounds per battalion of infantry. Attention is directed to special instructions for moving and vanishing targets and range appliances, which will assist in framing schemes and in selection of suitable targets.

To speak broadly, the main changes in Tables A and B introduced since the 1898 regnlations, which have been in force only up to the present year, are the abolition of volleys, the system of firing behind cover, and the permission accorded to recruits to use any kind of natural or artificial rest in their independent practices at 200,300 , and 400 yards. The increased encouragement of individuality in the preparation of special schemes by captains of companies, the closer attention paid to the use of vanishing and moving targets, and the introduction of the "sitting" position are other matters in which progress is indicated.

For the purpose of comparison, the course prescribed by the musketry regulations of 1898 for cavalry and infantry is griven below :

Table A.-Recruits.

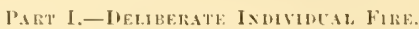

\begin{tabular}{|c|c|c|}
\hline Rauge. & larget. & Simbler of seores of $T$ sliots each. \\
\hline $\begin{array}{r}\text { Yarels. } \\
2(x) \\
2(1) 0 \\
3(11) \\
\text { tout }\end{array}$ & $\begin{array}{l}\text { Secomel class } \\
\text { Thive clase } \\
\text { secomel clats } \\
\text { - }\end{array}$ & 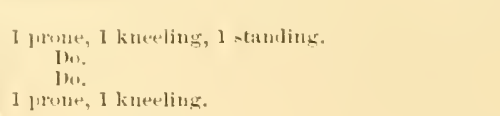 \\
\hline
\end{tabular}


Table A.-Recruits-Contimned.

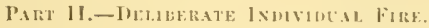

\begin{tabular}{|c|c|c|}
\hline liatluge. & Turget. & limble wi scores of $\bar{\tau}$ shots careh. \\
\hline 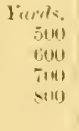 & 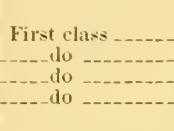 & 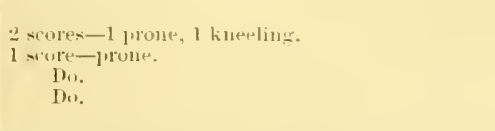 \\
\hline
\end{tabular}

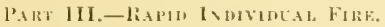

\begin{tabular}{|c|c|c|}
\hline $5+2010$ & $\begin{array}{l}\text { Sucond clims } \\
\text { First class }\end{array}$ & $\begin{array}{l}1 \text { kneeling, } 1 \text { stamling. } \\
1 \text { prone, } 1 \text { kneeling. }\end{array}$ \\
\hline & & Yart N-_Collective Fire. \\
\hline $\begin{array}{l}3010 \\
300 \\
300 \\
500 \\
600 \\
3010 \\
500\end{array}$ & 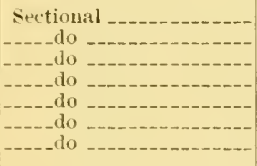 & 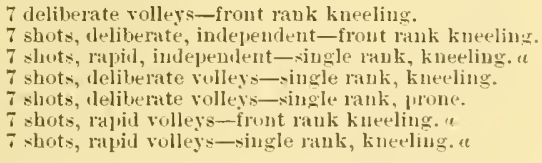 \\
\hline
\end{tabular}

TABLE B.-Truined Ien.

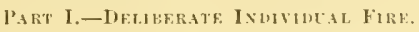

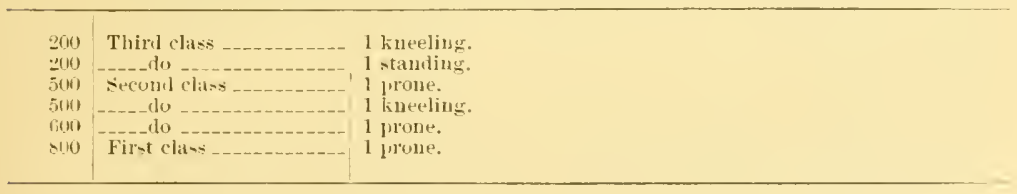

PIRT 11.

\begin{tabular}{|c|c|c|}
\hline 300 & Sectional & \multirow{10}{*}{ 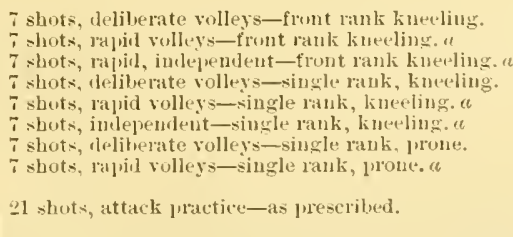 } \\
\hline $3(k)$ & $\begin{array}{c}-2 \\
\text { do }\end{array}$ & \\
\hline 3610 & - - do & \\
\hline 501 & - do & \\
\hline 5014 & - 10 - & \\
\hline 5011 & - & \\
\hline (iti) & _-_ do _... & \\
\hline (i) & --_-_do & \\
\hline soin? & & \\
\hline $20 i i$ & & \\
\hline
\end{tabular}

«. Magazine fire. Time allowante, one minnte.

A new system of instruction in field firing has been adopted at Aldershot. The general idea and the details of the system of skirmish runs were worked ont by Capt. E. L. C. Fielden, rtth (2d battalion) Highland Light Infantry. Capt. E. B. Cassatt, Thirteenth Cavalry, United States military attaché in London, who visited Aldershot in November, 1901, and 
through the courtesy of the British war office witnessed the setting up and working of the targets, describes it as follows:

The ground used at Aldershot for this purpose enables one battalion to advance to the attack with as near an approach to the conditions of actual warfare as I have seen. The battalion advances in column of route, when fire is suddenly opened upon it by a single gun, posted about 800 yards to the left front. Deployment is made at once and the gun is silenced. On the firing line reaching the crest of a long hill perpendicnlar to the front, the first position of the enemy is seen, about 900 yards distant, and the advance is subjected to artillery fire from a battery abont 2,500 yards. The enemy can hardly be distinguished, as their skirmishers show only their heads and shoulders, and that only occasionally. As the alvance continues, the enemy are supposed to have retired to a second position abont 800 yards away, with a deep ravine in its front, through which runs a main railway line. The enemy's object is to destroy this line before the advance can occupy it, and with this object in riew, an armored train is sent down to cover a party of men who cone rumning down the hill to blow up the tracks, which they are supposed to sncceed in doing. The adrance continnes beyond the railway and up the hill, when the enemy is found to have taken his last position near the guns aforementioned. The battalion thus strikes three positions, covering about 2,500 yards.

The targets are merely dummy figures of the simplest construction, and look as if they had been made by some post carpenter. They are all worked by men in pits by means of ropes and springs, with the exception of the armored train and the wrecking party. An extensive system of telephones connects all the pits. A pecnliar part of the arrangement is that the advance is the whole time subjected to shrapnel fire, which is obtained by means of the explosion of small, harmless bombs, suspended from wires above the men's heads or laid on the ground in front. This and the firing of the dnmmy guns by the same means are the only electrical features of the system. I must myself confess to having been startled when one of the imitation shrapnel exploded withont any warning at my horse's feet. The only thing in the system which conld not be made at any post is an ingenious spring by which the fixed targets are made to resume their npright position after being pulled down. I can heartily recommend the adoption of a similar system at some of our larger posts. I inclose an extract from the Strand Mragazine of December, 1901, containing plates of the only photographs of the new system.

In conclusion, it must be stated that over all the ground are covered pits for the use of umpires, who, by means of mirrors, can watch the advance in all its morements. The only drawback to the practical utility of this range is that the Government will allow only 20 rounds per man to be used in this practice.

The Strand Magazine, from which the accompanying illustrations are copied, says:

In order to give our readers an idea of a field day on the ranges we will imagine, for the time being, that we are part and parcel of the attacking force. Forward: Narch! We scatter and become units of a long straggling line of creeping, ever advancing foes. We avail ourselves of every particle of cover. What is that on the crest of the hill? The enemy"? 
Who sail the enemy" Why, res, surely there they are again. Watch these two men rumning along the crest of the hill, but hefore the worts are out they are gone again.

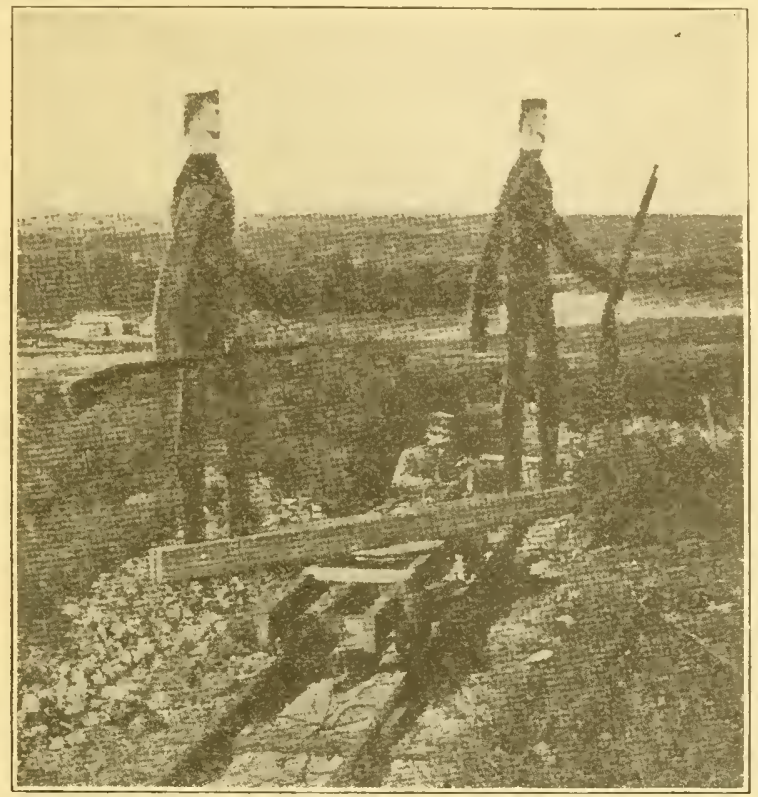

Fig. 1. - The running men, showing how they are worked from the pit.

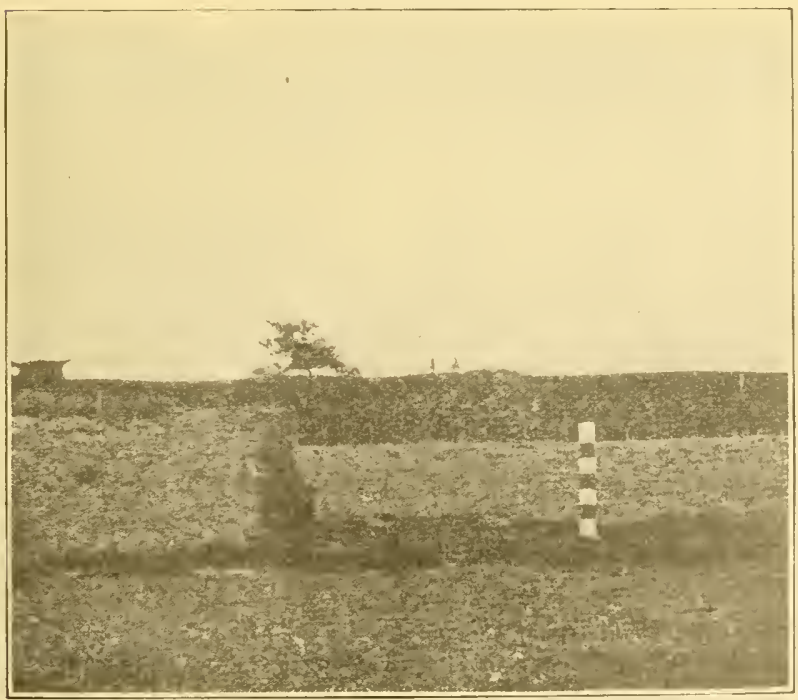

Fig. 2.-The same figures on the crest of the hill some 400 yards away. 
Someone on om left had taken a pot shot at them. A hit! No, it isn't. They are there once more. Let us get nearer. On we creep; we reach the coreted hill, we make a dash for the top, and lo! before ns are the dummy figures of the enemy. On our right we see a Maxim ready to fire. The gumer pops up and down behind the breech. "Shoot him if yon can, boys!" and the peppering begins

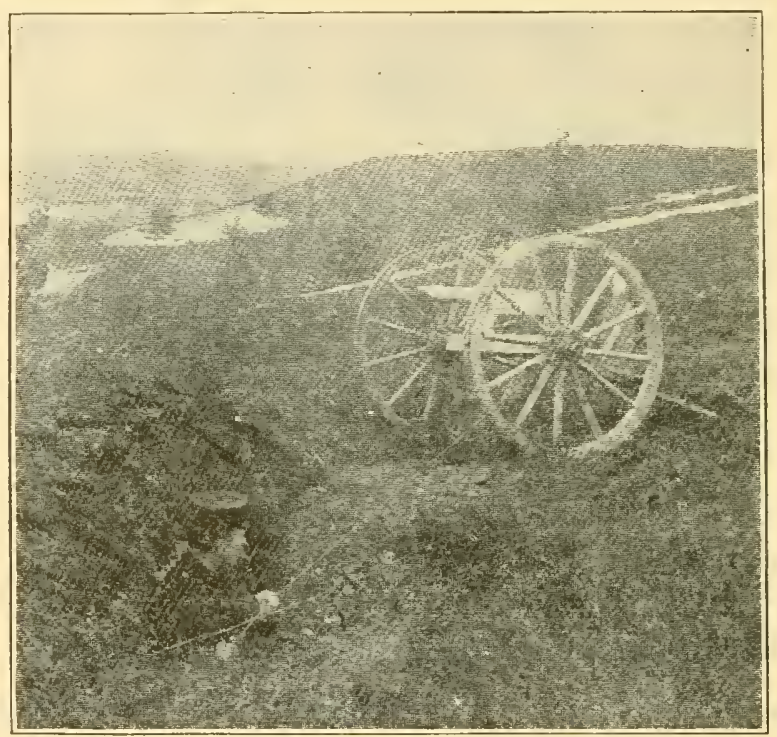

Fig. 3. - The dummy Maxim.

Then withont a moment's notice heads and shoulders appear in the heather, and before we can take aim they are gone again.

The magrazines are brought into use and we pepper away for our lives. The hearls appear again and are lost to view a moment after.

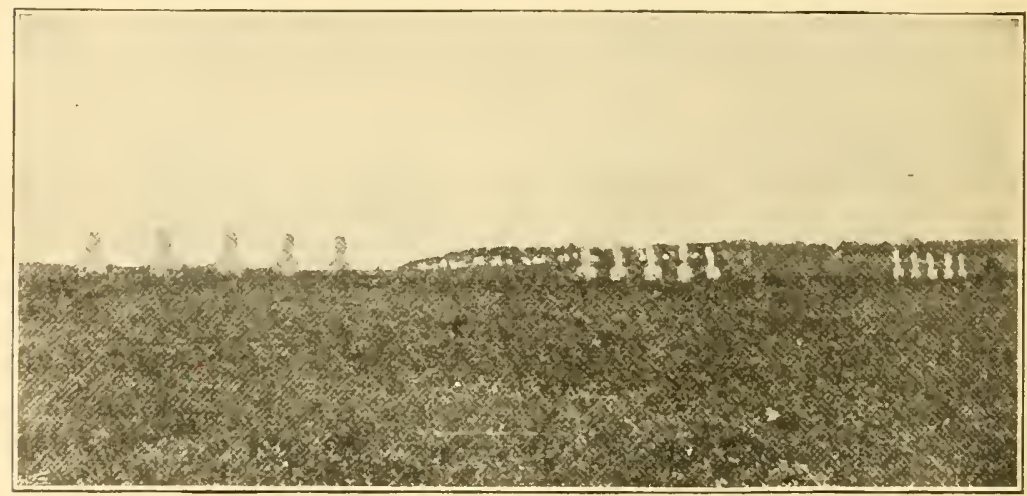

Fig. 4.-Heads and shoulders among the heather. 
We reach the hill. Behold a signaler. He wares his flag, evidently sending a message to his commander in rear, reporting onr adrance. He is gone, our excitement grows to a tremendons pitch. There he is argain! Ping, ping, ping; he's down. But, alas, it is not the rifle that had lone it, but the man in a protecting pit who has worked the life-like dmmmy.

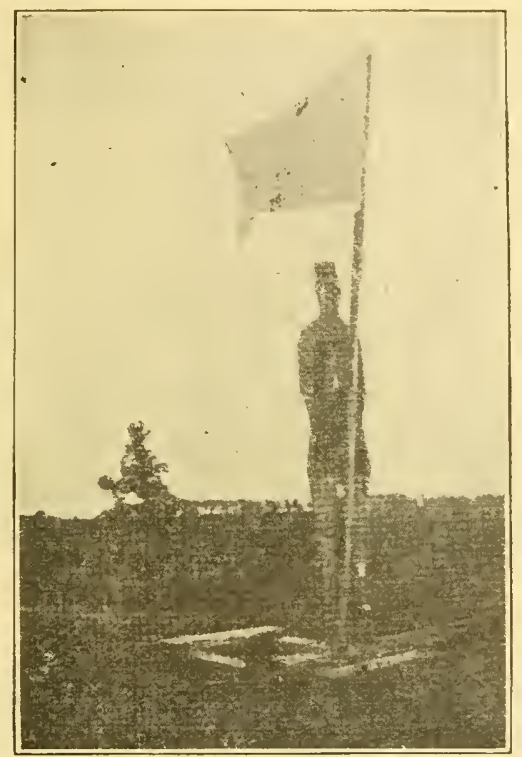

Fig. 5. - The signaler.

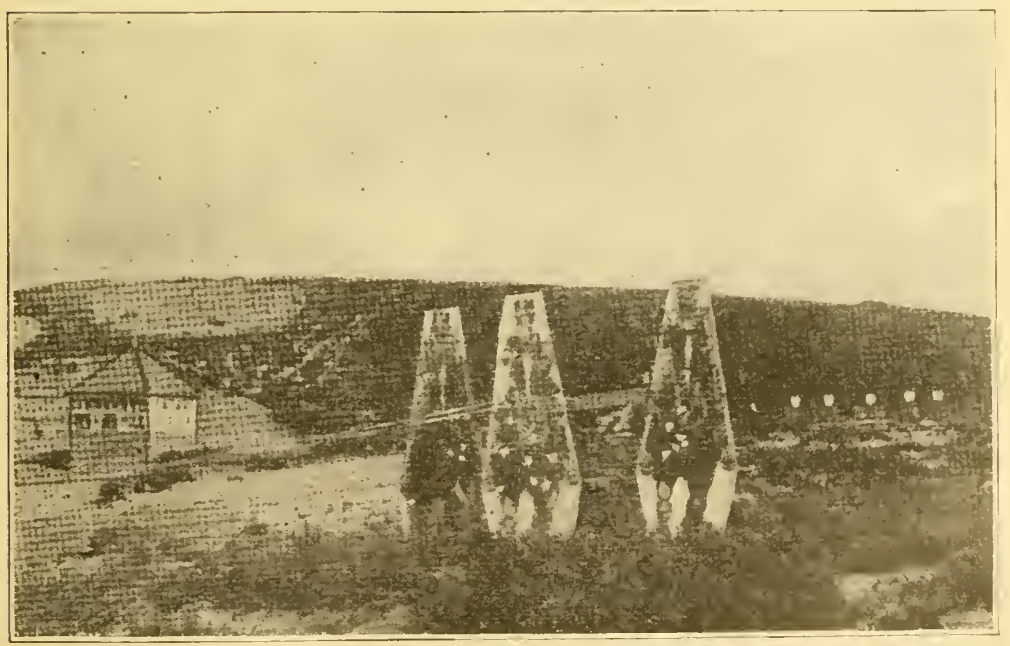

Fig. 6. - The dummy cavalry-note the ropes which keep the figures straight.

We advance continuonsly. Five hundred yards ahead there is a honsea Boer inn. We intend to capture it, but we are not there yet. We have 
to face a cavalry charge. The intrepid horsemen are dummies too, but none the less are swift of motion. Note the ropes which give them life. We give the momnted men a lesson. Look at the white patches, each of which rlenotes a bullet mark, and you will say that we have made good practice to-day.

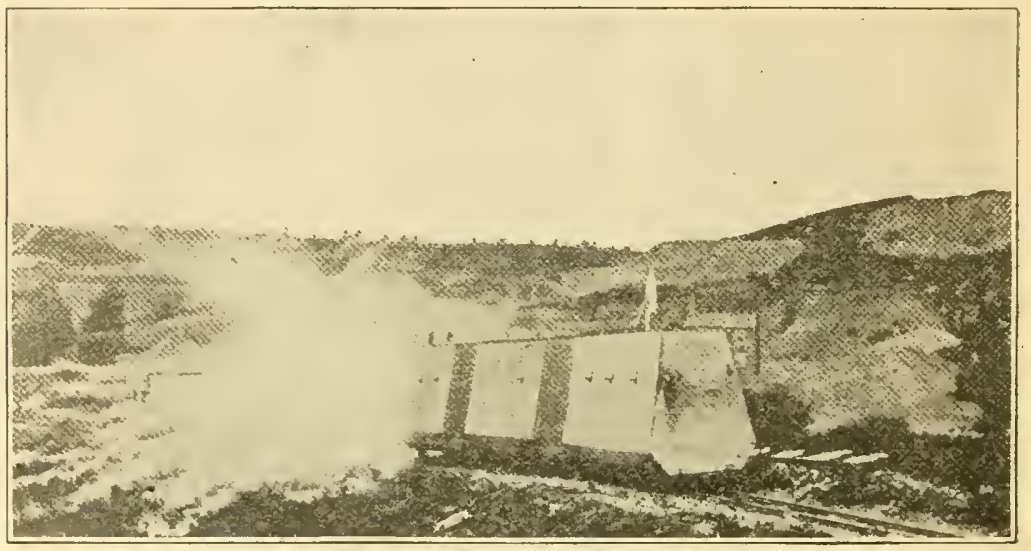

Fig. 7. - The dummy armored train spits fire.

We must get to the inn at any price; it must be stormed. We crawl again down hill, behind hillocks, across ditches and ravines. But what

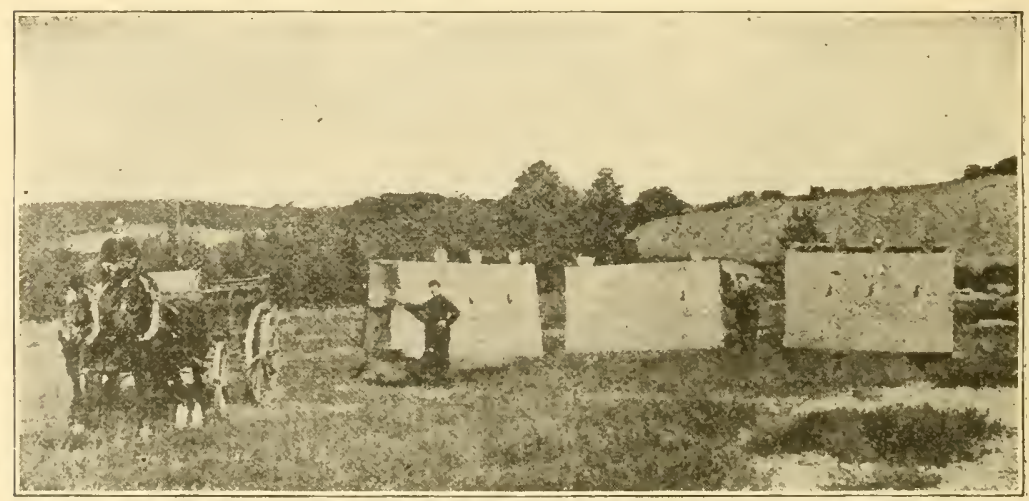

Fig. 8.-The armored train "going home." The white patches indicate the hits after a field day.

is this? Take cover! A roar and a rumble-it is the armored train! With a shriek it dashes across the valley and spits fire at us as it goes.

A party of the enemy has been sent to wreck the line as soon as the train has passed. They tear down the hill in front of us and disappear from view. They have had a bad time. Look at their poor dummy bodies. But see, they are ny) again for a few seconds near the signal box. 
What is that loud explosion? Hallon! they have succeeded; yes the line is blown up. They were gallant fellows, but they did unt know the valuw of taking cover.

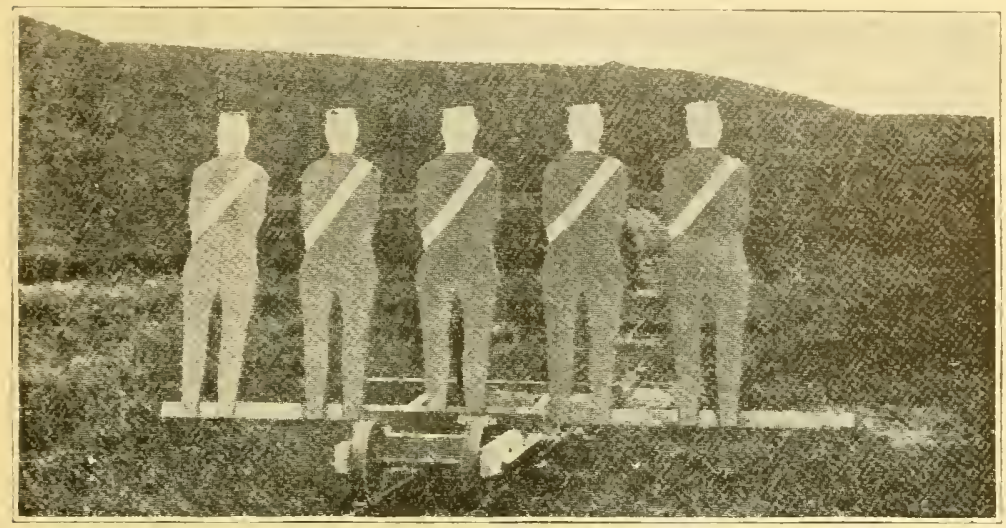

Fig. 9. - The dummy wrecking party.

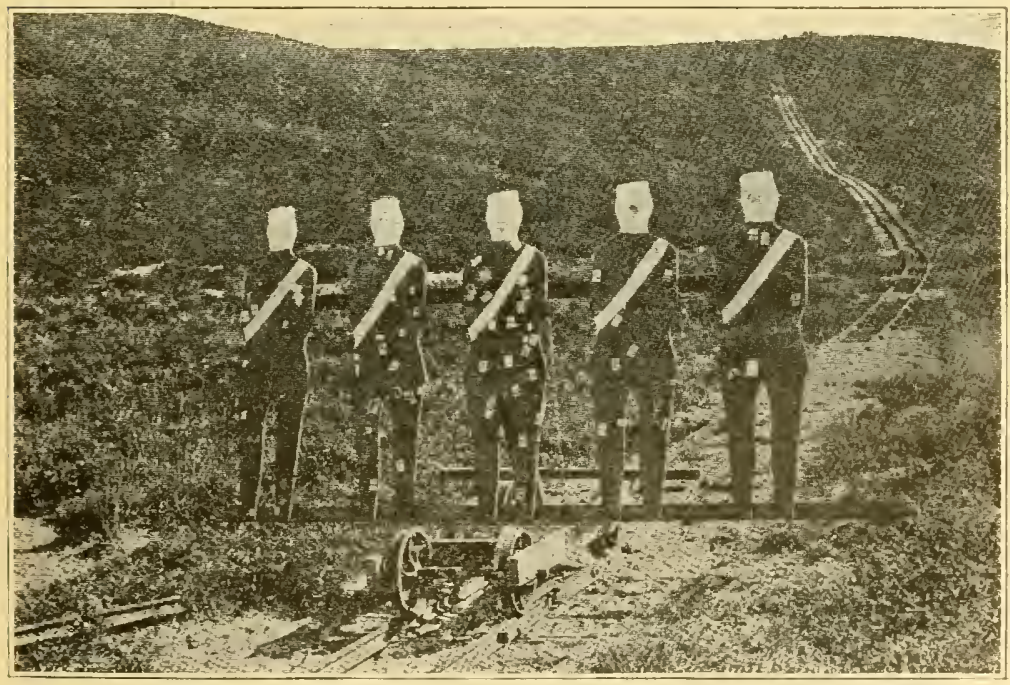

Fig. 10. - After the attack.

We do, and on we creep. There's a man coming out of the inn with a gun-probably the landlord. Steady, boys, bang! bang! We ve got him! No, he turns tail and enter's the house again. We do our best, however, and give him a parting shot in the back just as he gains shelter. As we 
advance we obtain a glance of the back of this structure, and we note with satisfaction that we have left our marks on the walls-canvas wallsand on the dummy figures that appeared at short intervals at the windows.

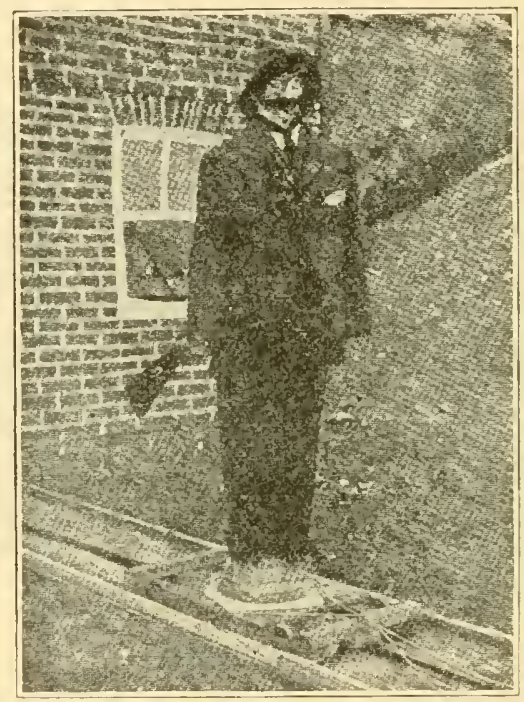

Fig. 11. - The landlord.

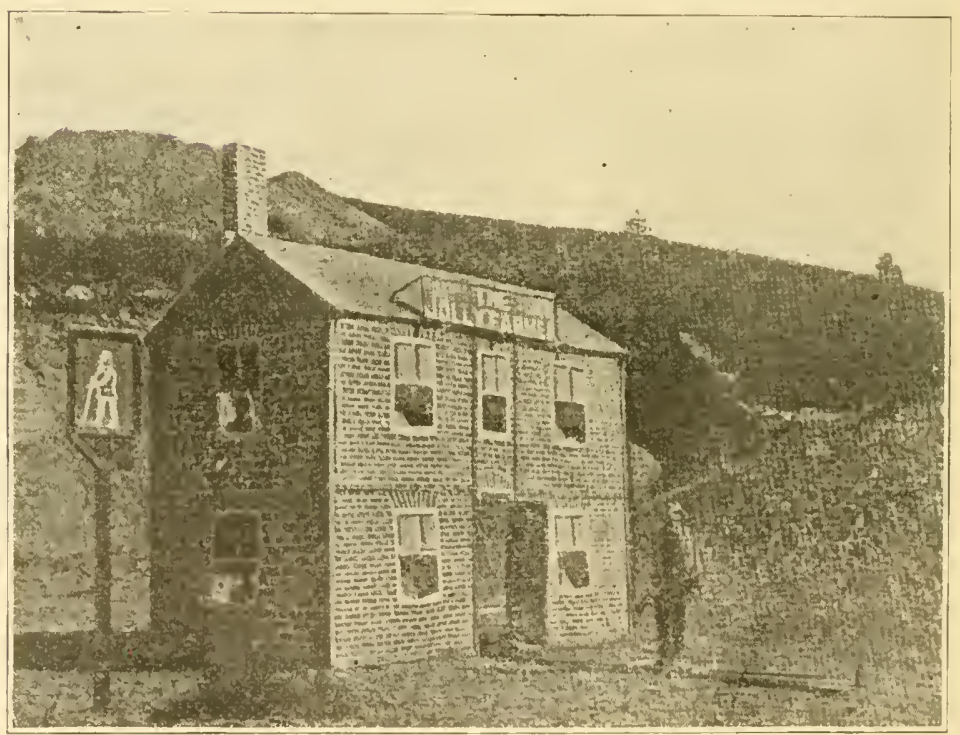

Fig 12. - The Boer inn. 


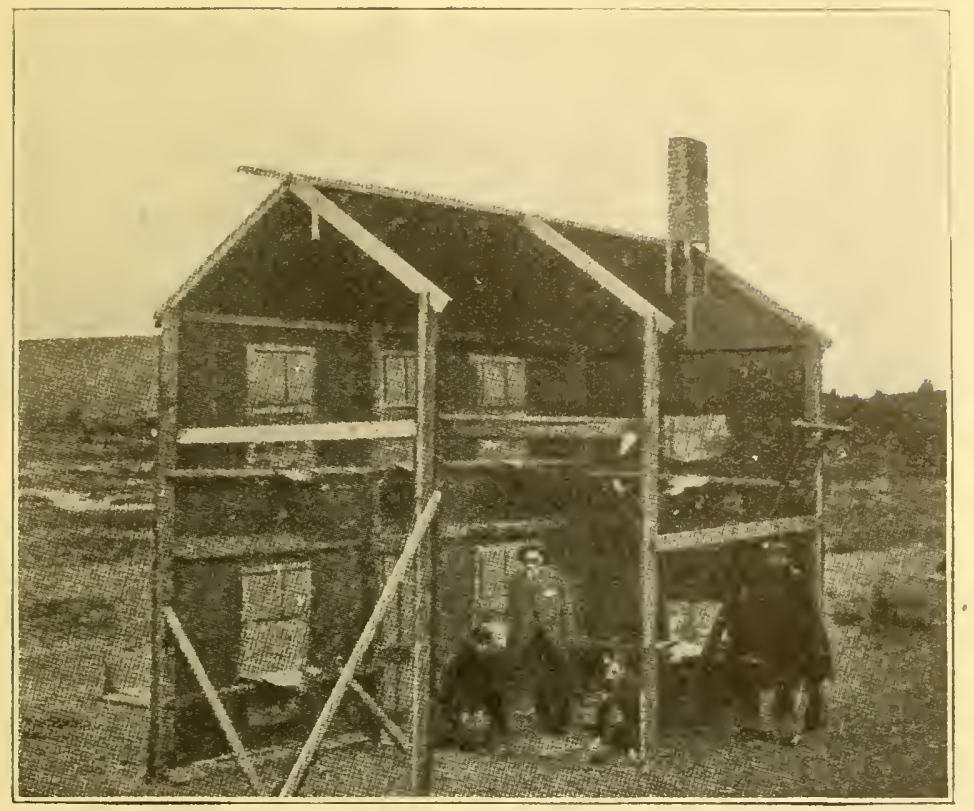

Fig. 13. - The Boer inn-behind the scenes.

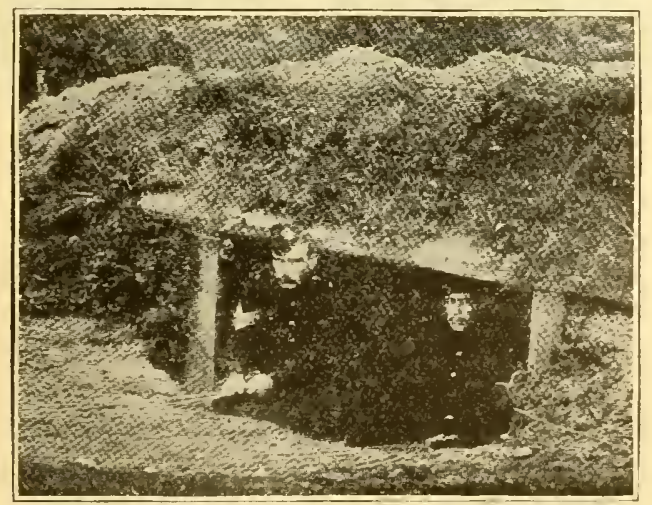

Fig. 14. -The pit, with men who "work" the innkeeper.

We climb another kopje and come nnder the fire of a battery, just visible in the far distance, craftily concealed under the shadow of a woot. We hear an explosion; it is the 1,j-pounders opening fire. Halloa! one of its deadly messages drops and explodes less than 20 yards in front of $u$. Shrapnel covers (sic) our advance, bnt nudaunted we move ahead unswerving toward the coveted groal. 


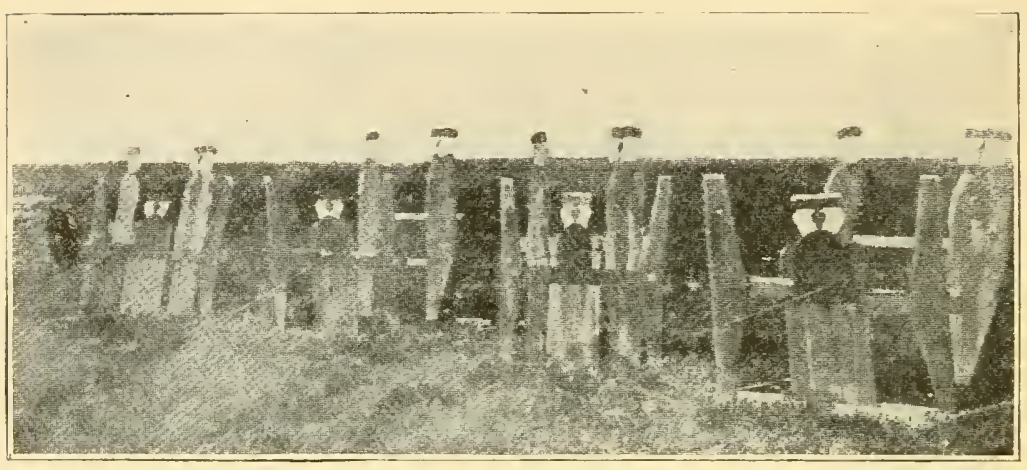

Fig. 15. - The dummy battery.

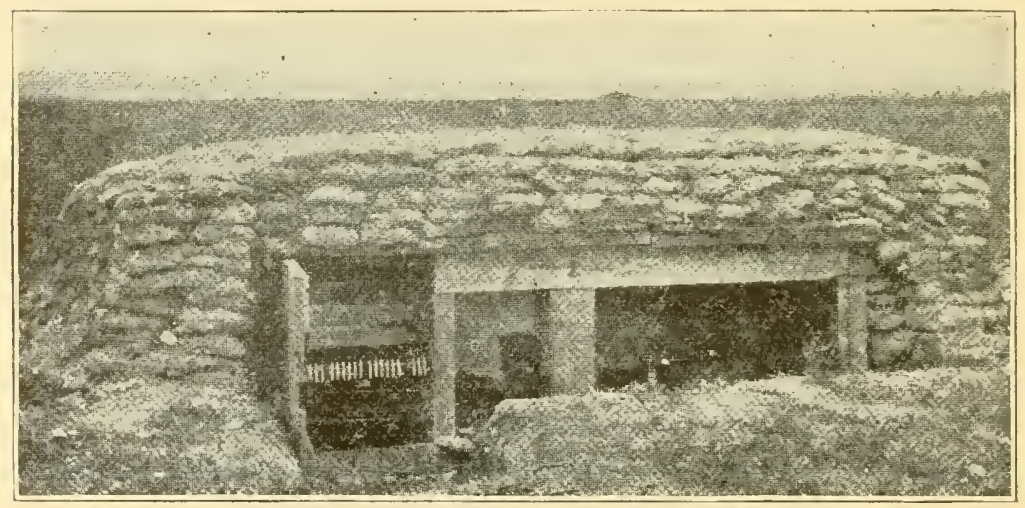

Fig. 16.-The switch.

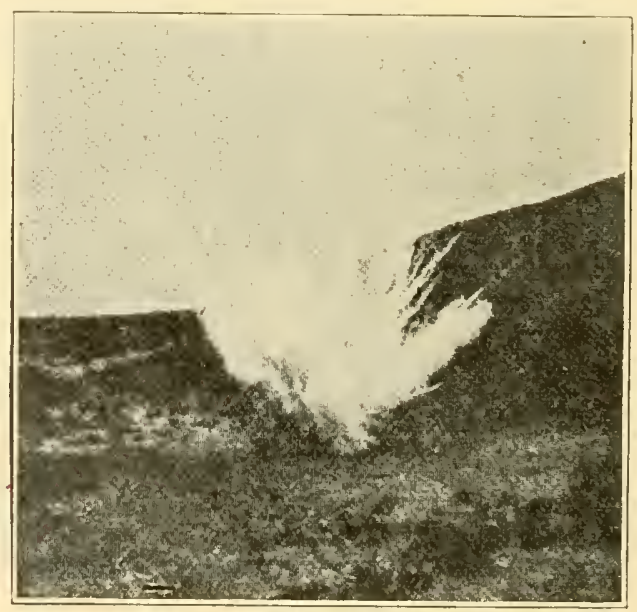

Fig. 17. - The explosion of a ground mine. 
We find out afterwards that the hattery fire was not so deadly as might have been anticipated by anyone who did not know that the bursting shells were nothing more than ground mines fired, as we advanced, by electricity from the switch shown on the preceding page.

So our illusion is over. We shake hands, for tre have done uncommonly well, but we want to come again. 



\section{VI.-RUSSIA.}

[Reported by Capt. S. L'H. slocum, Eighth Cavalry, Uniter] States Military Attaché at St. Petersburg.]

\section{INFANTRY.}

Instruction begins on the first of May and is conducted by the subaltern officers of the company under the superintendence and responsibility of the company commanders. The usual preliminary instruction is given and all preliminary drills are executed with fixed bayonets.

Every soldier fires 100 rounds annually with aiming tubes and shot.

For an infantry regiment the following number of drills is recommended:

\begin{tabular}{l|r|r|r}
\hline & Company. & Battalion. & Regiment. \\
\hline $\begin{array}{l}\text { Target practice } \\
\text { Estimating distances }\end{array}$ & $\begin{array}{r}19 \\
4\end{array}$ & $\begin{array}{r}12 \\
3\end{array}$ & 4 \\
\hline
\end{tabular}

TARGETS.

The targets used for ordinary practice are of two sizes.

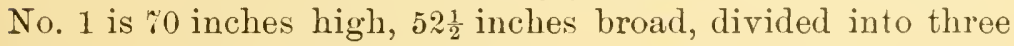
vertical belts, the outer belts being painted light gray and the center one white with a black band $4 \frac{1}{4}$ inches broad and widening in the center to a circle down the middle. No. 2 is 84 inches in length and 70 inches broad, painted light gray and divided by narrow black lines into 6 equal horizontal bands. There are also in use targets $17 \frac{1}{2}$ inches broad and, respectively, 70,35 , and $17 \frac{1}{2}$ inches high, on which are painted full-length, half-length, and head figures of Russian solitiers. For prize firing, a circular target 14 inches in radius and divided into 14 rings is used. Figures may be painted on No. 1 target. 
The course of target practice for active, reserve, and fortress infantry is as follows:

\begin{tabular}{|c|c|c|c|c|c|c|}
\hline \multirow{2}{*}{ No. } & \multirow{2}{*}{ Range. } & \multirow{2}{*}{ Position. } & \multirow{2}{*}{ Target. } & \multirow{2}{*}{ Description of fire. } & \multicolumn{2}{|c|}{$\begin{array}{l}\text { Number of } \\
\text { rou uds. }\end{array}$} \\
\hline & & & & & $\begin{array}{l}\text { lst } \\
\text { time. }\end{array}$ & $\begin{array}{l}\text { Other } \\
\text { times. }\end{array}$ \\
\hline 1 & $\begin{array}{l}\text { Peces. } \\
2000\end{array}$ & Stauding ........ & No. $1 \ldots$ & Individnal___-_-_ & 5 & 5 \\
\hline 2 & 200 & $\begin{array}{l}3 \text { roundsprone, } 2 \\
\text { roumds kneel- } \\
\text { ing. }\end{array}$ & Head on No. 1 & _. do n & 5 & \\
\hline 3 & 300 & Standing -.-_-_- & Half figure ---- & _-_-_do _.- & 5 & 5 \\
\hline 1 & 100 & $\ldots$ do $\ldots-\ldots$ & Full figure & -_-_-_do _...- & 5 & 5 \\
\hline 5 & 100 & Kneeling ......... & Haif figure & --_-_do _-_-_-_- & 5 & \\
\hline 6 & 400 & Prone & llead__.......... & - do & 5 & 5 \\
\hline 7 & $5(4)$ & - & 2 balf figures & 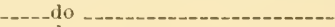 & 5 & \\
\hline 8 & 800 & $\begin{array}{l}3 \text { rounds prone, } \\
\text { with rest ; } 2 \\
\text { rounds kneel- } \\
\text { ing. }\end{array}$ & 4 figures........ & _-_._do _ _ & 5 & 5 \\
\hline 10 & 400 & Prone & $\begin{array}{l}1 \text { disalprearing } \\
\text { balf figure. }\end{array}$ & $\begin{array}{l}\text { ludividual; } 5 \text { seconds for each } \\
\text { round. }\end{array}$ & 5 & \\
\hline 11 & $\begin{array}{c}500 \text { to } \\
300\end{array}$ & $\begin{array}{l}\text { Prone or kneel- } \\
\text { ing, according } \\
\text { to ground. }\end{array}$ & $\begin{array}{l}\text { Half figure for } \\
\text { eaclı mau. }\end{array}$ & $\begin{array}{l}\text { Individual fire by command of } \\
\text { group leader, from one posi- } \\
\text { tion after a rush forward, each } \\
\text { man on his own target; slow } \\
\text { fire. }\end{array}$ & 5 & \\
\hline 12 & $\begin{array}{l}800 \text { to } \\
400\end{array}$ & 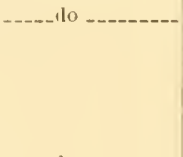 & $\begin{array}{l}4 \text { donble balf } \\
\text { figures. }\end{array}$ & $\begin{array}{l}\text { Individual fire by command of } \\
\text { group learler, from two posi- } \\
\text { tions after rushes forward; } \\
\text { slow fire from first, and quick } \\
\text { fre from second position; } \\
\text { marking of hits for whole } \\
\text { group. }\end{array}$ & 10 & 10 \\
\hline 13 & $\begin{array}{l}1,200 \\
\text { to } 8(0)\end{array}$ & 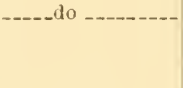 & 8 figures_-_.. & $\begin{array}{l}\text { Yolleys by squads in open order, } \\
\text { by command, after an arivance } \\
\text { in quick time, from one posi- } \\
\text { tion. }\end{array}$ & 5 & 5 \\
\hline 14 & $\begin{array}{l}1,800 \\
\text { to } \\
1,200\end{array}$ & - & $\begin{array}{l}15 \text { figures, } 2 \\
\text { praces apart. }\end{array}$ & $\begin{array}{l}\text { Volleys by half companies in } \\
\text { line, by command after an } \\
\text { advance at quick time; one } \\
\text { minute allowed. }\end{array}$ & 5 & 5 \\
\hline 15 & $\begin{array}{l}2,600 \\
\text { to } \\
\stackrel{2}{2}, 1000\end{array}$ & $\begin{array}{l}\text { Standing or } \\
\text { kneeling, ac- } \\
\text { cording to } \\
\text { ground. }\end{array}$ & $\begin{array}{l}21 \text { No. } 2 \text { tar- } \\
\text { gets in rows } \\
25 \text { paces dis- } \\
\text { tance. }\end{array}$ & $\begin{array}{l}\text { Company in line; volley by half } \\
\text { companies, by connand, al- } \\
\text { ternately, at two tlistances, } \\
\text { after an advance in quick } \\
\text { time; one anl one-half min- } \\
\text { ntes allowed in all for firing. }\end{array}$ & 10 & 10 \\
\hline 16 & $\begin{array}{l}2,600 \\
10 \\
400\end{array}$ & _-_-_do _....... & Field targets_-- & $\begin{array}{l}\text { Solution of a tactical problem } \\
\text { by the company, half in firing } \\
\text { line, half in sulport. }\end{array}$ & 20 & 20 \\
\hline 17 & $\begin{array}{l}2,600 \\
\text { to } \\
\text { the }\end{array}$ & 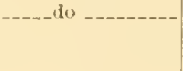 & --- 120 -.----- & $\begin{array}{l}\text { The balf compatu formerly in } \\
\text { firing line in support and vice } \\
\text { versa. }\end{array}$ & 20 & 20 \\
\hline
\end{tabular}

All officers shoot yearly the first to tenth practices. Noncombatants shoot yearly only Nos. 1, 2, and 4, and all combatant noncommissioned officers and men the whole course in their first year; in the following years the course, with the exceptions of Nos. 2, 5, r, and 11. Reserve men called in for training, or on mobilization, only shoot Nos. 4, 12, and 13. For each officer there are allowed 150 rounds of ball ammunition, and for each noncommissioned ofticer or man 
(combatant or noneombatant), 150 rounds of ball and 15 of blank ammunition yearly. The total of the rounds allowed for noncommissioned officers and men is expended as follows: Fifteen rounds a man for noncombatants; 125 ball and 15 blank cartridges for each man firing the course for the first time; 105 rounds of ball cartridges for each man firing the course for the second or subsequent times. The remainder is at the disposal of the commander of the unit for field-firing exercises on a larger scale, shooting in winter, extra rounds for bad shots, inspections, and prize firing.

After completing the eleventh practice, the combatants are divided into two classes, the first comprising those who in their first year have 33 hits out of 55 shots, or in subsequent years 21 hits out of 35 shots, the second class, all the others.

Those who for two years running have been in the first class receive badges. Prizes of from 1 to $2 \frac{1}{2}$ rubles are given, after a competition at 200 paces, to the best 10 shots of each company. Five rounds are fired for accuracy at a ring target, and 10 rounds in thirty seconds for rapidity. Prizes (weapons) are also given for good shooting among officers. In each regiment or independent battalion a certain number of men of vigorous constitution and good eyesight, and who are good shots, are chosen as scouts (okhotniki) and placed under a selected officer. A principal feature of their training is the hunting of wild animals, for which in a regiment, 500, and, in an independent battalion, 200 rubles are once and for all allowed for the purchase of rifles, dogs, etc., these being afterwards kept up by the sale of the game shot.

The object is to have specially trained men for difficult or dangerous duties in war. The number so trained should never be less than four per company.

TARGE'T PRACTICE FOR CAYALRY.

In March, target practice begins, and by the 1st of May recruits and old soldiers should have finished not less than six of the practices of the course (see below).

For target practice eight days per squadron, and six per regiment, are reserved.

For estimating distances four days per squadron. 
Cavalry target praetice.

\begin{tabular}{|c|c|c|c|c|c|c|}
\hline \multirow{2}{*}{ No. } & \multirow{2}{*}{ liance. } & \multirow{2}{*}{ Pusition. } & \multirow{2}{*}{ Target. } & \multirow{2}{*}{ Hescription of fire. } & \multicolumn{2}{|c|}{$\begin{array}{l}\text { Number } \\
\text { of rounds. }\end{array}$} \\
\hline & & & & & $\begin{array}{c}1=\mathrm{t} \\
\text { time. }\end{array}$ & $\begin{array}{l}\text { Uther } \\
\text { times. }\end{array}$ \\
\hline 1 & $\begin{array}{l}\text { Preces. } \\
\quad 200\end{array}$ & Standing _ _.... & No. 1 & 1ndjvidual & 5 & 5 \\
\hline 2 & 2010 & $\begin{array}{l}3 \text { rounds prone, } \\
2 \text { roun al s } \\
\text { knet ling. }\end{array}$ & IItad on Xo. 1 - & $\ldots$ - do .... & 5 & \\
\hline 3 & 400 & Stauding _..... & Full figure-_-_- & - - - - do - & 5 & 5 \\
\hline 4 & 400 & lineeling _-_. & llalf figure & --se-do -- & 5 & \\
\hline 5 & $g(k)$ & $\begin{array}{l}3 \text { romnds lone. } \\
\text { with rest; } 2 \\
\text { rounds kneel- } \\
\text { ing. }\end{array}$ & 4 figures------- & _-_-_do -. & 5 & 5 \\
\hline$\frac{4}{7}$ & $\begin{array}{l}1,0(0) \\
f(k)\end{array}$ & Momuterl & $\begin{array}{l}\text { S figures } \\
\text { sig. }\end{array}$ & do -2 & $\begin{array}{l}5 \\
5\end{array}$ & 5 \\
\hline$\therefore$ & $\begin{array}{l}1,200,00 \\
8000\end{array}$ & Any pusitiou & 8 figures_-_-_- & $\begin{array}{l}\text { squad volleys in open orier, by } \\
\text { command, after an advance in }\end{array}$ & 5 & 5 \\
\hline 9 & $\begin{array}{l}2,4(n) \text { to } \\
2,0(n)\end{array}$ & -..-_do -.. & $\begin{array}{l}21 \text { No. } 2 \text { targets } \\
\text { in } 3 \text { rows, } 25 \\
\text { paces apurt. }\end{array}$ & 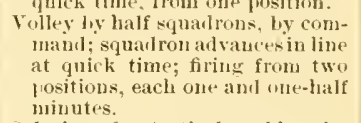 & 20 & 10 \\
\hline 10 & $\begin{array}{l}2,4100 \text { to } \\
400\end{array}$ & - do & Field targets -- & $\begin{array}{l}\text { solution of a tactical problem by } \\
\text { the syluadron, half in firing line, } \\
\text { rest in support. }\end{array}$ & 201 & 20 \\
\hline
\end{tabular}

All officers shoot every year througli the first to seventh practices. Noncombatants only shoot the first, second, and third, and all other combatants shoot, in their first year, all the practices; in their second and subsequent years all except Nos. 2 and 4. For each officer there are allowed 75 rounds of ball ammunition, and for each combatant or noncombatant noncommissioned officer or man 75 rounds of ball and 10 rounds of blank ammunition, and 100 rounds for use with aiming tubes (gallery practice) yearly. Cossacks go through the same conrse as regular cavalry.

There is no revolver practice for cavalry.

\section{FIELD ARTILLERY TARGET PRACTICE.}

It includes firing against a visible and stationary target, against a target invisible to the gunners and against moving objects. The field practices by single batteries are four in number, and are always executed with a battery of eight guns.

These practices are:

1. Direct firing with ring shell, changing to shrapnel, against a target in the open at 2,100 to $:, 800$ yards.

2. Firing against a target unseen from the battery, at 1,166 to 2,332 yards.

3. Case or shrapnel fire at short ranges.

4. Any field practice chosen by the brigade commander. 
The allowance of ammunition for the yearly course of practice in all field, reserve, sortie, and mountain batteries is 182 ring shell, 164 shrapnel, and 10 case, and in addition, for field firing, 15 ring shell and 30 shrapnel for field, etc., and $y$ ring shell and 13 shrapnel for horse or light batteries.

For the inspections there are allowed, for each battery, $y_{0}$ to 100 rounds, to be fired at about 3 rersts (about 3,300 yards), 50 to $: 0$ rounds to be fired at about 2 versts, and about 30 rounds to be fired at about 1 verst.

Artillery practice begins about the 1st (our 14th) of August, and is carried out in the great artillery camps, five in number.

For revolver practice, 20 rounds per pistol are allowed in the field, and 26 in the horse batteries.

\section{SEACOAST-ARTILLERY TARGET PRACTICE.}

No details obtainable.

RIFLE RANGES.

Each camp has a rifle range for the use of all troops stationed in it, and it must be so arranged that it can be used for tactical exercises also. It should be about 6,500 paces long, and firing should be capable of being carried on over 3,500 paces of it.

If sheets of water, marshes, hills, large woods, etc., are in the rear of the targets, the length of the range may be reduced to 4,500 paces. The total breadth of a range for an infantry regiment is 1,000 paces, for a brigade 1,300 paces, and for a division 1,900 paces. In these figures it is assumed that 8 ont of the 16 companies of a regiment will be using the range simultaneously. Only four marker's' butts are allowed for each regiment.

\section{FIRING SCHOOLS.}

The firing school for infantry officers at Oranienbanm is designed to give instruction in combat firing to officers detailed yearly for instruction. The number of officers detailed and range of subjects treated have been greatly increased since 1898. The instructional troops attached to the school have been increased from a company to a battalion. The courses of instruction last for seven months, and more stress is now laid on the training of captains as battalion commanders and as directors of the scientific investigations of young officers. 
The firing school of field, mountain, foot, and seacoast artillery is situated at Tsarskoye-Selo, near St. Petersburg. Captains of artillery are instructed in the same course as captains attending the infantry school. Other courses are held for junior lieutenants of field and mountain artillery in the summer at Ust-Izhora and Krasnoye-Selo, near St. Petersburg, and for those of foot and seacoast artillery at Ochakof (44 miles east of Odessa on the Black Sea). By an order of April 26, 1901, it is provided that generals of infantry and cavalry, and chiefs of staff of corps and divisions are to be detailed to artillery firing schools for instruction in material and fire action of artillery. The course lasts three weeks and is of a practical character. To illustrate the action of artillery in attack and defense, infantry and cavalry units stationed in the vicinity take part in the exercises, for which a special allowance of ammunition is made. 


\section{VII.-SWEDEN.}

[Reported by Lieut. Col. William R. Livermore, Corps of Engineers, United States Military Attaché, Copenhagen and stockholm.]

\section{INFANTRY.}

\section{The Course of Instruction.}

The course of instruction consists of preparatory drills, school shooting, drills in estimating and measuring distances, and field shooting, or a systematic course of drills in fire fight.

\section{PREPARATORY DRILLS.}

The preparatory drills are divided into loading, pointing, aiming, firing, and gallery shooting drills.

LOADING.-For drills in loading, dummy cartridges are used. The men are drilled in loading in all positions, at first slowly and then by degrees more rapidly. Finally they are drilled in loading while in motion and with cartridges.

For practice in quick loading the men are drilled in moving the mechanism quickly backward and forward, at first without cartridges and then with dummies.

Pointing.-Pointing is first practiced standing, then lying, with or without support, and then kneeling. The soldier is also taught to acquire the habit of taking good aiming positions behind such objects as can be used for protection and for support to the gun, kneeling on both knees, crouching or sitting down. For practice in placing the butt against the shoulder, the men are first practiced in bringing the gun in the direction of the target by the quickest movement; and then in placing the head in position on the butt, and the index finger of the right hand so that its middle joint rests against the trigger, which is thereby pressed somewhat back. Gymnastic exercises with the rifle are practiced as preparatory to the position drill. The object of the drills is to strengthen the muscles which are mostly called into play in shocting. These are the muscles of both shoulders and arms, 
the work of which consists in raising the rifle to the firing position and keeping it there as steadily as possible. No regular time is assigned for these drills, but usually abont five or ten minutes at the beginning and end of each hour of shooting drill. In gallery shooting and school shooting these drills are, however, practiced only at the end of the exercise, so that the men may not be tired during the shooting.

First the gun is brought slowly from the position of order arms to that of aiming, as, it is said, "The strength of the movement is increased by the time taken to make the movement, not by the number of times the movement is made. All the movements are to be made slowly. The left arm to be exercised as much as the right."

The drill is also to be practiced with a gun in each hand, the guns are lifted by command.

With the object of increasing the power of the left arm to support the gun and of strengthening the right wrist, the gun is brought up to the firing position at the command "Withont aim. Point," and is kept there for a period which is gradually increased to one minute; the gun is also held up with one hand.

When the right wrist is so well drilled that the gun can be kept in pointing position without the assistance of the left, the strength can be increased by repeatedly extending and bending the right arm.

AInivg. - The instruction begins by explaining the principles for aiming.

The aiming drills begin by teaching the men to correct the line of sight. This is done by placing a gun provided with a diopter in correct position of aim. Each man must observe this and afterwards regulate the diopter himself.

When the man has learned to get the correct line of sight, he is instructed in directing the piece at a target.

The same drills are then repeated without the diopter.

The men's skill in aiming is then tested by a so-called moving point of direction. At a distance of 15 meters a sheet of paper is fixed on the wall, and the grum is directed against some part of the paper. On the paper is held a small target for gallery practice. The target is then moved horizontally and vertically, and each man in succession without touching the gum says when he finds that the target is in the line of 
sight. The man who moves the target puts a small pencil mark on the place indicated. This is lone three times. The three points thus indicated are then connected by straight lines and the triangle thus formed shows the error in aiming.

The men are then taught how to make allowance for wind and other influences that affect the trajectory. For this purpose a target for gallery practice is so fixed that it can turn on its center of gravity. The point is marked which on account of disturbing causes should be the average point of impact for the gun in question, and the man must then indicate what point he should aim at to hit the center.

The gun is placed at 15 meters distance from the target, and the man must direct it so as to counterbalance the deflection. The target is then turned half around, and if the line of sight then hits the marked point, the aim has been correctly taken.

When the man can point correctly he is tanght to aim first with support, then without support, lying and kneeling, and finally standing. In these drills, especially where a support is used, the aiming can be controlled by mirrors, which are screwed on the ground behind the sight.

Pulling the Trigger.-The instructor first shows how the gun is to be fired by crooking the index finger of the right hand without jerk until the firing pin is released. The instruction proceeds gradually, first with support while lying or standing, and then without support. Attention is at first fixed on the movement of the index finger, but afterwards the gun is directed against the target and the instructor observes and controls it by means of a mirror.

Drills in pulling the trigger should be practiced at each school-shooting drill.

Londing, Pointing, Aming, And Firing, Combined.After going through a course of preparatory drills, they practice them all together, and in connection with drills in estimating distances. The targets should be such as would be required in war.

Knapsacks of gradually increasing weight are carried during the practice.

Galler Y Practice.-The object of gallery practice is to serve as a direct preparation for the school shooting and to give practice in the nse of the sight at long distance. 
The distance for gallery practice is always 15 meters. The targets are like those used when firing with loaded ammunition, but are reduced in proportion to the distance (fig. 1).

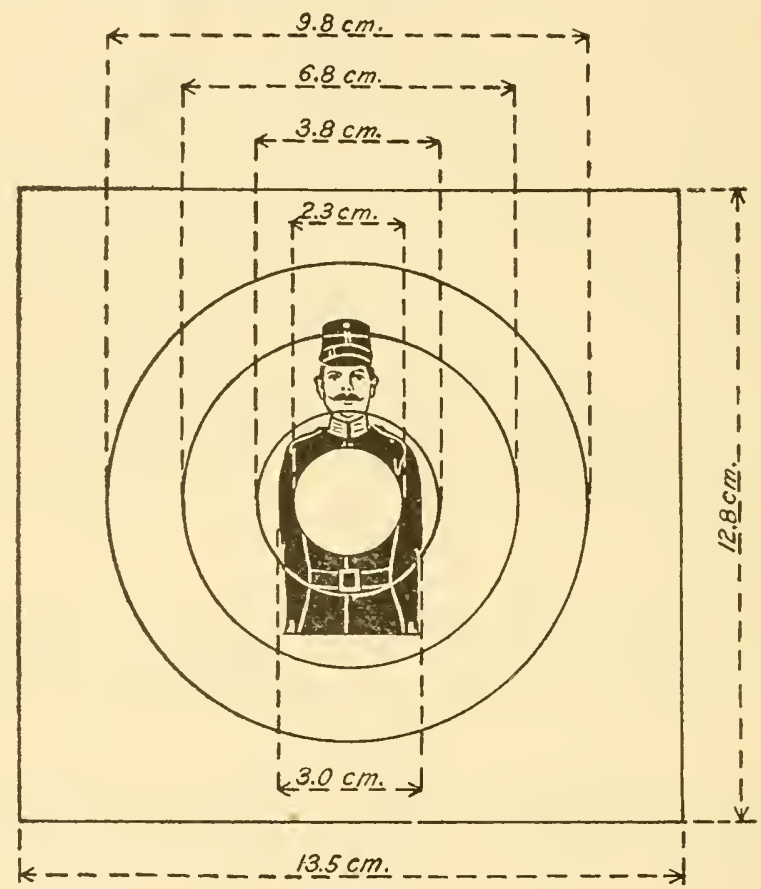

Fig. 1.

The 300-meter sight generally is used for gallery shooting.

For the drills in the use of the sight at long distances the aim is taken at a low point of direction, and the hits are canght on a higher target.

SCHOOL SHOOTING.

The school shooting includes precision drills and application drills, singly and in squads.

The object of precision drills is to acquire accuracy in firing at an ordinary target and to lay the foundations of fire discipline.

The object of the application drills is to give practice in shooting. against field targets, to develop fire discipline, and the knowledge of the results which can be expected from firing.

Ordinary targets are used for precision drills (fig. 2). 
The targets for the application drills are half figures and one-third figures (figs. 3, t, 5, and 6).

They are usually pasted on boards 170 centimeters high and 180 centimeters widle. When using three one-third size

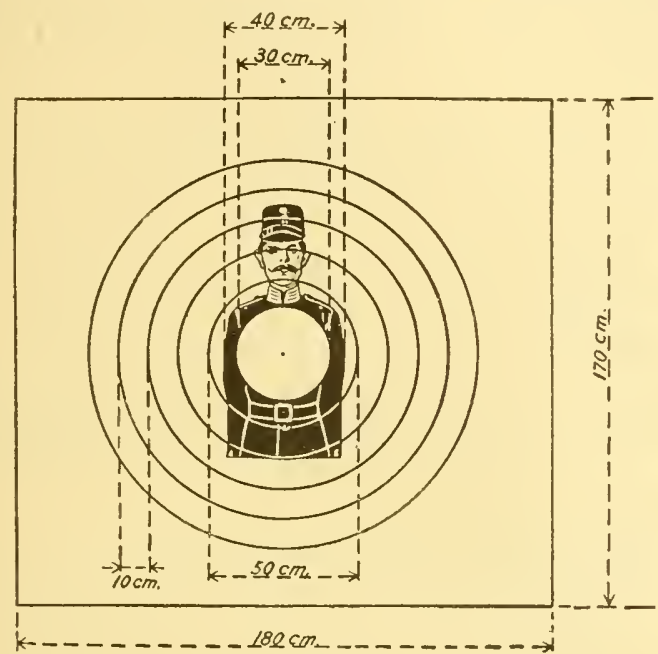

Fig. 2.

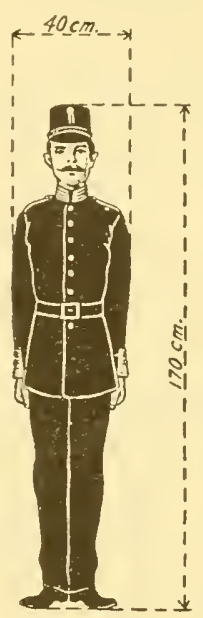

Fig. 3.

figures pasted on a board the figures should be erenly divided on the board and a vertical line should be drawn at 40 centi-

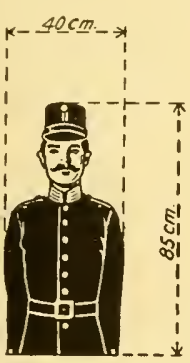

Fig. 4 .

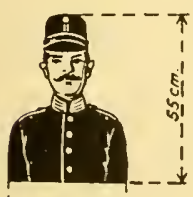
$k-40 \mathrm{~cm}$. $\rightarrow$ '

Fig. 5.

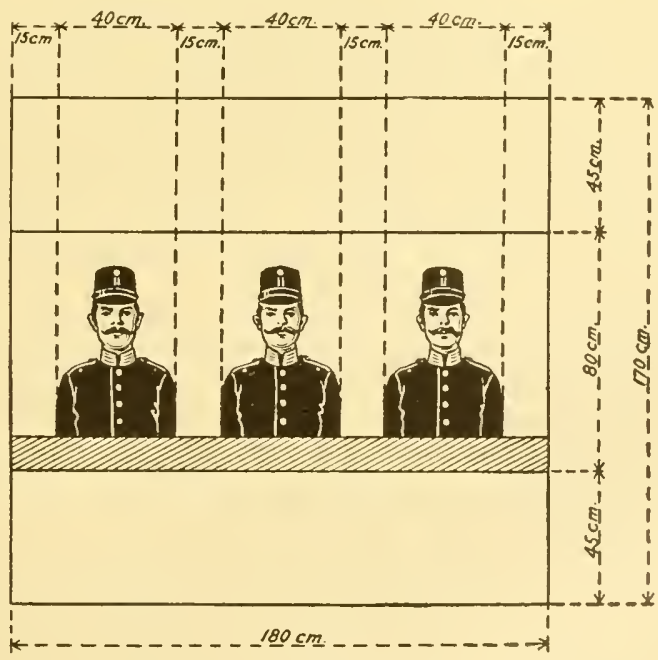

Fig. 6 .

meters' distance on each side of the central line of the target (fig. (i). 
On targets with pasted figures the lower part is shaded by dashes or gray color to represent the cover behind which the target is supposed to appear.

To each practice ground is assigned:

One officer as chief, the necessary number of officers or underofficers as detachment commanders, and the necessary number of underofficers as squad commanders.

Shooting squads, one to each target; one or two men to each target as markers, and one underofficer for each group of four targets, to have charge of the markers for these targets, and, if the shooting is directed against more than one group of targets, one officer for the markers' detachment.

If the practice ground is arranged with swing targets, one man for each signal apparatus, and if the ground is arranged for fixed targets, one, or, when shooting at long distances and in windy weather, two buglers or drummers, and finally, men for the necessary posts as sentries.

At precision drills, which are not competitive, the squad commander orders the position for firing, the placing of the sight, and the aim. When the command "Fire" has been given by the commander, the man himself fires when he is ready. When the man has fired, he reports to the squad commander how the line of sight seemed to be directed with relation to the center of the target, at the moment he fired.

The squad commander takes, during the shooting, a place from which he can observe the whole firing without causing the man any discomfort. He observes whether the man handles his gun properly, and tries during the drill by means of the controlling mirror to observe the errors, and gives the necessary information and instruction, but avoids disturbing the man while shooting.

During individual application drills, and during competitive precision drills, the men must have more freedom, but are still under the supervision of the squad commanders. If the ground is arranged for swinging targets each shot is usually marked as soon as it is fired.

When the ground is arranged for fixed targets the marking, as a rule, is made after every second or third shot.

In application drills in detachments, the respective detachment chiefs bring the cletachment to the firing position, and order the fire according to the drill regulations. The marking, as a rule, is done after the shooting is completed. 
MARKING. - When marking on a target, the value of the hit is first given, and then the position.

The value of the hit is given by holding the disk in the center of the upper side of the target for hits in the bull'seye (5); in the upper right corner of the target for hits in the ring (4).

The position of the hit is given immediately after by placing the center of the disk just over the hole caused by the bullet with that side turned to the firing point which will be best visible.

In individual firing at a figure target when the shot strikes, the disk is held straight up, and then the position of the hit is indicated as above.

When shooting by detachments, the results are reported by telephone, or by showing the disk to the left for the tens, and to the right for the units.

DRILLS IN ESTIMATING AND MEASURING DISTANCES.

Measuring Distances.-Distances are estimated in the field either by pacing, or by measuring on charts, or with a bicycle, or by trial shots. Both officers and men should be able to measure distances by pacing. All subaltern officers should have some knowledge of, and exercise in, the use of the distance measure adopted for the infantry.

Estinating Distances.-Men are practiced in estimating distances up to 600 meters; officers up to 1,500 meter's.

Privates who seem to have an aptitude for it are also to be exercised in estimating up to 1,500 meters. At least twelve men in each company are selected for this purpose. They are usually detailed as helpers in estimating distances, and as orderlies during a fight.

The drills begin by placing men at a distance of 200, 400, and 600 meters from the party to be exercised, and these men take different positions according to previously arranged signals. The leader explains to the detachment what the different distances are, how the fire is to be regulated, etc., all of which the men must try to impress upon their minds. This drill is repeated as often as necessary.

When some accuracy has been attained in these and other drills, the men begin to estimate distances in different terrain.

The drills are made from different shooting positions, especially lying down.

$23555-10$ 
For educating the officers, and the men detailed from the ranks, the usual course of instruction is taken first, and then extended to distances from 600 to 1,500 meters.

The instructions explain that, as a rule, the distances are estimated too long in the dusk, in cloudy and rainy weather; but, on the contrary, too short in a fine, clear atmosphere, especially if the sun shines on the target; too long over broken ground and along streets, alleys, and roads, but too short over ground sloping away from the observer, over water and over fields.

The drills for the men at last take the form of direct preparation for field shooting.

\section{FIELD SHOOTING.}

General Rules.-The field shooting must take place under war conditions.

Field shooting is of two kinds, individual and by detachment.

Individual Field Shooting.-This has for its object, to drill the soldier in adapting the skill acquired in previous drills to the conditions which will occur in the field, to teach him to adjust his aim to the distance, etc., and to take the best possible position for shooting.

In individual field shooting each man must, therefore, have his target, which, as far as possible, must be similar to those presented in actual warfare.

The man must be left entirely to himself in the choice of position and aim, but as soon as he has fired one or two shots he should be corrected if necessary, and to this end the shots should be marked.

These drills are best conducted by platoons. One or more targets are set up for each of the firing points fixed by the leader. Each man in succession must then practice against each of the targets.

Corrections are made, under the direction of the officer, by the underofficer for each target, who is the score-keeper.

The leader sees that the drills are made with a definite object in view.

After the man has finished shooting, the number and positions of the hits are marked and recorded in his presence.

Field Shooting in Detachuents. - Field shooting in detachments is a drill which as far as possible should have the 
character of a fight with loaded ammunition. In this exercise the object is to practice the leaders in guiding the fire under conditions as near like those occurring in the field as possible, and to exercise the men under all conditions, in keeping their discipline and steadiness.

These drills should be based on a simple supposition and have a certain object in view. The targets, which are to be like those in war, are to be arranged accordingly. It would be well if the movements and fire of the enemy could be marked.

Field shooting in detachment is always to be commanded by a specially appointed officer. This officer arranges the targets according to the supposition given, and takes the necessary precautions for safety. He gives to the respective commanders of the shooting detachments, the markers, sentinels, etc., the necessary instructions. He also decides when the maneuver is to commence, follows its course closely, and stops it when he finds cause. As many officers as necessary are placed at the disposal of the chief, to supervise the record, ete. Orderlies and trumpeters are also placed at his disposal. After the end of the drill the leader holds a critique.

The results of the shooting, which are always to be made known to the men taking part in the drill, are also to be criticised in the critique so that the causes of good and bad firing may, as far as possible, be made clear to the detachment.

The leader makes a report of the drill.

\section{APPORTIONMENT OF THE DRILLS.}

Recruit School.-The preparatory drills are practiced with great care. The recruit must, if he is to be regarded as well practiced in loading, pointing, aiming, and firing, be able to deliver, in any position 10 shots a minute against a target. In detachments of the size of a platoon the loading after a volley must be done in two seconds, and the filling of an empty magazine in eight seconds.

Gallery shooting is conducted according to a prescribed table, but the requirements of this table may be increased. For cadre recruits are assigned, at the utmost, 200 rounds per man, and for the conseript recruits, 100 rounds.

The prescribed school shooting for the cadre recruits of the first class comprises:

Precision practice of nine scores of 5 shots each at the school or ring target-two scores at 100 meter's, one at 200 meter's, - 
and six at 300 meters, position prone, kneeling, and standing, and with and without rest, as proficiency is attained. The requirements are that all shots shall be hits, 3 of the hits in the first five scores to be bull's-eyes, in the last four scores to be bull's-eye (5), or in the ring (4).

Individual applied practice, nine scores, two at 200 meters, at the one-third figure, two at 300 meters, at the half figure; requirements 3 and 2 hits, according to position-prone in first scores, and 2 shots prone and 3 kneeling in second scores at each range; one score at 400 meters at the full figure, and two scores at target 6 ; two scores at 600 meters at target 6 ; requirements, 2 or 3 hits according to position and size of target.

The detachment applied practice is of two kinds, first, where the detachment of four men in line, prone or kneeling, fires at the command of the chief, each man at his own target, and, second, where the detachment or platoon, also in closed line, prone or lineeling, fires, by command of the chief, at a common target. Eleren scores are fired in this practice at 300,400 , and 600 meters. The target used at 300 meters is the half figure and at the other ranges target 6 , the requirement being 2 or 3 hits when firing at individual targets, and 40 or 50 per cent of hits when firing at a common target, depending on the position, prone or kneeling.

After going through the applied drill they should, if occasion offer's, repeat at least fire times a precision score of 5 shots, 2 lying, 2 kneeling, and 1 standing, against a target at 300 meters, with no lestriction as to result; 250 cartridges are allowed each man for this practice.

For cadre recruits of the second class, drills according to a program fixed by the regimental chief, with 25 cartridges for each man; for conscript recruits, 90 to 100 cartridges for each man.

From the beginning of the application drills packs are carrierl, increasing in weight up to that carried in the field.

Cadre recruits who do not fulfill the requirements of a drill should repeat the same before the next drill commences, uncler careful guidance. The scores in which the recruit roes not qualify after the first shooting are to be repeated if occasion offers.

To qualify in shooting the cadre recruit must be able to fulfill the demands in at least ten scores of the applied drills, 
where each man shoots against a special target, and in at least three scores against a common target, and besides this he must make 30 points in precision drill with competitive scores.

Individual field shooting is practiced by the cadre recruits, and if possible also by the conscript recruits. At the most 20 cartridges for the cadre recruits and 10 for the conscript recruits are assigned to each man.

Field shooting in squads is practiced only by the cadre recruits; 20 cartridges are assigned to each man.

Regimental Drills.-After a few preparatory drills, school shooting is conducted as in the recruit school, but on a much smaller scale. Packs are carried in all the drills. Field shooting in detachments is practiced yearly with 20 cartridges for each man.

Corporals' and Underofficers' Schools.-After a few preparatory drills, school shooting is carried as far as the supply of ammunition permits.

Field shooting, singly and by detachment, and drills in firing against disappearing and moving targets, are conducted according to plans fixed by the respective chiefs.

To each pupil are assigned 120 cartridges.

Practice for Officers.-No more ammunition is used than the object in view demands.

\section{PRIZE SHOOTING AND PRIZES.}

General Rules. - Prize shootings are held by each regiment and "corps" or battalion.

The right to take part in the regimental competitions is limited to 40 ; in the "corps" or battalion to 20 of the men who have fulfilled the requirements of the school shooting at the regimental meetings and made the highest number of points in precision drills.

If necessary for the selection, preliminary competitions may be held.

Prize Shootixg. - Prize shooting takes place during the regimental meeting on a day when the conditions of weather, etc., are as farorable as possible, and when those who take part have not recently been fatigued by long field maneurers, etc.

The prize shooting is arranged and conducted like a precision drill "with competitive scores," excepting that no pack 
is carried, that officer's are detailed as detachment commanders, and as chiefs for the markers and that for each target an underofficer is detailed to watch the markers.

Prizes. - The prizes are:

Silver medals to wear on the breast; badges, two crossed rifles of red cloth, to wear on the right forearm; and money prizes; and as a distinction and reward for good distance judges, a five-pointed star of red cloth to wear on the right forearm.

For distribution as money prizes each regiment receives annually $300 \mathrm{kronor}$, for four prizes at $20 \mathrm{kronor}$, eight prizes at 10 kronor, and twenty-eight prizes at 5 kronor.

Each corps or battalion receives amnually 150 kronor, for two prizes at $20 \mathrm{kronor}$, four prizes at $10 \mathrm{kronor}$, and fourteen prizes at 5 kronor.

A "shooting medal" is given to the one who at the prize shooting makes 45 points, or who in two succeding years gets 43 points, if he has not already a medal.

Shooting badges are also given to those who receive shooting medals, and to those who in two succeeding years have fulfilled the requirements of the school shooting at the regimental meetings, and received at least 40 points in precision shooting.

Those who receive this mark of distinction are called marksmen.

Money prizes are given to all who at a prize shooting make at least 30 points.

Prize money not distributed may by order of the regimental commander be divided between the "distance judges."

The distribution of prizes takes place in the presence of the whole regiment, corps or battalion.

TARGETS.

Figs. 2 to 6 represent the ordinary forms of fixed target. Disappearing and moving targets are described in the account of artillery practice.

A detailed description of the method of using these targets at the rifle range at Rosersberg would be equivalent to a treatise ori applied tactics.

This rifle range lies at a distance of 15 or 20 miles from Stockholm and occupies the extensive grounds and buildings of an old palace or castle, including all kinds of terrain for 
preliminary and field practice. The exercises in the latter are made to approach as nearly as possible to actual warfare.

Each day's exercise is intended to represent part of some definite military operation.

The general and special ideas are explained as in kriegsspiel or at grand maneuvers. The men know only as much of the movements of the enemy represented by the moving and disappearing targets as they are asșmed to know during the battle in which they are supposed to be engaged. These targets are placed and colored as much like the enemy as possible, and sometimes no little skill is required to find them when they appear suddenly at a considerable distance in the shade and with their heads just showing from time to time behind the rocks or bushes. The discussion which follows each day's practice gives to both officers and soldiers a most vivid and practical idea of the use of varied ground in military operations.

This rifle range and infantry shooting school is also a college for the development of the scientific as well as the practical side of the subject, where new arms and new methods are thoroughly tested, studied, and discussed.

\section{CAVALRT.}

The practice in shooting for the cavalry is essentially the same as that for the infantry excepting that the cavalry do not carry their knapsacks.

They are practiced in estimating distances when mounted as well as dismounted.

\section{Apportionment of the Drills.}

RECRUIT SHOOTING.

Gallery shooting is conducted according to a prescribed table, but the requirements of this table may be increased by order of the commanding officer. One hundred cartridges per man are allowed for these drills.

The school shooting for the cadre recruits comprises seven scores of 5 shots each, at ranges from 100 to 300 meters, firing at the school target; requirements, all shots to be hits, and 3 of the hits in each score to be in the bull's-eye or in ring 4.

Five scores of individual and detachment applied practice, at the one-third and half figures, at 100, 200, and 300 meters, 
and at target 6 , at 400 and 500 meters. The first two shots in each of the first four scores are delivered individually, and the last three by the squad in line, each man firing at his own target. In the fifth score the men of the squad all fire at the same target.

Twelve shots, 5 lying, 5 kneeling, and 2 standing, are fired in competitive shooting at the school target. Requirements, 25 points. One hundred and twenty cartridges are allowed each man.

For conscript recruits only a few exercises are prescribed.

Cadre recruits who do not fulfill the requirements in a drill should repeat the same under careful supervision. The scores in which the recruit, after the first shooting, does not qualify, must, if possible, be repeated.

To qualify in shooting the cadre recruit must have fulfilled the requirements in at least two of the applied drills, where each man shoots against his own target; in at least one drill where the shooting takes place against a common target; and in precision drills with competitive scores he must have made at least 25 points.

Field shooting (single and in squads) is practiced only with the cadre recruits. Twenty cartridges per man are allowed for the field shooting, besides the ammunition left over from the school of shooting.

REGIMENTAL DRILLS.

A short course of school shooting is held, one score of precision practice at 300 meters, one of applied practice at 400 meters, and 12 shots in competitive firing, the same as in the recruit school, at which 35 points must be made to qualify.

Preparatory drills for field shooting and field shooting in detachments are practiced yearly. Twerty cartridges are allowed for each inan taking part in these drills.

CORPORALS' AND UNDEROFFICERS' SCHOOL.

The preparatory drills are repeated and school shooting is practiced to the extent allowed by the ammunition according to a program fixed by the respective chiefs.

Field shooting, if possible both single and in squads, is practiced according to the instructions of the respective chiefs.

Sixty cartridges are assigned to each pupil. 
DRILLS FOK THE OFFICERS.

No mor ammunition is used than necessary.

Captains and senior underofficers may be excused from these drills.

PRIZE SHOOTING.

Prize shooting is arranged yearly in each regiment.

The right to take part in these prize shootings in a regiment of 10 squadrons is limited to 40 , in a regiment of 5 squadrons to 20 , of the men who have fulfilled the requirements of the school shooting in the regimental drills, and who in the precision drill with competitive scores have gained the highest number of points.

If necessary for the selection, preliminary competitions may be held.

\section{REVOLVER PRACTICE.}

The course of instruction consists of preparatory drills, and firing with loaded ammunition.

PREPARATORY DRILLS.

The preparatory drills are divided into: Handling the rerolver, positions, etc., loading and unloading, pointing, aiming, pulling the trigger, and firing with blank cartridges.

Haxpling.-After the recruit has been taught the mechanism of the revolver and the use of its several parts, he is taught to take the positions "Revolver in " and "Revolver out." In the former the pistol is in its holster, in the latter, as shown in fig. 10.

LOADING AND UNLOADING are then practiced from the position of "revolver out."

Poincrixg.-The recruit is taught to take the position with his revolver cocked, the arm extended, and the line of sight horizontal, etc.

Amrng.-The line of sight, etc., is explained to the recruit. As the revolver is, in general, used only for short ranges, not over 40 meters, the point of aim is for all distances taken at the upper part of the enemy's body. This point is marked on the target (fig. ${ }^{7}$ ) by an ordinary patch or paster used to cover the bullet holes.

The revolver is then set on its stand (fig. 8), the line of sight directed upon the bottom of the patch at a distance of 10 meters, and each man is called in turn to see how it is pointed. 
Each man is then taught to place the revolver himself, and criticise the position taken by the others.

They are then taught to aim with support. The man first takes the position of aim and then the support is brought under his hand (fig. 9). He is then told to retain the aim as long as possible and when either his arm or eye is tired, or when so commanded, to take the position of "revolver out."

The same exercise is then repeated without the rest.

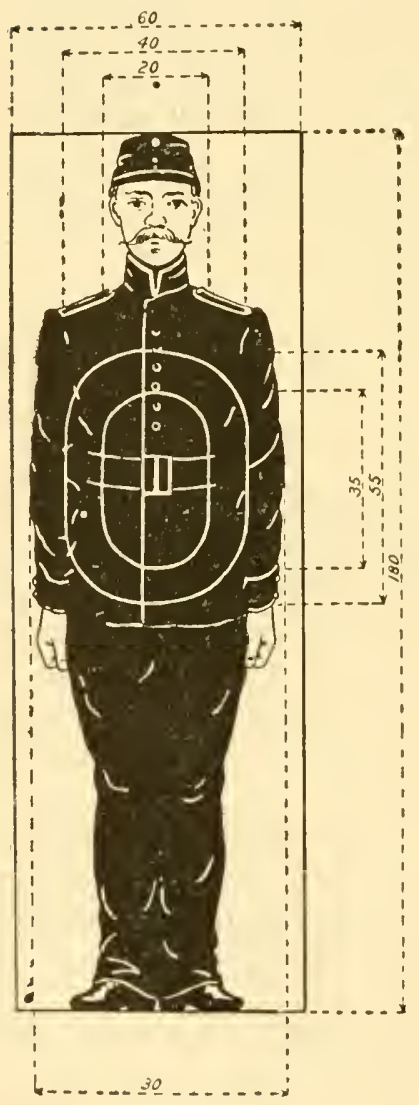

Fig. 7.

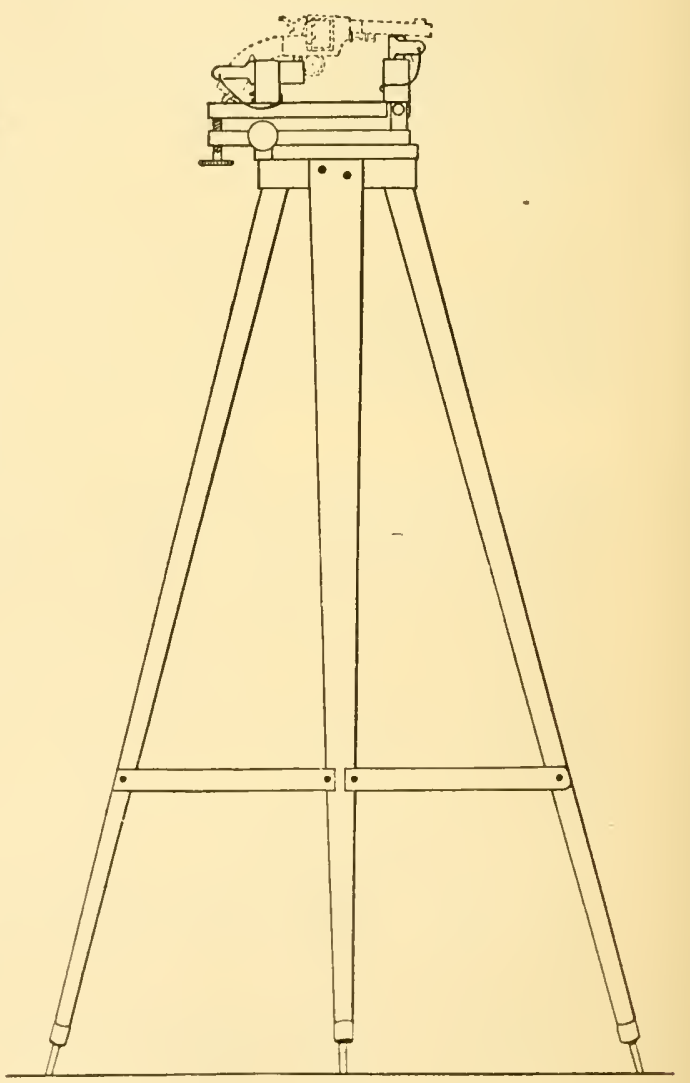

Fig. 8.

The instructor must not allow the pistol to be pointed at his own eye, in order to test accuracy of the aim, but it may be pointed against the image of his eye in a mirror.

Pulling the Trigger. - So much depends upon skill in pulling the trigger without disturbing the aim that these 
exercises should be repeated frequently at unexpecter moments, as well as at the time expressly set apart for the purpose.

The instructor first explains how to pull steadily with the finger without disturbing the aim or moving any other part of the body; first with support (fig. 9), and then without. If he can not keep the sight on the target long enough to pull the trigger gradually he is taught to come to the position of "revolver out" and rest.

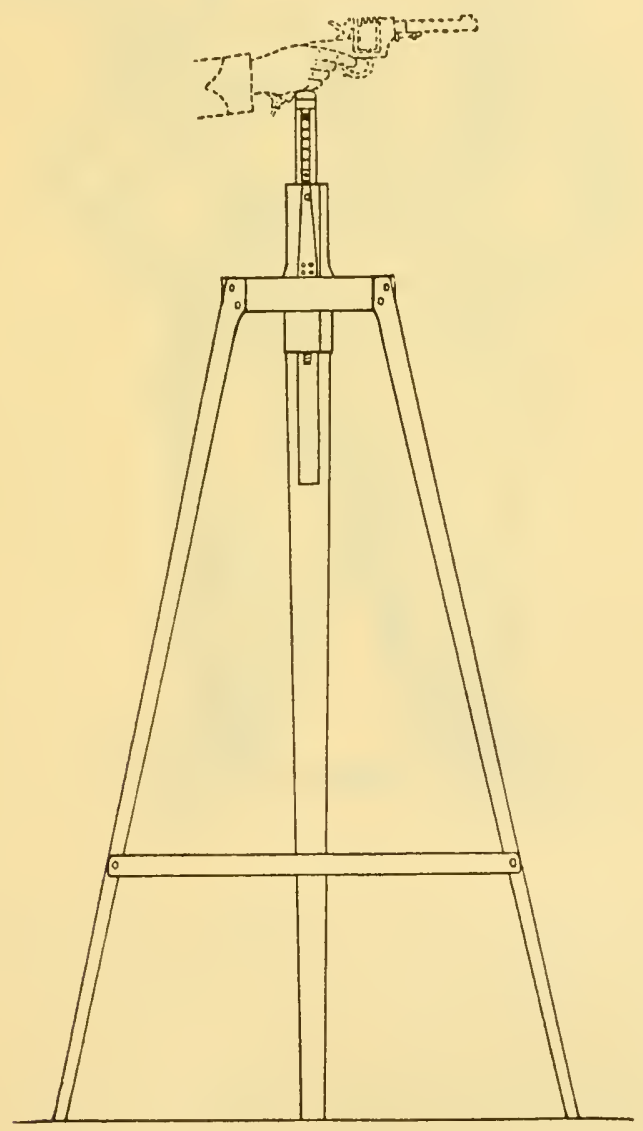

Fig. 9.

The recruit is then instructed to combine the movements of pointing, aiming, etc., by command, and then go through the motions of firing one, two, three, etc., shots by command; finally at the command "Fire," to go through the motions of firing six shots. 
Firixg with Blank Cartridges is practiced to accustom the recruit to the report of the piece. Sometimes without the knowledge of the recruit the cartrirges are not all loaded, so that his unsteadiness will be more erident.

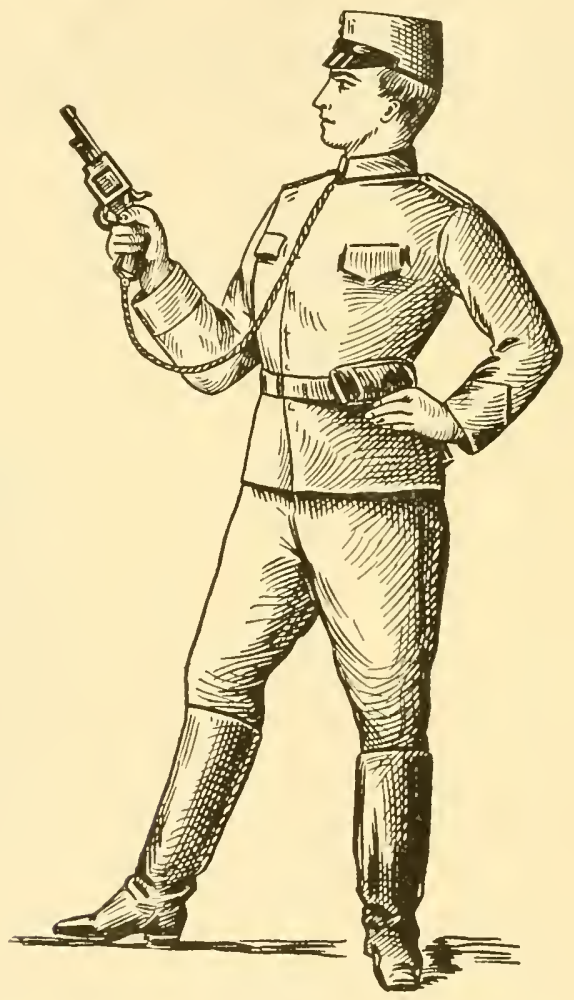

Fig. 10.

Each man fires 3 blank cartridges with support, and 3 without.

FIRING WITH LOADED AMIUNITION.

These exercises are at first conducted under the most favorable circumstances of weather, light, etc., and nothing is permitted to disturb the recruit in his first effort.

The target is a colored figure of a soldier (fig. 7). A hit within the inner oval line (bull's-eye) counts 3 , the next, 2 , on the figure, 1.

The men come up in turn and fire after the instructor has given the command "Point; aim; fire 1, (2, 3, etc.) shots" 
or simply "Fire." If not otherwise specified, 6 shots are fired in succession. After all are fired and the man comes back to the position of "revolver in," the instructor commands "Forward." They go to the target and the shots are marked and covered (see figures).

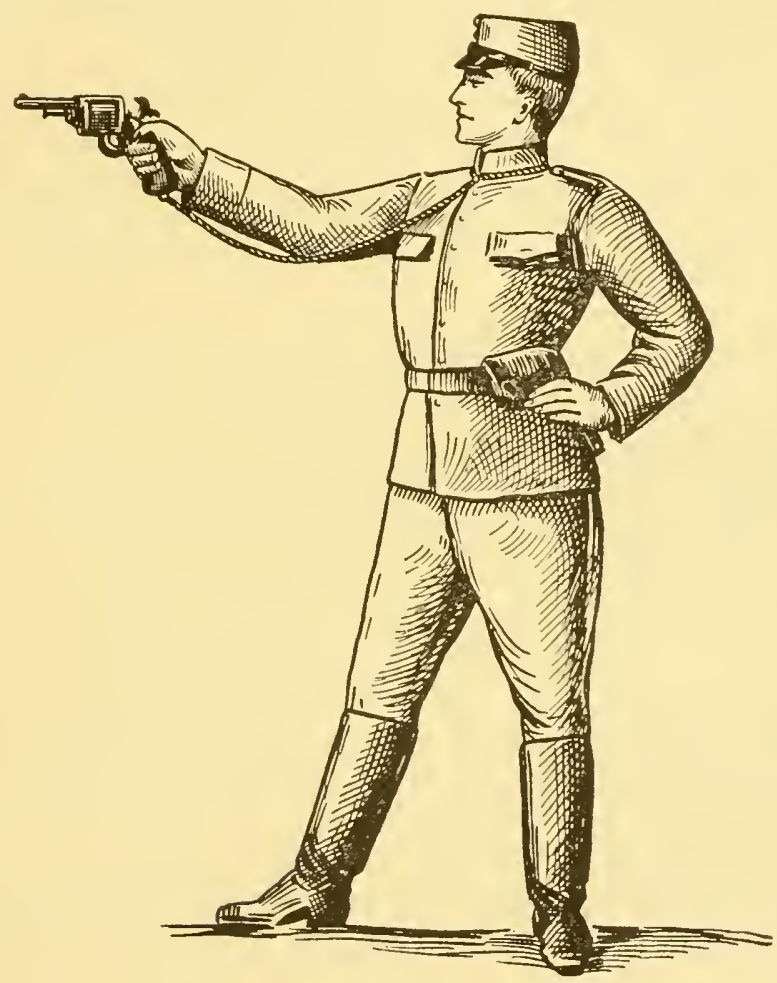

Fig. 11.

APPORTIONMENT OF THE EXERCISES.

OFFICERS AND UNDEROFFICERS. - Captains and older underofficers can be excused from the school-shooting drills.

PRIZE SHOOTING AND PRIZES.

General Rules. - Prize shooting is held by each regiment, and corps or battalion.

The right to take part in the regimental competitions is limited to 40 , in the "corps" or battalion to 20 , of the men who have fulfilled the requirements of the school shooting at the regimental meetings, and made the highest number 
of points in precision drills. If necessary for the selection, preliminary competitions may be held.

Prize Shooting.-Prize shooting takes place during the regimental meeting on a day when the conditions of air, weather, etc., are as favorable as possible, and when those who take part have not recently been fatigued by long field maneuvers, etc.

The prize shooting is arranged and conducted like a precision drill "with point calculation" excepting that no pack is carried; that officers are detailed for detachment commanders and as chiefs for the markers, and that to each target an underofficer is detailed to watch the markers.

Prizes.--The prizes are:

Shooting medals of silver to wear on the breast.

Shooting marks, two crossed rifles of red cloth, to wear on the right forearm; and

Money prizes, and, as a distinction and reward for good distance judges, a five-pointer star on red cloth to wear on the right forearm.

For distribution as money prizes each regiment receives annually 300 kronor, for four prizes of $20 \mathrm{kronor}$, eight prizes at 10 kronor, and twenty-eight prizes of 5 kronor.

Each corps or battalion receives annmally 150 kronor, for two prizes of 20 kronor, four prizes of $10 \mathrm{kronor}$, and fourteen prizes of 5 kronor.

A "shooting medal" is given to the one who at the prize shooting makes 45 points, or who in two succeeding years gets 43 points, if he has not already a medal.

Shooting badges are also given to those who receive shooting medals and to those who in two successive years have fulfilled the requirements of the school shooting at the regimental meetings, and received at least 40 points in precision shooting.

Those who receive this mark of clistinction are called marksmen.

Money prizes are given to all who, at a prize shooting, make at least 30 points.

Money prizes not distributed may, by order of the regimental commander, be dirided between the "distance judges."

The distribution of prizes takes place in the presence of the whole regiment, corps, or battalion.

Records and reports are required of all kinds of shooting. 
Revolver practice for officers and underoficers.

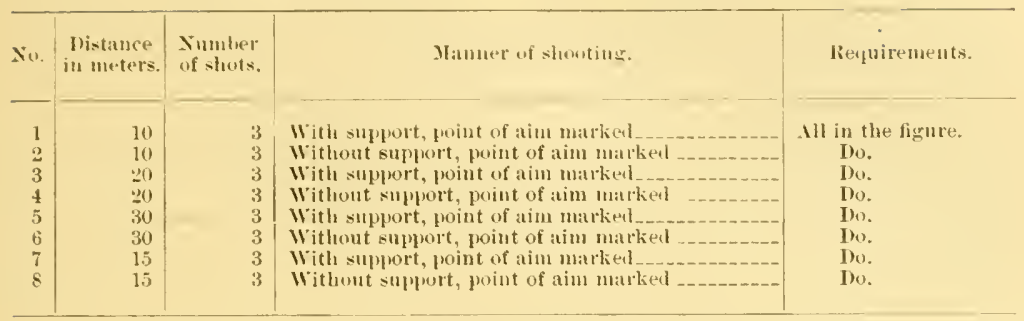

In exercises $r$ and $s$ the weapon is used as a self-cocker, and the time for each exercise is limited to 10 seconds at the most.

Anyone who does not qualify must, in a subsequent year, repeat the preparatory exercises as well as those in this table. Anyone who has qualified is excused from preparatory exercises and practices according to a program drawn up by the chief of the regiment, with the restriction that the target shall be the figure of a soldier, and that 6 shots shall be fired with the revolver used as a self-cocker and within the specified time.

\section{MISCELLANEOUS TROOPS.}

Special tables are prepared for caralry sergeants and musicians, men of field artillery, the field-telegraph companies, for the train, and for the hospital troops.

In all cases, except for the officer's and underofficers, those men who do not qualify shall, whenever there may be an opportunity, repeat the exercises preceded by the preparatory exercises.

PRIZE SHOOTING.

Prize competitions are held annually for each field-telegraph company, and each company of hospital troops.

Prizes.-For each fieli-telegraph company one of 20 kronor, one of 10 kronor, and three of 5 kronor.

For each hospital company one of 10 kronor and one of 5 kronor.

\section{FIELD ARTILLERY.}

The field artillery is equipped with 8.t-centimeter guns, model 's1 and model '94, and with $\% .5$-centimeter guns, model 's7 (Krupp). 
Field artillery practice in Sweden is partly regimental and partly special. The former is conducted by battery, division. etc., the latter in the shooting schools.

The exereises in firing comprise instruction shooting for recruits, practice shooting, field shooting, and prize shooting.

If local conditions and other circumstances permit, there is held yearly, during the repetition exercises, instruction shooting for recruits, practice shooting and field shooting with the whole battery, field shooting in division with the whole dirision, and prize shooting.

At the summer exercises of the constable school, practice shooting and field shooting by battery.

The artillery ammunition assigned to every regiment for its year's shooting is divided among the batteries by the regimental commander after he has set aside what is required for instruction shooting, prize shooting, and the constable school; and he then takes into consideration the proficiency of the different batteries, so. that, as far as possible, all the batteries may obtain the same skill in shooting. The chief of the regiment indicates also the amomnt of ammunition which is considered sufficient for field shooting by division. He also instructs the proper chief of division, or the chief of the underofficer's' school, abont the distribution of the ammunition for various kinds of shooting. For field shooting it is not definitely stipulated how much ammunition should be usert. The battery commander only indicates what kind of ammunition is a vailable, and the shooting continnes until it is stopped by the leader when he considers that the object has been attained, or when the ammunition has been used up.

The captain who, as below indicated, directs the instruction shooting for recruits, draws up a program for the purpose, which is submitted to the chief of division who supervises the shooting.

To carry out the practice shooting, and the field shooting' by battery, more definite instructions are given by the chief of dirision, or the chief of the underofticers' school, and for the field shooting by division, by the chief of the regiment.

As it is impossible in one year to solve all the problems which should be eonsidered, it is necessary to follow a scheme prepared beforehand for sereral years.

In assigning the problems, consideration is taken of the relative proficiency of the officers. 
In order to develop uniformity in their instruction, the problems should be interchanged as much as possible.

After the battery officers have reported upon their task, explaining how it was solved by them, and the motive for a possible deviation from the regulations, the leader holds a critique in the field. He criticises the selection of the firing position, the method of coming into battery, the battery commanders' method of conducting the fire, arrangements for the observer, etc.

Immediately after the written report of the shooting of the school has been received, the leader holds another critique in which he explains how far the problem has been solved and whether it was solved in the simplest manner.

Special attention is given to the effect of errors in observation.

In criticising field shooting, great attention is given to the time required to develop an effective fire, and the nature and extent of the results of this fire.

\section{POINTING DRILLS.}

The men are taught, first, to point the.gun at a vertical and then at a horizontal line, then at a bull's-eye, then at a target moving forward and back; and then, for firing with canister, against disappearing targets; and finally against such targets and other objects as would be presented in the field.

INSTRUCTION SHOOTINA FOR RECRUITS.

The object of this shooting is partly to accustom the troops to firing with loaded ammunition, partly to show the accuracy of the piece and what influence the changes in elevation and azimuth exert on the shot, and partly to show the effect of the projectile and the circumstances which influence it.

The firing is conducted with one gun at a distance of from 300 to 1,000 meters, and it is instructive in its nature, so that no change is made in elevation or azimuth, or in setting the fuse, without explaining the object to be attained and showing immediately the result.

In firing with shells the influence of greater or less accuracy in pointing is shown, as well as that of changing the elevation or azimuth, that of the point of burst, and of the nature of the ground where the shell strikes. 
In firine with shrapmed it is shown how the affect of this projeciile is dependent upon the hejght and listance of thr. point wi hurst, and huw this point is affected hy the elevation and hy the secting wf the fuse.

In tiring with canister. the complatatively slight effect of eluangres in pointing is explaned both in elevation and in azimull.

School taresets and plateon tarerets are used in this drill.

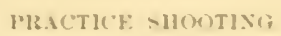

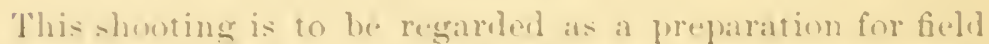
showins and has for its ebject to instruct and practice oflicers. underotlicers. and men in their nuties in shouting.

shenting is always comducted hy hattery. and the communal is taken in turn hy the second catptain with the battrory. and] ly the lientenants. Who are chicfs of scetion, and sometimes hy the ordinaly hathey chief. Juring these shootings the umderefticers have. frem time to time, opmortumity to act as chiefs of seetion. and the second constables as chiefs of piece. ln protetice shootine at a comstable school. as many pupils as poseithle should have an opportunity to act as ellief of piree.

'The larerets are platom figures arranged as firing lines, sun and limbers: but the supperts and the cannomeers should not be malkid. hecause in this exereise the effect is not comsinterent.

'The tiring is continuerl only until the sierlots have heen adjusted and the tire has heen rearulated.

Coming ino position shemlet he executed as far as possible as it would he in action.

As this practice is rsentially for instruction rapidi? is mot as important as it is in ticlel shooting. hut more atteution is griven to see that the men follow their instructions atecurately in handling the gum and the ammunition.

No instruction is eris an eluring the shooting. When is is necessiry the tire is stopped. The regular ehied of the hattery. especially when he is not directing it. follows the course of the firing in order to learn what defects in instruction are develemert:

"The chief of division w 'hief of the underothicers' school is present at the practice shouting and acts as a leader. 
FIFLD SHOOTIXI BI BATTERY.

The object of this shooting is to accustom the battery chief to direct the fire. and to teach the rest of the personmel their duties in action.

If local circumstances permit. every fieh exercise should be based on a tactical problem which is giren to the battery chief by the leader immediately before the firing is to take place.

In accordance with the problem. the battery chief select= the site to be acenpied by the battery. unlimbers, and selects the kind of projectile if this has not been specified, and opens fire.

If local conditions do not permit of giving a tactical basin to the problem, the leader tells the chief of hattery where the battery should unlimber and at what tarset he should fire.

In firing, the regulations for drill and for shooting should be strictly observed. Especial weight is given to the rapidity of finding the range and completing the trial shooting.

The shooting is watched by the chief of division, or chief of the underofficers" school who acts as leader.

\section{หั MIVION.}

This shooting is chiety designed to practice chiefs of dirision in directing the fire of two or more batteries, and to accustom the rest of the personnel to those circumstances that make the firing of a division more difficult than that of a separate battery, and to the greater difheulty in hearing the word of command and observing the shots, etc.

As the chief of division can not have an opportunity to perform his functions in directing the fire unless it be kept up for some time. as much ammunition is allotted for each field practice by division as the supply on hand permits.

The exerises are so planned as to require the immediate direction of the chief of division. This is effected by the changing of the target for the whole division, or by orders from the regimental commander to the chief of dirision either to divile the fire of the dirision betreen different targets or to concentrate it against the same target, and it is left for the chief of dirision to specify how this change shall be effected. 
At times also in division shooting a target should appear against which the battery chiefs should turn their fire without waiting for orders from the chief of division.

The regimental commander himself should act as leader at this shooting and conduct the critique of the work of the chief of division. The critique of battery commanders is incumbent upon the chief of division.

PRIZE COMPETITION.

Each gun fires $\delta$ shells with bursting charge and smokeless powder against a target placed at 600 meters' distance, the target being 3.2 meter's square and provided with a bull's-eye of a diameter of 40 centimeters, and seven rings of respectively 40,60, 80, 100, 120, 140, and 160 centimeter's' radius. The first 3 shots are trial shots and are fired with the same elevation and rleviation. The center of impact is marked with a small point and the chief of piece makes the necessary alterations in the elevation and azimuth corresponding to the distance of the center of impact from the center of the target.

After these adjustments have been made, the remaining 5 shots are fired for "points." Each hit, the center of which falls in the bull's-eye, is counted for 8 points; between the bull's-eye and the first ring, 7 points; the first circle and second, 6 ; the second and third, 5; the third and fourth, 4; the fourth and fifth, 3 ; the fifth and sixth, 2 ; the sixth and seventh, 1 ; other hits, 0 .

The number of hits for each gun is recorded and the time occupied in the shooting for points, which is counted for each gun from the firing of the fourth shot to the firing of the eighth shot, inclusive; and the order in which the prizes are distributed is regulated oniy by the number of points received if the time occupied in the shooting for points has not exceeded two minutes, unless a projectile has either failed to hit the target, or only hit in the ricochet, in which case no prize can be given.

If an even number of points be made, the distance of the hits, made during the shooting for points, from the center of the target is measured and preference is given to the one for which the sum of these distances is the least. When the sums are the same the preference is decided by drawing lots.

Shooting medals of silver are distributed yearly to the chiefs of piece who in the prize shooting have received prizes 
and at least 32 points, and a requisition for the shooting medals is sent to the inspector of artillery as soon as possible after the competition, accompanied by drawings showing the hits, provided that more than 32 points have been obtained. Shooting medals are given but once to the same person.

SHOOTING SCHOOL.

Shooting School For Senior OfFicers.-The purpose of the school is to give the officers of the field artillery practice in making a correct and rapid application of the shooting regulations, and to give them clear and correct ideas about the use and effect of artillery fire, also to give the underofficers of the field artillery practical skill, as well in firing as in other duties which may devolve upon them in the field.

The school is under the orders of the chief of ordnance and inspector of artillery, who inspects it and directs its work according to the requirements of the moment, as well as those published as general orders.

The personnel of the school consists of the staff, officers ordered to go through the course, the helpers, an instruction battery, and, during that part of the course which is fixed by general orders for each year, the underofficers' schools of the first and second Svea artillery regiments, which are placed at the disposal of this school.

The staff consists of the chief, the adjutant, 2 range officers (one of whom is range captain), surgeons, veterinary surgeons, 3 underofficers ( 2 range underofficers for duty with the range captain, and 1 in the kitchen), and 4 privates.

The officers commanded to go through the course consist of 2 regimental officers and 10 captains.

The helper's are 1 first constable, 24 privates, and 3 artisan soldiers (1 smith and 2 wood-workers).

The personnel of the battery of instruction consists of 1 chief of battery, 3 chiefs of detachment, 1 battery adjutant, 6 to 7 sergeants, 40 constables, 1 detachment trumpeter, and $5 t$ privates, of which 1 is a hospital soldier and 2 are horseshoeing soldiers.

Besides the horses of the regimental officers, the school is allowed 3 to 6 service horses, 35 saddle, and 60 draft horses.

The personnel is appointed for each course of instruction as follows :

Officers belonging to the staff, the regimental officers, and the chief of the instruction battery, are appointed by the king 
on the recommendation of the chief of ordnance and inspector of artillery.

The remaining officers, the underofficers who belong to the staff, and the artisan soldiers are appointed from the regiment which the king designates, on the recommendation of the chief of ordnance and inspector of artillery.

The surgeon and veterinary surgeon are appointed by the medical department.

Of the privates of the staff, two are appointed from the regiment to which the chief of the school belongs, and one from each of the regiments to which the regimental officers ordered to the course belong.

Of the helpers, eight privates are ordered from each of two artillery regiments, and one constable and eight privates from the Norrland artillery regiment.

Of the persomnel of the instruction battery, the battery adjutant and the detachment trumpeter are ordered from the regiment to which the chief of the battery belongs, and the underofficers and privates are detailer from the different regiments.

The ten captains take the course of instruction before they are appointed chiefs of the battery.

Sergeants who have shown special ability in aiming are detailed as chiefs of piece, and constables who are likely to become underofficers are detailed as pupils in the instruction battery.

The privates, who are assigned to the instruction battery, are used as drivers, horse-holders, and grooms.

The school is established at the Marma range and is allowed to use the buildings and the matériel, etc., of the artillery there. It begins each year on the day appointed by general order and lasts 42 days.

Duties, Instruction, And Practice.-The chief of the school directs the education and is responsible for the discipline and maintenance of order.

The chief of the instruction battery is under the direct command of the chief of the school, and regulates the duties, as well as the education and drills of the battery.

The range captain, who is under the direct command of the chief of the school, observes strictly his instructions with regard to the shooting as well as those of the regimental 
officers in command, and is responsible for order on the firing ground, and for the record of the results of firing.

The education in the school is as follows:

For the officers ordered to take the course.--Shooting drills with field pieces in battery and in division, and shooting drills with revolver.

Besides this, the chief lays out a course of short lectures by the officers, illustrated, if possible, by examples, explaining the shooting regulations, the method of shooting with field artillery in foreign countries, the construction and use of the distance measurer, fire tactics, ếc.

With the instruction battery. - Theoretical education, as a necessary preparation for, or explanation of, the practical drills; drills with the field pieces in connection with aiming lrills, partly under difficult circumstances; shooting drills with field pieces; drills in accurate management of the gun, the mechanism and the ammunition; shooting drills with revolver; setting up telephone wires and telephoning; field fortification drills; the use oi maps on the terrain, and the solution of tactical problems.

In the shooting drills with guns in battery attended by the officer's, the regimental officers act as leaders under the supervision of the chief of the school, the captains act as battery commanders; the chiefs of section ordered to the instruction battery, commonly as chiefs of section; the sergeants orlered to the same battery (with the exception of the battalion adjutant) alternately as commanding the fourth section, if chiefs of piece, or, as the chief of the school so directs, as chiefs of section; and the constables ordered to the same battery serve in turn as chiefs of piece.

The division shooting takes place when the underoflicers' schools of the first and second Svea regiments (artillery) are placed at the disposal of the chief of the school by general order, and at these exercises the division is commanded in turn by the regimental officers ordered to the course, and the instruction battery and the underofficers' school batteries by the officers attending the school.

OTher Regulations. - The ammunition allotted each year by a general order for the exercises of this school is supplied from the magazine at Marma, when required by the chief of the school.

The personnel ordered to the school receive pay according to regulations and the budget for the scliool. 
SHOOTING SCHOOL FOR SUBALTERN OFFICERS.

The object of the school is to give subaltern officers, and if possible also the sergeants, as complete an education as possible in the duties of chief of section in firing.

The school is under the orders of the chief of ordnance and inspector of artillery, who acts as inspector and gives the necessary instructions about its duties which are in addition to those fixed by general orders.

The personnel of the school consists of the staff, the officers and sergeants ordered to go through the course, the helpers, and an instruction battery placed at the disposal of the school.

The staff consists of the chief, who is the teacher, the adjutant, the second teacher, the range officer, surgeon, veterinary surgeon, and 3 underofficers ( 2 range underofficers for service with the range officer, and 1 for the kitchen).

The chief, the adjutant, the second teacher, and the range officer are detailed for each course by the king, on the recommendations of the chief of ordnance and inspector of artillery.

The surgeon and veterinary surgeon are assigned by the medical corps.

Instructions about the orders for the rest of the personnel of the school are given by the king, on recommendation of the chief of ordnance and inspector of artillery.

Duties, Instruction, and Practice.-The chief of the school regulates the course of instruction and is responsible for the discipline and the maintenance of order. During the drills with the guns he acts as leader.

The second teacher helps the chief with the instruction as directed. At shooting drills with the guns, he generally commands the battery.

The range officer, who is under the direct command of the chief of the school, observes strictly his instructions with regard to the firing, and is responsible for the order on the range and for the record of the results of firing.

The chief of the instruction battery may, at shooting drills with guns if the chief of the school so decides, command the battery, and is, like the ordinary chiefs of section and chiefs of picee, altogether at the disposal of the chief of the school.

The education includes slooting drills with field guns in battery, at which the officers and sergeants ordered to the conrse act in turn as chiefs of section and chiefs of piece; exercises in making reports and keeping records of the results 
of the firing; practice in measuring distances with the instrument used by the field artillery; shooting drills with revolver.

Besides these, the chief and the second teacher deliver short lectures, illustrated, if possible, by examples from the results of the shooting, on topics connected with these subjects.

The ammunition assigned to the school, which is regulated each year by a general order, is obtainer on requisition by the chief of the school from the depots.

The personnel ordered to the school receive pay according to regulations and the budget for the school.

EXPENDITURE OF AMMUNITION.

During the year 1901 the expenditure of ammunition at the regimental practice was as follows:

\begin{tabular}{|c|c|c|c|}
\hline & Shells. & shrapnel. & Blank. \\
\hline First Svea artillery reginuent___ & 100 & 1,600 & 5,000 \\
\hline First Göta artillery regiment & 500 & 1,300 & 3,000 \\
\hline Wendes artillery regiment ..... & 180 & 3,000 & 5,500 \\
\hline Norrland artillery regiment & 250 & 1,550 & 4,500 \\
\hline Second Svea artillery regiment & 250 & 1,550 & $4,5(x)$ \\
\hline Second Göta artillery regiment & 100 & 1,600 & 5,000 \\
\hline Gotland field corps artillery & 50 & 500 & 60 \\
\hline
\end{tabular}

EXTRACTS FROM REPORT OF THE SHOOTING SCHOOL FOR SENIOR OFFICERS OF THE FIELD ARTILLERY, 1901.

The course lasted from June 9 to July 20.

The officers ordered to attend the course were 10 captains, 3 lieutenants for chiefs of section, 11 sergeants, 40 constables, 1 detachment trumpeter, 82 cannoneers, and 3 artificers.

Thirty-five saddle and 60 pack horses were placed at the disposition of the school.

Two underofficer's' school batteries were, for a short time, stationed at Marma and took part in the exercises for two days in division with two batteries without loaded ammunition for three days' target practice in divisions.

The exercises at the school were as follows:

1. Lectures, "skjutspel," critique, etc ...............hours _- $31 \frac{1}{2}$

2. Making reports and records ...................... do _.. 72 t

3. Revolver shooting ........ _.

4. Shooting with loaded cartridges ................. do_.. 16

5. Sharpshooting with gums in battery .............. series.. 90

6. Sharpshooting with guns in division .............. do _.. 10

7. Drill in division withont loaded ammunition _.... hours _. $\quad 4 \frac{1}{2}$

8. Witnessing the sharpshooting of the constable

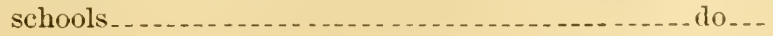


The shooting school expended during the exercises the following 8-centimeter ammunition with smokeless powder:

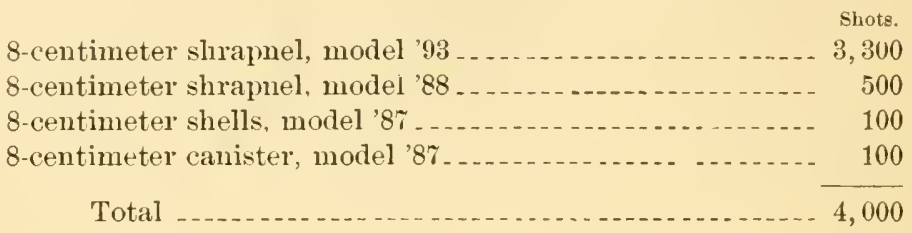

The firing took place every day, and the allowance of ammunition proved to be well calculated for the time of the shooting.

The following record shows the distribution of the work:

When shooting by battery:

Against unlimbered battery

Shots.

Against skirmish line, standing still .................. 26

Against skimish line with reserve. . .................. 5

Against advancing skirmish line.................. 5

Agairst skirmish line advancing at a rum ............ 5

Against retreating skirmish lines .................... 5

Against companies in file, deploying to skirmish line .. 2

Against companies in line, deploying to skirmish line - 6

Against advancing cavalry -.................... 4

Against retreating cavalry _...................... 2

When shooting by division:

Against unlimbered battery -.................. 8

Against advancing skimish line . . . . . . . . . . . . . . 3

Against retreating skimmish line .................... 3

Against advancing cavalry ....................... 1

Targets were changed 46 times during the series. In one series indirect fire was practiced.

EXTRACTS FROM THE REPORT OF THE SUBALTERN SHOOTING SCHOOL FOR FIELD ARTILLERY, 1900.

The course lasted from the 1Sth of May to the Sth of June.

Twenty-one subaltern officers were detailed to attend the course, an average of 3 to each regiment.

The following exercises were carried out:

1. Lectures, alternately by both teachers, as an introducHours. tion and preparation to the other exercises and to discuss the results of the shooting ................. 8

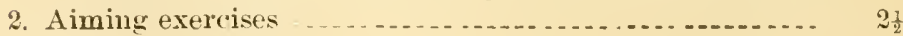

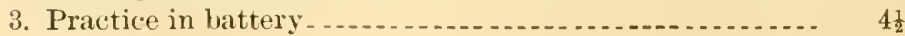


4. Sharpshooting with the gums............... 40

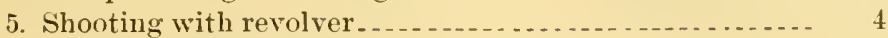

6. Distance measurement__._. 9

7. Shooting with redncel charges and practice with ex-

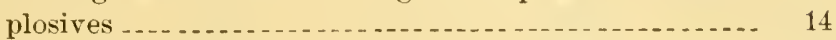

8. Making ont reports and records of the firing ......... 98

9. Discussing reports, etc.......... 6

The lectures were on the following topics:

Aiming drills and means for aiming, the duties of the detachment chiefs and the gun conmanders luring firing in battery; the making up of reports and firing records, Unges distance measurer, the distribution of fire, explaining the results by examples from the shooting, and the scont service.

The shooting school fired over 1,000 shots from 8-centimeter guns with smokeless powder.

At the firings the officers were divided as follows:

Detachment chiefs.................................

Gun commanders . . . 6

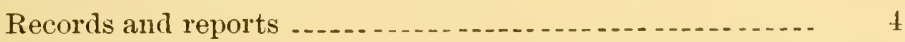

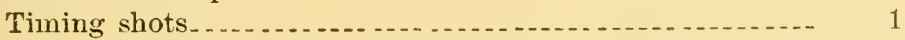

On duty at the target as observers, etc ................ 3

To follow the shooting and keep the shooting books....... 2

The work was distributed in this manner every forenoon and changed in the afternoon, so that the same pupil had several opportunities to practice different duties in turn.

TARGETS.

Targets for elementary or precision shooting are comparatively simple. Those for field shooting are more and more complicated until in the final exercises they form a perfectly dramatic representation of the hostile forces advancing, retreating, firing, or charging under all the conceivable circumstances of actual warfare.

Figures and Designs. - The targets are usually composed of figures which represent the object on which the fire is supposed to be directed, and these figures are arranged separately or collectively according to the nature of the problem.

These figures, etc., are made of wood, pasteboard, or cloth.

Wood is used for permanent targets of small dimensions, and for certain special problems. 
Pasteboard is generally preferred because it is easily worked and is quite durable.

Cloth is used for disappearing and moving targets.

The designs are classified as:

(a) School targets.-Generally of wood, 5 meters square (fig. 12). The dimensions are given in meters and centimeters.

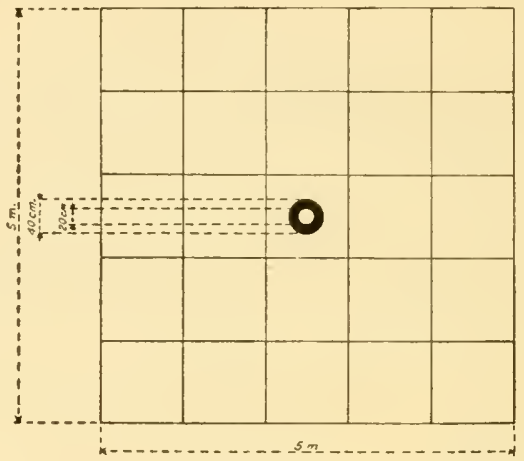

Fig. 12.

(b) Prize shooting targets.-Also of wood and of the dimensions specified for the competition.

(c) Field targets.-Figures representing men, horses, etc., viz :

Infantry figures of full length or of half, one-third, or onefourth the full length, of the form and dimensions shown in

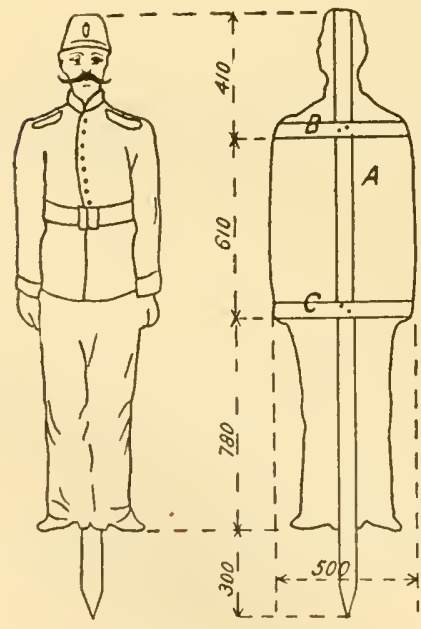

Fig. 13. figs. $13,14,15,16$, and $1 \%$. They are made of pasteboard tacked on a skeleton of wooden laths.

Cavalry figures are sketched on cloth of the pattern shown in fig. 18. The dimensions in millimeters. The cloth is tacker on a wooden frame. Those for the horses without riders are similar in design.

Artillery figures are made of pasteboard. That for the piece nnlimbered is shown in fig. 19; for the limber, fig. 20: for the personnel the infantry figures are used. For artillery limbered up 
the figure of a caisson, fig. 21; for the mounted men, fig. 22; for horses without rider, fig. 23.

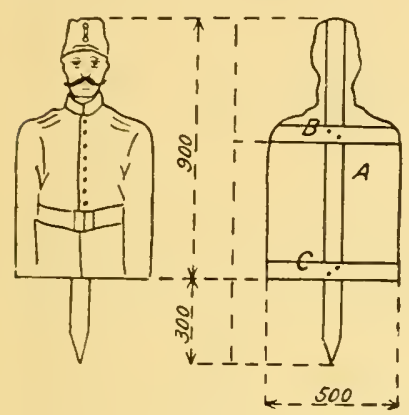

Fig. 14.

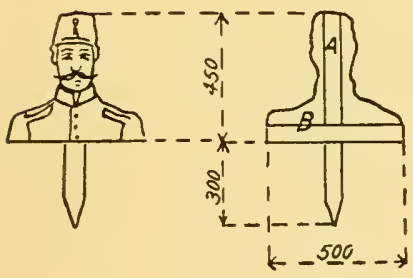

Fig. 16 .

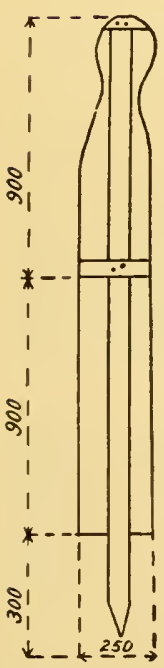

Fig. 17.

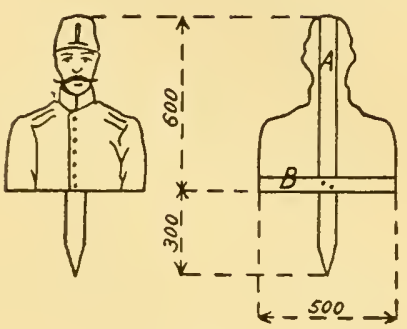

Fig. 15.

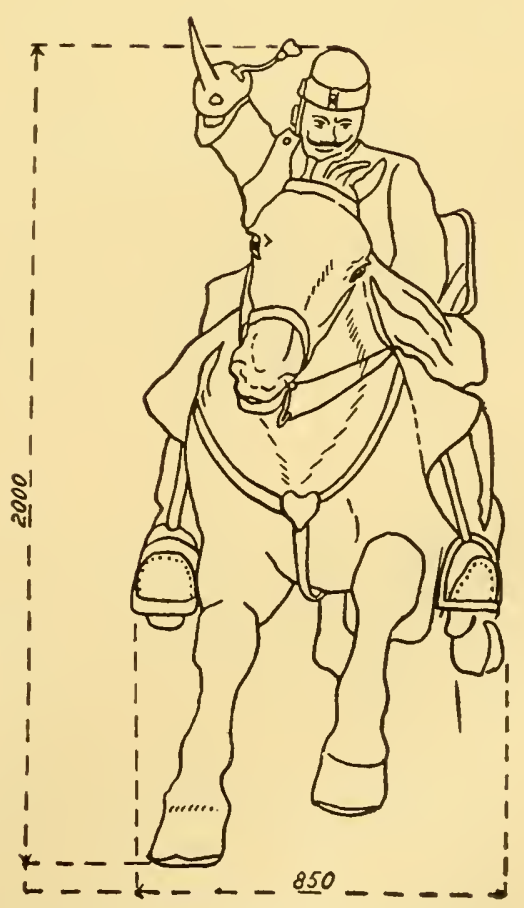

Fig. 18. 
Simple TARgets.-Suitable targets for artillery practice are formed by combining several figures, and arranging them in different formations.

They are classified as:

(a) Immovable targets.

(b) Appearing and disappearing targets.

(c) Movable targets.

(d) Balloon targets.

(a) Immovable targets. - Infantry in firing line, or in close order when it is supposed to be exposed to view, is represented by lying or kneeling figures, only when in motion by whole figures.

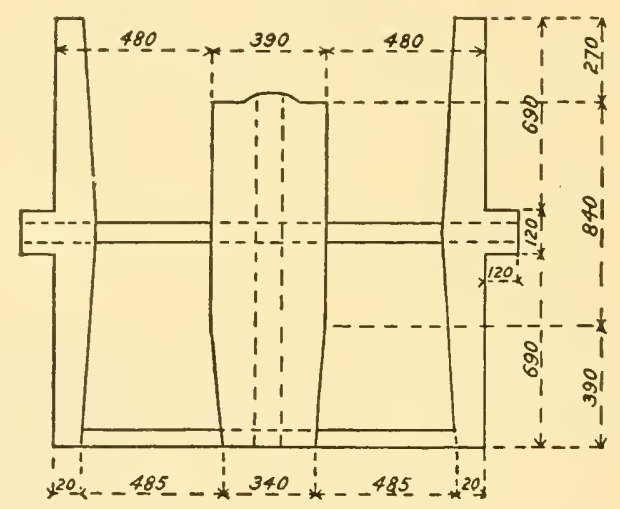

Fig. 19.

Infantry in fighting formation is represented by a line of one-third or half figures arranged according to the terrain.

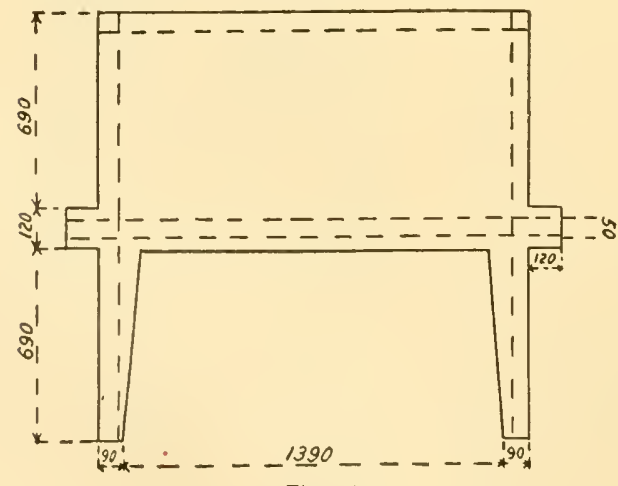

Fig. 20 .

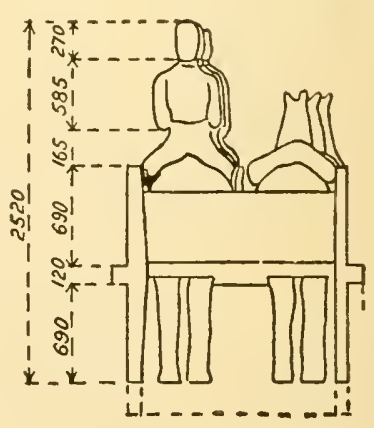

Fig. 21.

Company reserves are placed about 300 meters behind the firing line, well sheltered, and if possible hidden by the 
ground. When a large body of truops is to be represented, the reserves in close order are so disposed as to be withdrawn from the observation of those who are firing. When close columns are concealed by the ground the targets are made of

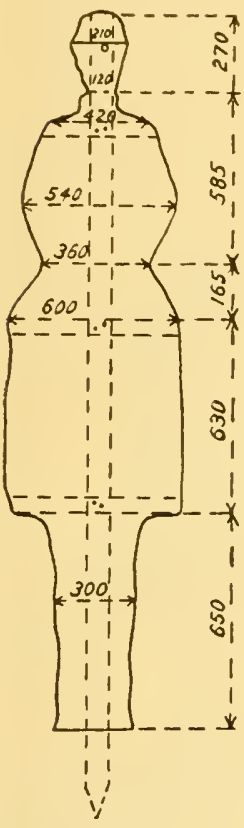

Fig. 22. pasteboard screen on woorten frames 1.8 meters high and 10 meters long, and on them are sketched whole or lialf figures. Three such screens in each line represent a platoon, etc.

Immovable cavalry targets are not used for the fire of field artillery.

For artillery targets a bat-

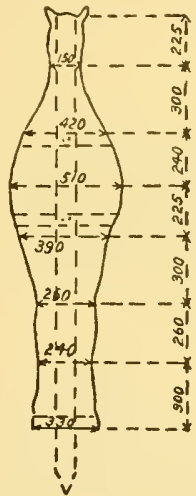

Fig. 23. tery unlimbered is represented by artillery and infantry figures set up as shown in fig. 24 . Only in exceptional cases, when there is no shelter available, are the rest of the personnel, the limbers, horses, etc., represented; they are then placed in line or column on one side of the battery.

The number of tignres representing a six-gun battery is given as follows:

(ordinarily. Exceptionally.

Front figures (rarious sizes)

Profile figures (various sizes)

Horse figures

$27-51$

Gun figures

Limbers without horses

Limbers with horses

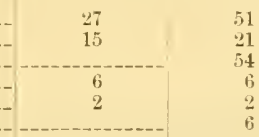

(b) Rapidly appearing and disappearing targets.-An infantry target arranged to appear suddenly is shown in fig. 26 . It swings on two pivots (fig. 25) at the top of the frame, and is held in a horizontal position by a prop. A long cord or wire is led to a place of safety from which the prop is removed at the proper time; the target then drops to the vertical position shown in the figures and becomes visible from the firing point. The cord or wire is sometimes protected from the fire by laying it in a furrow. Figs. 27 and 28 represent a target arranged with a counterpoise to appear or disappear. When the cord 
is loose the counterpoise is so adjusted that the target falls back a little below the horizontal position. When the cord is tightened it rises to the position shown in the figures. This target is used in the open or behind earthworks, etc.

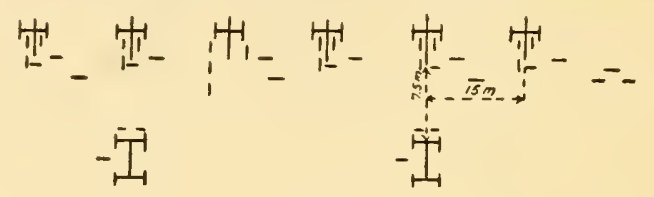

Fig. 24.

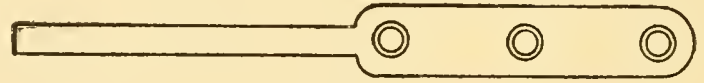

Fig. 25.

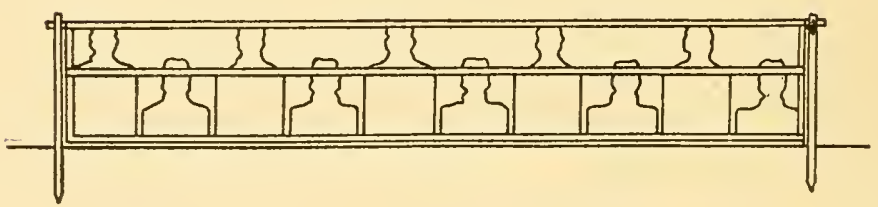

Fig. 26.

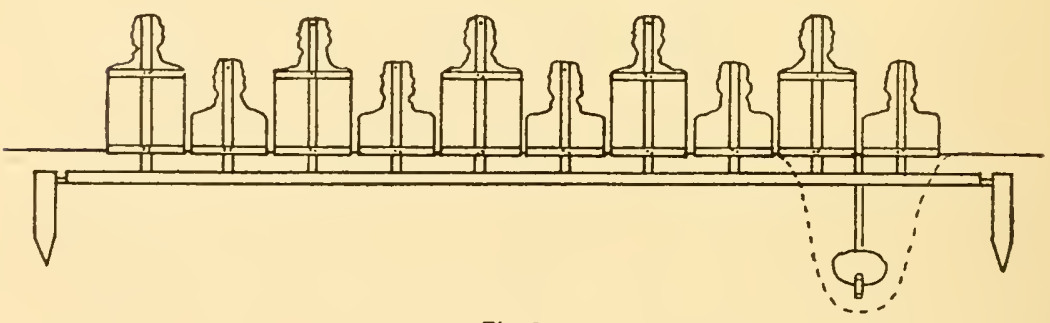

Fig. 27.

An infantry target at first visible, but arranged to disappear under fire, is made like that shown in fig. 26, but with the pivots at the foot of the frame instead of at the top. Several groups are represented side by side and one or more are made to fall from time to time by pulling out the props.

Figs. 29 and 30 represent a full-length infantry target made to appear and disappear. It falls back to the horizontal position when the cord is loosened and is brought back when the cord is tightened.

Thin lines, patrols, outposts, etc., are represented by several targets like that shown in fig. 31. The target and the prop are both hinged to the footboard and when struck, 
the vibration releases the prop from the shallow notch in the target so that both fall down.

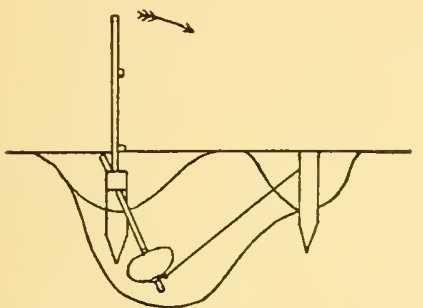

Fig. 28.

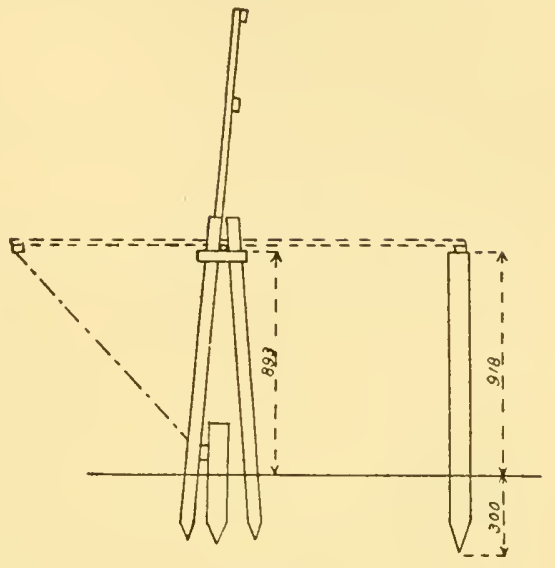

Fig. 29.

For cavalry the figures are drawn on a cloth target 10 meters long and 2 meters high; swinging horizontally on a pivot made of an old artillery axle and wheel (figs. 32, 33).

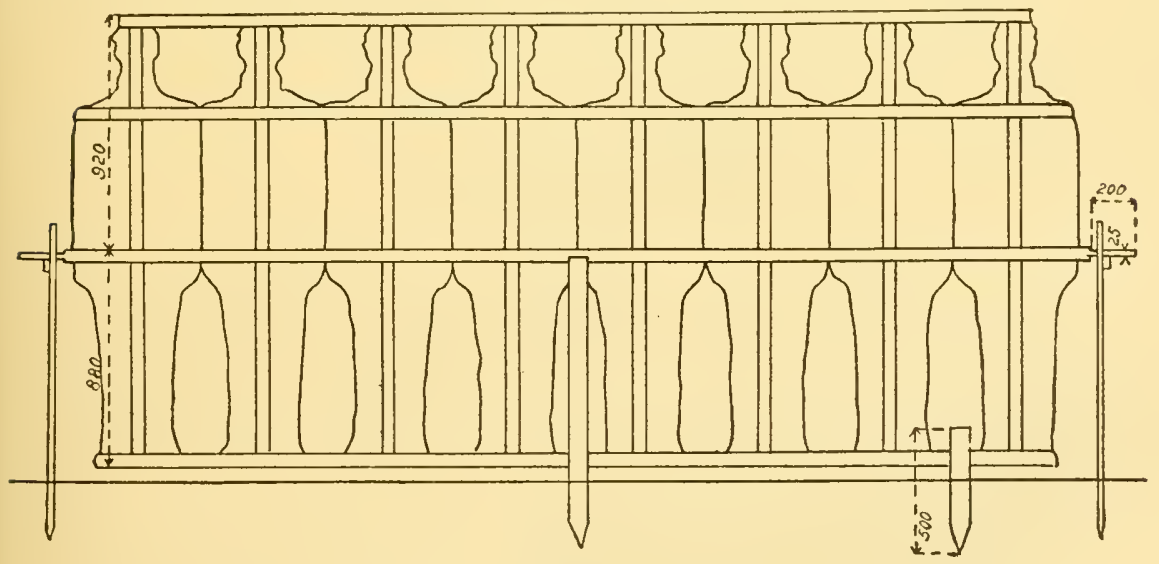

Fig. 30 .

It is turned normal to the plane of fire to make it appear, and parallel to make it disappear.

The artillery targets (fig. 35) are operated in the same way as the infantry targets; each of the figures for the guns, limber, personnel, etc., may have its own cord, or some may be made automatic, or all may be made to rise together. 
(c) Movable targets. - Movable targets are moved on trams or sleds. Tramways are more expensive but more serviceable for targets moving across the line of fire either perpenclicularly or obliquely so that they can be properly protected. Figures of all kinds are mounted on cars or wagons with four, six, or eight wheels, and hauled by motor's or by the inclination of the track.

Sleds are more common and are used for all targets moving in the line of fire. The runners are of wood or sheet iron. Sleds with wooden rumners are heavier and are considered more serviceable for heavier targets, especially when moving over a soft, moist, and comparatively level field. But sleds with sheet-iron runners like those shown in fig. 38 are most. commonly used. The runners are of corrugated iron 1 millimeter thick; a wooden block is bolted to each runner by the same bolts that hold the two crossbeams. The runners are connected also by braces in front and behind, and the iron or steel cords that are attached to the blocks serve also as diagonal braces.

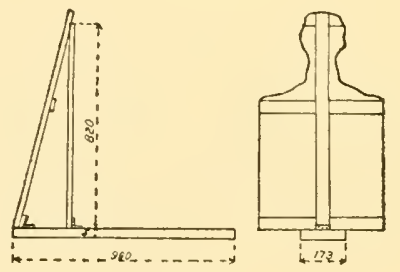

Fig. 31 .

These lines are led by snatch blocks to a distant part of the field, 2,000 meters, more or less, where it is convenient to apply the motive power by horses or steam or otherwise. When practicable the part of the line most exposed to the projectiles is laid in a furrow.

When the figures on the sled are fixed, the sled is so turned that they will present their edges to the firing point until they are to become visible, and so that the sled is turned on starting.

Figures 39, 40, 41, and 42 represent devices by which infantry targets are made to rise on the sled when the cord is tightened, and figure 43 a target with two sets of figures which impersonate a skirmish line advancing by rushes and then lying down to fire. 


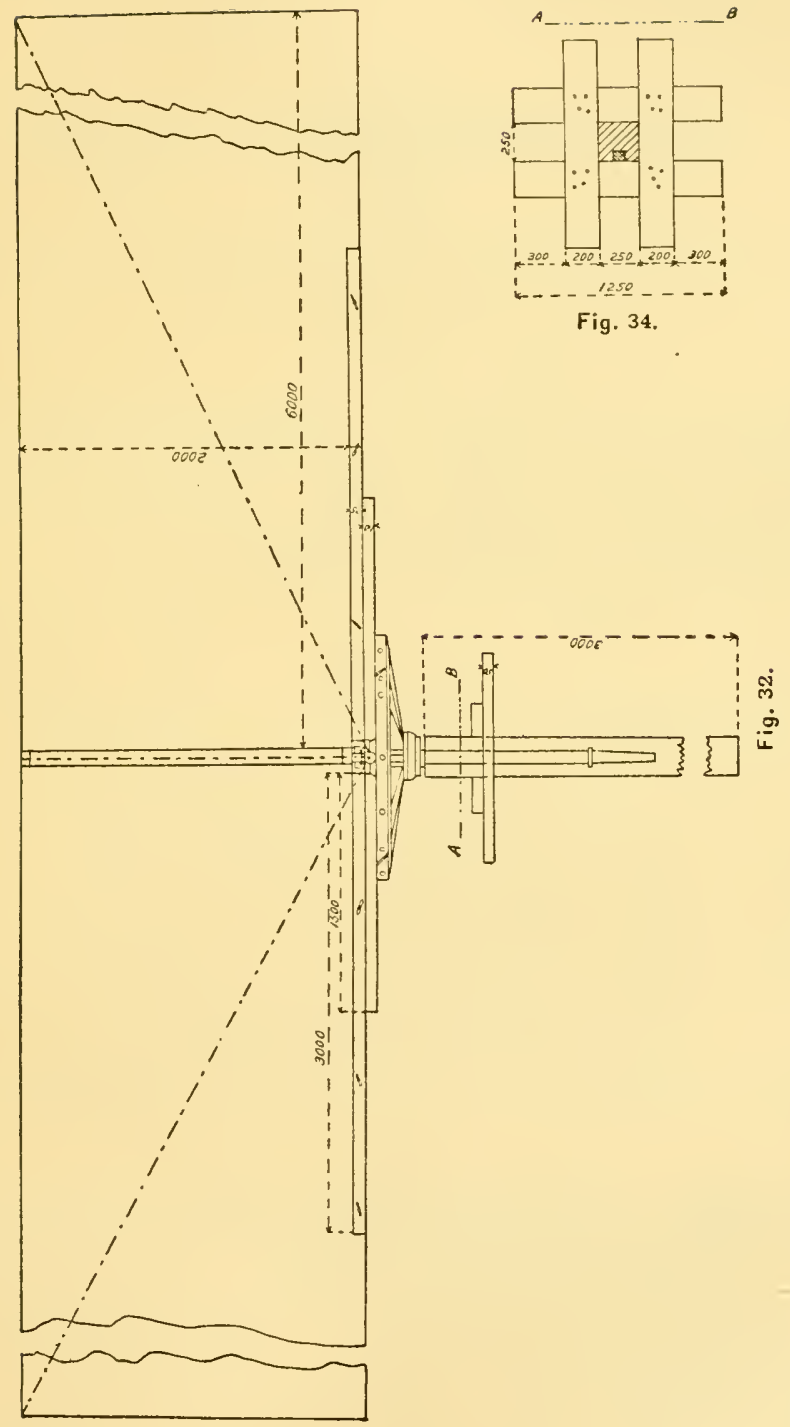


Figure 44 represents the frame for a movable cavalry target that disappears by turning on its hinges.

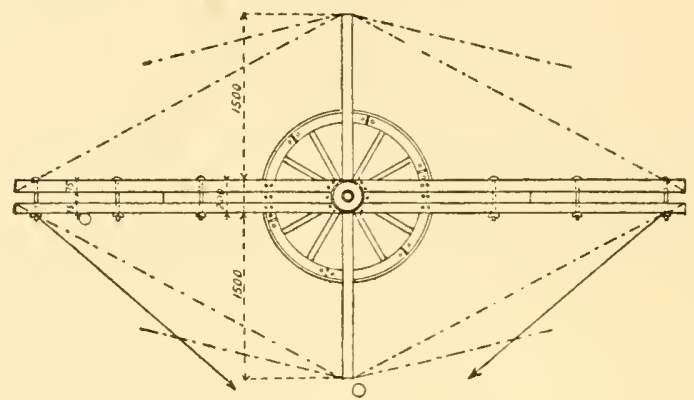

Fig. 33 .

Figure 45 is the frame of a disappearing and movable artillery target, and 46 a sled which shows a target for artillery unlimbered (like figure 19) when it halts, and limbered up (like figure 21) when it is in motion.

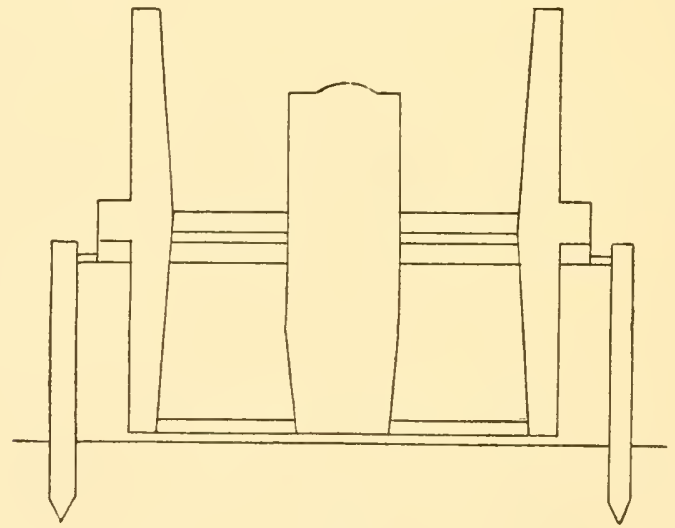

Fig. 35 .

(d) Balloon targets. - If there is a suitable elevation on the firing ground, a staging is built on it, 10 or 15 meters high,

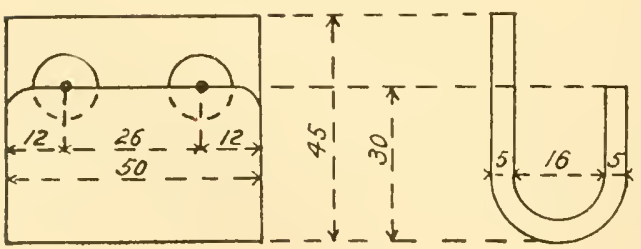

Fig. 36 .

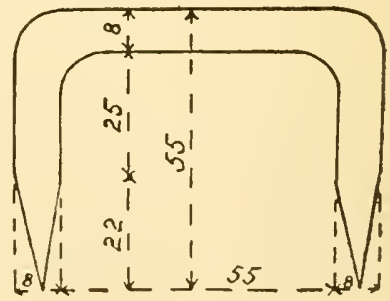

Fig. 37. 
on which is displayed a target representing a balloon $\gamma$ meters in diameter with its gondola and lines. If no such elevation is available, a balloon is made of paper and inflated with hot air. To maintain the heat a sponge saturated with alcohol
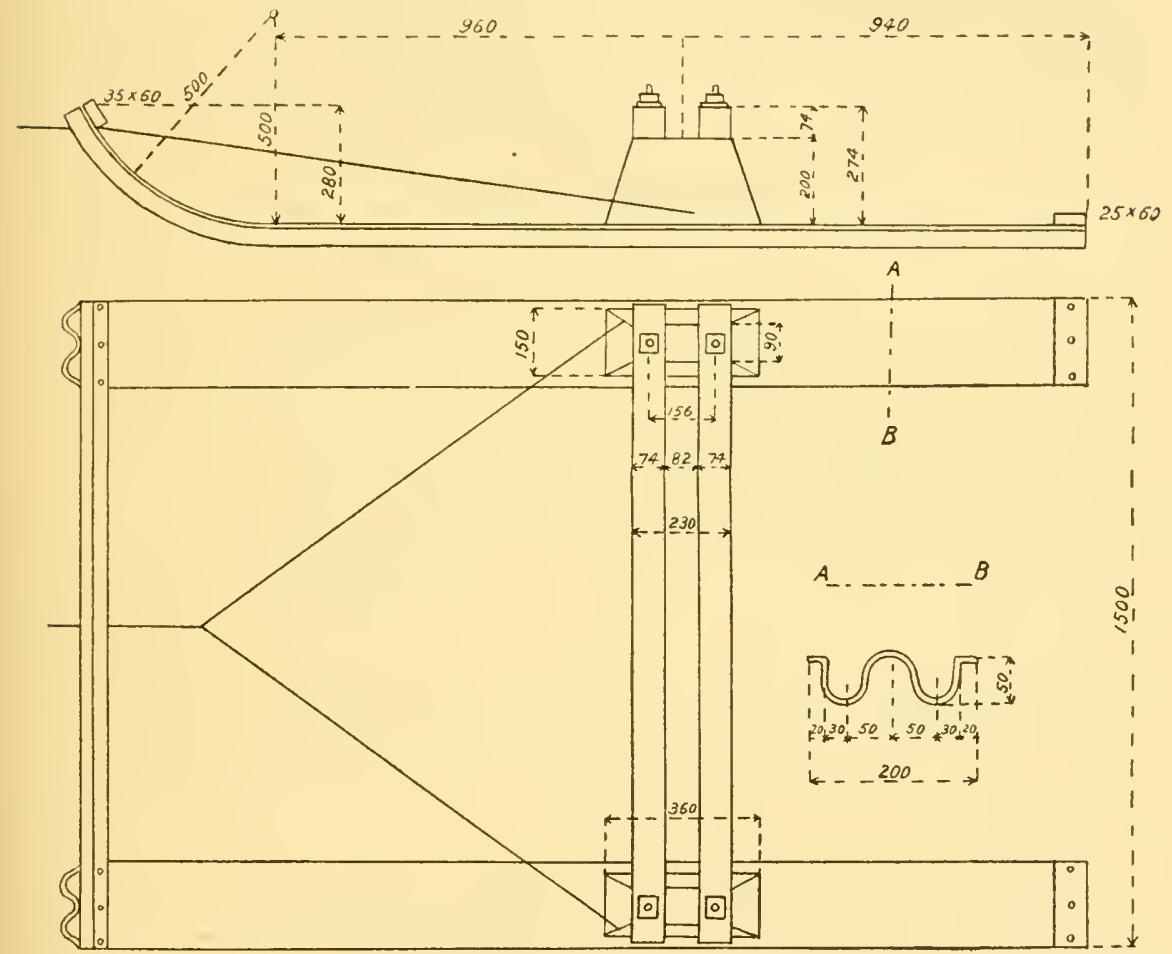

Fig. 38.

is held under the hole in the bottom of the balloon by cross wires. The alcohol is ignited when the balloon is to ascend.

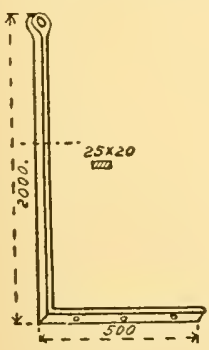

Fig. 39.

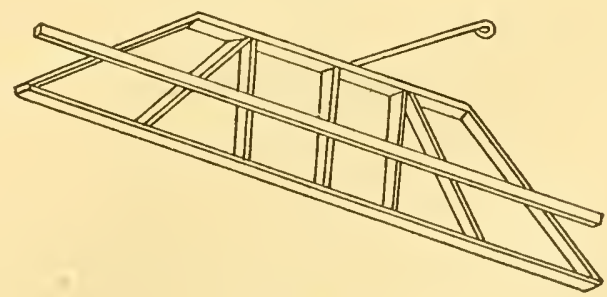

Fig. 40.

It is controlled by a marline cord which leads to a place of shelter from which the balloon can be raised and lowered. 
For longer practice a balloon is made of varnished linen and filled with water gas or illuminating gas. This balloon is controlled by a fine steel wire, and is raised and lowered by a windlass or other machinery.

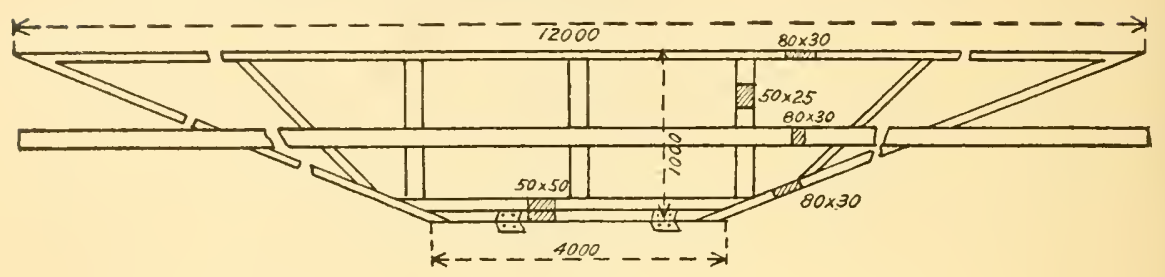

Fig. 41.

Combined Targets. - If a terrain is supposed to be occupied by infantry, targets that fall automatically (fig. 31) are set up in the proper places to represent patrols, and infantry figures to represent a firing line, at distances of one or two paces along such a line as it would probably occupy. Com-

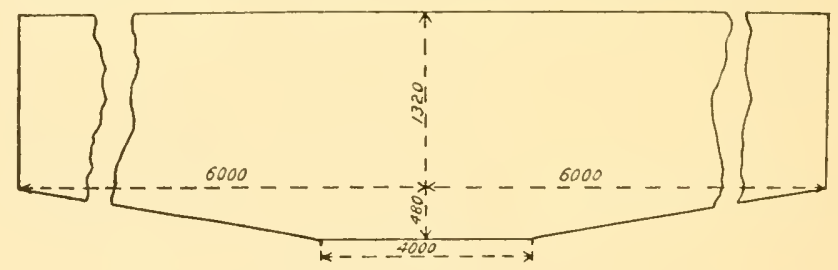

Fig. 42 .

pany reserves are represented by full-length figmres 300 meters behind the line, if possible well sheltered. They are represented by such targets as those shown in fig. 30 .

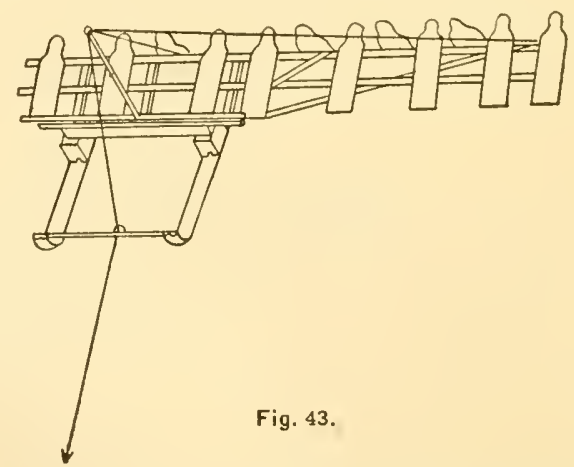

If the firing line is to be reenforced it can be represented by suddenly appearing targets (fig. 26), which must be set up on the firing line before the firing begins. 
If the reserve is also to advance to reenforce the firing line it is represented by sleds as shown in fig. 43. The sleds are advanced from the reserve to the firing line, and this adrance

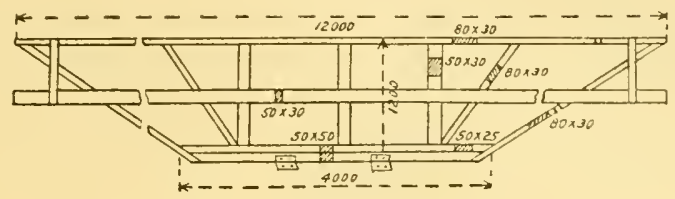

Fig. 44.

is made by rushes unless the distance is too short, or unless the ground affords them great protection while adrancing.

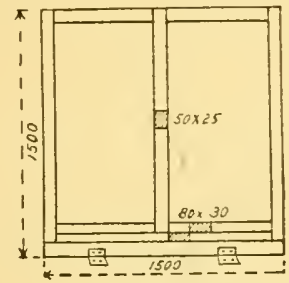

Fig. 45.

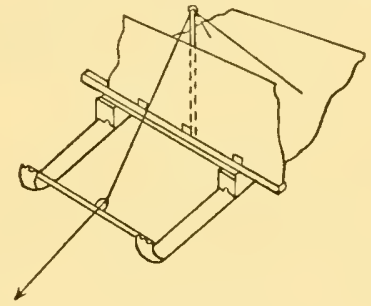

Fig. 46.

When a large body of infantry is to be advanced over the fire-swept zone to the assault, it can be represented as shown in fig. $t \%$.

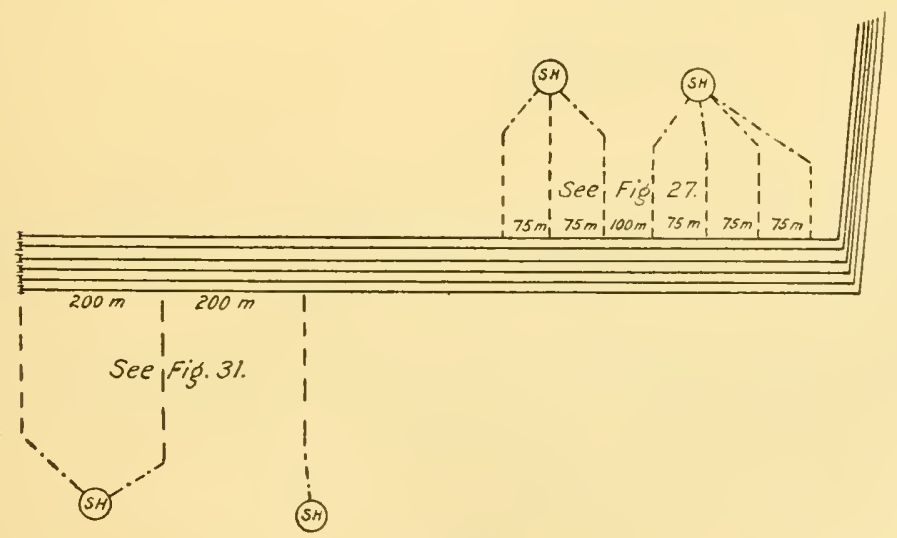

Fig. 47.

The limit must first be fixed to which the assault can come. Up to this limit at distances of about 100 , 75 , or 50 meters apart, depending upon the nature of the ground, are placed 
appearing and disappearing targets (figs. 27, 28). By the side of them are laid the drag lines for the sleds on which are brought up figure targets like fig. 43 . At somewhat greater distances, about 1,500 to 2,000 meters, are placed disappearing full-length figures (fig. 30), and besides them sleds are kept concealed. When the exercise is to begin, there are first shown the disappearing full-length figures which, after they come under effective fire, disappear. Then the sleds are put in motion. If the ground is open, after the artillery fire has become effective, the sleds can advance by rushes; otherwise the sleds move $u_{p}$ at once to the line of figure targets most remote from the firing point. The sleds stop and are metamorphosed into a firing line and the stationary figure targets
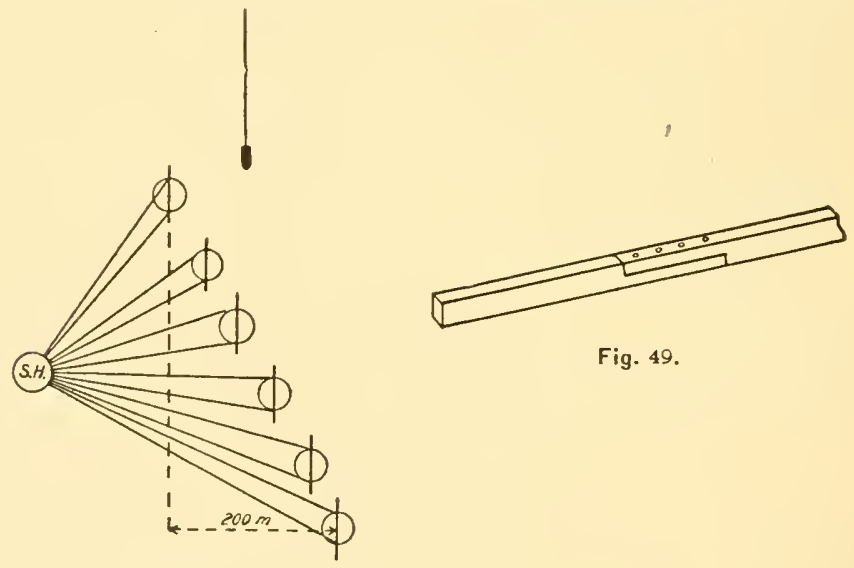

Fig. 49.

Fig. 48 .

appear. After the fire has continued some time, or the following sled has reached the firing line, all the sleds set themselves in motion to the next figure line, which then becomes visible, and the former line disappears. In this manner the attack advances from line to line up to the most advanced fignre line. If the lrag lines are laid around snatch blocks about 100 meters from the firing point, even the final assault can be represented.

By similar means the retreat of an infantry force can be represented.

If the advance of a large body of cavalry is to be represented, six or eight sheet-iron runners are laid side by side at distances of $t$ meters and a great sled is built on them and hauled by several drag lines (fig. 50). 
Artillery.-To represent the advance of artillery, the figures (fig. 21) should be set up on 6 sleds 15 meters apart. The drag lines of three sleds are united and the movement is so regulated that they keep abreast of each other. If the battery in advancing is to halt and unlimber, sleds with donble targets, like fig. 46 , are employed.

When a large body of artillery is to advance, the drag lines are so disposed that they will move together.

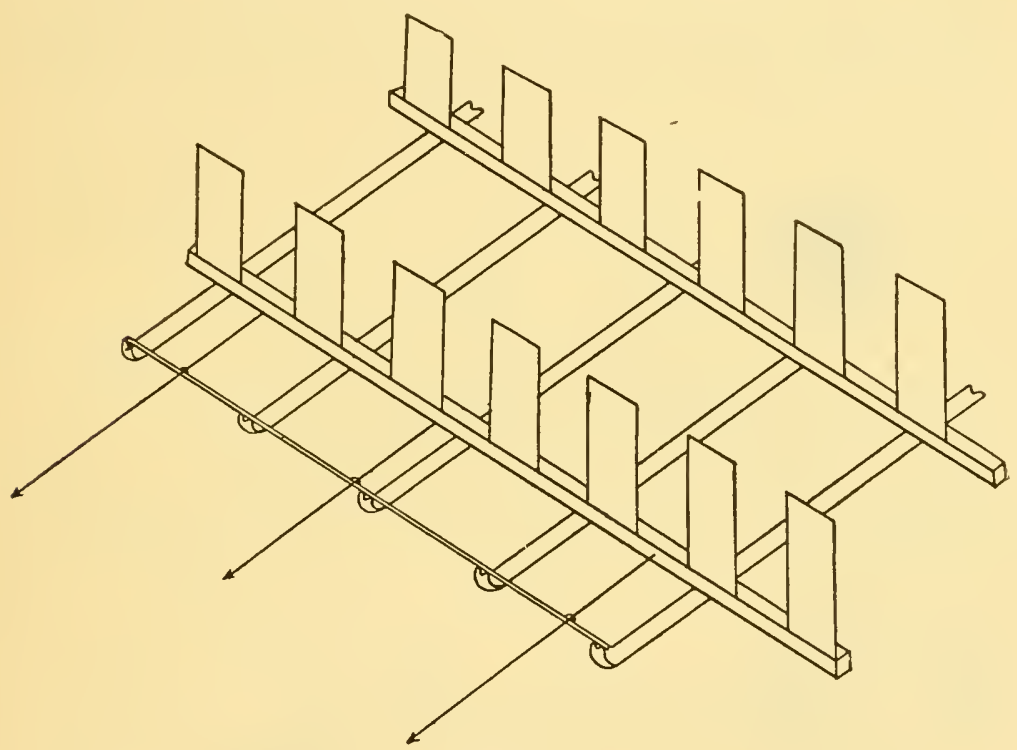

Fig. 50.

Fire of the target.-When it is desirable to represent the fire of a target, several cartridges are laid in a row parallel to the line of fire in front of each gun and connected by a slow fuse so that each will be ignited in turn.

Signals. - Both semaphores and telephones are used for communication between different parts of the range.

\section{HEAVY ARTILLERY.}

PREPARATORY EXERCISES.

After the use of the sights, and the nature of the trajectory, have been explained to the men they are taught to direct the piece upon some object that is described to them. If no natural objects present themselves, targets on a reduced scale or even objects on a wall painting, are used. 
The time required to direct the piece is observed and recorded.

All kinds of pieces, and all the different methods of aiming, are practiced in this manner, both direct and with an auxiliary point of aim. Fig. 51 shows an apparatus for making a disappearing target; fig. 52, one for a movable target; figs. 53 and 54 are objects which may be made to move along the apparatus.

For practice in aiming at unseen objects a gun is fired, or a cartridge is exploded behind a hill, and the piece is directed from the indications of the smoke.

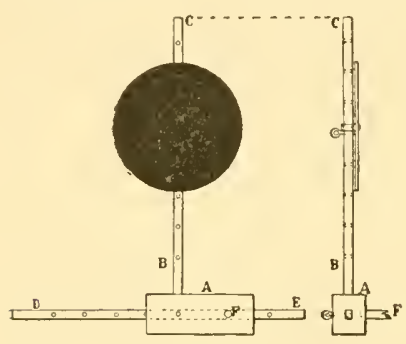

Fig. 51.

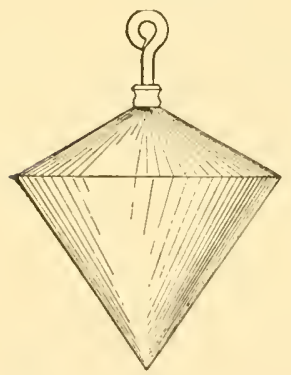

Fig. 53.

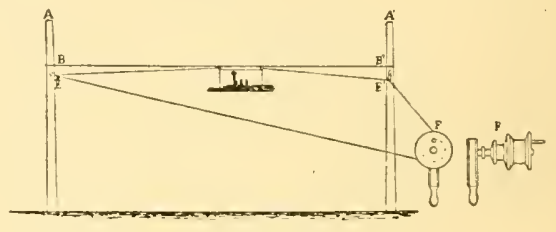

Fig. 52.

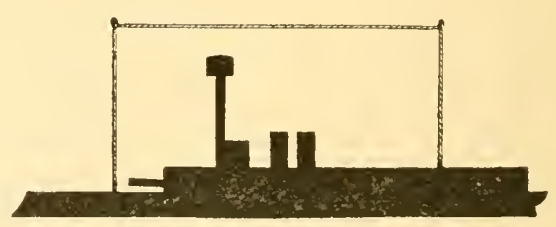

Fig. 54.

Night shooting is simulaterl against a movable point, or against a target either fixed or movable.

Prize competitions in pointing are held erery autumn.

The men are also practiced in observation of shot by firing with blank cartridges, the explosion of the shot being simulated by cartridges previously laid at the proper distances and explorled as ordered by telephone.

FIRING WITH LOADED AMMUNITION.

Firing with loaded ammunition comprises instruction shooting for recruits, practice shooting, field shooting, and prize shooting. 
When circumstances permit, these firings are conducted during the repetition exercises, except the prize shooting, and this should be completed before October 1 .

The ammunition allotted for the year's shooting is divided among the companies by the chief of the corps, after reserving what is required for recruits and prize shooting. It is so distributed that the companies may as far as practicable receive like instruction in shooting. As it is impossible in one year to go through all the necessary exercises, it is necessary to follow a program laid ont for several years in succession.

The shooting is conducted in a manner similar to that of field artillery.

Field Shootixg. - Field shooting, like that for field artillery, should be based upon some tactical supposition, but as

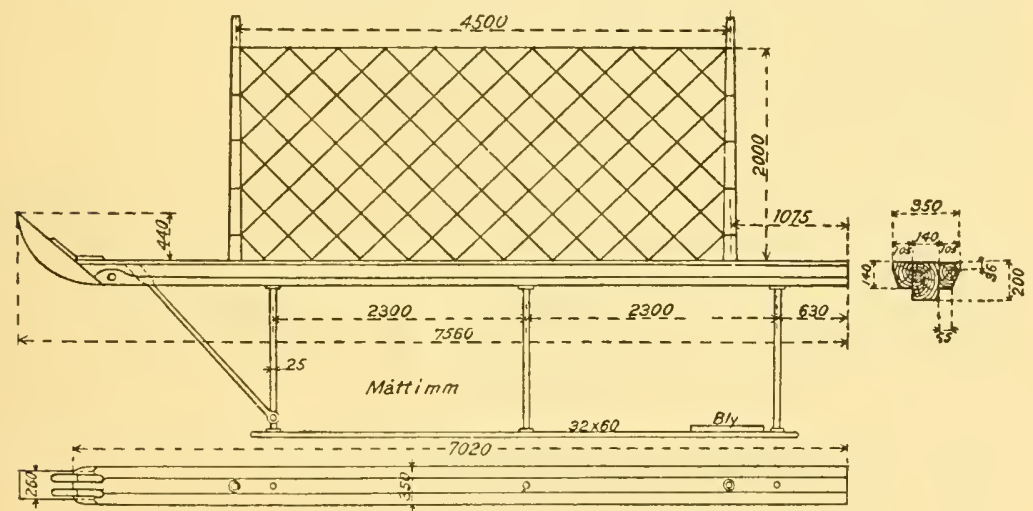

Fig. 55.

it is usually impossible to vary the ground very much, the changes are generally made in the character and movements of the targets. If practicable the same targets should sometimes be fired upon simultaneously by two widely separated batteries directed by the same officer.

Prize Shooting is practiced annually with an 8-centimeter gun at the time specified by the chief of the corps. Each gun fires 8 shells against a target set up at a distance of 600 meters. The target is 3.2 meters square with a bull's-eye 40 centimeters in diameter, and circles $80,120,160,200,240,280$, and 320 centimeters in diameter.

Hits in the bull's-eye count 8 ; inside of the first circle 7 , etc. The time between the fourth and eighth shot should not exceed five minutes. 
The prize shooting is conducted on principles similar to that of field artillery.

TARGETS.

All kinds of figures may be set up at points visible or invisible from the guns.

Torpedo boat targets are made of a wooden framework covered with a network or with strips of cloth (figs. 55, 56, and 57 ).

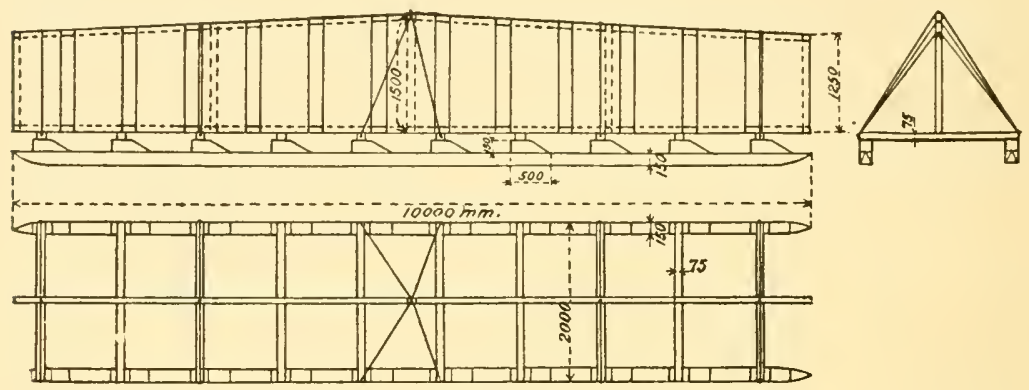

Fig. 56.
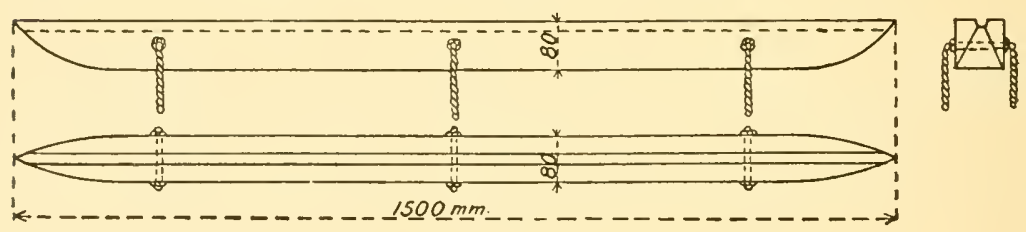

EXTRACT FROM THE REPORT OF THE SHOOTING SCHOOL FOR THE ARMY AND NAVY FORTIFICATION CORPS, 1900.

The session lasted from the 1st of May to the 11th of June. Those who took the course of instruction were 2 captains, 3 subaltern officers, 3 underofficers, and 17 constables, of which 2 captains and 7 constables were from the artillery corps of . the navy.

To the instruction company there were ordered so pupils, of whom 40 were from the artillery corps of the navy.

The daily work was on the average eight hours.

The time was divided for the officers and underofficers as follows:

Lectures, shooting regulations and making reports

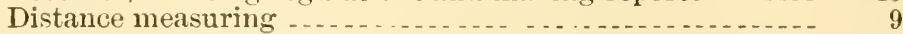

Examination of matériel ............................ 9

Visiting the forts at Vaxholm and Oscar Fredericksborge and Karlskrona _................................ 8

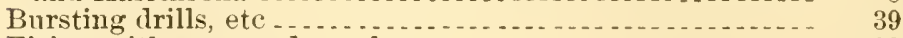

Firing with guns and revolver

Total . . . . 
The school shot 37 drill series and 46 field series as follows: Hours.

Against immovable mocovered target, shell .............. 4

Against immorable uncovered target, shell and shrapnel. 19

Against immovable uncovered target, shell and shrapnel_ 4

Against immorable covered target, shell ........ ........ 4

Against immorable covered target, shrapnel ............ 3

Against immorable covered target, shell and shrapnel_._ $\quad 2$

Against targets representing balloon, shrapnel _...____ 9

Against marked ship's deck, shell ...................... 1

Against towed target, and distance measure. .......... 17

Against towed target, shell ....................... 8

Against towed target, shell and shrapnel............... 16

Against anchored target on the sea, and mitraillense .... 2

Of this year's shooting the one which took place on the $23 \mathrm{~d}$ of May with a 24 -centimeter howitzer, model 94, was especially interesting.

From this shooting it is apparent that the pieces in question could be used with advantage against an anchored fleet or even against a large anchored ressel in windy weather.

The target represented the deck of the German armored vessel Fürst Bismarch, and it was struck by not less than 45 per cent of the shots, although the wind blew with a force of at least 4 , that is, 10 to 15 meters in a second.

In connection with the subject of target practice under "field conditions," it is suggested that such exercises might be made to conform still more closely to reality if, after officers and men have first been practiced deliberately in this kind of firing, the problem should be so arranged as to simulate the disturbing influences which affect both officers and men in action.

This can be effected to some extent if they understand that a few seconds more or less may turn the scale of the battle for or against them, if noncommissioned officers and soldiers who acquit themselves creditably are rewarded by prizes or even by promotion, and if, in case of failure, the exercises are repeated under more arduous conditions, and if by all possible means the men are given to understand that, their own record and that of their company or regiment depends upon their exertions for each fraction of a second during the decisive period. 
They should understand that it is often necessary to balance carefully the advantages of running to the firing point with the disadvantages of arriving out of breath.

When a detachment is itself exposed to hostile fire, those who by calculation and lot are found to be killed or wounded, should be required to fall out or at least to cease firing for the day, thereby reducing the fire effect and chance of success of the detachment. If the man is killed because he has wantonly exposed himself to hostile fire it might be advisable to assign him such extra drills or practice as the case demands, and proper measures of discipline should in all cases be applied to men who are disposed to regard the exercise as a representation and not as a reality. 


\section{VIII.-SWITZERLAND.}

[lieported ly Mij. George li. Cecil, Thiri Infantry, Luitel States Military Attaché, Berne.]

In Switzerland skill in the use of the rifle is much sought after, and male citizens of all ages able to handle the rifle are to be found practicing at shooting stands as members of the shooting clubs that are scattered throughout the country. This spirit of emulation extends so far that a very large percentage of the youths have attained a fair degree of proficiency before reporting for duty at the recruit schools, yet in these recruit schools a course in target practice is included.

The targets used are shown in figs. 1 to $10 \mathrm{~b}$.

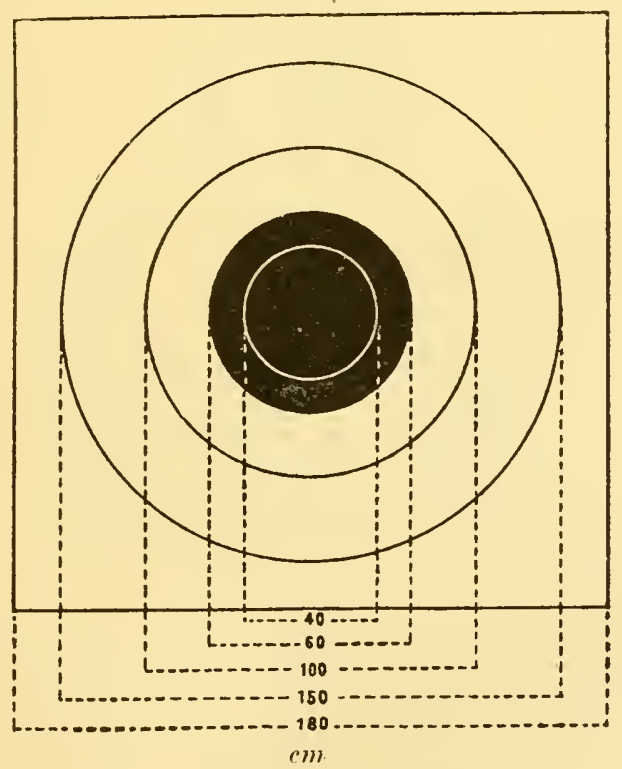

Fig. 1.-Target $A$.

Prior to the assembling of the recruits the officers and noncommissioned officers forming the cadres for the schoois 
are given a preliminary course in individual practice with conditions according to the following table:

\begin{tabular}{|c|c|c|c|c|c|c|}
\hline \multirow{2}{*}{ Exercise. } & \multirow{2}{*}{ Kiut of fire. } & \multirow{2}{*}{ Iristanere. } & \multirow{2}{*}{ Target. } & \multirow{2}{*}{ Positiou. } & \multicolumn{2}{|c|}{ ronditions. } \\
\hline & & & & & Points. & Hits. \\
\hline $\begin{array}{l}1 \ldots \ldots \\
2 \ldots \\
3 \\
4 \ldots \ldots\end{array}$ & $\begin{array}{l}\text { Single shots } \\
\text { Magazine fire. }\end{array}$ & $\begin{array}{r}\text { Weters. } \\
300 \\
300 \\
400 \\
3101\end{array}$ & $\begin{array}{l}\text { A } \\
\text { B } \\
\text { C } \\
\text { D }\end{array}$ & $\begin{array}{l}\text { Kneeling } \\
\text { Prone, with arm rest } \\
\text { Kneeling } \\
\text { Prone }\end{array}$ & $\begin{array}{r}9 \\
9 \\
5 \\
12\end{array}$ & $\begin{array}{l}4 \\
4 \\
3 \\
6\end{array}$ \\
\hline
\end{tabular}

The conditions to be filled are the following:

In the exercises 1 to 3 inclusive, in 5 consecutive shots, maximum $s$ cartridges, if after the fifth shot the required score has not been made, another shot will be fired and the

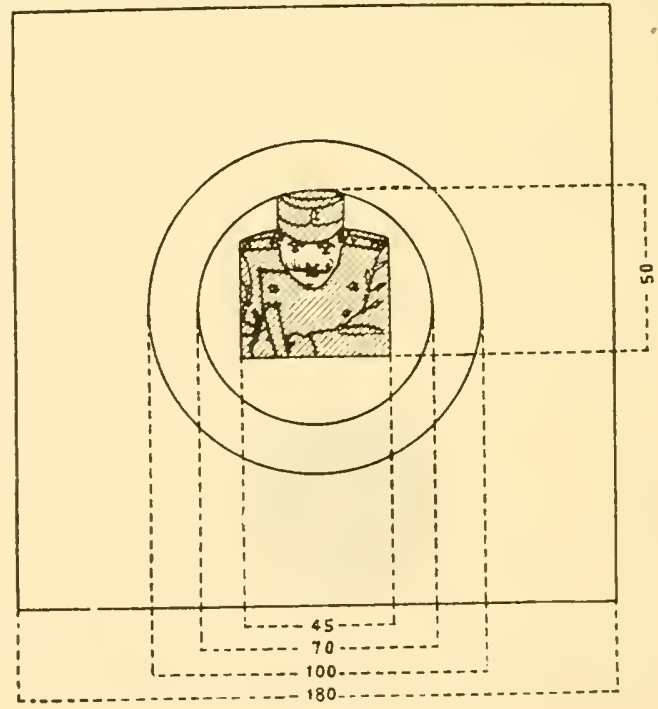

Fig. 2.-Target $B$.

last 5 considered, and if the required number of points and hits have not yet been made, another will be firerl, and so on up to 8 cartridges. In exercise No. 4,2 cartridges will be put in the magazine; the soldier will fire these and refill the magazine, which holds 13 cartridges, and fire them, all in forty seconds. If he fails to make the required score, he may repeat this exercise once only.

The recruits having reported, they are put through a course of sighting, position, and aiming drills with the sights adjusted 
to distances up to ?,000 meter's, first with rests and then without, until they are able to take the proper positions, hold the piece steady, and pull the trigger without flinching; then a

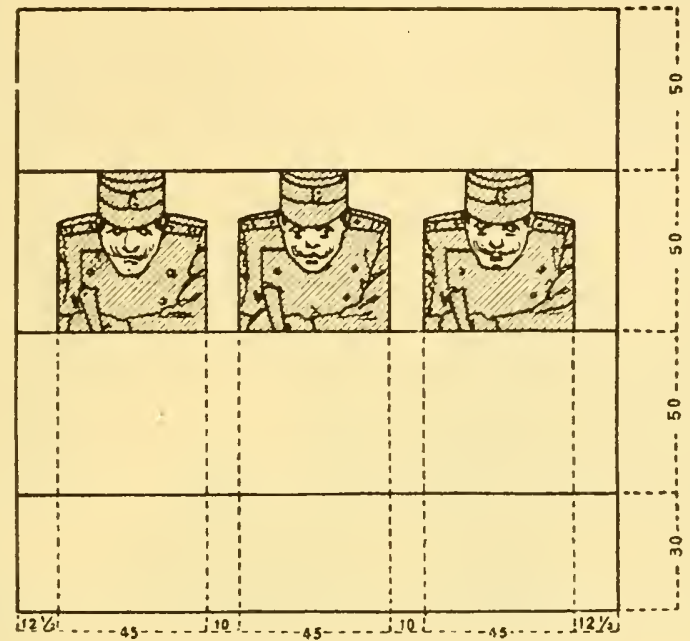

Fig. 3.-Target C.

few rounds of blank cartridges are fired, followed by a few rounds with ball cartridges to accustom the recruits to the

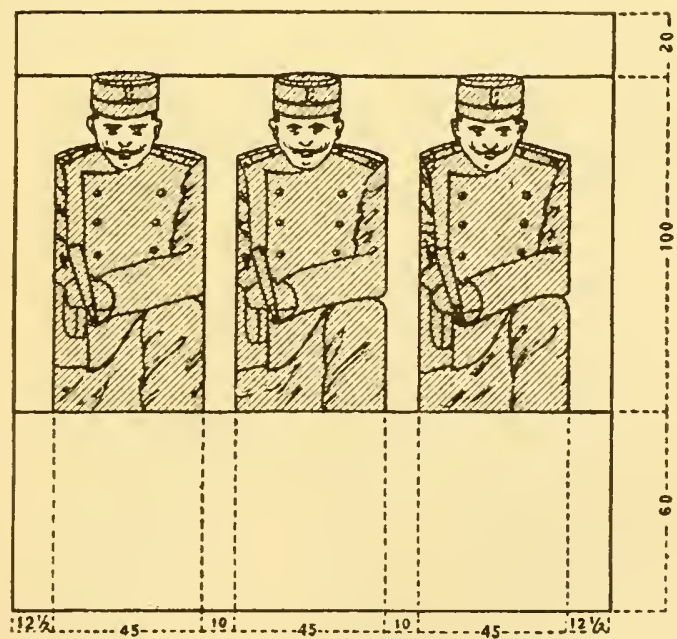

Fig. 4.-Target D.

noise and to the recoil. For this preliminary course 15 ballcartridges are allowed, and all the exercises are in front of targets. The instructing officer is given great latitude in the 
method of his instruction, only so that no man shall approach his regular practice until he can aim and fire without flinching, but in no case will he begin his regular practice before the third week.

It may be well to add that gallery practice finds very little favor, and is seldom resorted to in the instruction of the

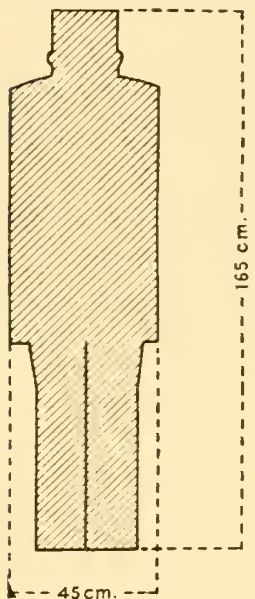

Fig. 5.-Target E. recruits, though five cartridges of reduced strength are authorized for each recruit, which may be employed after what is known as the Gysi system. It is

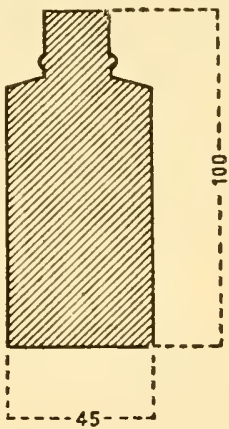

Fig. 6.-Target F. claimed that they are not sufficiently accurate to inspire confirlence; besides, there being

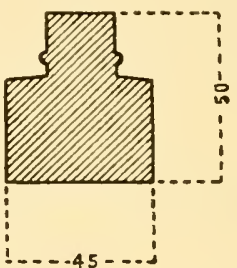

Fig. 7.-Target G. no recoil and very little

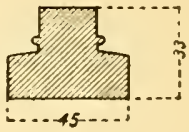

Fig. 8,-Target $H$.

report, it does not materially tend to diminish the tendency of nervous men to flinch, which is the greatest obstacle to be overcome.

The individual practice is a fire with conditions according to the following table:

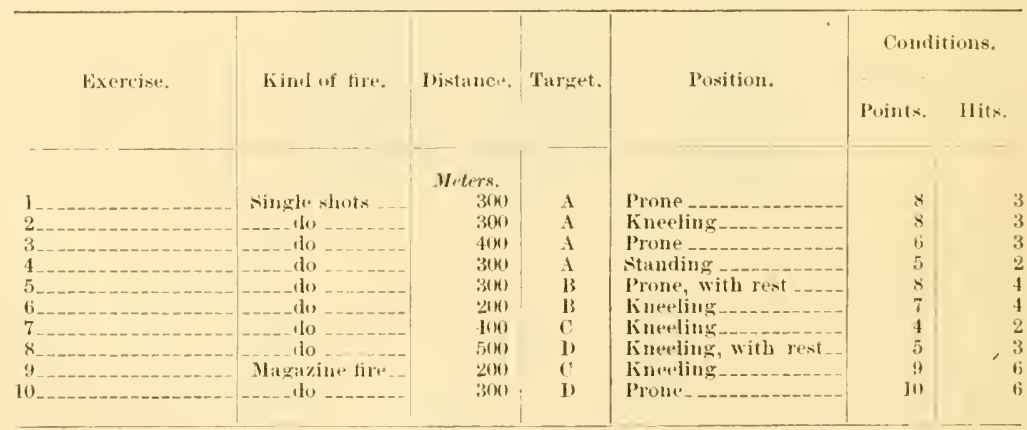

The conditions to be fulfilled are the following:

Exercises 1 to $s$ inclusive, in 5 consecutive shots, maximum 8 cartridges, if after 5 shots the required score is not made, another will be fired and the last 5 counted, and in case of 
failure, still another, and so on up to 8 cartridges. In exercise 9,8 cartridges will be placed in the magazine, and forty

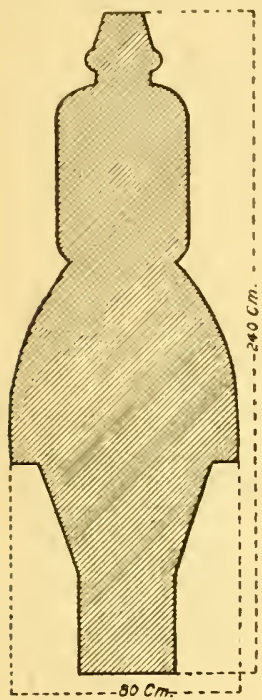

Fig. 9.-Target J.

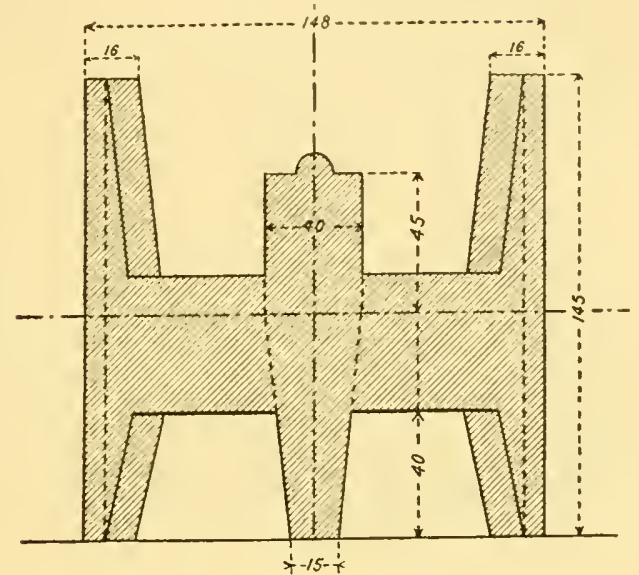

Fig. 10a.-Target $K$.

seconds allowed to fire them. In exercise 10,2 cartridges will be placed in the magazine and sixty seconds allowed to

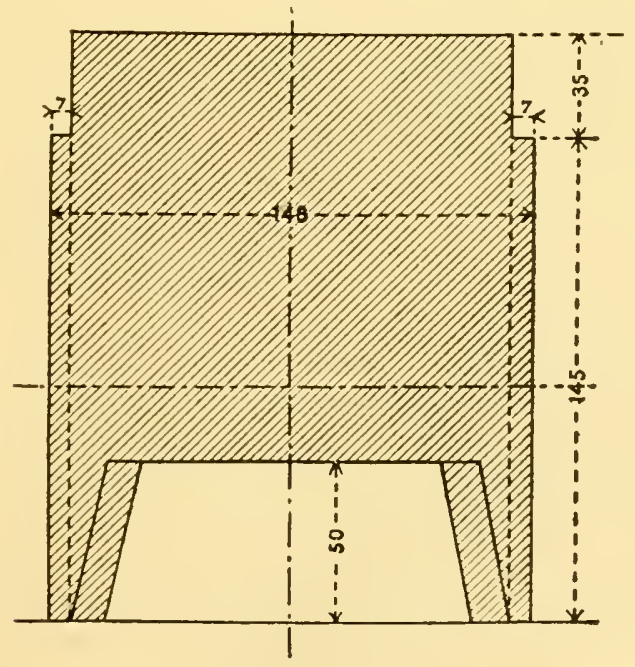

Fig. 10b-Target K.

fire these, fill the magazine, which holds 13 cartridges, and fire them. 
In case of failure to make the required scores, exercises 9 and 10 may be repeated once. Any recruit who has not fulfiller the conditions has noted on his record "resté," and he passes to the following exercises:

Applied Fire.-This indiridual applied fire at field targets is to habituate the recruit to put in practice the training he has received, and he is allowed to assume his own position and select his own point of aim.

Program.-Exercise 11: Single shots 300 meters at target F disappearing (visible during six seconds).

Exercise 12: Single shots at less than 300 meters, at 5 falling targets $G$, arranged as a line of skirmishers, five shots at each exercise.

After the firing the results are criticised by the instructor.

Insignia of Goop Shots. - Those who fultill all the conditions in the fire with single cartridges with the minimum number of shots, and the magazine fire without repeating the exercise, and make a total of 140 points, by the addition of all the points and hits of the fire with conditions, will receive the insignia of marksman (bon tireur). Others who fill the conditions 1 to 8 with 45 cartridges, and 9 and 10 without repetition, receive honorable mention, which is also noted in the soldier's target book, which contains a recort of his target practice during all the years of his service.

The inlividual practice completer, the recruits are then practiced in collective firing, both by section and by company. These consist of raried exercises illustrative of campaign work. The following exercises will serve as illustrations:

1. Exercises by section in extended line, firing as single loader, at 400 meters, at a line of skimishers formed of falling targets $\mathrm{H}$ and $\mathrm{G}$ mixed.

2. Exercise by section in extended line, at 500 meters at an (extended line of falling targets $\mathrm{G}$ and $\mathrm{F}$ mixed.

3. Exercise by section in line in close orler at 600 meters, at a line in close order of falling targets $\mathrm{F}$ and $\mathrm{G}$. The front of the targets should always exceed half the front of the section, and in the appreciation of the results, the time employed enters as an important factor; 25 ball-cartridges are allowed for this kind of practice.

The recruits are next practicer in the fire of combat, which is in fact more an instruction for the commander than for the men in the ranks. For this purpose several sets of targets 
are placed so that they may be seen at about the same time. The chief marches his section on the ground, discovers the targets, selects his objective, determines the range, and orders the fire. At first he may fire a few shots till he gets the range, and then he directs the rapidity and distribution of the fire. For this purpose about 30 cartridges are usually allowerl. The same problem is given by company on an unknown terrain, if possible, for which 50 cartridges per man are allowed, but the company is required to approach the terrain after a rapid march, or some exercise requiring great effort.

If time and ammunition permit they may fire against targets representing disappearing cavalry.

In appreciation of the results it is estimated that a superiority of fire is obtained when one-third of the targets have fallen; when one-half have been hit the objective is beaten.

In the schools for noncommissioned officers the individual fire with conditions is according to the following table:

\begin{tabular}{|c|c|c|c|c|c|c|}
\hline \multirow{2}{*}{ Exercise. } & \multirow{2}{*}{ Kind of fire. } & \multirow{2}{*}{ Distance. } & \multirow{2}{*}{ Target. } & \multirow{2}{*}{ Position. } & \multicolumn{2}{|c|}{ Conditions. } \\
\hline & & & & & Points. & Jlits. \\
\hline $\begin{array}{l}1 \\
3 \\
3 \\
5 \\
5 \\
6 \\
6 \\
8\end{array}$ & 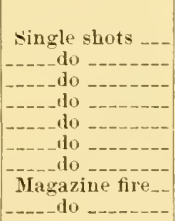 & $\begin{array}{r}\text { Meters. } \\
300 \\
400 \\
300 \\
300 \\
200 \\
400 \\
500 \\
200 \\
300\end{array}$ & $\begin{array}{l}A \\
A \\
A \\
B \\
B \\
C^{\prime} \\
\text { D } \\
C \\
C\end{array}$ & $\begin{array}{l}\text { Kneeling } \\
\text { Prone- } \\
\text { Standing } \\
\text { Prone, with rest } \\
\text { Kneeling } \\
\text { Prone } \\
\text { Kneeling, with rest } \\
\text { Kneeling } \\
\text { Prone. }\end{array}$ & $\begin{array}{r}0 \\
7 \\
5 \\
0 \\
8 \\
5 \\
6 \\
10 \\
8\end{array}$ & $\begin{array}{l}4 \\
3 \\
3 \\
4 \\
4 \\
3 \\
3 \\
6 \\
5\end{array}$ \\
\hline
\end{tabular}

The conditions are, exercises 1 to $\%$, in 5 consecutive shots; maximum 8 cartridges, same as for recruits.

Exercise 8, magazine charged with 8 cartridges, time 30 seconds; exercise 9, 2 cartridges in magazine to be fired, magazine refilled with 13 cartridges and fired, time forty seconds. Exercises 8 and 9 may be repeated once.

Applied Fire.-Exercise 10: Single shots, between 200 and 300 meters at target $\mathrm{F}$ disappearing, risible five seconds, o shots, each marked as fired.

Exercise 11: Single shots, between 300 and 400 meters, two falling targets $\mathrm{F}$ placed near together, 5 shots at most fifty seconds.

Exercise 12: Magazine fire, 300 meters, four targets $\mathrm{F}$ falling, placed in line, magazine filled with 13 cartridges, to 
knock down all the targets with the least possible number of shots, time thirty seconds.

Exercise 13: From 200 to 500 meter"s, targets falling or disappearing silhonettes. Will be used in this exercise what are left of the 95 cartridges allowed for the individual practice.

The insignia of marksman and honorable mention will be given on the same conditions as for recruits, that is, a total of 140 points made with minimum of cartridges in exercises 1 to $r$, and without repeating exercises 8 and 9 .

Similar problems are giren in collective firing to those preriously described in the recruit course.

The course of practice for the newly appointed officer's is a little more difficult, and each officer is allowed 15 cartridges for preliminary practice, after which the following program is followed:

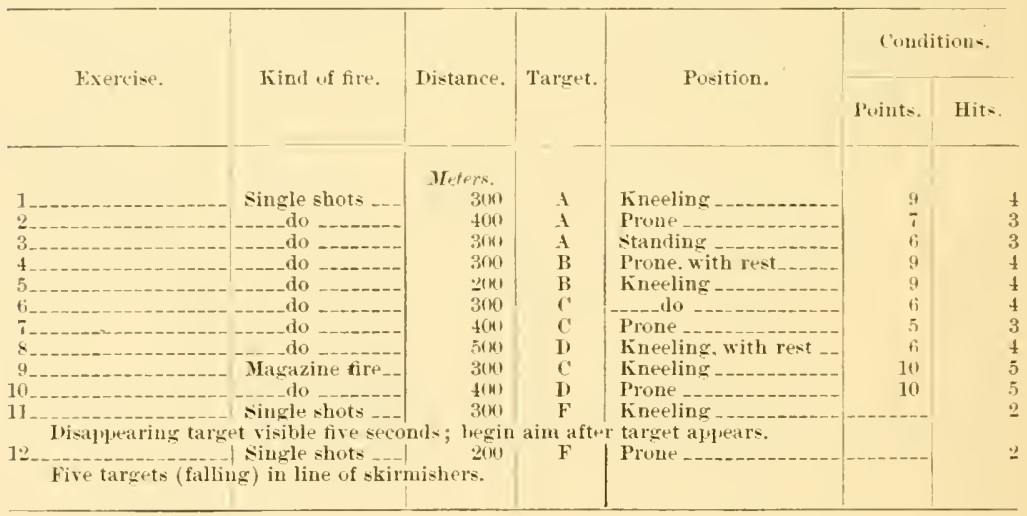

Exercises 1 to 8 and 11 , in 5 consecutive shots, maximmm $s$ cartridges; exercise 9, magazine filled with 13 cartridges, time thirty seconds; exercise 10,4 cartridges in magazine, refill once, time forty seconds; exercise 12,5 shots, time forty seconds. Numbers 9, 10, and 12 may be repeated once. In case of failure to make the requisite scores the officer is reported "resté."

The officer is given other practice in collective fire and as instructor of men.

After the courses of instruction in the schools preriously described, the men are expected to keep themselves in practice by exercises at the shooting stands and at their homes, but during the cours de répétitions of the élite the men are 
given the following practice, to see if they have kept up their training:

1. Single shots, 400 meters, Target $C$, prone, 8 cartridges.

$\therefore$ Magazine fire, 300 meters, Target C, kneeling, 8 cartridges in the magazine, time forty seconds; also 60 cartridges for collective firing under the company commanders.

The same allowance is made for the landwehr, except that only 30 cartridges are allowed for collective firing.

\section{MARKIN(: AND SCORING.}

For marking, two disks are used, preferably of sheet iron, of 40-centimeter diameter for the longer ranges, and 30 centimeters for $: 00$ and 300 meters. They are painted the same color as the pasters, that is:

$\left.\begin{array}{l}\text { Red with white band.. } 4 \\ \text { White ............. } 3\end{array}\right\}$ On one side red, white on the other.

Orange .............. 2)

Black _........... 1) Orange on one side, black on the other.

The disk is placed with the center over the hole made by the bullet and held there a few seconds; a miss is marked by balancing the disk in the hand. The law provides very severe penalties for false marking or false scoring, and great care is taken to prevent errors.

\section{MARKING.}

Target A (fig. 1) : Points. Interior circle, 40 centimeters in diameter................. 4

Exterior circle of black, 60 centimeters in diameter....... 3 Interior circle white, 100 centimeters in diameter......... . 2

Exterior circle white, 150 centimeters in diameter ........ . 2

Other parts of the target............................ 0

Target B (fig. 2) :

Hit in figure . . . . . . . .

Interior circle, 70 centimeters in diameter............. 2

Exterior circle, 100 centimeters in diameter.............. 1

Other parts of the target............................. 0

'Target C (fig. 3):

Band containing figures, 50 centimeters wide.............. 2

Band next below figures, 50 centimeters wide_............ 1

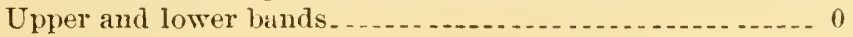

Target D (fig. 4):

Band containing figures, 100 centimeters wide ...........

Lower band, 60 centimeters wide .................... 1

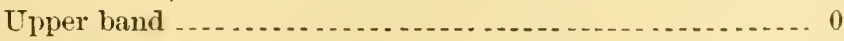

On the other targets, known as field targets, each hit counts 2 points. They are marle of wood, painted a neutral 
color, gray or light brown, and are, except those representing artillery, provicted with an apparatus to cause them to fall when struck.

Targets B, C, and D are of paper, light. brown in color. $\mathrm{A}, \mathrm{B}, \mathrm{C}$, and $\mathrm{D}$ are mounted on wooden frames, arranged in pairs and counterpoised over pulleys so as to slide vertically, very similar to the Brinton targets used in our service. At most of the stands, if not all, the markers' pits are sunken in front of the targets, and a stone wall or other substantial butt is constructed behind the target to stop the projectiles.

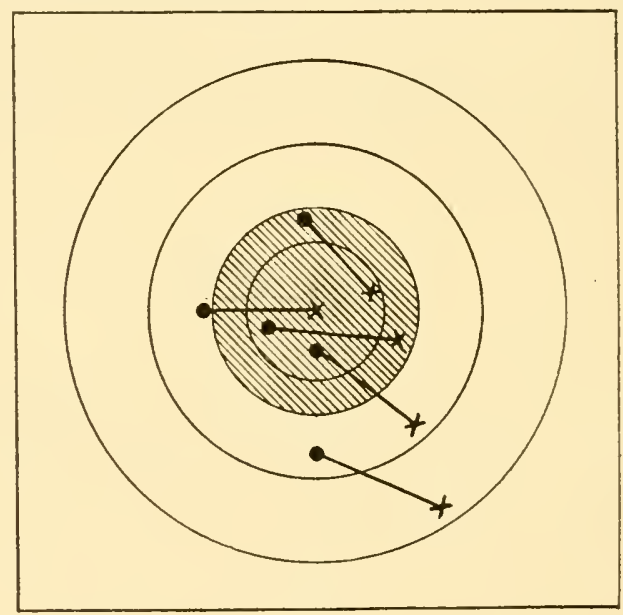

Fig. 11 .

Each recruit is provided with a target book, and when he fires he at once announces to the officer who is instructing him the place on the target upon which he thinks he was aiming when the gun was discharged; this point the officer marks with a dot (-) on the target in his book. When the shot is marked the place hit is marked with an oblique cross $(\mathbf{X})$ and the two points are joined by a line. Many men are inclined to close the eyes when they pull the trigger, and it is believed this helps them to overcome this difficulty, as well as to correct errors in sighting. See illustration (fig. 11).

\section{POSITION AND FORTRESS ARTILLERY.}

The recruits for these two branches of the artillery service are given the same instruction and individual practice as the infantry recruits, and the same individual practice in the cours de répétition. They are armed with the short rifle. 
CATALRY.

A copy of the program for the target practice for the caralry recruits not being obtainable, the details of the practice can not be given, but from inquiries it is learned that the preliminary instruction and the individual practice do not materially differ from the course pursued with the infantry recruits, but to this pistol practice is added, almost identical with that given the newly appointed officers.

\section{PISTOL PRACTICE.}

In the preparatory course of cadres assembled before the recruit schools, there is a short course of pistol practice for the officers, all of whom carry pistols. There are three exercises of 6 shots each at 50 meters at Target $\mathrm{A}$, and four exercises under such rules as the commandant of the school may direct, and at whatever targets he may choose, in series of 6 shots each at distances from 25 to 50 meters. Then in the target practice school for young officers newly appointed there are provided three exercises of 6 shots each at 50 meters at Target $\mathrm{A}$, and seven exercises at such targets and under such conditions as the commandant of the school may direct, at ranges varying from 25 to 50 meters. All the cavalry have similar pistol practice dismounted.

There is no provision for mounted practice.

\section{ALLOWANCE OF AMIIUNITION.}

Ammunition allowance is as follows:

Rifle:

Preparatory practice, cadres recruit schools

Each recruit, infantry -

Each recruit, fortress and position artillery -..._-..... 95

Noncommissioned officers, target school _............ . . 335

Officers newly appointed _.....

Cours de répétition élite ........................... 75

Cours de répétition landwehr . . . . . .

Carbine:

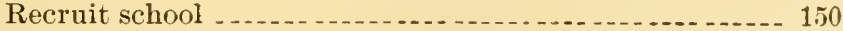

Pistol:

Cours de répétition . . .

Officers forming calres of recruit schools .............. 42

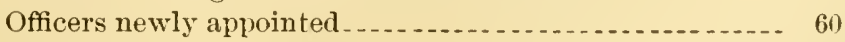

Cavalry recruits.................. 60 
Besides the foregoing, there is allowed for obligatory practice at the shooting stands and paid to the societies on their returus of practice:

Francs.

For each man carrying the rifle or carbine. ..... . . . . . 1.50

For each man carrying a revolver _. _. . . 2. 3.00

There are other subsidies to these shooting societies encouraging additional voluntiry practice for men held to military service, also for all citizens of the country.

AMMUNITION ALLOWANCE FOR MACHINE-GUNS.

Machine-guns, Maxims:

Cartritges.

For recruit school

60,000

For cours de répétition, per company with 8 guns ... 15, 000

ARTILLERY.

The schools of recruits for field and mountain artillery devote much time to target practice, using as targets the same forms as the field targets for infantry, grouped in sections or companies, sometimes in column, then again in line, close or extended order; those representing artillery usually in battery. Infantry sections are formed and mounted on wheels with a long cable attached which is deflected by pulleys and by means of horses; these targets are made to move at varying rates, while the artillery fire at them. Practice is given at known and unknown distances, from short to extreme ranges for the guns employed, including the methods of getting the range with both time and percussion shells.

Similar practice is given the recruits for position and fortress artillery.

The following is the allowance of ammunition for field and mountain batteries:

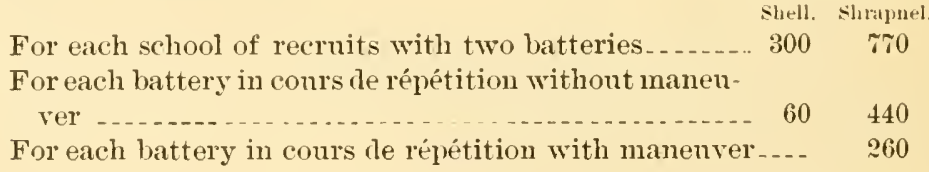

At the maneuvers a quantity of blank ammunition is consumed, prescribed in orders, each year.

NotE.-The Nene Militärische Blätter, Berlin, Jannary 1, 1901, says: "There are no firing schools, as the term is molerstood in Germany, in the militia system of Switzerland. Lientenants of infantry are required to complete a forr weeks' comrse at a so-called firing school, during which they are instructed both theoretically and practically in individnal and 
platoon fire. Occasionally more extensive firing exercises are held in ele vated localities, as, for instance, in 1898 on Momnt de Banlmes on the platean of Crébillon. The military department has appointed a commission for the study of the question of firing instruction, but the suggestions refer only to exercises in the recruit schools and conrs de répétition. Nothing is done in the way of firing instruction for field artillery, the target practice held being thought to be sufficient.'

There is an experiment gronnd at Thun where new weapons for infantry and artillery are tested. 



\section{REMOUNT SYSTEMS OF FOREIGN ARIIIES.}

(205) 



\section{REMOUNT SYSTEMS OF FOREIGI ARIIIES.}

Military remounts have been shown by recent events to be a factor on which, more than any other, success in war may depend. Three hundred thousand horses, costing $\$ 62,000,000$, were purchased by Great Britain for the South-African war, where 95 per cent of the British field army is mounted. Germany has 130,000 horses in the army, France has 142,000 , and Russia 175,000. As high as 500,000 more would be required to bring one of these countries up to a war footing.

The systems herein described have been reported by our military attachés, or compiled from other sources, and show how and where the principal armies of the world obtain their remounts, and the methods practiced for improving them.

\section{I.-AUSTRIA-HUNGARY.}

[Reported by Lient. Col. J. B. Kerr, Ninth Cavalry, Inited States Jilitary Attaché at Berliu.]

There are in Austria-Hungary 3,857,000 horses; of these, 1,548,300 are in Austria, and 2,308,700 in Hungary. The number of stallions in Austria is 133,145, in Hungary, 198,845. Both geldings and mares are used in the army. The geldings and mares over 4 years number in Austria 1,040,412, in Humgary, 1,553,155; total, 2,593,567; under 4 year's in Austria, 374,743 , in Hungary, 556, 700 ; total, 931,443 .

In time of peace all horses and pack animals for the army are purchased by remount commissions, acting under the orders of the imperial war ministry. In case of mobilization the additional horses required are furnished by the horse owners, who give their serviceable animals to the government, receiving proper indemnification for the same. Only in case of a partial mobilization of small extent may the horses be purchased as in peace. Horses purchased in peace are distributed directly either to the troops requiring them or to the remount depots. The cavalry and artillery may be 
permitted by the war ministry to purchase their remounts directly. Organizations which have not this permission may occasionally buy particularly good horses, rendering a detailed report of the transaction to the war ministry.

There are seven permanent remount purchasing commissions, stationed as follows: At Budapest, Szegedin, NagyKaniza, Bilak, Lemberg, Rzeszow, and Miskolcz. Each of these commissions is composed of a colonel or lieutenant colonel of cavalry as president, a retired officer as recorder and accountant, and of a veterinary surgeon. Certain of these commissions have at their disposal a retired field officer of cavalry to replace the president when deemed necessary. The purchasing commissions of the troops that buy their own horses are each composed of a field officer or captain of cavalry as president, a retired officer as recorder and accountant, and of a reterinary surgeon. Certain of these commissions have also at their disposal a retired field officer of cavalry to replace the presictent when deemed necessary. The commander of the troops is nevertheless responsible for the military value of the horses bought by these commissions, and it is also his duty to see that the necessary number of horses is obtained. All the horses purchased are procured within the limits of the empire. Ilost of them are bought during the autumn. In the spring and summer only as many are purchased as are necessary to supply the losses that have occurred, and the $3 \frac{1}{2}$-year-olds which go to the remount depots. The purchasing commissions publish in the newspapers the dates of their meetings. Horses are procured as far as possible from the raisers; it is only exceptionally and only in the ausence of the latter that the commissions have recourse to the merchants. From 50 to 60 per cent of the horses are bought without an intermediary. In addition to the horses purchased at the seats of the commissions, the presidents of the permanent commissions visit the markets, the raising centers, and the private breeding stables in order to procure especially suitable animals. The horses acquired for issue direct to the troops must be at least 5 years old, $r$ at the most. The commissions are authorized to buy a limited number of t-year-olds if particularly strong and well developed. Only healthy and serviceable animals are purchased. The minimum height is 15 hands 1 inch for horses for the cavalry, for noncommissioned officers' saddle horses, and 
saddle liorses for the train; 15 hands 3 inches for draft horses; $1+$ hands 2 inches for pack horses. Saddle horses, however, below 15 hands : inches are not bought unless they are particularly strong animals. The minimmm height for draft horses is reduced only in rery exceptional cases. The saddle horses of the horse artillery are preferred between 15 hands 1 inch and 15 hands 2 inches. The maximum height is 16 hands 1 inch for the saddle, and 16 hands 3 inches for draft. For mules for mountain service the height depends upon the breeding conditions of the country where they are bought.

There is no export duty on horses or mules. The import duty on horses over 2 years of age is $\$ 4.06$ each, colts of 2 years and under being free, mules \$ $0.81 \%$.

The use of the mule is confined to pack purposes, principally for mountain artillery.

The prices of the horses are fixed each year in the budget; they average $\$ 101.32$ for saddle horses, and $\$ 141.4 \%$ for draft horses. These are the average prices. The commissions may pay more in special cases. The commissions have also at their disposal a fund for increasing the purchase price of cavalry horses and horses for noncommissioned officers of artillery. The fund amounts to an annual allowance of $\$ 5,790$, or 38.6 cents for each animal bought. The number of horses annully acquired is about 12,000. Descriptions of the horses, at the time of purchase, are enterer in a book by the recorder. The horses are then branded on the left side of the neck. When the horses reach their regiments they are branded with the regimental number on the left hip. Each organization of troops receives anmually 12 per cent of its authorized strength in saddle horses and 10 per cent in draft horses. The average service duration of the former is therefore $8 \frac{1}{3}$ years and of the latter 10 years. The purchase of horses of 5 and even 4 years is very difficult, as the raisers generally sell the animals under these ages, or else have spoiled them by work. The military administration, therefore, has been obliged either to raise the price, or to buy younger horses, from $3 \frac{1}{2}$ years and over. For these young horses the creation of horse depots became necessary, in which the animals could be kept until $+\frac{1}{2}$ years old, the age at which they can be delivered to the troops.

The remount depots number five, and are located at Bilak, Nagy-Daad-Sari, Labod, Klecza Dolna, and Ihaszi Marczalto. 
Each one of these depots includes a large domain where young: horses are raised on the range for a period averaging one year. These horses are not ridden at the depots. There is joined to each depot a farm, which permits the supplying of all agricultural products for the depot by means of its own resources. The depot at Nagy-Daad-Sari has a capacity for 1,000 remounts, at Labod 600 , and at each of the three others 400. For superintending the remount service a general is appointed, who has the title of general inspector of remounts and who is directly under the orders of the imperial war ministry. He exereises direction over the purchasing commissions and the remount depots in all that concerns the purchase, raising, and distribution of horses. His attention is given principally to the kinds of animals bought, and the formation of groups of horses for assignment to the different troops. He assists at the purchases on the days the commissions meet at important fairs. Under orders of the minister of war he inspects the horses in the different organizations, in order to keep himself informed of the value of the remount horses as to their adaptability for the service and to watch their derelopment. He submits to the war ministry all propositions which appear to him to be of a nature to improve the remount. He acquaints himself with the horse production of the monarchy, in order to be able to direct purchasing commissions to the places where they will find the most and the best horses. A field officer is detailed to assist him.

After the month of May each year, 3-year-olds are bought, but the best only; that is, those which give promise of making good mounts for officers. They are sent to the remount depots.

Each regiment receives annually about 65 horses, 12 to 15 of which come from the remount depots.

The remount depot of Nagy-Daad-Sari is in Hungary. Its grounds extend over a domain of 8,000 acres. It is in two tracts, one containing 4,700 acres and the other 3,300 , located abont $t$ miles from each other. In addition to the pastures reserved for the horses, much of the land is placed under cultivation. The management is entirely military. It is administered by 1 field officer, as commander; 1 captain, 4 lientenants, one of whom is the aceounting officer, 12 sergeants, 10 corporals, and 60 privates, furnished by the regiments to which the horses are sent. The privates are chosen 
from the sickly men of the reguments and those against whom continual complaints are entered. The agricultural labor is done by civilians. In busy seasons the number of laborers reaches 600. All kinds of agricultural products are raised, but principally oats and corn. Oxen are used for work. Horses which have been injured or have in other ways become unsuitable for army use are also employed in work and as saddle hor'ses for the attendants. The dwellings and the stables, as at all the other depots, are on high ground. The pastures, from 500 to $\% 50$ acres in extent, are inclosed by wire fences. The horses are distributed in herds of about 100 each, and are always guarded by two or three men, the noncommissioned officer of the stables making frequent inspections. The horses are kept outside as much as possible, but never over night. They are taken out early in the morning. In summer during the heat of the day they are brought in, and then taken out again in the afternoon until night. The ration consists of 7.2 pounds of hay and 4.4 pounds of straw, no grain.

The purchasing commissions take only those 3 -year-olds which seem susceptible of making good mounts for officers. They pay for these young animals from $\$ 119.66$ to $\$ 138.9 \%$ These horses are very uniform, there being but little variance among them. Fewer than one-fourth of the horses purchased go to the depots, the remainder go directly to their regiments. There are found in the depots only picked horses. When they first arrive at the depot they are quarantined for six weeks in a special stable, and are pastured in a field completely isolated. Afterwards they are put in common stables. This undoubtedly prevents the spread of contagious diseases. Horses of similar size and form are placed in the samestable, but they are not selected or set apart for the different branches of the service until it is time to forward them to their regiments. After a stay of six months at the depots the horses are examined and marked by the commandant in classes from 0 to $\%$ Classes 7 and 6 contain the perfect and very good, which enter definitely into the category of officers' horses. Classes 5 and $t$ are marked as almost very good and good, and are noted to be inspected again. Another examination of them is made before they can enter the first-named category. Classes 3 and 2 will make noncommissioned officer's' horses, unless they greatly improve before leaving the depot; 1 and 0 go to the troops. The young horses frequently change for 
the better or worse during their stay at the depot. The inferior horses go to the artillery. When they have reached their fourth year, the horses are classed by the inspector general according to the number to be furnished to each regiment. The different lots are krawn for before starting for their regiments.

All the remount depots are similar in every respect, their managements and resuturces being uniform.

The lorses are not shod and are not trained under the saddle at the depots.

The description given of the remount depot at Nagy-DaadSari will serve to illustrate the manner in which the horses are cared for at the other remount depots mentioned.

In the army the trot is very little nsed. It is never practiced beyond the regulation speed. The gallop is more generally in use, the degree of blood of the horse lends itself to it. The reins are loose during the walk, which is an easy one. It is a principle not to inconvenience the horse, but to leave him at liberty as much as possible. Long distances are moved over at an easy and smooth gallop. The rider's guide their horses well. The stirrups are short and the legs well forward.

There being comparatively few hard roads in the empire, especially in Hungary, the horses of the army are not habitually shod. The metaler roads generally have paths of earth on the sides for riding, so that the horses are seldom ridden on hard ground. They have, as a rule, very fine feet. When shoes are used they are made of iron, with a groove, and have holes for 6 mails. The foot is cut by the farrier the least possible. The condition of the ground has guided somewhat the choice of the locations of the cavalry garrisons. Some of the regiments are near immense moors where the horses gallop on elastic ground. Horses are groomed three times a day. They are not vaccinater.

The officers are well mounted, often purchasing superior horses in the markets for their own use. Mounted officer's in part receive gorermment service horses, and in part supply themselves with horses, for all of which they receive forage.

In time of peace the following officers have mounts free of cost: Adjutants of infantry and fortress artillery, lieutenants of cavalry, captains of cavalry of the second class, and the subaltern officers of the field artillery and of the train. 
In war, in addition to these, all supply officers, officers of the pioneer troops, field telegraph and ficld sanitary officers, etc., are furnished mounts by the government. The infantry adjutants are remounted by the cavalry regiments, those of. the fortress artillery by the regiments of corps artillery. The horses put in their possession must be under 10 years of age. Each regiment of cavalry always has on hand six horses for this purpose. At the end of eight years the horses become the property of the officer's having them in their possession.

The cavalry officers, remounted free of cost, take chargers from among the troop horses. These horses should as a rule, barring accidental injuries or disability, remain five years in the hands of the holder. After five years the officer can ask to become the owner by the payment of three ammuities, amounting in all to one-quarter of the value of the horse. After eight years the officer has a property right to the horse. The artillery officers are remounted in the same manner from among the saddle horses of the noncommissioned officers of their corps. The officers of the train choose from among the horses of their train divisions. All the other officers, the field officers and captains of foot troops and of the technical troops, of the staffs, of the foot artillery, captains of the first class and the field officers of cavalry, are remounted at their own expense. The loctors and officials of the supply departments are not mounted in time of peace, troop horses being furnished them temporarily during the maneuvers. Upon mobilization they mount themselves at their own expense from among the requisitioned saddle horses.

The officer's remounted at their own expense can be authorized by the war ministry to be furnished horses by the permanent purchasing commissions, in which case they pay for the same in monthly installments, the number of which may vary from 12 to 48 . The field officer's, excepting those of the caralry, may also, though exceptionally, obtain similar anthorization to take mounts from among the horses of the cavalry, artillery, or train. A uniform price of $\$ 131.63$ is paid for these horses. The horses taken directly from the purchasing commissions can be acquired at the price of $\$ 162.12$, which is the price limit authorized for officers of the cavalry, artillery, and the staff. In this case, the permanent purchasing commission serves as intermediary between the seller and the ofticer in whose interest it acts. All officers of 
caralry and of horse artillery, mounted free of cost, are obliged to own also one or two horses purchased at their own expense. Thus, in the cavalry each field officer and captain must own three horses; each lientenant, besides the charger furnished free of cost, one horse. The higher officers draw forage for and have to keep a greater number of horses. A mounted officer receives an allowance (extra pay) for each horse held at his own expense. For cavalry officers the extra pay is $\$ 12.16$ for each horse per year. For officers of the other arms \$1\%.02. Lieutenants of cavalry and captains of the second class of cavalry receive also a special indemnity of $\$ 48.64$ per annum. Mounted oflicers receive extra pay for stable hire, and the higher officers entitled to carriages receive extra pay for carriage-house hire, when stables and carriage houses are not furnished by the government. The allowance of horses is, for a general, from 3 to 7 , according to his duties; for a colonel of cavalry, 4 ; other caralry field officers, 3 ; colonel of infantry, 3 ; colonel of artillery, 3 ; captains of the staff, 2; and field officers of the diverse arms, 2. Commutation of forage is che all officers entitled to mounts, whether the animals were acquired at their own expense or free of cost. The allowance for mounts is drawn ammally, the other allowances are drawn either every five days or monthly, and are paid in advance.

The daily forage ration for horses of the army in time of peace is as follows: For saddle horses of all kinds $9.2 \pm$ pounds oats, r.4S pounds hay, and for bedding 3.44 pouncls straw. For draft horses of artillery 10.16 pounds oats, 9.9 pounds hay, and for bedding 3.44 pounds straw. For draft horses of the train 9.24 pounds oats, 7.9 pounds hay, $1.8 \%$ pounds straw, and for bedding 3.44 pounds straw. For draft horses of the schools :9.24 pounds oats, 9.9 pounds hay, and for bedding 3.44 pounds straw. In time of war the forage ration is the same for all categories of horses; it consists, however, of three types: First, the strong ration, 12 pounds oats and 6.6 pounds hay; second, the ration furnished from the provision colmmus, 11 pounds oats and 6.6 pounds hay; third, the reserve ration, 5.5 pounds oats and 6.6 pounds hay.

There are sixty-two largestorehouses throughont the empire for forage ind rations. These storehouses themselves have permanent or temporary annexes in the principal garrison centers. In suall garrisons the forage is furnished directly by contractors. Compressed forage is not used. 
In time of peace the total number of horses in the army is 69,950 . Of this number 46,700 belong to the cavalry, 14,900 to the artillery, 1,620 to the infantry, and 6,730 to the train, pioneers, and other services. In aldition there are abont 5,000 officers' horses. In case of mobilization the cavalry requires a great many more trained saddle horses. In order to have them available and not to be compelled to maintain them in peace, every year a certain number of horses of the cavally regiments are given, after six montls' training, to civilians for use. These persons must be in assured conditions of life and must take the obligation to maintain the horses in a serviceable state, and to return them within twenty-four hours to the regiment in question, in case of mobilization. In addition these horses are assembled annually luring the autumn manenvers, for periods not to exceed twenty-eight days each, and every spring they are submitted to a mustering commission which reports their degree of serriceability. In case of good maintenance, the holder receives an annual prize of $\$ 4, \$ ?$ of which is paid in the autumn and s. in the spring. If the horse, by the fault of the user, is not serviceable for war, the holder must render indemnification. At the end of six years in Austria and five years in Hungary, the horses become the property of the users withont payment. They are, nevertheless, subject to requisition upon mobilization. In this case, however, their owners receive pay for them from the public treasury. The number of these horses in the service of private persons is 26,260 . They are bought over and above the amnual contingent and are commonly known as. "horses on leave." The practical application of this system lias caused no criticism.

In case of mobilization the horses can not be procured in the same manner as during peace, as this would require several months, and the mobilization would be delayed. For this reason the horses required in case of mobilization are supplied by conscription (requisition). This is regulated by the horse-conscription laws of 18\%: By these laws every horse owner is obliged to give the government the horses owned by him which are serviceable for war, for which he receives proper indemnification. Horse owners disobeying the call to present their horses will be forced to do so, and will be fined if they can not justify their delay. The entire horse supply is divided between the two states of the monarchy 
in the ratio of the total number of horses they contain. The number of horses to be furnished by the prorinces and districts is fixed according to the number of horses they have. In order to determine this number, a horse classification is made every three year's by mixed commissions, composed of army officers and civilian rejresentatives, which divide the horses into two classes, the "serviceable" and the "mnserviceable." In the interval between these periods, the horse owners have to report their horses, and the heads of the local communities submit, with these reports, evidence as to the serviceability of the horses for war. For each levying district there is appointed during peace a commission, consisting of a field officer or captain. one reckoning officer, one reterinary or farrier, representatives of the civil authorities, and three sworn civil appraisers. As soon as the order to present the horses has been issued the communities are requested by the rivil authorities to bring to the designated place, at a fixed time, all those horses which in the last classification were found serviceable, as well as those which by the 1st of the last January exceeded their fourth year of age. These horses are presented and are then classified by the commission as serviceable or unserviceable; then as saddle, draft, or pack animals. The following are specifications for serviceability: minimum height for saddle horses, 15 hands 1 inch; for draft horses, 15 hands 2 inches (if strongly built, 15 hands 1 inch): for pack animals, from 12 hands 2 inches to 13 hands 3 inches. In the Tyrol and Dalmatia smaller minimum measures are required, viz, 14 hands 2 inches and 13 hands: inches, respectively, for saddle horses; 1 : hands 2 inches for pack horses, and mules 10 hands 2 inches. The minimum age is 4 years; no maximum age is fixed. Unessential faults not rendering the animals mnserviceable, but which in time of peace might exclude their arceptance, are disregarded. The remount prices fixed by the war ministry are published, and the owners of serviceable horses are requested to offer them at the fixed prices. Those roluntarily offererl are purrhased by selection made by the commissions, at the prices fixed. If the number of horses to be furnished by the community is not thus obtained, then all the other serviceable horses are appraised. The appraisement is done by the sworn appraiser's. who are not bound by the remount prices (the prices fixerl), but serviceable horses may be taken at a price 
below the remount price. No objection against the appraised price is allowed. Those horses are first taken which receive the lowest appraisement. The appraised prices are paid at once. As a mle persons owning more than one horse are not required to furnish more than abont one-half their number of horses. If the number of horses is not sufficient for this method to be employed, some other method is adopted, all horse owners being treated impartially as far as possible. As soon as a mobilization is ordered trained service horses are no longer furnished to officers: they can then get only the horses furnished by the country, that is, untrained horses. Officers, therefore, during a campaign can depend for trained horses only upon those they have already acquired in time of peace. The number of horses required upon mobilization is about as follows: cavalry, 91,350; artillery, 87,440 ; infantry, 25,150; train, pioneers, and other arms, 47,000; total, 250,940. The number of additional horses required is, therefore, 175,000 .

The administration of the studs of Austria-Hungary may be said to be a military one. The officers and men of the stables have a military organization. While the personnel is amenable to the minister of war and to the commanders of the organizations, it is paid, as provided by the budget, by the minister's of agriculture of Austria and of Hungary. The ministers of agriculture have the direction of the studs in the corresponding parts of the monarchy.

There are two kinds of establishments: First, breeding establishments where the state produces and raises horses; second, stallion depots. The officers at these establishments belong to a special corps, which has two divisions, one for Austria and the other for Hungary. This corps of officers is recruited from the officers of the cavalry and of the train who have served three years in a body of troops, and who have also shown special aptitude. To verify this aptitude, the officers must pass an examination before a board under the presidency of the inspector of the Anstrian or Hungarian studs, at the veterinary institute of Vienna or of Budapest. The examination is both theoretical and practical, and bears npon the knowledge of the horse, its anatomy, and the raising, riding, and driving of horses. The examination is followed. by a period of six months of probation before the officer is definitely admitted. Exceptionally, the carlets acting as officers of cavalry and of the train can be admitted, after one 
year of service, subject to examination before the board, and a probationary period. Once officers of this special corps they can not, as a rule, be transferred back to the arm from which they came. In particular cases their transfer may be approved by the minister of war, but only after the officer has, by a probationary period with troops, given proof that he is still capable of serving there. This corps numbers 128 officers, of whom 45 belong to Austria, and 83 to Hungary. These officers have charge of the following establishments: In Austria, the breeding stables of Piber and of Radautz, and the stallion depots of Stadl, Graz, Göding, Pisek, and Drohowyze. In Hungary, the breeding stables of Mezöhegyes, Kis-Ber, Babolna, and Fogaras, and the stallion depots of Stuhlweissenburg, Nagy-Körös, Debreczin, Sepsi-SzentGyörgy, and Agram. Each of these establishments has at its disposal the necessary number of surgeons, reterinary surgeons, and accountants belonging to the various organizations. There are on duty at these establishments 94.3 noncommissioned officers, 18 accountants, 3,578 privates of cavalry, and 135 orderlies; total, 4,6it. Under the orders of the commandants of the establishments is also the management of the civil personnel necessary for the cultivation of the land comnected with the breeding establishments.

The stallion depots furnish stallions for a certain number of permanent posts commanded by officers. Each post furnishes its stations with stallions during the covering season. The number of posts in Austria is 16, and in Hungary 20, in all containing 8,067 stallions, and supplying 1,118 corering stations. The state rents to private persons 191 stallions. It does not loan stallions free of rent.

The Hungarian breeding establishments contain :3,686 animals, distributed as follows: At Mezühegyes 2,049, at Kis-Ber 698, at Babolna 584, and at Fogaras 355. The breeding stables influence to some extent the national raising by their selections of stallions and mares for reproduction, the products being disseminated by sales, and furnishing a considerable number of brood mares of superior type. There results from this, in the horse production of the monarchy, a uniformity by which the remount service has profited in a great measure, to furnish the army with horses of a standard type and of similar gaits.

The royal Hungarian breeding establishment of Mezühegyes is the most important, on account of the number, variety, and 
quality of its horses. It extends over an area of 50,000 acres, in one tract inclosel by a ditch and forest. The domain has 6,000 civil and military employees, and includes a sugar factory and an alcohol distillery. Cereals cover about onequarter of the ground. The stables were founded in 1\%85. In $18 s t$ a number of stallions and mares rere acquired in Turkey and Moldavia.

The chief of the agricultural ministerial section of breeding stables classifies the horses, excludes animals unfit for reproduction, distributes stallions, admits brood mares and directs the annual sales. The horses are never tied up in the stables, but range in the padlock. The service animals of the breering stables, 98 saddle horses and 56 draft horses, are chosen from those excluded. Mares may be boarded at the st: bles during the covering period. They are stabled free of cost, but the forage used by them is paid for by the orners at its market value, which is on an average about $\$ 6.08$ a month per mare. The owner pays $\$ 1$ to the men who take care of a mare. The price of the serving is fixed each year by the minister of agriculture. Thoroughbred mares foaled in Hungary and belonging to Hungarians are server for half the fixed price, and any who have won a race are served free of charge. There is in connection with this establishment a school for noncommissioned officers. Each year the pupils have a six months' course, including hippology, horse raising, and the care of horses in case of sickness or of ordinary accidents. The agricultural department operates eight farms, on which range 9,000 horned beasts of the Hungarian or Simenthal breed. The methods are similar to those for the raising of horses. There is a chief veterinarian, assisted by two military and three civil veterimarians. Each one examines all the stock in his jurisdiction every day. The chief veterinarian makes once a month a general inspection of all the animals. The hospital contains special places for animals that should be isolated.

The shoeing is placed under the direction of a veterinarian, who has under him nine farriers, one of whom is a master farrier. They use only about 1,200 horseshoes pel year, principally for the horses of the agricultural department. Those of the breeling stables are shod only exceptionally, even the service horses going barefoot. Experience has proved that leaving the horses unshod has a salutary effect 
on the horn of the hoof, the quality of the foot becoming fixed in the breed, so that there are but few defective feet.

The brand of the breeding stable, II surmounted by the royal Hungarian crown, is placed on the right side of the back behind the withers. An initial indicating the pedigree of the sire is branded on the left side opposite.

All the horses are very gentle, being accustomed to man from an early age. They are never ill-treated. The price of the stallions raised at the breeding stables is estimated at \$t63. On the whole, these liorses are good, but are lacking somewhat in style. The stallions are worked every day from two and one-half to three hours at a walk or trot, and once or twice a week they are galloped five or six minutes. During the covering season they are not exercised at the gallop.

The stallions are divided into two classes, those that remain permanently at the stables for reproduction, and those sent to the stallion depots. The former class consists of 5 English thoroughbreds, 6 half-English-breds, 4 Anglo-Normands, 3 Gidran, and 13 Nonins. The price of serving the best English thoroughbreds is from $\$ 32$ to $\$ 38.60$. In general the gaits are not fancy, as only the gallop is cultivated for horses for the army.

The stable has an anction sale erery year at Budapast during the month of October. Eight horses are annually sent from the stables to the cavaly school at Vienna to be ridden, in September and Oetober, at the hunts with hounds at Holics.

Stallions are furnished by the Government to the communes (districts) at a price ranging from $\$ 1 \geqslant 0$ to $\$ 200$ each, under the following conditions: Good maintenance, which is rerified; maximum price to be charged for covering $\$ 1.16$; to corer not of tener than twice a day; and not more than 88 mares annually.

The Hungarian breeding stables at Kis-Ber have 18,000 acres of land. The specialty of this stable is the reproduction and acclimatization of English thoronghbreds and of halfEnglish thoronghbreds to improve the native breed. The celebrated stallion Buccaneer, purchased in England, in twenty-one yeurs corered 726 mares, and his offspring have Won \$1,100,000, including the English Derby and the Grand Prix in 18r6. Draft horses for agricultural purposes are also bred here. In addition, silver-gray Hungarian cattle and sheep and hogs are raised. There is an anmal sale at the 
stable in June. Since 186\%, tis thoroughbred colts have been sold at an average price of $\$ 90 \% .30$. The highest arerage price was in 1885 , when the remarkable arerage of $\$ 1,865.60$ was reached.

The breeding establishment at Babolna extends orer 10,117 acres. The specialty of this stable is the improvement of races of oriental blood. The results were not satisfactory with Arabian blood, consequently Syrian mares and stallions have been introduced. The stable sends to the stallion depots 50 horses each year.

The Hungarian breeding stables at Fogaras are of the least importance. 'There is much Arabian blood there. The smallness and absence of distinction in the breed is somewhat indicative, perhaps, of its proximity to Turkey. Many sheep of good quality are also raised here.

The stallion depot of Sepsi-Szent-György contains 150 stallions, the other stallion lepots of Hungary about 200 each.

There are also two imperial breeling stables, one at Lipitza and the other at Kladrüber, which raise horses almost exclusively for the emperor's stables. The first raises fullblood Arabian horses, and crosses from this blood with Spanislr stock. The first Arabian stallion sent here was a white 9-year-old taken from Napoleon's stables after the battle of Leipzig. Nearly all the horses at this stable are white.

The breeding stables of Kladriber furnish the heary horses of Spanish breed, which serve for the imperial gala carriages. Their gaits are very poor.

The breeding establishments of Austria, Piber and Radautz, and their stallion depots and stallion posts, have similar organizations and administrations to those described for Hungary.

There are a great number of private breeding stables, but none of very great extent. Among the most important of these may be mentioned the stables of John Becker, Stephen Blaskovics, Eleck Forster, Count Alvis Karolyi, Count Albert Apponyi, and the stables of the city of HódmezöTásárhely.

More than one-half the horses of the army are raised by civilians, without any assistance from the breeding establishments or stallions of the state, as the number of remounts influenced by these government institutions are insufficient for the army. The horses raised by private breeders naturally 
are not so uniform in size, gaits, and other qualities as those influenced by the govermmental breeding.

The saddle horses in general may be said to belong to two distinct types, the Galician and the Hnngarian breeds. The Galician horse is perhaps, for army use, superior to the Humgarian. This is due in part to the fact that the animals purchased by the remount commissions in Hungary, owing to the low buying price, are seldom of the first class. The best animals go to other countries, which make extensive purchases in Hungary. The Hungarian horse is, nevertheless, a remarkable cavalry horse. He has an excellent back aml loins, perfect legs and feet, a large neck, and much style. A striking trait is also the extraordinary uniformity of the type of the various animals influenced by the breeding establishments. Both types of horses are extraordinarily gentle, which results from the absence of brutality in their treatment.

As for the stallions sent by the various breeding stables to the hunts at Holics, they are noted, when the hunts are orel, by their riders, who are army officers, as to their endurance. ability, condition of breathing organs, etc. These notes are considered when the stallions are distributed to the breeding stations, and an unfavorable report may lead to the animal's being put out of service.

The training of the horses for the army begins at 4 years. It is conducted with the greatest method and is very extended. In addition to the military institute at Vienna, each cavalry brigade has a riding school, where officers are taught the principles and practice of training troop horses. This assures great uniformity in the service. A peculiarity of the riding to be mentioned is that all men are provided with a small rattan switch $\frac{3}{4}$ of a yard in length, which is carried when monnted, excepting dress occasions. This does away with the touches of the spur, which are, especially among mares, frequent causes of restlessness.

At the military institute the instruction does not stop with the riding school and training, the young lieutenants being sent during the months of September, October, and Norember to the hunts at Holics. For this purpose the emperor puts at the disposal of the institute his mansion, which has accommodiations for a great number of officers, and stables for 300 horses. The royal breeding stables of the monarchy furnish about 150 stallions, chosen from the animals of 8 or 9 
years, the riding institute contributing also a certain number of horses. The domain keeps 80 deerhounds bought in England. The object sought is not only to practice the officers in riding at the gallop, in order to render them energetic goers, but to acquaint cavalry officers with the amount of effort they can clemand of a horse, and of the strength of the latter. The horses are highly trained for the hunt, the training including the jumping of ditches, hedges, etc. The hunt consists of letting loose, in a very much cut up but untimbered country, a deer caught in the forest on the opposite bank of the March. The animal being out of his country is. hunted, often in sight of the logs. The horsemen follow the dogs, crossing behind them all the obstacles which they encounter. These latter consist principally of ditches, slopes, etc., the most difficult being a ravine from 11 to 13 yards wide, with 2 yards of water at the bottom. The officers ride well at obstacles, are well seated, but yield little to their horses, who jump pressing on the bridoon. The pace is severe, and to follow it good horses are required. These hunts are a military sport, and afford an excellent method of practicing riding in the open. 



\section{II.-BELGIUM.}

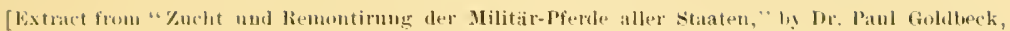
lierlin, 1901.]

The total number of horses in Belgium in 1895 was $271,52 \%$ The type of horse generally raised is a heavy pack animal, known as the Flemish horse in its heavier form, and as the Ardennes horse - the horse of the mountains-in its somewhat lighter form. There has been developed, however, a considerable industry in the raising of fine-bred stock.

As late as the seventies Belgium produced but one-tenth the horses necessary for her cavalry remounts, the remainder being purchased abroad, principally in Ireland. Horse breeding has become so extensive of late, however, that of the 825 saddle horses needed in the army in 1895 , only 399 had to be purchased abroad.

The breeding of thoroughbreds is not very extensive in Belgium, the number of stallions for this purpose in 1899 having been 28 .

In 1901 there were 8 regiments of cavalry, with a total of 40 squadrons, 8 depots, and 4 field-artillery regiments. The number of service horses in 1901 was $10,8 \% 5$, distributed as follows: Cavalry, 5,578; infantry, 258 ; artillery, 2,933 ; engineers, 39; gendarmerie, 1,814; general staff, train, etc., 253 . In time of war the total strength is 143,000 men and 28,600 horses.

The remounts are supplied on the basis that artillery horses are serviceable abont eight year's and cavalry horses nine years.

The size of saddle horses must be from 15 to $15 \frac{1}{4}$ hands for the chasseurs; $15 \frac{1}{4}$ to $15 \frac{1}{2}$ for the lancers; $15 \frac{1}{2}$ to $15 \frac{3}{4}$ for the guides, and $15 \frac{1}{2}$ for the artillery. That of draft horses must be from $14 \frac{1}{2}$ to $15 \frac{1}{4}$ hands.

The supply of draft horses for the artillery is purchased almost entirely at home, the number so purchased in 1895 being 213 . The average price is about $\$ 164$. As high a price as $\$ 231.60$ is paid for specially heavy horses from Ireland, for use with large guns. The number of such animals purchased in 1895 was 19 . 
The horses were formerly purchased from a contractor by a government committee and then assigned to the regiments. This system, however, led to many complaints, as the regiments were unable to keep the quality of their liorses up to the standard. Of late the mamer of procuring horses for the cavalry and saddle horses for the artillery has been such that each regiment has to do its own purchasing. For this purpose a board is convened consisting of the regimental commander, two other officers, and a reterinary surgeon. The draft horses of the horse batteries are purchased by a board of oflicers from various regiments. The remounts for the train are supplied from condemned artillery horses. There are no remount depots, each regiment training its own remounts. An officer is allowed to purchase his mounts where he wishes or he may select them from the horses of the regiment. In the latter case the officer is not allowed for four years to dispose of them unless they become unfit for service. 


\section{III.--CHINA.}

[Extract from "\%ucht und Remontionug der Militar-1'ferele aller staaten," by Ir. Paul Goldbeck, Berlin, 1:n11.]

As in the greater part of Eastern Asia, the horses of China are small, with the exception of those from Turkestan, which are somewhat larger. The following races are distinguished:

(1) The Manchurian race, seldom over 12 hands high. These are enduring little animals and are very sure-footed in rough, difficult country. They are used almost entirely as remounts for the Chinese cavalry, especially in the broken country of northern China.

(2) The West-Mongolian horses. These are considerably larger, sometimes $15 \frac{3}{4}$ to $16 \frac{3}{4}$ hands high, but they are genuine steppe horses and useless in mountainous countries.

The methods of breeding in Mongolia and Manchuriawhich, by the way, are the only parts of China where horse breeding is carried on-is mostly the unrestrained breeding in herds. Although the Chinese settlers raise some horses on their farms, the native Mongol allows his herd (often numbering 1,000 head) to run wild on the range generally without even a herder. Owing to the extreme cold of winter nights, these horses have very long coats (sometimes measuring 2 inches in length) which give them a shaggy appearance. They live by grazing on the steppe grass summel and winter. The Mongol, being zealous to preserve his breed of horses for himself, sells only geldings-never stallions or mares. The geldings are sold by small breeders direct to soldiers or freighters. The large owners sell only in lots to dealers.

The price of horses varies from $\$ 10$ to $\$ 24$. The principal feed consists of a kind of rice mixerl with small black beans. Clover, mixed with chopped straw and dampened, is used as fodder. Hay is unknown to the Chinaman; grass is seldom used, and oats are raised only in the northernmost regions for export to Russia.

In the whole sonthern part of China horses are seldom found even as domestic animals, asses and mules being preferred for 
driving, the Chinamen (except soldiers) caring little for riding. II ules are also bred quite extensively in the north, but it is in the south that they are most valuable, being able to endure the damp climate much better than the horse. 


\section{IV.-DENM.IRK.}

[Reporterl by Lient. Col. W. K. Livermore, Corps of Engineers, l'nited States Military Attaché at ['op'shagen and stockholm.]

The horses are obtained only by purchase. They are obtained in Denmark, Germany, England, and Ireland. In Denmark the horses are bought from breeders and agents, in foreign countries only from horse dealers.

The average price for the ordinary calle horses is $\$ 21 \% .08$, for officers' horses \$233. 44 . Expenses in purchase, amounting to about $\$ 21.44$, are included in this price.

Horses are purchased and inspected by the remount board. For cavalry they are half-bred geldings or mares. The gaits required are the walk, trot, and gallop. There are no regulations for weight. The same regulations apply to the saddle horses of the artillery as to the horses of cavalry.

The draft horses for the artillery are bought only in Denmark and are required to be Danish-bred horses. They are as a rule larger and heavier than the saddle horse and need not be as highly bred. Pack horses are not used. About 400 horses have been recently purchased.

There is no government breeding establishment. In a remount depot on Fyen are kept smme of the Danish-brerl cavalry remounts, of which about 20 are bought each spring when 3 years old. After about a year at the depot they are delivered to the regiments and replaced by 20 others.

The war office has two English thoroughbred stallions and four German half-bred stallions which each year in the cover season are stationed with horse-breeding associations or with the farmers who have an interest in and knowledge of horse breeding. The price for covering is $\$ 2.68$ to $\$ 8.04$. These stallions have been nsed some few years.

There is no import or export duty on horses.

There are about 120,000 horses and no mules in Denmark. About :3, 60 horses are in the army-2.455 in the cavalry. 1,014 in the field artillery, 38 in the train, 28 in the riding school, 15 in the officers' school, and 200 horses of mounted officers outside the mounted arms. 
In case of mobilization for war about 12,100 more horses would be required. About 6,000 are to be delivered by the local governments, the remainder to be bought by the army itself in the neighborhood of the garrisons, and by the remount board in Denmark and foreign countries.

The horses of the cavalry serve on an average 9.7 years; the horses of the artillery and train on an average 9.9 years. There are required yearly 400 horses.

The horses are broken and trained at the regiments, the saddle horses for one year, the draft horses for one-half year.

The brand of the remount board ( $\mathrm{R} \mathrm{K}$ ) is on the left thigh, also the brand of the detachment (E A R, D R, G H R).

The horses are, as a rule, not vaccinated. Inoculating with blood serum has been practiced a few times recently when there were many cases of lung diseases.

The shoes are ordinary handmade iron ones of various forms, as a rule, with calks cluring winter and without cluring summer.

The horses are, as a rule, groomed twice a day.

The forage allowance is 11.02 to 12.13 pounds of oats, 4.41 pounds hay, and S.82 pounds straw a day, of which 4.41 pounds straw is for belding. Compressed forage is not used.

There are no special regulations for officers' horses.

EXTRACTS FROM THE LAW OF $18 \% 6$ ABOUT THE HORSES AND WAGOXS NECESSARY IN CASE OF WAR.

In case of war, the horse owners in the comntry are under obligation to furnish for the use of the army all the necessary horses snitable for war purposes, according to the regulations established by this law.

The number to be supplied for the army in case of preparation for war are apportioned to the city of Copenhagen, the towns, and the connties, according to the regulations established by the minister of the interior. The county coumcils make the apportionment to the communities in each county, also in accordance with regulations male by the minister of the interior.

The magistracy in Copenhagen, the town conncil in each movincial town, the comty comncils in Frederiksberg, Frederiksvaerlk, Lögstör, Marstal, Noirre Sundby, and Silkeborg, and the parish comncil in the rural commmities are to procure at twenty-four hours' notice one and one-half times as many horses, snitahle for war purposes, as the communities are to deliver according to the anportionment at the time.

Every horse owner, in case of war preparations, is bound to comply with the orders of the above-named anthorities immediately, and to deliver for the use of the army all horses belonging to him. Any of the authori ties naned, however, are authorized to huy for the community as many horses as it is obligated to leliver, on condition that those which are not taken are to be retmined. 
The horses which are offered are to be smpplien each with fom good shoes, a corer, girth, and hemp halter.

The horses for the quota are selected by boards, one appointed for each county, and each consisting of three members, namely, the sheriff (in Copenhagen the mayor) as president, a member chosen by the county council (in Copenhagen the magistracy), and a member appointed from the war office.

If the board finds any horses nnsnitable, the owners may present others within one hour after all the horses submitted have been judged; if any of these are also rejected, the board is authorized to purchase as many horses as are lacking to complete the quota, and the community unst make up the difference between the sum paid and that of the valuation. The board, if necessary, may complete the quota by taking the horses from the community itself, in which case the authorities of the community must assist if necessary.

The horses thus procured are delivered immediately at the place of muster to the army.

The owners of the horses thus olntained receive at delivery a pecmiary compensation equal to the valne of the horses, and pail from the treasury, either in cash or by check, the price paid being decided by the county raluation boards according to the market price for horses.

The county valuation boards consist each of three expert and responsible men, chosen by the county council (in Copenhagen by the magistracy).

The anthorities above named, when choosing horses, are, as far as possible, to avoid horses of especially high value.

The transportation and feeding of the horses on the way to and from the places of muster must be provided ly the horse owners, who subsequently receive compensation from the treasury at a rate fixed by the minister of the interior.

If a horse owner fails to comply with orders given in accordance with these regulations, he is fined in the public police court not exceeding $\$ 26.80$ for each horse involved. These fines accrue to the treasury.

The minister of the interior and the minister of war jointly draw up regulations concerning the purchase of horses, and jointly take the necessary measures to execnte the law on the subject.

\section{EXTRACT FROM THE REGULATIONS OF THE REMOLNT BOARD,}

The remount board is to consist of four members, viz, one colonel or lientenant colonel of cavalry, president of the board: one captain and one first lientenant of caralry (the last named may be of the artillery) or two first lientenants of cavalry, or one of cavalry and one of artillery, and one veterinary surgeon.

One of the members shall, if circumstances permit, be garrisoned in the same town as the president, and, like him, exclusively do duty on the board and also perform the duties of secretary. The other memhers serve with their detachments when the board is not assembled.

The board is mnter the immerliate command of the war office.

The duties of the board are:

(a) To purchase the horses necessary for the supply of the army, except those neederl at the riding school and shoeing school. 
(b) To form the inspecting board in connection with the civil members.

(c) To make reports or decisions about questions connected with the remount service and other matters relating to horses when called for by the war office.

(d) To make suggestions about such reforms in the army remount service as it considers advisable and necessary.

The horses are hought in the antumn at an age of from $4 \frac{1}{2}$ years to $6 \frac{1}{2}$ years, and in the spring at from 5 to 7 years.

The height of the horses must be from 15 to $15 \frac{1}{2}$ hands when they are under 6 years; after this age up to $15 \frac{8}{4}$ and 16 hands.

The board can, however, in special cases, make exceptions to these rules governing height and age, but in such cases it must be noted in the report of the board to the war office.

The horses which are sent to troops are put down on a list as officers' horses or cadre horses. With regard to the last named it is noted whether the horses in question are fit to "station out." The horses thus designated must be at least 5 years old and be so strong that, if they are sent to the cavalry, they can be trained for three months and then stationed out, or, if sent to the artillery, be stationed ont and used by private keepers at once.

To insure proper competition for the delivery of horses, the president of the board gives, in the public newspapers, advance notice of each purchasing journey of the board.

In purchasing and distributing horses, it must be considered that threefifths of the horses which are annually sent to the cavalry regiments and artillery regiments are to be stationed out.

The president of the board distributes the purchased horses.

INSTRECTIONS FOR THE SUPERIOR MUSTERING BOARD,

The "board of inspection" consists of four military members and is assisted in some of its duties by three civilian members. The militaly members are, a staff officer, who is president of the board, a captain, and a first lieutenant (or two first lientenants), and a veterinary surgeon.

The civilian members are appointed by the ministry of the interior from each "brigade district."

The board assembles upon the order of the war office.

The duties of the board are:

(a) To make once a year, in at least three places of each brigade district, an inspection of all the horses stationed out there.

(b) To determine whether private keepers have fulfilled the obligations in regard to the horses stationed out.

(c) To revise decisions of the combined regimental muster boards on appeals by private keepers.

The three civilian members conperate with the board in (b) and (c).

LXTRACTS FRON THE INSTRURTIONS FOR TUE COMBINED MLSTERINA BOARIS OF ('AYARY REGIMENTS ANI) ARTILLERY REGIMENTS.

The combined mustering hoarl of each cavalry regiment and artillery regment is to consist of the mustering board of the regiment and two civilian meinbers appointed by the minister of the interior. 
The board assembles only by regimental orders, and, as a rule, in the garrison of the regiment.

The board is to observe the regulations fixed by the war office for the stationing out of the horses to private keepers.

The duties of the board are:

(a) To distribute and deliver horses to the private keepers who meet after notification by the regiment.

(b) To muster the out-stationed horses when they return after notification by the regiment.

(c) To make examinations of the ont-stationed horses when called in by the regiment for that purpose.

(d) To revise the decisions made by inspecting officers, and appealed from by private keepers.

EXTRACTS FROM THE REGULATIONS FOR THE STATIONING OUT OF ARMY HORSES WITH PRIVATE KEEPERS.

The horses must be used in such manner that they can at any time be delivered back to the detachments in serviceable condition. They must be used for riding, light driving, and for field work in good soil. But stone work, work in a thrashing machine, mill work, and public driving are prohibited. The horses must not be let ont by the keepers to others. They must not be absent over forty-eight hours at one time from the place of stationing out without permission from the detachment.

If healthy, the horses must be in good, hard condition, and must be grain-fed, except in the grazing period. If a natural sickness is the cause of a bad condition, such fact must be proved by a certificate from a veterinary surgeon. From the 1st of June to the middle of September, it is allowable to graze the horses. If the horses are called in during this period, they should, if the order is received in time, be stabled and grainfed at least three weeks before the day of assembling.

The horses must be handled with care in every respect and always be kept clean. They shonld always be well shod, and the shoes must be removed or replaced as often as necessary to keep the hoofs in good condition. The out-stationed mares must not be covered.

If a horse gets sick, it must be treated promptly by an anthorized reterinary surgeon, and the detachments must be notified at once, and again when the horse recovers.

The keepers must comply with any order received from the detachment regarding calling in of the horses, but, if circumstances permit it, keepers will be given from two to three weeks' notice.

The delivery of the horses is made to the same board from which received, or to one similarly constituted. The board examines each horse to see if the keeper complied with his agreement and reports the result. The keepers must deliver for each horse 4 good shoes and a serviceable hemp halter. The shoes and halter are supplied by the government.

The horses stationed out will be inspected by a detachment officer at irregular intervals, at points so fixed that no horse need be lrought more than 2 miles (Danish)* from the place where it is stationed.

* One Danish mile equals 4.68 English miles. 
The horses are examined annually by the superior mustering board, which consists of fonr military and three civilian members, the last named being appointed by the minister of the interior. This board selects at least three different localities in each brigade district in which to hold meetings. The horses which this board fincls unserviceable are at once condemned.

For a violation of these regulations a keeper may be fined by the inspecting officer up to $\$ 2.68$; by the combined mustering board up to $\$ 8.04$; by the superior mustering board nu to $\$ 16.08$.

If, on examination, a horse is found to have deteriorated abnormally, any of the boards above mentioned can impose on the keeper a fine equal to the loss sustained by the treasury. In snch a case the horse will, as a rule, be withdrawn from the keeper.

A finding of an inspecting officer may be appealed from to a combined mnstering board, and one of this hoard, if involving a penalty of over s8.04, to a superior mustering board. The sentences of the last named are not subject to appeal.

Agreements to keep horses are linuling for three months. and thereafter also, milil withdrawn after a notice of one month.

Keepers must retain each horse at least one year. If they wish to return him after that time they must give three months' notice to the detachment. No modification of this rule is allowed by the fact of horses' being called in for service. The detachment can, however, call in the horses without any notice, if required to do so by the exigencies of the service.

The only compensation due the keepers is included in the "pay for feed." This is calcnlated by the day and is paid by the detachment intendants each month, either to the keeper himself or to a representative anthorized in writing by the keeper to receive it.

EXTRACTS FROI THE REGLLATIONS FOR THE PLRCHASE OF HORSES BY THE IMMEDIATE AGENCY OF THE DETACHMENT.

The highest average price which may be paid is fixed for the officers' horses at $\$ 268$, for other saldle horses and for draft horses at $\$ 241.20$, but a detachment must always endeavor to obtain the horses at the ordinary market price.

In prurchasing horses (they must he geldings or mares) the use which is to he made of them must be kept in view, especially if they are for saddle purposes or draft purposes. They must be in good condition when purchased.

The following are the requirements for saddle horses purchased:

1. They must be between 6 and 10 years of age.

?. They must not be under $15 \frac{1}{\frac{1}{4}}$ hands and not over 16 hands in height.

3. They must have frames adapted to riding purposes, must have strength, endmance, and lightness, have somml and strong legs, and even, easy, ground-covering gaits.

Horses that amble must not be bonght.

The following inmst be observed in purchasing draft horses:

1. They are to be of the same age and of the same height as the saddle horses. 
2. They must nnite sonnd and strong legs with depth and width of body, have a gromud-covering, even, and fairly easy gait, but with regard to the exterior, as for instance, the length of the neck, and the junction of neck and head, the requirements need not be so rigid as with the saddle horses.

In the advertisements abont the purchase of horses it must be plainly stated that sellers must guarantee against hidden faults, such as asthmatic afflictions, staggers, cribbing, wind-sucking, etc. The seller must be required at the close of the transaction to grarantee against such faults. The horse must be examined before it is received. This examination consists of testing the eyes and the tongue. The tongne must be whole and free from old and deep scars. It must also be ascertained whether the horse suffers from founder, ruptures, as umbilical rupture, etc., or scrotal hernia, or hanging spermatic cord, and, as far as possible, that the geldings are clean cut and the mares not with young.

The muster itself must take place on a parement and not on soft ground, as otherwise lameness may not be detected. Horses that are ricions, shrieking, or ticklish, and horses that, on account of former injury by saddle or harness, try to aroid touch by shaking themselves, must be rejected. Kicking and biting animals must also be rejected.

If practicable, each horse must be tried at the inspection with a rider, or, if a draft horse, with a wagon, to see if he is restive or liable to bolt. If this trial can not take place, the seller mnst be held responsible for each horse's being broken to riding or driving, as the case may be. Horses that are ridden together or driven together shonld be preferred to unbroken horses or snch as are only matched on the spot.

If a detachment of infantry is ordered to purchase horses in the absence of either an officer of cavalry or artillery, or a military veterinary surgeon detailed to assist it, the detachment is anthorized to seek expert civilian help and to pay a suitable salary for it. 



\section{V.-FRANCE.}

[Reported by Capt. T. 13entley Mott, Artillery Corps, [nited stutes Military Attaché at Paris.]

Horse And Mule Census. - The horse census of 1900 gives the following figures:

Total horses in France........................ 3, 203, 229

Total mules in France .... . . . . . . . . . . . . . . . . . . $\quad 24,155$

Total horses in Algeria ........................ 77,123

Total mules in Algeria ............................. 2, 2,199

Total

IMPORT DUTIEs.-The import duty is as follows:

Francs per head.

Horses, stallions, geldings, and mares .................... 30

Foals _...

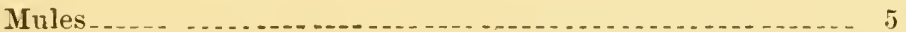

Asses ....

The total effective of horses in the army, both those belonging to the goverument and those owned by the officers, is as follows (190:):

\begin{tabular}{|c|c|c|c|}
\hline & $\begin{array}{l}\text { Ofticers' } \\
\text { horses. }\end{array}$ & $\begin{array}{c}\text { Enlisted } \\
\text { meu's horses. }\end{array}$ & Total. \\
\hline Staffs _- & 4,305 & & 4,305 \\
\hline Military schools & 132 & 2,266 & 2,398 \\
\hline Personnel outside of staffs, schools, and the liue & 575 & & 575 \\
\hline Troops of the line & 17,342 & 106,277 & 123,619 \\
\hline \multirow[t]{2}{*}{ Gendarmes and republican guard } & 702 & 11,047 & 11,749 \\
\hline & 23,056 & 119,590 & 142,646 \\
\hline
\end{tabular}

This is the actual effective of the whole active army, including the gendarmes (military police) and the republican guard.

The effective which forms the basis of estimates for the appropriations is smaller than this, by the following items:

\begin{tabular}{|c|c|c|c|}
\hline & Ofticers. & $\begin{array}{l}\text { Enlisted } \\
\text { men. }\end{array}$ & Total. \\
\hline $\begin{array}{l}\text { General and field officers: } \\
\text { Active army } \\
\text { Genlarmes and republican guard }\end{array}$ & & & \\
\hline $\begin{array}{l}\text { In remount depots available for service } \ldots+\ldots 1,360 \\
\text { of genlarnes and republican guard }\end{array}$ & & 12,407 & $19,94=$ \\
\hline $\begin{array}{l}\text { Remainder aiter deduction of these items from the preceding } \\
\text { ones }\end{array}$ & 15,518 & 107,183 & 122,701 \\
\hline
\end{tabular}


These last figures are known as the "budgetary effective" of horses, becanse on this basis money for the remount is furnished in sufficient sum to replace each year one-seventh the number of officers' horses (subalterns) and one-eighth the number of troop horses. The general and field officers have to provide their own mounts, and the gendarmes and the republican guard are mounted from condemned cavalry horses.

The tables which follow show:

The budgetary effective (that is, public animals in service) for 1902 and the number to be bought in 1902;

The same items for each branch of the service, for the stafts, schools, etc.;

The average prices allowed this year for the several categories of animals.

The various items are given separately for officers' hor'ses and troopers' horses, and again, for those intended for service in Algeria and Tunis.

Each year are replaced one-eighth the number of horses for troops, one-seventh for officers, and one-eleventh of the stallions and brood mares; that is, each year there are condemned 14 per cent of officers' horses, 12 per cent of troop horses, and 9 per cent of stallions and brood mares. In other words, for troop horses (saddle and draft mules and horses) the average length of service is considered to be eight years, for officers' horses, seven year's, and for breeding horses eleven years. The condemnation and replacement for all arms is effected on that basis.

The number of horses and mules for the various services bought in the last ten years has not greatly varied, so that the tables represent not only the figures for this year, but also a fair average for other years.

In examining the item "horses for infantry, officers," it is to be remembered that all infantry captains are mounted.

There are about 4,000 mules used in the army for all purposes.

The officers' horses with which these tables deal are the horses of subalterns: generals and field officers buy (usually from the state, as explained later on ) their own horses; hence the appropriation for these horses is not expended, but only advanced. To this end about 1,000,000 francs are annually made available, but this amount eventually returns to the treasury. 


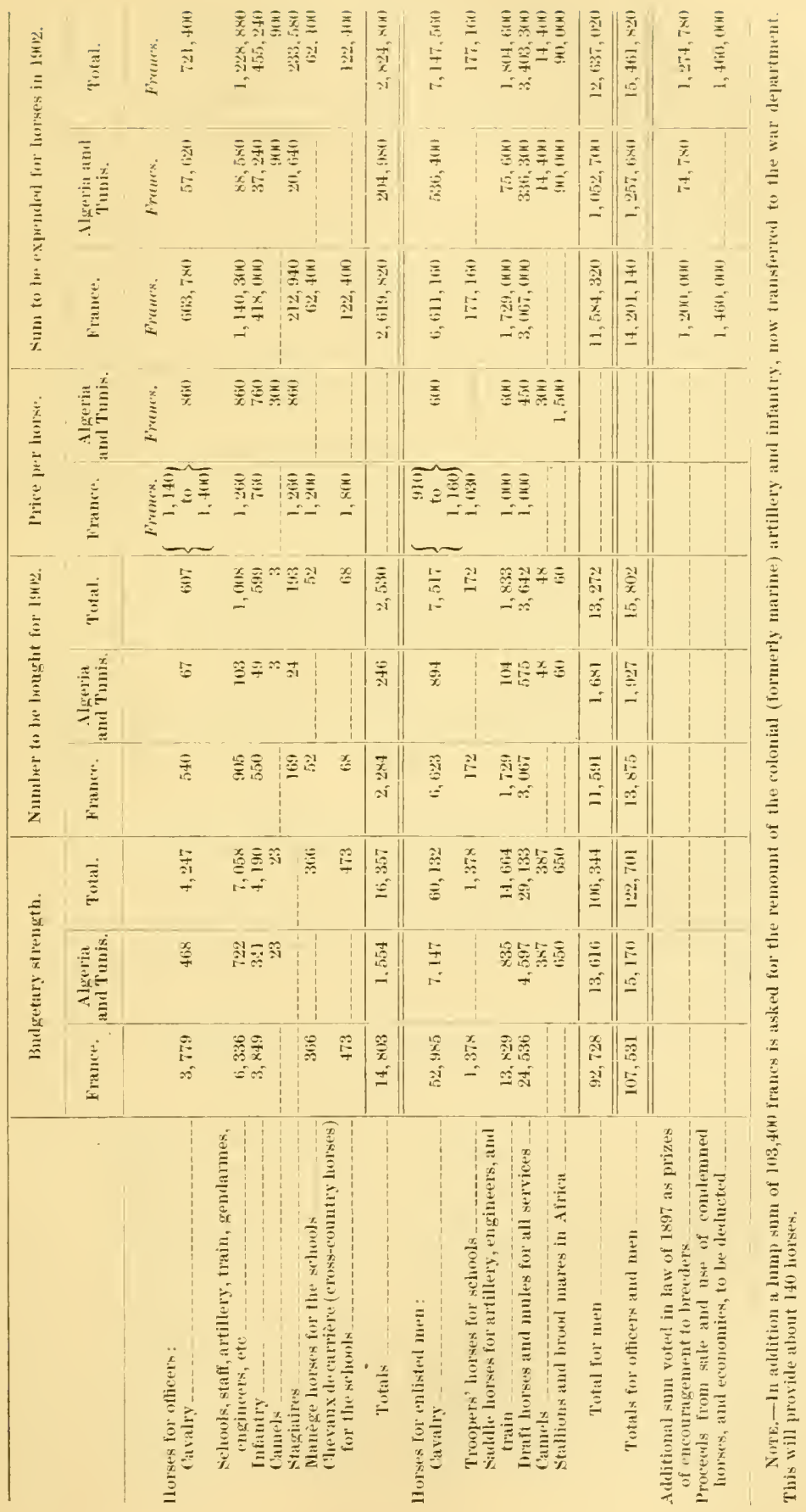




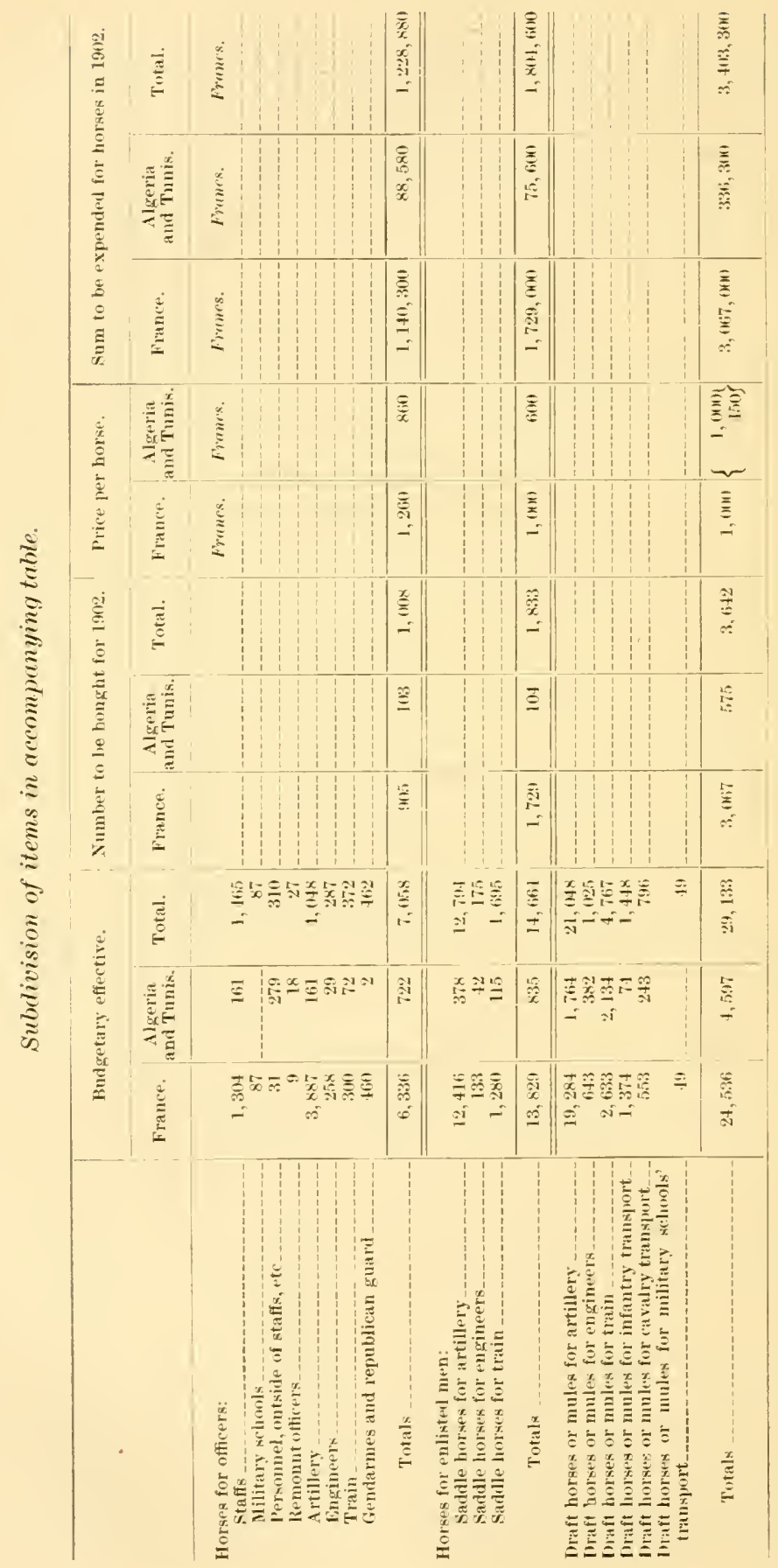


THE REMOUNT SERIICE IN FRANCE.

It may be said that all horses and mules for the French Army are bought in the open market. The only exception will be mentioned under the heading "Studs and Breed Farms."

The remount service is charged with the purchase and delivery of all horses and mules needed for the military service. For the purpose of the remount, France is divided into two "circumscriptions" or districts, each of which is commanded by a colonel or lieutenant colonel of cavahry; Algeria and Tunis constitute a third district. In these two districts there are 10 depots and 11 subdepots or "annexes," each depot with its annex being commanded as a rule by a major of cavalry. Besides these depots belonging to districts there are 6 depots (having 11 annexes) which are commanded directly by the inspector general of the remount service.

For the purpose of discipline and police the remount establishments are under the authority of the corps commanders.

Personnel of the Service.-The personnel is as follows:

1. An inspector general holding his position permanently and an adjoint (maijor general and brigadier general, respectively);

2. Commanders of districts (colonels or lieutenant colonels);

3. Commanders of depots (with command and supervision of one or more annexes; generally majors of cavalry);

4. Commanders of annexes (captains, or veterinarians of the second class);

5. Eight remount companies (five in France, three in Algeria and Tunis);

6. Enlisted men belonging to mounted organizations detailed for duty at remount depot annexes.

The depots are intended to receive and care for the horses bought by boards until ready to be sent to the troops (they are never kept longer than twenty days); the annexes to receive horses under 5 years, to keep and train them from the time they are bought until ready for delivery to the troops, and to deliver them.

The inspector general of the remount service directs the service in France, Tunis, and Algeria, being responsible to the minister of war only, with whom he communicates directly. Commanders of districts and of depots not in a 
district may correspond directly with the minister on current matter's.

The commander of a district supervises the work of his remomnt depots, apportions the men of the remount companies in his district, and has in general the attributes of command, visitation, and inspection.

The depot is the business mit of the remount service. Its commander is regularly a major of avalry detacher; he has under him a captain or lientenant of cavalry detached who bears the designation of "permanent buyer" (at some depots two such officers are employed), a veterinary, a disbursing officer, and a detachment of remount men.

Horse Bonrds. - The depot commander and his assistant are permanent members of the board for buying horses all the year round. During the active period, from October 1 to Mlay 15, when the board trarels about the country, a third officer is usually detailed from a mounted command in the region, and attached as "temporary buyer." Depots which buy horses chiefly for the artillery may be increased by the addition of a captain or lieutenant of that arm; he may be permanent or temporary buyer. A horse board must in no case, lowever, have more or less than three members. In order that the requisite three members may be had for buying horses that may be presented at any time at the depot, for attending fairs, etc., the commander of the depot mar, when he thinks it advisable, appoint his disbursing officer or veterinary as third member, or he may ask for the detail of an officer from the troops in the vicinity. He may make this request directly to the commanding officer concerned. It is to be noticed that horse boards do not use a veterinary in their regular buying trips.

The depots are scattered throughout the country at points best adapted for receiving and caring for the animals purchased, and are all in the horse-raising sections. The most important annex is at Suippes, department of Marne, where a great part of the young horses are collected and trained. At Saumur there exists a special breaking and training school for horses intended for the use of the other military schools and for the use of general officers. Unmanageable horses from the cavalry regiments are also sent to Sammur for speeial training. The extent of these lepots and the money expenditures involved in their operations may be 
realized when consideration is given to the fact that annually there are disbursed for horses and mules for the French army about $15,000,000$ franes.

Remount Coupaxies. - There are eight remount companies, all composed of selected cavalrymen, but they are not comted in with the fighting strength of the cavalry. The strength of each company varies, according to location. A company is commanded by a captain with a variable number of lieutenants. Four of them are divided among the various depots, one serves for all the military schools and three are assigned to Algreria and Tunis. Their principal duties consist in caring for the animals at the depots and conducting them to the regiments or batteries. The company which does duty at all the schools is essentially marle up of stablemen and grooms, but the atministrative control of the company remains with the company commander, through his lieutenants or other detachment commanders, subject to the ultimate direction of the general officer commanding the remount service. At depots, the depot commander controls the companies or detachments of the remount. Officers as well as men all come chiefly from the cavalry and are selected.

Mode of Purchase.-Amnually, the minister of war fixes the total number of animals to be purchased and designates the commands which are to be supplied, as well as the dates and sources of delivery. According to this allotment the animals are bought by the boards and sent to the depots or delivered directly to the commands. The former is the regular method, the latter being used only when considerable saving of expense would ensue.

Before starting out on a trip which will require the risiting of several points, the board senils notice of its route and the dates when it may be expected at each locality to the "préfets" or mayors, who post notices to that effect so as to give as much publicity as possible.

The method of making the purchase is describerl at length on page 250, "Mode of Operation of Horse Boards in Algeria."

SPEcifications. - The official specifications governing the boards in their purchases relate only to the age and height of the horses; for the most part the whole matter is left to the judgment of the members of the board. These officers are very carefully selected horsemen and they are supposect 
to know better than any orders could teach them the requirements of a horse for the military service.

The following rules are made for guidance of the boards:

Purchases for the military service are made only of geldings fully cured from effects of castration, and of mares not in foal; the horses must be of French origin, free from blemish, with mane and tail uncut, and must have the conformation and quality requisite for the arm of service to which they are destined.

A board is authorized to pay a higher price to a seller who presents a young horse-especially one coming 5 yearsbridled and saddled, broken to the three gaits, and uniting the conditions of a good military horse.

Height.-The height must be as follows:

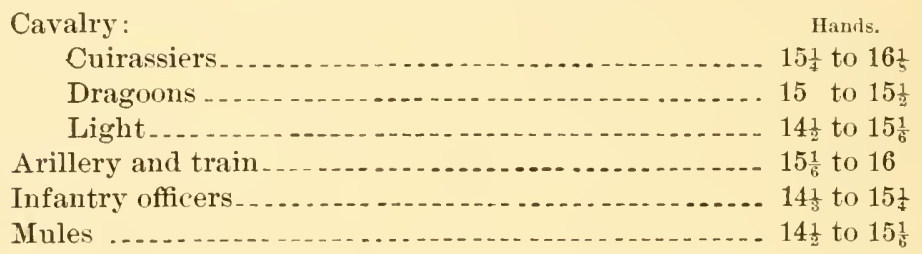

AcE.- - Horses over 8 years old will not be bought. Officers' horses (all arms), cavalry horses, and horses for the horse artillery of independent divisions of cavalry, are bought any time after October of the year they reach 3 years of age. Sometimes, by permission of the minister, a few of these horses may be bought after July. About 10 per cent of the horses annually bought are 6,7 , or 8 years old; the rest, 90 per cent, are 5 years or under.

Artillery horses, except tho-e just mentioned, must be over 4 years, and are bought after January 1 of the year in which they reach that age.

The boards are anthorized to buy thoroughbred horses after the 15th of November of the year in which they reach $2 \frac{1}{2}$ years, provided the seller gives a certificate that the animals have been trained. These thoroughbred horses are divided as equally as possible among regiments, and are intended for officers' mounts. These animals, if mares, are sent direct to the regiments; if stallions, to a depot to be castrated, where they remain till healed, after which they are sent to the regiments.

Ordinarily the horses are sent as bought to the depot, where they are kept under observation (never more than twenty 
days) for vices or diseases. The horses over 5 years are then sent in convoys to their destinations; those under that age are sent to the annexes to be handled and kept till the month of October, when they are sent in lots to their destinations. The remount men are used to take the horses (usually by rail) to their destinations, or the organizations may be asked to send men for this duty. Generally one man is sent for every four horses. Horses undergo no training at the depots. When horses are received at the depots the greatest care is exercised in the matter of hygiene. Horses that are at all sick are separated from the others; lots are kept together; each horse has his own grooming kit, which is used for him alone; the watering troughs are regularly disinfected, in fact every precaution is taken against the transmission of disease.

Besides the regular purchases by the remount service, special animals may be purchased by any of the mounted troops, but at a price not exceeding the annual average fixed amount. This is accomplished by a commission within the regiment composed of a field officer, a captain, and a veterinary surgeon, who are appointed by the brigade commander.

The authorities of the cavalry school at Saumur are also authorized to purchase, through a commission appointed by the commanding general of the school, horses of pure blood or other's of suitable quality. Indeed, the better-bred horses are not purchased largely by the remount service, as the prices asked are higher than those authorized to be paid by that service, so that special authority has to be obtained for the purchase of superior animals, whether at the school, in the regiment, or by the remount service.

In all purchases whatsoever a written guarantee of soundness and suitability is always exacted from the seller, who, also, is required to give his name, address, and residence. That, together with the date and place of purchase, the price paid, etc., form the basis of the entry in the horse-descriptive book opposite the animal's number, which number is branded on his near forehoof as soon as he is bought. Later the number of the regiment and the initial of the arm are branded on the off forehoof. During the purchasing period an abstract of the animals purchased is sent to the ministry of war every fifteen days.

Colts dropped by mares at the depot are taken up on the returns and are sent to Suippes, the special depot for young horses. 
White or gray horses are not bought if the supply of suitable horses of hardy color is sufficient for the number needed.

As much as 1,000 franes are allowed for a mule in France; 450 franes in Algeria and Tunis.

Pack mules for the Alpine mountain batteries and Alpine chasseurs à pied are bought in the Alpine region. Mules bought in Algeria and Tunis are chiefly for the train.

About 250 horses are bought each year in France for use in Algeria and Tunis. No discrimination whatever is maile against mares in the purchases.

At the depots the horses are classified and grouped according to the arm of the service for which they are intended, after which they can not be changed without a special report. Horses over 5 years are usually delivered to the regiments or batteries in separate lots of 20 or more, as bought, each animal accompanied by his descriptive list. Horses under 5 years are kept at the annexes and sent in one lot to their destinations on October 1 of each year. On arrival at the stations of the troops, the herd is at once looked over by the veterinary surgeons, who certify to the sanitary condition of the animals, and a copy of the certificate is retmned to the issuing rlepot for file. After the animals have been a month in the hands of the troops, a special report as to their characteristics is made to the ministry of war through official channels. Horses which, after delivery, are found to be musound or of vicious habits, are pronounced upon by a board of experts and the seller is obliged to take them back and pay expenses.

Condeminatoxs.-Throughout the regiments and batteries animals may be condemned by inspectors general at any period, although in the cavalry it is usual not to present such animals oftener than once a quarter, and it is customary at such periods to make requisition for animals to replace those which are to be condemned or which have died. Any animal, however, which has come from the remount service within a year and has become unfit for service from any but accidental causes, must have a special report of the case made to the ministry of war. Cavalry horses which have become unfit for saddle purposes, but which are otherwise still sound and available ats draft animals, are reported for transfer to the artillery or to the train, but they must be ascertained to be susceptible of at least two years' additional service as such. All condemned animals are sold within fifteen days after 
approval of comlemmation, each animal being accompanied by his descriptive list, which must show the nature of his disability, accompanied by a certiticate that the state guarantees only that the animal is free from grlanders. The proceeds of the sales are depositerl by the intendance oflicer in the nearest subtreasury. 'The condem ned animals are suitably marked.

Funds. - The items of expenditure for the remount service to be considered and accounted for are: The purchase of animals, expenses of travel of boards, fees to veterinaries and troopers (really extra pay), extra pay to noncommissioned officers, brokerage, purchases of halter's or yokes, revenue stamps (for receipted bills), adrertisements, etc., and feed for animals in transit, all which is provided by the amnual budget.

In addition thereto is an allowance of harness and equipments, tools, stable fumiture, merlicine, instruments, etc., for each depot or subdepot according to its needs, and a money allowance or fund for keeping it in order, for horseshoeing, etc. Returns for all expenclitures are made quarterly, hut the supplies are based upon monthly estimates.

Books.-The principal books kept are those relating to the special functions of the remount service, such as a register of animals purchased or turned in, a register of issues to officers or to troops, a register of colts dropped in the depot, a register of animals returned to sellers for vicious habits or unsoundness, a register of animals sold to oflicers, a register showing changes in original classification, a register of mares in foal and animals lent to civilians, a register showing transfer of animals from one depot to another by order of the minister.

Every month a report is sent in by the corps commander of each army corps of the number of horses or mules purchased and issued within his district, the number remaining on hand to be disposed of, and, annually, on the 10th of January, a report of the number of condemned animals sold during the year.

Horse boards are instructed to be careful to send horses of similar type to each regiment and even to each brigarle of cavalry, and to see that not only each lot fills this condition but that the lots sent in succeerling years do likewise, so that the horses of the mits may be of homogeneous types.

As regards artillery draft horses, in time of peace, care is taken that all are also fit for the saddle, becanse they are then 
used alternately as near and off horses; while upon war mobilization they are all to serve as near horses and the off ones are to be supplied by requisition.

A distinction is made between sergeants' horses and those for corporals and men. The former should be really dragoon or cuirassier horses and should be chosen with an idea of furnishing material also for the remount of officers of a regiment, the latter horses need not have so much regularity or be as well-bred.

Hor'se batteries demand especial attention, as they are called upon for long marches at rapid gaits on all sorts of ground. Only horses of particnlar resistance, quickness, and mettle are chosen for this service, and colonels of regiments and commander's of remount depots are directed to be careful not to furnish field batteries with horses suitable for horse batteries, since the latter horses are not easy to find.

AnNexEs.-These are establishments of transition where young horses (under 5) are kept from the time they are bought until they are delivered to regiments. They are maintained on ground belonging to or rented by the gorernment, or the commune. Their number is regulated from time to time by the minister of war. An important part of the duty of a depot commander is the supervision of his annexes, and he is expected to visit them frequently and unannounced.

An annex is, according to its importance, either commanded by a captain of cavalry or managed by a veterinary of the second class; but there is always a veterinary on duty at each annex. The enlisted men are recruited for this special service, being chosen from jockeys, stablemen, etc. They are given very little military instruction, most of their time being devoted to the horses. There is also usually a small detachment of men detailed from the organizations supplied by the ammex. The number of men is generally one for erery ten horses.

The annexes are kept with scrupulons regard to health and cleanliness. They have ample paddocks in which the young horses are turned ont whenever the weather is not bad. The horses are also given some work on a small track. They are hardly ever mounted, but are handled as much as possible and initiated in military habits. Their grooming is not very thorough, as the strength of the detachment would indicate, but they are kept clean and in grood health. 


\section{REMOUNT DEPOTS IN ALGERIA AND TUNIS.}

The operations of the remount service in Africa are in general similar to those in France, and need no further description in addition to what has been said. The depots supply the mounted troops stationed in Africa with practically all their horses and most of their mules, and sencl about 430 mules each year for the train in France. This is only about oneeighth of the total number of horses and mules bought each year in France for the train. On the other hand, a few artillery horses and mules are sent each year from France to Africa.

Specifications.-Horses purchased by the depots must combine the qualities required for the army as regards distinction, strength of back, and sturdiness of frame, must be of Arab, Barbary, or Arab-Barbary origin, whole or castrated, exempt from blemishes, and with flowing tail, that is, with the dock of the tail intact. Mares are not bought for troops. The great majority of African troops are mounted on stallions and a small percentage on geldings.

AGE Lmits. - Not less than 4 and not more than 8 years. It is understood by the stipulation that only horses completing their fourth, fifth, sixth, seventh, or eighth year of age in the current year will be admitted. Nevertheless, horses of 4 years should be bought only when the supply of horses of 5 years is not sufficient to meet the demand. In any case they will not be admitted before the 1st of May in the year in which they reach the age of 4 .

The same rules apply to the purchases of male and female mules. In regard to mules for the colonies, however, the conditions as to age and size may be modified by the minister.

Height.-The height must be as follows:

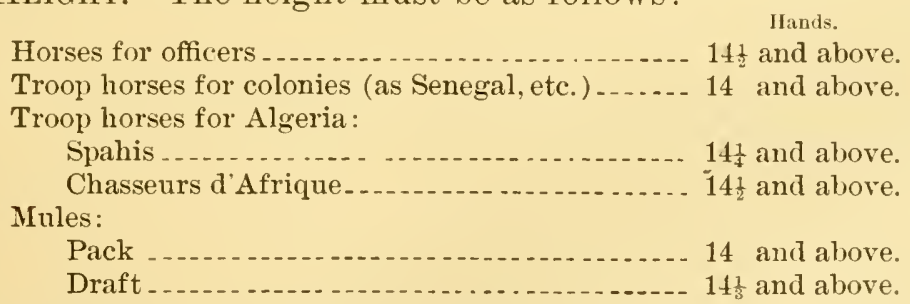

A tolerance of $\frac{2}{5}$-inch is allowed for animals of excellent conformation.

All the horses are sent, within twenty days, from the depots to their destinations in bunches of from 10 to 20 from time to 
time during the whole year, there being no "establishments of transition" as in France.

An effort is made to continue the same type and breed in each regiment.

The Algerian spahis furnish their own horses. For loss incident to service they are reimbursed in the sum of 500 francs each. They are furnished forage or commutation. Each squadron of spahis has a remount fund, coming from various interior economies, to cover losses, to pay for horses for indigent members, etc.

Mode of Operation of Horse Boards in Algeria.The operations of the horse board are carried on in public in the most favorable places. Order is maintained by police (gendarmerie, spahis, or other mounted men, according to the territory occupied). The members of the board wear uniform. The horses are examined individually. The places chosen for the reception of the horses are selected in such a way as to spare the breeders too much trouble in bringing up their horses, the interests of the treasury being kept in view. Wherever practicable, these places are near a railway station. The horses presented are accepted only upon a majority vote of the members of the board. If a horse is adjudged acceptable, each member notes the fact in his pocketbook with what seems a fair price for the animal. The bases for the purchase prices are determined by the budget. The horses offererl are received by the board without discussion, in accordance with memorandums which the members hand to the president. The memorandums state whether a horse is adjudged acceptable or not, and, in the former case, the sum of money it seems to be worth. The president of the board receives the memorandums of the members only after he has drawn up his own. The members of the board, in making their estimates, should not lose sight of the fact that the budgetary standards of price are but averages, and that it is permissible to go below or above them. The price of the horse passed as fit to be bought is provisionally fixed by the president. This price is the exact average of the prices set down on the memorandums of the members.

When one of the members, other than the president, consider's that the horse is not acceptable, the animal may nevertheless be bought, but in such a case the name of the member who has voted adversely, with his reasons therefor, are 
inscribed on the register of purchase. When, however, the president himself considers that a horse is not arceptable the animal is refused on his opinion alone.

Before letting the seller know the amount of the average price decided, the president asks him how much he expects to get for his horse and communicates his reply to the other nembers of the board. When the latter have decided, by a last and rapid examination, that the seller's demand is in agreement with or in excess of the first estimate, the president asks each of the members whether he maintains or modifies his estimate, and then finally fixes the average figure of the board, which must be accepted or refused, without discussion by the owner of the hor'se. Nevertheless the price demanded by the seller must be considered as a maximum which shall never be exceeded by the purchase board in fixing the sum to be paid. The board should use great reserve in making refusals, so as not to depreciate the value of the horse by publicly pointing out what are considered to be faults. The board should confine itself to declaring that a horse is not suitable for the service of the army, unless the refusal be based on causes altogether apparent, such as faulty build, insufficient or excessive age, etc.

In the course of the operations, the president of the horse board should neglect no opportunity of entering into relations with the breeders and discussing with them all matters relating to the horse-raising industry of the district.

When the price is accepted by the seller, it is proclaimed in a loud roice by the president in presence of the public. Exception is made, however, in the case of natives, so that no offense may be given, in this connection, to the amour propre of certain among them.

A description of the horse is then taken, but this description must be verified by the commanding officer of the depot.

At the end of each session held in the open air, the horses bought are collected in the order in which they have been received, and a serial number is lightly branded on the left side of the neck of each. After the horse has reached the depot, his number is branded on the near forehoof. Later the number of the regiment and the initial of the arm are branded on the off forehoof.

In the colonies outsirle of Algeria and Tunis the remount is effected by means of purchases in the colony if suitable 
horses are obtainable, otherwise the necessary number is sent from France and Algeria.

\section{PEMOUNTS OF OFFICERS.}

To officers of all grades and arms and to all military officials and employees horses are furnished for the most part gratuitously or else upon easy terms.

Horses are furnished in three ways: (1) gratuitously; (2) on the installment plan; (3) by sale outright.

The number of horses which officers are entitled to acquire and keep at the government expense is given in the table following:

\begin{tabular}{|c|c|c|}
\hline & $\begin{array}{l}\text { Peace } \\
\text { footing. }\end{array}$ & $\begin{array}{l}\text { War } \\
\text { footiug. }\end{array}$ \\
\hline Major general & 6 & \\
\hline Brigarlier general & 4 & \\
\hline Colonel and lieutenant colonel (staff) $\rightarrow \ldots$ & 3 & 3 \\
\hline Gaptain (staff) & 2 & 3 \\
\hline Colonel or lieutenant colouel of infantry & 2 & 2 \\
\hline Colonel or lieutcnant colonel of catvalry or artillery & 3 & 3 \\
\hline Major of infantry & 1 & 2 \\
\hline Major of cavalry or artillery & 2 & 2 \\
\hline Captain of infautry & 1 & 1 \\
\hline Captain of cavalry or artillery & 2 & 2 \\
\hline Lientenant of cavalry _. & 1 & 2 \\
\hline Lientenant of artillery & 1 & \\
\hline Surgeon wajor of infintry & 1 & 2 \\
\hline Surgeon major of artillery & 2 & 2 \\
\hline
\end{tabular}

1. Gratuitous.-All mountel officers below the grade of major are mounted gratuitously on both peace and war footing; for those above this rank, the number of horses required on a war footing is furnished gratuitonsly, prorided the officers own already the horses required on a peace footing. All reserve and territorial officers are mounted gratuitously upon war mobilization. Officers who are entitled to gratuitons mounts, but who prefer to provide their horses at their own expense, lave to make in writing application for this privilege. Some officers who can afford it prefer to do this as they then have complete control of their mounts and can use them in harness or lend them out, which in case of horses furnished by the state gratuitously is absolutely forbidden.

If among the horses furnished to his regiment for officers' mounts an officer does not find a horse that would suit him, he can buy one in the market and present it to the horse board for purchase. If the horse is accepted, the officer is paid back the estimater price within the regulation amount 
allowed, and the horse is regarded as the property of the state furnished to the officer as a gratuitous mount in the regular way and is subject to the usual restrictions. Such a horse can not be exchanged, returned, or condemned within eighteen months without anthority of the minister.

2. On the Installuent Plan.-All officers above the rank of captain are obliged to own the number of horses indicated in the table given above. Upon his promotion, a captain can buy at a reduced price (depending upon how long the horse has been in his hands) the mount formerly furnished him giratuitously, paying either outright or by installment, all these amounts being minuteíy regulated according to how long the horse has been in service.

Any officer above the grade of captain can buy on the installment plan from the remount service the number of horses to which he is entitled, selecting the horses from among those on hand for the purpose, and paying $\$ 3$ a month per horse. The horses remain the property of the state, which not only maintains them, but even replaces them if lost incident to the service. When the total of the installments equals the price paid for the horse by the state, plus one-tenth, he becomes the property of the officer.

Officers may select in the market any horses which they would like to take on the installment plan, and submit them to the boards. If a horse is accepted, the board pays his estimated value and then the officer receives his mount under the conditions just stated. Such a horse may not be returned or condemned within eighteen months.

3. By Sale Outright.-All officers above the grade of captain can select from available horses provided by the remount service the number to which they are entitled and purchase the horses at the estimated value, paying the price in two installments. These horses become their absolute property, but if they desire to sell the horses the state has the right of refusal.

Subalterns who have renounced their right to gratuitous mounts are obliged to buy their horses in the market. Any officer may keep at the expense of the government one horse above the number allowed him by regulations, provided he has bought his horses in the market.

The minimum age of horses furnished by the state to officers by either of the three methods above cited is as follows: Four 
years for thoroughbred horses; 5 years for Alabian or Barbary or full-bred Anglo-Arabian horses; if years for horses of all other breeds.

Officers are pecuniarily responsible for accidents resulting in the loss or injury of horses which they hold as property of the state, if such accidents result from their own fault. A permanent board of survey is provided for passing on all such matters. If the officer is relieved from responsibility he is furnished another horse. Another horse is likewise furnished when the horse the officer holds is condemned as unfit for service.

Corps or brigade commanders may, under certain restrictions, authorize officers to exchange horses.

Establishunents w Hich Mocxt Officers.-In general an officer of a mounted organization may select his mount from the whole number of horses available in the organization. with the exception of those already assigned to officers or noncommissioned officers or those reserved for the remount of ufficers not belonging to a mounted organization. General officers, if they do not buy their horses in the market, are permitted to choose among the horses of the war school at Paris, at Saumur, or in the remount depots of Paris and Suippes, where special classes of horses known as "general officers' horses" are trained for their purposes. At the various schools officers generally choose among horses furnished to the school, omitting of course the expensive "chevaux de carrière" and "chevaux de manège." Officers not belonging to mounted organizations are mounted from horses of designated mounted regiments; thus officers of the general staff, of foot artillery, engineers, etc., are mounted by the light artillery and dragoons: infantry captains, from horses of French blood in the light cavalry, etc. Field officers of foot organizations are mounted from the animals selected for the purpose in the cavalry regiments of their region. They may also select a horse from a depot if they pay for his delivery. Officers of the remount service choose their horses at the depots and it goes without saying that they are well mounted. Officers who are mounted gratuitously may not choose among horses intender for the officers buying their mounts for cash or on the installment plan. Officers choose, in general, according to rank. 
Gray horses are ridden by officers of the noncombatant category-surgeons, quartermister's, commissaries, ete.

Under no circumstances is an officer allowed to sell a horse obtained from the state, directly either to a civilian or to another officer; the sale must be effected through the remomnt service.

A horse, after having been once assigned, is rarely taken from the trooper without his consent.

About 250 thoroughbred horses are bought by the remount service each year for delivery to officers.

In mounted regiments the extra horses, subject to sale or assigmment to officers, are divided into five classes.

1. Those to remount the officers of the command

2. Those to remount officers of the general staff and of engineer troops, besides ten horses of the lots pertaining to the cuirassiers and the dragoons (extra-heary animals) reserved every quarter to remount officers of the gendarmerie.

3. Those to remount infantry officers (of the rank of captain and above), intendance officers, surgeons, administration officers, all at the rate of ten horses per regiment of the light cavalry (chasseurs ì cheval and hussars).

4. Those specially selected for general officers, the cavalry schools, and the superior war school.

5. Those intended for the enlisted men of the gendarmerie being aged horses of 12 years or more and not possessing the necessary aptitude for war service in their arm (cavalry), but still susceptible of good use in time of peace, particularly for the gendarmerie (mounted military policemen). The horses of class 5 are never, for any reason, again given out to caralrymen.

These classes are made up and their numbers completed every quarter. Horses turned in by officers aot belonging to a regiment are classed with those of the category to which they properly belong. In giving out horses from any of the classes, priority of the applications is observed.

Officers who are required to own their mounts, particularly majors and those of higher rank, with the exception of general officers, are granted, besides forage, shoeing, and veterinary expenses, an extra allowance at the rate of from $\$ 6$ to $\$ 1$ ? per month. In addition to this allowance for horses owner, all ofticers who are required to be mounted, whether they draw their mounts from the state or purchase them, are allowed 
the cost of the first horse and equipments, which cost varies, according to grade, from $\$ 90$ for a newly appointed sublieutenant up to $\$ 230$ for an officer of cuirassiers.

\section{"CHEVAUX DE MANÈGE" AND "CHEVAUX DE CARRIÈRE."}

A regular effective of about 366 horses of the first category and 473 of the second is maintained for the use of the schools where riding is taught, as, for instance, Saumur, St. Cyr, the artillery schools at Versailles and Fontaineblean, the war college at Paris, etc.

The "cheval de manège," as the name indicates, is a riclinghall horse, used for this purpose alone and never for outdoor work. The "cheval de carrière," on the other hand, is used solely for outdoor work, in the outdoor riding school (a regular adjunct of the "riding hall" at all schools and most cavalry posts). The nearest English equivalent for "cheval de carrière" is "cross-country horse." These horses are selected and trained with great care and will exhibit to the instructor the smallest mistake committed by their riders. They are of course taught to jump ordinary obstacles, but they are not used in the military steeplechases nor as troop horses. The ideal type of the "cheval de carrière" is the Irish hunter. The arerage price allowed for this type of horse is about $\$ 360$, but authority may be and often is obtained to pay much more--even as high as $\$ 500$ and $\$ 600$. The price allowed for the riding-hall horse is $\$ 250$, but often more is paid. Some magnificent animals of both types are to be seen at the schools. Besides these two types of horses, there are maintained for the schools about 1,375 "troop horses" for outdoor drills and exercises under arms

\section{STUDS AND BREED FARMS.}

As already stated, horses are obtained for the French army almost wholly by purchase in the open market. The only exception is furnished by a few young horses, raised on the military breed farms in Algeria and Tunis, which are found unsuitable for breeding purposes and are, therefore, sold or turned over to the troops.

Government STUDS.-The 22 government studs existing in France proper are administered by the department of agriculture and do not furnish horses to the army. The object 
of these stids is to furnish good sires of every race to horse breeders, especially small farmer's throughout France, for the purpose of improving the blood of French horses. The services of the stallions are paid for, by the owners of the mares served, at rates fixed according to the value and reputation of the stallion.

Especial attention is of course paid to selecting stallions suitable for military purposes, because the government wishes to increase the production of such animals and to encourage breeders to raise them. A ready market and good prices exist for military horses. But the army has nothing to do with these establishments and is not supplied by them.

ARMy Studs AND Breed FArus.-These exist only in Tunis and Algeria, and the former are maintained at and in connection with the remount depots in those countries. There are four depots, three branches, two annexes, and two breed farms, located as follows:

\begin{tabular}{|c|c|c|c|c|}
\hline \multirow{2}{*}{$\begin{array}{l}\text { Kemount ilepots and } \\
\text { studs. }\end{array}$} & \multicolumn{3}{|c|}{$\begin{array}{c}\text { Establishments attached to these depots } \\
\text { and studs. }\end{array}$} & \multirow{2}{*}{$\begin{array}{l}\text { Military divisions in which the } \\
\text { depots, annexes, aud farms } \\
\text { are located. }\end{array}$} \\
\hline & Branches. & Annexes. & Breed farms. & \\
\hline 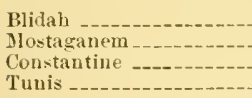 & $\begin{array}{l}\text { Miliauah }- \\
\text { Oran } \\
\text { Setif - }\end{array}$ & $\begin{array}{l}\text { Mustapha - } \\
\text { L'Allelik -- }\end{array}$ & $\begin{array}{l}\text { Tiaret } \\
\text { L'Allelik }\end{array}$ & $\begin{array}{l}\text { Algiers. } \\
\text { Oran. } \\
\text { Constantine. } \\
\text { Tunis. }\end{array}$ \\
\hline
\end{tabular}

The breed farm is maintained for the purpose of rearing stallions for the government studs. The expenses of all these establishments come from the appropriations for the army, the number of stallions to be maintained being fixed in the appropriation bill each year; for 1902 it is 600 . One-eleventh of these animals is replaced each year, the average price this year being \$2.22.50 per stallion, or the total for the 5.5 stallions required in $1902, \$ 16,08 \% .50$.

The ofticial reason for the existence of these studs in Algeria and Tunis is "to increase the number and improve the race of horses in those countries."

As each stud is attached to one of the remount depots, the same personnel of officers and men suffices for both services.

PERsonnel. - This consists of a colonel or lieutenant colonel, director of the remount and stud establishments, who has the same functions as an officer commanding a remount circum scription in France. He directs and controls the operations of the various establishments in all that concerns the purchase 
of the horses and their hygiene, appoints the noncommissioned officers, grants or forwarls applications for leaves of absence, makes recommendations to the inspector general of the remount service, inspects the various depots, presides over horse boards when he sees fit, makes recommendations to the inspector general as to stallions which should pass from the remount to the stud service, advises the inspector general as to the composition, number, and location of the stations, and supervises the matter of service of the mares. His reports go, one copy to the inspector general of the remount service and the other through the general commanding the nineteenth corps (Algeria) to the minister of war.

The general officer, who is the permanent inspector general of the remount service, inspects and directs this service in the same way as he does the remount service in France, being responsible to the minister alone. His reports and orders do not go to the generals commanding cavalry brigades and territorial divisions in Algeria and Tunis, but are sent directly to the minister or the commanding officers of the remount depots, as the case may be.

Commanding Officers of Depots.-Each depot and annex is commanded by a major of cavalry (detached), aided by two officers (one a "permanent buyer") who are detailed generally from the troops stationed in the region-a veterinarian and a company or detachment of enlisted men of the remount service. Each branch depot is commanded by a captain detailed from the troops of the region, with a reterinarian and detachment of remount men under an officer of the remount service. The persomnel of each establishment constitutes a horse board for purchasing horses and also conducts the affairs of the stud. During the buying time, i. e., from January 15 to July 1, each horse board may be increased by one officer, taken from mounted organizations serving in the region. In cases of large horse transactions the boards may be doubled by details of additional officers. In general, the commanding oflicers of depots have the attributes of post commanders.

There are actually three remount companies of abont 300 men each, detailed for service at the establishments in Africa. They have a special uniform, are armed with the revolver only, are given extra pay (from 5 to 13 cents a day), and are not put through drills and exercises. These men are usually old soldiers, selected for their knowledge and love of horses, and 
the best of them are detailed for work with the stallions. The officers of these companies are employed chiefly in the stud, though they may serve on horse hoards. They are sent on frequent inspections of the stallion stations. Those that show most ability are proposed for appointment as "permanent buyers."

During the season each station is visited, without previous notice, by officers of the depot twice during a month and oftener if necessary. The greatest latitude, however, in this and in all matters is left to the commanding officer of depots.

Early in January each year, all the noncommissioned officers and privates thought to be capable of taking charge of stations are brought together at each depot and branch and given theoretical and practical instruction in their functions. Conditions under which a stallion should be used for serving, kind of stallion to be used for registered mares, etc., and everything else possible for their instruction on this detached service is tanght.

The service of stallions in all the army studs is absolutely gratuitous. All horse raisers, European or native, have a right to these services without discrimination. However, light-draft mares of European blood are not to be served except by Barbary or Arabian stallions chosen among those of stocky build. Registered mares are served only by stallions registered in the Algerian stud book or thoroughbred stallions of French register. Each locality is obliged (through its civil and military authorities) to furnish stable and housing for men and horses during the serving season. If in any locality such accommodations are not supplied, or are not satisfactory, no station is established there. The season begins on January 15. The service of the mares begins at each station four days after the arrival of the stallions, and lasts till the 15 th or sometimes the 30th of June. Generally speaking, service is made by each horse once a day, in the morning preferably, though some horses may be allowed to serve twice in the same day. All stallions, without exception, have one day of rest in the week.

Grooming AND Forage.-The stallions are generally groomed but once a day, ustrally in the evening; but they are rubbed down before and after exercise. After grooming they are watered and then fed oats and barley.

The ration for a stallion is as follows: Hay, $6 \frac{1}{2}$ pounds; straw, 11 pounds; vats or barley, 11 pounds. All stallions 
of French register, and other horses also if deemed necessary, may be allowed oats instead of barley. Draft stallions are allowed te pounds oats extra during the season. For thirty days at the end of the season, each stallion gets 9 pounds of carrots a day, in addition to the ration.

In July, August, and September the stallions are exercised only at a walk, and where it is possible baths in salt or fresh water replace grooming every two or three days. During this period an effort is made to treat all troubles caused by the fatigue of the serving season. From October 1 to January 31 they are given progressive exercise to reduce fat, which is the chief cause of debility. They are ridden at least two hours a day from 8 to 12 miles. At whatever hour the exercise takes place, they are never watered until two hours after coming in.

Source of Supply.-The stallions for these army studs come from two sources: First, those from the army breed farms in Africa, and second, those bought by horse boards in their regular rounds. When a board buys stallions which it thinks would make good breeders, this fact is noted on their descriptive lists when they are sent to the depots, and when the director makes his inspections he selects from among them the best, which in the next season are given trials. Those not so selected are sent immediately to the troops. Later the director recommends to the inspector general those which he thinks should be transferred permanently to the stallion depots, the number each year being, of course, determined by the appropriations for this purpose. The others are sent to the troops.

These "trial stallions" are used during the season according to their maturity. Those 4 years old and some of 5 years serve not oftener than once or twice a week.

The latest figures are for 1901, and among them the following are of interest:

The total number of stallions employed in the army studs was 845 , thus divided as to race:

English thoroughbred _...

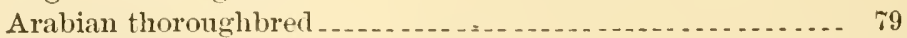

Arab-Barbary -... . . . . . . . .

Barbary - . . . . 661

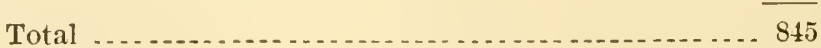


The total number of mares served was $3 \%, 80 \%$, and the number of colts reported by breeders, 9,960 .

There are about 250 fewer stallions appropriated for in 1902 than there were in 1901 . The reason for the difference has not been officially explained.

Army Breed Faris in Algeria.-There are two of these, one at Tiaret and the other at l'Allelik. The latter has been recently established and is not so important as the former, which will be described.

The object of maintaining these farms is to rear and furnish the government studs in Algeria and Tunis (and eventually in France) with (1) breeding stallions of the thoroughbred Oriental, that is, Arabian type; (2) breeding stallions of the Barbary race improved by an Arabian cross; (3) breeding stallions of the Barbary race improved by any other advisable selected cross.

The establishments are governed in the same way as the stallion and remount depots and are under the direction of the same higher officers. Each comprises a farm on which the forage, etc., is raised, and the necessary stables, barracks, and buildings, grooms, and laborers.

The personnel consists of (1) a captain or lieutenant of caralry, commancling; (2) a lientenant of cavalry, assistant or disbursing officer; (3) a lieutenant of the remount service, commanding a detachment of his men; (4) a veterinarian; (5) a sufficient number of noncommissioned officers and privates of the remount service, and laborers.

The effective is established by the minister on the recommendation of the director general of the remount service, according to the needs and development of the farm. The men are chosen from among the lightest and best horsemen in the three companies of remount in Algeria.

The maximum number of animals prescribed for the service is: (1) 4 stallions of either Arab or Barbary stock; (2) 45 mares of Arab or Barbary or Arab-Barbary stock; (3) colts gotten of the foregoing on the farm; (4) the mules or oxen necessary for the farm work.

The officers of the breed farm conduct all its affairs, supervise the rearing and training of the horses, form boards for purchasing horses in the neighborhood for the establishment and for distributing prizes to breeders, keep the stud book, and inspect the stallion stations during the season. 
All colts are regularly trained from the age of 3 rears, their track records carefully kept and copies sent to the inspector general of the remount service. During July and Angust, however, no work is required of these young horses. When stallions 3 rears old have been well broken they are sent to the various studs in Algeria and Tunis; the mares of corresponding age are served the following spring. Stallions and mares which are no longer valuable as breeders, and colts and fillies which are not adjudged suitable for reproducers, are recommended to the inspector general either for sale or for distribution to the troops.

Generally the work of the farm is done by soldier labor, but civilian labor may be hired or military-prison labor used.

The expenses for buildings, extra pas, and incidentals for 1902 is estimated at $\$ 7,304 . i 0$.

\section{FORAGE ALLOWANCE.}

The allowance in oats, hay, straw, etc., is prescribed for each class of animals and for each kind of serrice, as peace footing, war footing, birouac, marches, camps of maneurer, on trains, at sea, etc. The following extracts from the tables are deemed sufficient :

\begin{tabular}{|c|c|c|c|c|c|c|c|c|c|c|c|}
\hline \multirow{3}{*}{ France. } & \multicolumn{11}{|c|}{ Each horse, jwonds jer day. } \\
\hline & \multicolumn{3}{|c|}{ Peace footing. } & \multicolumn{3}{|c|}{ War footing. } & \multicolumn{5}{|c|}{ At sea. } \\
\hline & 11 ay. & straw. & (lits. & Ilay. & Straw. & Wats. & Ilay: & $\begin{array}{l}\text { Bar- } \\
\text { leg. }\end{array}$ & $\begin{array}{l}\text { Barley } \\
\text { meal. }\end{array}$ & Bran. & Water. \\
\hline & & & & & & & & & & & frals. \\
\hline $\begin{array}{l}\text { 'uirassiers, artillery at- } \\
\text { tarked to incl.div. cav }\end{array}$ & 7.7 & $\therefore$, & 11.5 & 7.7 & 5. 0 & 12.7 & 7.7 & 5.5 & 3.3 & 1.1 & 4.:2 \\
\hline $\begin{array}{l}\text { Fielul artillery and foot } \\
\text { artillery }\end{array}$ & 5.5 & 7.7 & 11.5 & 5.5 & 4. 4 & 12.6 & 6.6 & 4.4 & 3.3 & 1.1 & 4.11 \\
\hline $\begin{array}{l}\text { Pragene, train, chevanx } \\
\text { demanege, fendarurs. } \\
\text { cte }\end{array}$ & 5.5 & 7.7 & 11.0 & 5.5 & 4.4 & 12.1 & 6. 5 & 4. 4 & 3.3 & 1.1 & 4.11 \\
\hline $\begin{array}{l}\text { Lizht cavalry. infontry, } \\
\text { nomcombatant oflicers }\end{array}$ & 5.5 & 7.7 & 111.1 & 5.5 & 4. 4 & 11.0 & 5.5 & 4.0 & 3.3 & 1.1 & 4.11 \\
\hline $\begin{array}{l}\text { All mule. and in . Mreria } \\
\text { all horses antl mules -.. }\end{array}$ & 5.5 & 7. 7 & $\therefore, x$ & 5.5 & 4.4 & 10.0 & 5.5 & 4.11 & 3.3 & 1.1 & 4.0 \\
\hline
\end{tabular}

Oats may be replacerl as follows: By corn, barley, or rye, at weight for weight; by wheat, beans, or pease, at two-thirds weight of oats.

Wheat, beans, and pease are not allowed in total substitution; the other grains are so allowed when absolutely necessary. The regular articles of issue are oats, hay, barley, and straw. Barley meal, bran, carrots, parsnips, green fodder, 
linseed, ete, are obtained as substitutes for sarings on the regular ration. Temporarily, in France, the practice now is to substitute 2.2 pounds of barley for an equal weight of oats in the daily ration. In Algeria, barley is usually fed instead of oats.

Certain army corps are now experimenting with a ration which with straw serves as a food component and increases the hay and oats allowance. The weight of oats is carried to 10.4 and 13 pounds according to the arm; that of hay to 6.6 and S.S pounds according to the arm. An allowance of 3 cents a day per horse is paid. With this the captains may buy turf, gorse, heather, sawdust, fern, etc., for bedding. Formerly straw alone was used as bedding.

The straw for all purposes is chiefly wheat straw, that of rye, oats, and barley being less frequently distributed. No special straw is selected for feed, all coming from the same loft.

Both spring and winter oats are fed; good oats are gray, white, or black, clean, smooth to feel, without odor and weighing from 55 to 60 pounds to the bushel.

During one month, generally from May 15 to June 15, the majority of horses are fed green forage, about $2: 2$ pounds a day. For convalescents and other special cases, this green forage may be raised to $S 8$ pounds a day. The only compressed forage used is hay. This is considered to assure the preservation of the hay (if perfectly dry when pressed) for two or two and one-half years. The pressed bales weigh from 110 to 130 pounds each. The results obtained from use of compressed hay have been uniformly excellent.

\section{GROOMING.}

In winter horses are groomed twice a day, once between 8.30 and $10 \mathrm{a} \mathrm{m}$., and again about $3 \mathrm{p} . \mathrm{m}$.

The squadron commander regulates the method of feeding his horses, but as a rule hay is fed at reveille, one-half the day's ration of oats about $10 \mathrm{a} . \mathrm{m}$. along with hay and straw, and the rest of the day's ration of oats, hay, and straw about 4 p. m.

\section{FARRIERS.}

In each squadron of cavalry (which is about the strength of a United States troop of cavalry) there are one farrier and two assistant farriers. All farriers are men who have served 
their three obligatory years and have voluntarily reenlisted. Promising assistant farriers are selected, one from each brigade, and sent to the farriers' school at Sammur, where they mndergo a thorough course in their trade, and upon passing an examination receive a brevet which quickly promotes them to farrier and chief farrier. Only men who agree to reenlist are accorded this privilege. Farriers are given competitive examinations for the grade of chief farrier.

The farrier receives, besides the pay and allowances of his grade (private, corporal, or sergeant), an additional pay regnlated by the number of horses he keeps shod. This amounts generally to 5 cents per month per horse unshod, 16 cents per horse shod in front, and 32 cents per horse shod all around. $\mathrm{He}$ is required to renew each horse's shoes once a month. $\mathrm{He}$ must keep at all times an extra set of shoes, carefully fitted, for each horse under his care, and labeled with the horse's name and number. This is in addition to the reserve shoes kept on hand in the "mobilization stores." The farrier is required also to renew on the forehoofs, whenever necessary, the branding of the horse's number and the letter of the organization. The farrier has many privileges, such as living at the canteen, sleeping out of barracks, etc. His wife is given preference as cantinière.

\section{SHOEING.}

In the army the adjustment of the shoe is either a la française or à l'anglaise, generally the former. In the former the upper surface of the shoe is made slightly concave, the lower or wearing surface is made convex, and there is no beveling of this face. The incurving is greatest at the toe, diminishes to nothing at the quarter, and from there on to the heel the shoe is flat. No channel is cut on the lower surface for the nail heads, but each head is countersunk.

The front shoes are of uniform width from toe to quarter; the hind shoes are appreciably wider at the toe than at the heel. Nail holes are evenly spaced; hind shoes have no nails at the toe; generally, eight nails for front and hind, sometimes six.

In the adjustment i l'anglaise, the exterior circumference of the upper surface of the shoe, where the horn bears, is flat; the part where the sole bears is beveled off. The lower or wearing surface is flat, and the nail holes are made in a 
deep channel, the nail heads, when the shoe is on, being flush with the surface. In other words, the method is that commonly in use in America.

It generally takes two men to shoe a horse in France, one to hold up the foot and the other to do the shoeing. In the army this assistant is prescribed for the farrier, though in

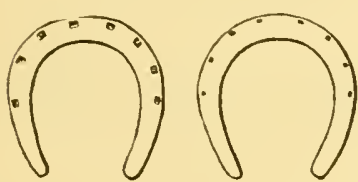

Front.

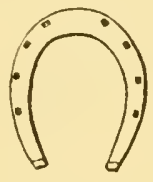

Hind.

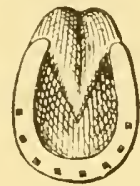

Feet correctly shod.

Fig. 1.-French shoeing.

the shoeing i l'anglaise the farrier is supposed to work alone, as is our custom; this, however, he rarely does. The hoof is prepared for shoeing about as is customary in our army, cutting away the sole and trimming the frog being prohibited. The frog is, however, cleaned and loose parts removed; it is even prescribed that its point shall be brought to the center of the sole and superfluous parts of the bars removed. After the shoe has been accurately formed to fit the prepared hoof, it is set on hot and held firmly till the hoof is evenly burned on its whole bearing surface. The shoe is then removed, quenched, reset, nailed, and clinched.

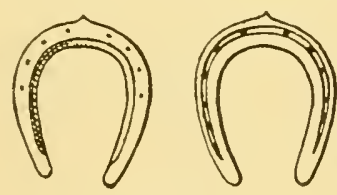

Front.
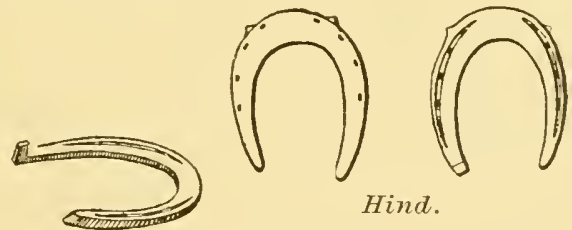

Hind.

Fig. 2.- Shoeing à l'anglaise.

Most shoes are now machine marle. Orders regulate the dimensions of the shoes for the various units.

Rough Shoeing. - In winter, horses may be shod with shoes having holes for the reception of ice calks; permanent rough shoemg is almost never practiced. The calks are provided for the heels only, or two for the heels and two at each side of the toe. The calks are of steel, square in cross section, about $\frac{1}{2}$ inch high and screw into place. 


\section{VACCINATION.}

Vaccination is practiced for two diseases only, riz, anthrax and tetanus (lockjaw). The first is so rarely observed in the army that veterinary statistics hardly erer mention it, and raccination for it is therefore rarely employed. When it is, the spring is the most favorable time, as vaccination then gives immunity during the summer, at which season the anthrax is most likely to appear.

Against tetanus, as a measure of prevention, raccination is regularly recommended to army veterinarians and is constantly practiced in cases of wounds, etc., in parts of the animal's body which experience has shown to lead to lockjaw, the most frequent causes being castration and nail in the hoof. The serum employed comes directly from the Pasteur Institute in Paris. Before using the serum, the veterinarian should assure himself of its perfect clearness; he then makes two subcutaneous injections of 10 cubic centimeters each on the neck or behind the shoulder of the animal. The first injection is made at the moment the operation is performed, or as soon as possible after the traumatic condition is observed. A second injection is made $S$ or 10 days later. The veterinarian should not, because he has used the preventive serum, neglect also to treat the wounds aseptically till cured.

The results obtained with this tetanus serum in France have been very satisfactory theoretically and practically; the disease has become more and more rare, and some military installations which had grown to be considered as veritable tetanus breeders have been entirely cleaned of the disease.

There is also employed more and more each day in the army a therapeutic anti-tetanus serum, but while the results have thus far been encouraging, it is not yet possible to say to what extent they have been clue to the serum and to what extent to the therapentic treatment concurrently employed.

While these are the only raccinations employed in the reterinary practice of the army, it may be added, as a matter of interest, that in France they now begin to employ an "antistreptococique" serum in affections of dropsy and erysipelas; this, however, is, strictly speaking, a therapeutic method and not vaccination. 


\section{MOBILIZATION EFFECTIVE.}

The number of horses, in addition to the peace effective, which would be required upon mobilization of the army is supposed to be kept secret. This number can be roughly estimated from the number of army corps to be mobilized and from the knowledge of the peace effective in horses. However, in a discussion on the budget a few years ago (1897) in the chamber of deputies, the following table was officially furnished as setting forth the needs of the war effective:

\begin{tabular}{|c|c|c|c|}
\hline & $\begin{array}{l}\text { Peace } \\
\text { effective. }\end{array}$ & $\begin{array}{l}\text { War } \\
\text { effective. }\end{array}$ & $\begin{array}{l}\text { Additional } \\
\text { horses re- } \\
\text { yuired in } \\
\text { war. }\end{array}$ \\
\hline Cavaly & \multirow{3}{*}{$\begin{array}{r}55,645 \\
30,2600 \\
4,5(4) \\
4,120\end{array}$} & \multirow{3}{*}{$\begin{array}{r}87,360 \\
250,260 \\
110,060 \\
1+0,060\end{array}$} & \multirow{3}{*}{$\begin{array}{r}31,665 \\
220,1091 \\
95,500 \\
1.5,880\end{array}$} \\
\hline $\begin{array}{l}\text { Artillery - } \\
\text { Other arms. }\end{array}$ & & & \\
\hline Train _...-. & & & \\
\hline Total & 94,575 & 577,620 & 483,045 \\
\hline
\end{tabular}

These figures being for France proper, it will be seen that the peace effective given is about 15 per cent less than the peace effective for 1902. We may then say that to put her army on a war footing for a great continental war, France would need at the start at least 500,000 more horses than are now in service, not taking later needs into account.

These horses would undoubtedly be procured by requisition, and it is for this reason that the census of animals fit for the various military requirements is taken each year in France. This document contains all the data required by the war department for requisitioning liorses, should the need arise. It is not believed that the necessary number and quality would be forthcoming from home sources.

Experiments have been made at different times to test the possibility of mounting regiments of reserve cavalry as the law contemplates they should be mounterl upon mobilization, that is, by requisition. The results, even in horse-raising districts, have not been satisfactory; in two weeks' time sufficient numbers of cavalry animals were not found in the territories assigned to the regiments to mount their men. About onefourth the horses taken were light-draft and not saddle horses.

Now of the 500,000 horses needed immediately upon mobilization, about one-half are saddle horses for the artillery and 
cavalry. The draft horses could easily be gotten, but the saddle horses continue to present a serious difficulty. The general horse-raising business has been on a steady decline for the last fifteen years. In 1888 the exports exceeded the imports by about 25,000 head; in 1895 the imports exceeded the exports by about 15,000 head and they have not since decreased.

The raising of saddle horses as distinguished from draft horses has been in former years and is even now considered more remunerative by breeders; the result is that the remount officers, notwithstanding the high prices allowed for saddle animals, have some difficulty in finding the 15,000 annually required (most of these are saddle horses).

Premiuns to Breeders of Military Horses in France.-It was an endeavor to rectify this situation that the French chambers in 1897 passed a law which puts in the army appropriations each year an item of $\$ 234,000$, which is used to encourage horse raisers in the production of military saddle horses. This sum enables the remount service to pay a higher price than heretofore, the increase being in the nature of a preminm to the producers of good military animals raised in France, and especially to the small farmers who can not compete with great ranchers. This preminm is in addition to the average price allowed for each class of animal.

As a safeguard thrown around this increased expenditure for horses, the ministry of war has given strict orders that the purchasing boards shall demand from the horse raisers certificates showing ages and pedigrees of the animals they sell. Prospective sellers must send to the remount stations at least ten days before the purchasing boards start out descriptions of the animals they propose to present, stating pedigree, etc. This arrangement also serves to prevent the presentation of foreign-bred-especially American-horses by French breeders along with those of their own raising. The object of the premium is to encourage French breeders, so that premiums are not paid on any foreign-bred horse, whatever his quality.

The average price paid previous to 1897 for a young, serviceable, cavalry horse, either for the heavy cavalry or the light, was about $\$ 204.95$. It is contended by the horse raisers that this price is insufficient, even for a horse $3 \frac{1}{2}$ years old. They contend that a mare is worth $\$ 156$, and that, allowing 
that she may produce eight colts, which is a heavy arerage, $\$ 19.50$ should be added to the value of each colt when sold. Then comes the cost of maintenance of the mare during gestation, which is never less than $\$ 48.75$, and the cost of each colt during the three years that he is being maintained by the raiser is at least $\$ 39$ per year, so that the raiser can not sell his 3 -year-old colt for less than $\$ 185.25$ without incurring loss.

It is estimated that the horse-raising interest presents annually 120,000 horses to the remount purchasing boards, although only about 16,000 are accepted.

Premium for Encouraging Horse Raising in Algeria. Each year the appropriation bill for the army contains an item of varying amount for this purpose; in 1901 it was $3 \%, 680$ francs; in 1902, 74,780 francs. For 1902 there is also an item of 30,300 francs for prizes for military horse races in Algeria. (There is regularly roted 3,000 francs for prizes for military horse races in France.) The sum for Algeria was obtained from savings due to the present low price of mules in Algeria.

The funds for premiums to breeders is divided among the various districts of Algeria in proportion to their importance in the matter of horse raising. In each district a commission is appointed consisting of two officers, a veterinarian, and two civilians (one European and one native), which awards the premiums. The premiums are in sums of 150,100 , and 50 francs, and are awarded to colts and fillies of 2 and 3 years and brood mares in foal or shown with their get of that year, the sires to be stallions belonging to the state or Arab, Barbary, or Arab-Barbary stallions approved by the state. Mares receive one-half the sum allotted to the district, colts and fillies the other half.

Owners must establish the pedigrees of the animals and prove that they have owned them at least three months. 



\section{VI.-GERMANY.}

[Reported by Lient. Col. J. B. Kerr, Ninth Cavalry, Cuited States Military Attaclé at Berlin.]

The production and improvement of horses for the German army have been for a long time the object of active vigilance, and the results obtained have been most satisfactory. The Germans have encouraged and developed the propagation of military horses until they now have better-bred nounts than those of any other European army. Aside from the private breeding stables, they have organized government breeding establishments, where are kept both stallions and mares, and stallion depots, in each of which are kept from 80 to 120 stallions which are distributed among the stallion stations during the covering season, from January until May.

Horses from 3 to 4 years of age are purchased for the army by remount commissions. The horses are then assembled in remount depots. These depots are also agricultural establishments on large scales, are under the direction of the military, and grow the necessary forage and other products for their own use. Horses are sent from the depots to the regiments and other organizations when between 4 and 5 years of age. The only ones not sent to the depots are some older heavy draft horses purchased for the artillery and the train, which go immediately to their organizations; this is permitted for only a limiter number of horses namely, those that are bought from $t$ to 6 years of age and at an average price of $\$ 301$.

There are 25 remount depots, of which $1 \%$ are in Prussia, 5 in Bavaria, 2 in Saxony, and 1 in Wurttemberg. They are distributed over the Empire, in the principal horse-raising centers. The total anmual receipts of the 17 depots in Prussia are abont $\$ 289,500$, the expenses about $\$ \% \% 2,000$; the difference $\$ 482,500$ is appropriated for in the budget. This raises the average cost of a horse to an amount between $\$ 173.90$ and \$22\%.4. Bavaria maintains in its remount depots about 1,200 horses. In Saxony the remount depots of Kulkruth and Skassa contain together ahout 700 horses, but these two depots 
have four annexes which contain 400 more. Horses for the Saxon army are purchased to a great extent in East Prussia and Hanover at an average price of $\$ 214.20$ each.

The remount depot for Wurttemberg was established in 189:; before this date its horses were bought in the market, generally in Prussia. The depot of Breitholen can not furnish all the horses necessary for the army of Wurttemberg; some direct purchases are therefore still made, and arrangements are made also for obtaining horses from the remount depots of Prussia.

The province of East Prussia is celebrated for its fine horses, and furnishes nearly half the horses for the Prussian army. In all the depots the horses are kept in stables, and have stalls, but are not tied up, being left free to walk around. A tin tag bearing a number is hung on the neck of each horse. By this number the animal is known until the end of his military service. The numbers differ in the various depots, so that it can be immediately determined from which establish. ment a horse comes, also by whom he was purchased. The horses distributed to the light cavalry (hussars and dragoons) must be from 15 liands 2 inches to 16 hands in height, and for heavy cavalry (uhlans and cuirassiers) from 16 to 1 ; hands. The horses of East Prussia are regarded as the best horses in Germany.

The purchasing commissions for the remount horses consist each of one permanent president and two officers of caralry or field artillery detailed each year. Each commission has also one veterinarian, one secretary, and one or two orderlies. Each commission operates in a designated district. This plan enables the members to become well acquainted with the character of the animals within their zone of action. The commissions are in session only during the time necessary for the purchases. They are convened during the month of May and adjourn by the 15 th of September. The president is the only permanent member. During the winter the presidents work at the office of the minister of war. 'The other members are detailed amnually from among officers having special knowledge of the horse, and who show promise of becoming qualified to act as presidents of commissions. After the purchases have been made, these officers return to their organizations. The commissions publish in the newspapers the dates on which they will hold what is called here "the 
lemount markets," and on these clates they make the purchases. The remount commissions purchase only serviceable and healthy remounts. No standard of weight is prescribed, no training demanded. The sellers must furnish foal certificates. Cold-blooded horses are not accepted. The horses must be from 15 to 17 hands in height. They may be either geldings or mares.

The horses are rounded up in bunches, placed in charge of detachments furnished by neighboring regiments of caralry, and taken to the nearest remount depot. A few of the horses are kept at the depots for as long as two years each. The president of the commission determines definitely whether an animal is suitable for purchase; the ranking lieutenant alone discusses with the owner of the horse the conditions of bargain and the price, and the junior lientenant takes the measurements.

The distribution of the horses to the different arms is made by the inspector general of remounts, who risits the depots for this purpose. The regiments send detachments to the depots for the horses, which are transported to their regiments by rail, except where the distance is short. The distribution is now made in July. As the discharges of horses unfit for service are made from the various organizations after the fall maneuvers, the numbers of horses on hand are therefore for some time above the regulation allowances. The regiments, in consequence, are authorized to sell 20 horses each immediately after the arrival of the remounts. A regiment of cavaliy receires annually 63 horses; each squadron from 12 to 13. There is supplied in addition the necessary number of officers' horses, known as officers' chargers. All lientenants, and captains of the second class (captains drawing first lieutenants' pay), of cavalry and horse artillery are entitled to one goremment horse each. Each of these officers must also procure and keep one additional mount. The service horse is delivered only after complete training, as it is not considered desirable for the officer to spend his time at the work necessary for the training. At the end of four years the charger becomes the property of the holder. The officer who does not take advantage of his right thus to select a horse, receives in its stead the average price of a remount horse, paid in five annuities. An officer thus waiving his right to a government charger is obliged to keep two horses of his own. The $23555-18$ 
inspector of remounts, in making the distribution of the horses at the depots, places the best mounts in the category of officers' horses ("chargers"). This designation, howerer, does not restrict the choice of the officer, who may select from all the remount horses through the intermediary of a commission to approve the preference. If the horse assigned to an officer does not, in the first year of possession, answer the requirements of the service, it may, upon the recommendation of the commission, if sound and healthy, be exchanged for another, generally of the same remount. As a rule such an exchange is permitted only once. The regimental commander may, for very particular reasons, authorize a second exchange. With the exception of captains of the second class and lieutenants of cavalry and horse artillery, all mounted officers receive a special allowance with which they purchase horses in the markets.

The remount depots are all conducted in a similar manner. A description of a few will be given. The depot of PreussischMark is situated in the province of East Prussia. It has an area of $2,03 \%$ acres; the stables have a capacity for 330 horses. The average cost of the maintenance of a horse at this depot for one year is $\$ 5 \% .12$. The cultivation of the land furnishes the depot forage, oats, and hay, and also other grain, which is sold. Cattle, donkeys, mules, etc., are also sold. In 1897 the sales amounted to $\$ 22,230$. The extra costs are compensated for by the increase in value of the animals during their stay. The stables consist of two buildings arjoining, having in front a common yard. Hayracks are not used, although they exist in all the stables. The hay and straw are placed on the ground. The hayracks are beliered to tire the loins of the horse when he raises his head. The price paid for 3 -yearolds varies; it now arerages $\$ 155.89$. The average cost of maintenance being $\$ 5 \% .12$, the $4 \frac{1}{2}$-year-old costs the government $\$ 213.01$. In other depots the annual expense of maintenance is less, so that the average cost of one of their horses up to the time of his arrival in a caralry regiment is reduced to $\$ 20 \% .28$.

The inspeetor general of the remount service designates the horses for the different organizations in the month of June; letachments are then sent by the organizations for them. To care for 330 horses at the depot twelve stablemen with an orerseer and stable chief are employed; each man cares for 
about 30 horses. None of these employees belong to the army, but all are ex-soldiers. To this personnel are added an accountant, a veterinarian, and a director of the establishment. The horses are not ridden while at the depot. By purchasing 3-year-olds, advantage is taken of the market, which finds no other call for horses of this age. The government has thereby a wide choice, and the horses are thus fed grain a year sooner. The horses also have the advantage of not having been worked and thus spoiled for cavalry purposes. Against this system are the expenses of maintenance, of the land, buildings, etc. Most of the depots were founded, however, at a period when land was not so valuable as it is now. The state then possessed large tracts and was able to choose, for the installation of the depots, very favorable sites from its own possessions. The number of horses at any depot is regulated by the area under cultivation.

The remount depot at Kattenau, in East Prussia, has a domain of 2,516 acres. It contains a central establishment and three branches. There are 600 horses attached to this depot. A very large amount of green forage is used. In fact the grazing at all the depots is much more restricted than formerly, the feeding of green forage having taken its place. A special isolated place, divided into box stalls, is set apart for the hospital. The ration of forage is fed on the ground in small portions, the grain being put in a box fastened to the wall. All the horses are unshod. The feet are carefully watched by the veterinarian. The farrier also goes over and fixes them every month. There is a list made of the horses in each stable. This list contains the number, description, and the arm to which each animal is assigned. The soil in the ricinity of the stables is sandy and dry. The horses are very gentle. The average daily ration is $7 \frac{1}{2}$ pounds oats, $12 \frac{1}{2}$ pounds hay, and 15 pounds straw. In the summer the feed consists for the most part of green forage. Pasturing is almost abandoned at this depot. The cost price of the stay of a horse for a year at Kattenau is about $\$ 68.40$.

The remount depot of Baerenklau has a central establishment and five branches, with a capacity for 500 horses. Its management is similar to that of Kattenau. Soon after the arrival of the horses at the depots they are almost invariably sick with influenza. 
While at the depots, the young horses are systematically exercised in so-called " movement grounds," inclosed grounds, 21 to 26 yards wide, and from $\$ 25$ to 1,250 yards long, and oral in shape. They are daily for two hours driven on these grounds in bunches of 100 head each, at moderate paces (slow trot and gallop) with front and rear herders. They thus obtain free step, develop muscle, good hoofs, and healthy internal organs, and acquire a certain discipline.

Immediately after purchase the horses are branded on the left side of the neck with the year. After the transfer of the horses from the remount depots to the regiments, they are branded on the left hip with the regimental brand, from which, in an abbreviated form, the regiment to which they belong may be seen: Dt, U6, A3, etc. The brands, however, are not placed over others, such as those of breeding stables, etc.

In the army the average length of service of horses of the cavalry and train is ten years, of field artillery nine years, and of the military riding institute from seren to eight years.

There is no regulation fixing the length of time that a horse may serve in the army. A great number of them are discharged between 14 and 15 year's of age. This matter is left entirely with the squadron commander, who may allow them to stay in the service up to the age of 20 years. In a few of the organizations particular horses are allowed to stay until 22 years of age, which is the extreme limit. The number of animals to be annually received in each organization is fixed, varying only in consequence of more or fewer horses being selected for officer's chargers. As a result a squadron commander having received his allowance (which is 10 per cent of his authorized strength), say 13 horses, in July, will not have more than 13 altogether sold and discharged after the fall maneuvers, although he may have more in his squadron that should be discharged. For instance, if a horse dies he is not replaced, but the squadron commander, in order to keep the number at the authorized limit, discharges one horse less. If a captain is compelled to condemn more horses than he has received from the remount, the deficit continues during the year, and the number of the effective files of the squadron for the time being is reduced. If a horse becomes unfit for service, and the squadron commander judges it impossible to keep him in the ranks, he reports the fact to 
the regimental commander, who convenes a board, composed of a captain, two lientenants, and a veterinary surgeon, to examine the horse. The decision of the board as to the disposition to be male of the horse is final, its findings being subject to no approval by superior authority and to no appeal. If the horse is declared unfit for the service he is immediately sold at auction. (It may be worthy of remark that the tendency in the German army is to the decentralization of power in the hands of the war ministry. Initiative and authority is being extended to and centralized in the officers present on the spot, who are held responsible for their actions. This relieves the war ministry and heads of departments of many details of which they can have only a paper knowledge.)

The money received for the sale of the horse is taken up in the special fund which exists in all squadrons, batteries of field artillery, and divisions of the train, for the improvement of the horses. This fund accrues not only from the proceeds of such sales, but also from the sales of the forage rations which are authorized to be drawn for the animal after he has been sold and until he has been replaced, and also from payments made by the one-year rolunteers for the hire of the horses used by them. The commanders of the organizations purchase from this fund, in the open market, a horse to replace the one sold. The number of horses thus bought is very limited.

There are, in round numbers, 4,200,000 horses in Germany. The number in the army is as follows: In the caralry, 65, 700; in the artillery, 33,750 ; in the other branches, 5,270 ; draft horses, 25,900; pack horses, 12 ; total, 130,632. There are no mules in the army.

The number of horses imported into Germany annually averages: From France, about $\%, 000$; from Russia, 3ะ,000; from Belgium, 21,500; from Denmark, 16,000; from AustriaHungary, 12,000; from Holland, 8,000 ; the total imports being about 102,000 , while the exports reach only about 10,000 . The import duties on horses over 2 years of age are $\$ 4.76$ each; under 2 years, $\$ 1.19$; colts following dam, free; mules, $\$ 1.19$. No export duties are charged on horses or mules.

For use outside the continental empire, the horses for the expeditionary corps in China were the only ones provided by the army administration. No horses for use of the troops in 
the colonies have been shipped from Germany. The few horses used in the colonies are native horses furnished by the local civil administration. For the East-Asiatic expeditionary corps the horses were bought partly in the United States of America and partly in Australia. For those purchased in the United States the same conditions were required for their acceptance as are established by the United States Government for its remounts.

The forage ration varies according to the service performed by the horse. There is a ration for garrison duty, for the march, and for field service. The heary ration consists in garrison of 11.16 pounds oats, 5.58 pounds hay, and $\%$.81 pounds straw; for the march, 12.25 pounds oats, $3.3 \pm$ pounds hay, and 3.9 pounds straw; for the field, 12.61 oats, $3.3 \pm$ hay, and 3.9 straw. The heary ration is allowed to the horses of the cuirassier and uhlan regiments, to the horses of the generals, general staff, adjutants general, officers on duty at the war ministry, artillery of the guard corps, regimental and artillery battalion commanders, artillery and train horses (when used for draft purposes), and, when in the field, for all cavalry and artillery horses.

Besides the heavy ration there is also a light-cavalry (guard), a middle, and a light ration. The light-cavalry (guard) garrison ration consists of 10.6 pounds oats, 5.58 hay, and $\% .81$ straw; the march ration, 11.5 oats, 3.34 hay, 3.9 straw; the field ration, 12.61 oats, 3.34 hay, 3.39 straw. 'The light garrison ration consists of 9.48 oats, 5.58 hay, $\% .81$ straw; march ration, 10.6 oats, 3.34 hay, 3.9 straw; the field ration, 11.16 oats, 3.34 hay, and 3.9 straw. The horses of the light cavalry of the guard are entitled to the light-cavalry (g'uard) ration; the horses of the dragoons and hussars of the guard to the middle ration; and the horses of all other troops, officers, physicians, and officials to the light ration.

Akditional allowances are anthorized for certain prescribed cases; for instance, for railroad travel of over eight hours' duration the hay ration is increased by 6 pounds 11 ounces. An increase is authorized also for the heav horses during maneuvers.

The rations for the officers' horses of the cavalry are the same as those for the service horses of their regiments; thus an officer of the cuirassiers receives the cuirassier ration, an 
officer of the hussars, the hussar ration, etc. They are entitled to rations as follows:

\begin{tabular}{|c|c|c|}
\hline & Peace footing. & War footing. \\
\hline 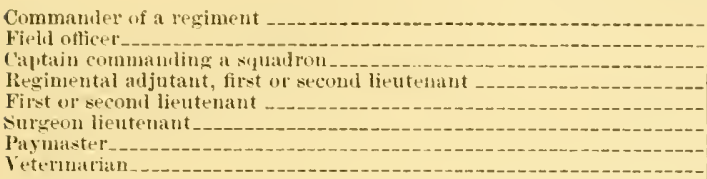 & $\begin{array}{l}4 \\
3 \\
3 \\
3 \\
2 \\
1\end{array}$ & $\begin{array}{l}5 \\
4 \\
3 \\
3 \\
3 \\
1 \\
1 \\
1\end{array}$ \\
\hline
\end{tabular}

The forage rations constitute a personal allowance of the officers entitled to them, who may dispose of the rations as they desire. Instead of the rations officers may draw money either for all the rations allowed for their horses or for any part of the same.

In the cavalry the following extra pay for the purchase of horses is allowed per month:

First lieutenant . . . . . . . . . .

Captains of the second class ..... . . . .

Captains of the first class. .

Staff officers not regimental commanders _............ 5.95

Regimental commanders . . . . . . 11. 90

Officers of the horse artillery have the same allowances. The generals do.not receive any extra pay for horses. The allowance of forage for general officers is for 3 to 8 horses each according to said officer's' duties. In time of peace they are not required to keep their full number of horses, but they may draw and sell their full allowance of the forage. Compressed forage is not used.

A squadron is allowed each month from $\$ 10.23$ to $\$ 10 . \% 1$ for shoeing its horses. On a peace footing there are 139 horses in a squadron, and this monthly allowance not only proves for them sufficient, but often is not all expended, so that a reserve fund is constituted to provide for unexpected needs. The squadron commander's are entirely free to have or not to have the horses of their squadrons shod. It is customary not to shoe the horses during the winter, that is, from the 1st of October to the 1st of April. During this period, which is devoted to the instruction of recruits, the horses work only in the riding hall or on the exercising grounds, which are prepared for the purpose and are soft. They can then, barring exceptions indicated by the veterinary surgeons, go without shoes. During the summer all depends upon the 
special conditions in the vicinity of the garrisons. If, in going to drill, the squadron is obliged to traverse a considerable part of the city, the front feet are shod. If on the contrary the ground in the neighborhood is not too hard, the horses are left entirely unshod until the fall maneuvers. For these maneuver's the horses are shod all around, as it is difficult to foresee what kind of ground may be encountered. But in exceptional cases, where it is known that they will be used only on soft ground, economy is preserved by shoeing only the fore feet. In the cities the cavalry never furnishes mounted patrols or mounted orderlies. All this service is done by soldiers on foot. This permits doing without shoeing the greater part of the year, thereby incidentally saving a part of the fund allowed for shoeing. There is, nevertheless, always in the storehouse a large supply of shoes, enough not only for shoeing the squadron horses all around, at the moment of mobilization, but also for a reserve supply to take along.

Until recently no vaccination of any kind was prescribed for military horses. In the last few years, trials have been made to guard by vaccination against influenza, that is, to protect the healthy horses by vaccination before the infection. The vaccine used for this purpose consists of the lymph of such horses as have recovered from the disease. The results of these trials have not been sufficiently satisfactory to lead to a general adoption of such vaccinations.

During winter horses are groomed three times a day.

When the horses are brought from the depots to their regiments and organizations, they are trained for one year before being placed in the ranks, after which they are trained another year in the ranks before their education is regarded as completed.

When horses are discharged from the cavalry, they are put in the train, if adjudged suitable for the purpose.

The mounted organizations of the army have some other horses which are known as "Krïmper" horses. These are maintained in excess of the regulation effectives, and rations may not be clrawn for them. They are fed on the savings of the whole. The number of Krümper horses is fixed by regulations at 3 or 4 per squadron, 2 to 5 per battery or train company, 6 at the most for the officers' riding institute, or not over 4 for the noncommissioned officers' riding institute. 
These horses are used as draft animals for the stable wagons and in the squadron or company fatigue duty. They may also be hired out to other organizations of the garrison. Under certain conditions they may be driven also by officers of the regiment or organization, on payment of a certain charge, which goes into a special fund.

In case of mobilization the horses necessary to put the army on a war effective are obtained by requisition.

The number of horses to be added to the peace effective in case of a general mobilization is 350,000 . It is expected that these horses will be procured in Germany upon mobilization, as they are now ready and listed for such service. The law of 187.3 affecting military requisitions, and the regulation of 1886, concerning the conscription of horses, indicate in detail the rules to be followed in all that concerns these operations. Concisely they are as follows: A general census of horses is made every ten years by the civil authority. This is followed by a classification made by commissions, each composed of an army officer and one official of the civil administration. Districts are then assigned to the different army corps, and, in case of mobilization, the corps commanders call for the required number of animals of the desired classes. The horses are inspected by commissions established during time of peace and composed of 3 members each. The work is laid out in such a manner that each commission will not have more than 1,200 animals to examine. Upon the civil anthority is incumbent the duty of assembling the horses and of seeing that they are collected at the points wished at the time indicated in the order of mobilization. The horses selected by the commissions are taken by the owners to designated points where military receiving commissions appraise the animals and fix the amounts to be allowed the owners. The horses are then sent to the organizations by men of the recruiting service or men of the landwehr or landsturm, assembled for this purpose in advance at the different receiving points.

There are in Prussia three government breeding stables, containing stallions and mares. They are the stables of Trakehnen, Beberbeck, and Graditz. Their object is to raise blooded stallions for the purpose of supplying the stallion depots, of which there are 15. The latter send out their stallions to the rarious stallion stations established throughout the empire during the breeding seasons. After the breeding 
season is orer each year the stallions are brought back again to the stallion depots.

The breeding stables, stallion depots, and stations are all under the management of the ministry of agriculture, and are in no way connected with the war ministry or the army.

The breeding stable of Trakehnen was established in 1625. It has a domain of 10,000 acres, and comprises 13 farms where stallions, colts, and brood mares are kept. The stables now have 15 stallions, 350 mares, and 730 colts of different ages. Among the stallions are 10 first-class English thoroughbreds; their average cost price was $\$ 1 \%, 850$. The well known Trakehnen breed of horses is about one-half English blood, one-quarter Arabian, and one-quarter blood of the ancient coursers of the Teutonic order of knights who raised with great care and success their steeds in East Prussia during the thirteenth and fourteenth centuries. These horses are suitable for all the services, and make remarkable saddle lorses and carriage horses. The finest products go into the emperor's stables. Mares of private persons are also served at the stables. The stables possessed two Arabian stallions, but they were recently discharged, as their product lacked size. There are, howerer, at the stables, four Arabian mares, which gire fine products. The few officers who possess these horses mention them with pride. All the stallion depots have a certain number of Trakehnen horses. At 3 years of age the stallions are divided into two classes, the principal stallions, which are to serve in the breeding stables, and the stallions of the country, which are sent to the stallion depots.

The breeding stables of Graditz have an area of 7,500 acres. They contain seven stallions, among which is Chamont, bought at the price of $\$ 32,000$.

In addition to the stallions raised, the government purchases about 200 stallions each year.

The effectives of all the government stables of Prussia are, for the principal breeding stables, 35 stallions, 640 brood mares, and 2,000 colts; for the stallion depots, 2,250 stallions; 4,925 animals in all. The price charged for covering mares is from 50 cents at some of the stations to $\$ 100$ at some of the breeding stables. The ordinary price through the country is about \$1. All horses have foal certificates. They are not inbred. Stallions are not lent to cirilian horse raisers; their services are paid for. 
Bavaria has 1 royal bretding stable, 2 principal breeding stables, 5 stallion depots, and 123 stallion stations.

Saxony has 1 breeding establishment for the production of draft horses; it is of limited extent and of not much importance.

Wurttemberg has 3 small breeding stables, which are also stallion depots. The government stallions in Wurttemberg number 126 .

The total number of government stallions in Germany is 3,000 , exclusive of the colts.

SUMMARY OF THE VETERINARY MEDICAL REPORT OF THE PRUSSIAN ARMIY, 1900.

The Militär-Wochenblatt publishes a summary of the reterinary medical report of the Prussian army for 1900 . The total number of service horses was 81,039 , and of these 32,996 or $40 . \% 1$ per cent came nuder treatment, with the result that 30,399 or 92.12 per cent of the treated horses were cured, 320 were declared unfit for further service, 1,148 or 3.48 per cent died, and 365 or 1.11 per cent were killed, making a total loss to the service of $1, \$ 30$ horses or 5.58 per cent of the horses treated, and 2.26 per cent of the total strength. Compared with the previous year there was an increase of $t ;, 416$ in the number of cases treated and 284 in the number lost. Deaths from glanders were more numerous than in the two years immediately preceding, the figures being 13 in 1898, 1 in 1899 , and 52 in 1900 . Of the $52,4 r$ cases came from one regiment, but in 21 of these there was some doubt as to the real nature of the disease. Chest murrain affected 1,618 horses, of which 1,498 were cured, 0 died, 1 was killer, and 4 ? remained under treatment. No less than 1,019 cases, with $4: 3$ deaths, occurred in the first quarter of the year. The cases were less numerous than in either of the four precelling years, the numbers for these years being $2,2 \% 4,3,116,3,265$, and 2,301 . The far less dangerons murrain or intestinal ferer showed a great increase in the number of cases, the figures being 4,325 for 1900 and only 861 for 1899 , but only 1 horse died from this disease and 1 was shot. Colic was, as usual, much more fatal, as out of $3, \% 46$ horses treated, 528 horses died, both these numbers being higher than those of any of the five preceding years. Inflammation of the throat and larynx affected 5:6 horses, but only 1 died; 420 of the cases 
were infectious and $2 s t$ of these came from one regiment. The number of cases treated for saddle and harness galls was 596, against 440 in 1899 . The number of cases of inflammation of the tendons also show an increase, it being 4,039 , with a loss of 39 horses. The hot-iron treatment, which at one time was common in these cases, is now very exceptional, cold-water bandages and other cooling treatment, with massage, being substituted for it. The general increase in the numbers treated for the various complaints is attributer chiefly to the greater amount of work the horses were called upon to do.

\section{GERMAN COLONIES.}

[From "Zucht und Remontirung der Militär-Pferde aller staaten," hy Dr. Paul Goldbeck, Berlin, 1901.]

Little is known concerning horse breeding in the German colonies, in many of which the principal draft animals in use are mules or oxen. In German Southwest Africa the number of horses is estimated at from 3,600 to 4,000. Mules were formerly imported from Argentina, but they are now being bred to a considerable extent. The number of animals in possession of the protective force in 1899 was 1,162 horses, 220 foals, 350 mules, and 1,050 oxen. There is a stud establishment, from which 70 horses were delivered to the troops in 1899 .

In German East Africa horses are kept only for purposes of mule breeding, the principal transport animals being asses, mules, and oxen.

In East Asia the mounted troops possessed, in 1900, 69 horses and 92 mules, besides which ti officers, surgeons, etc., were obliged to keep horses. The ration consists of 8.82 pounds of barley, 6.61 pounds bran, and 1\%.6t pounds of straw; for mules of $\% . \%$ pounds barley, 6.61 pounds bran, and $1 \% .64$ pounds of straw. When the troops were mobilized for China, in 1900 , a cavalry regiment and a field artillery regiment were formed, the horses for which were purchased in America and Australia. 


\section{VII.-GREAT BRITAIN.}

[Rejorted by Cajıt. E. B. Cassatt, Thirteenth Cavalry, [nited states Military Attaché at London.]

1. The remounting of the British army at home is carried out under the order's of the inspector general of remounts, the details of whose work are shown below.

2. The regular army abroad, in normal times, has no mounted troops except in South Africa, Egypt, and India. For these it has been the custom to purchase locally. In South Africa and in Egypt the horses for the British and the native cavalry are Syrian Arabs.

The artillery in Egypt is remounted from England.

In India all the remounting of the army is done under orders from the local government.

The only irregulars are the troops of the native states who are remounted by their own rulers.

The regulars are, first, British cavalry, horse artillery, field artillery, mule batteries, and elephant batteries; second, native cavalry regiments, which are, for the most part, what is termed "silladar," that is to say, horse, clothing, arms, and equipment are the property of the trooper. In former times the trooper enlisted bringing with him his own horse and equipment, but now he brings money, and everything is found for him, the money being refunded on his discharge.

The Madras cavalry regiments are not "silladar," but are remounted by the government.

3. There are no mounted troops maintained in the colonies, except a few in Australia who are remounted by local arrangements.

4. In the United Kingdom horses are acquired by purchase in the open market, from any dealers or private individuals who may produce suitable horses when required. They are purchased by the inspector general and assistant inspectors of remounts, assisted by veterinary surgeons, who examine for age and soundness. 
The department furnishing this information is not at liberty to announce the prices paid.

5. The general requirements of the different arms are as follows:

For cavalry :

Heights-

Lancers and dragoons .... ........... 15. 2 hands.

Hussars . . . . . . . . . . . . . . . . . . . . . . . . 15. 1 hands.

Household cavalry . ..................... 16 hands.

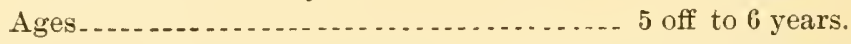

These may, generally speaking, be described as of the hunter class.

For artillery, engineers, and transports:

Heights 15.1 to 15.3 hands.

Ages 5 off to 6 years.

These should be described as good draft horses, those for transport being somewhat heavier than those for artillery.

For mounted infantry and yeomanry:

Heights 14. 2 to 15 hands.

Ages 5 off to 6 years.

Of the polo pony stamp.

6. Sex is not considered in mounting the army.

7. The subject of gaits or paces is not considered, the idea being that all horses can be trained to the regulation speed of trot, walk, and gallop.

8. Color is not considered, except in special units as follows: Household cavalry, black; second dragoon guards, bay; second dragoons, gray. Gray horses are not supplied to any other corps except for trumpeters and, it is believed, to the bands.

9. Horses are not weighed in the United Kingdom.

10. In connection with the ages mentioned above, in past years a certain number of 4 -year-olds have been issued in the autumn, but it is now proposed to make a strict rule that no horse shall be issued that is less than full 5 years old in the antumn.

11. No pack animals are used except one or two per unit selected from the lighter draft animals, or, in some cases, mules for reserve of small-arm ammunition with infantry.

A considerable amount of pack transport is used in India, but there is no information at present of the numbers maintained. 
12. The following is a table of horses purchased in the United Kingdom in recent years:

\begin{tabular}{|c|c|c|c|c|}
\hline & ('avalry. & Royal astillery. & Mounted infantry. & Trausport. \\
\hline 1897 & 1, titis & 1,140 & 30 & 325 \\
\hline $1898-$ & 1, (1til & $1,2 \infty 6$ & 59 & 179 \\
\hline $1893_{-}$ & 7,336 & $9,9 \div 5$ & 2,276 & 184 \\
\hline
\end{tabular}

13. There are no government studs in England or the colonies.

14. As far as I know, no duties, whether for import or export, are charged in this country.

15. At present this office has, with regard to the number of horses and mules in the United Kingdom, no accurate information, but such information is promised.

16. In the army, with the exception of South Africa, the numbers at present are as follows:

\begin{tabular}{|c|c|c|c|c|}
\hline & Cavalry. & Royal artillery. & Mounted infantry. & Trausport. \\
\hline $\begin{array}{l}\text { Home } \\
\text { Egrut }\end{array}$ & $7,8+7$ & 9,940 & \multirow{3}{*}{$\begin{array}{l}120 \\
120 \\
100\end{array}$} & \multirow{3}{*}{$\begin{array}{r}2,884 \\
48 \\
1010\end{array}$} \\
\hline Jalta & & & & \\
\hline ludia & a 4,725 & 7,455 & & \\
\hline
\end{tabular}

17. On mobilization for home defense about 186,000 horses will be required. It is not known when or where they will be obtained. The number of horses required on mobilization for over-sea warfare will, of course, depend on the extent of the operations.

18. The anmual loss at home and in Egypt from all causes is 12 per cent.

19. Horses are retained from ten to eleven years.

20. In normal times the average number required anmually for the United Kingdom is 1,300.

21. No training is required of horses before they are issued to units, and they are bought broken or unbroken.

2:. No depots exist for breaking in horses before they are issued to units, but in normal times there are two depots for assembly of remounts, namely, Woolwich for artillery and transport; Dublin (including Lusk) for all branches.

23. All horses are branded with an army number, figures of over three digits, on the near hind foot; three digits and under on the off hind foot; squadron, battery, and company numbers on the fore feet.

24. According to the department furnishing this information, vaccination of horses in the British army is not carried 
out, but section 10 of the Regulations for Army Veterinary Services reads as follows:

The army vaccine institute of Aldershot will be under the direction of the professor of the army veterinary school, subject to the orders of the district veterinary officer of the command. He will be held responsible for the raccination of calves, and for the collection and issue of lymph. In these duties he will be assisted by the assistant professor of the school. He will submit to the district reterinary officer, for the information of the war office, a monthly return showing the amount of lymph issned from the institute, together with the results obtained by lymph issued during the previons month. He will furnish an ammal report on the working of the institute and its results, through the district reterinary officer, to the general officer commanding.

The district reterinary officer will ascertain, from time to time, that the stock of lymph on hand is not in excess of the quantity required to meet immediate demands, and that no lymph, which may have deteriorated from age or other canse, is issued.

This seems rather inconsistent with the statement that no vaccination is carried on.

25. Shoenck.-The following is taken from Regulations for . Army Veterinary Services:

\section{I. -REGULATION SHOE.}

The kind of shoe to be used in all branches of the service, mless otherwise specially ordered, is the "concave shoe"-that is, one which is concave on its ground surface and flat on its foot surface-for both fore and hind feet. The inner margin of the web in contact with the foot should be brought to a thin edge. The thickness and breadth of the web of the shoe will be miform all round. The lieels of the shoes will be rounded and well sloped.

The nail holes will be from six to eight in number, according to the size of the foot and weight of the shoe, and placed in the groove or "fullering " on each side. The nail holes on one side of the shoe will be opposite those on the other side; when only five nails are used, the inside heel nail will be left ont.

One toe clip is to be used with the fore shoe, and two toe clips with the hind shoe. In the case of draft horses, one toe clip only in the hind shoe may be allowed. A quarter clip may be used when required, in the case of "kickers." Calks may be used, when considered necessary, on light or draft shoes.

Tips, or half shoes, in cases of contraction, chronic thrush, sandcrack, corns, or other diseases or defects, also shoes with tumed-up toes, or other shoes for special purposes, may be used at the discretion of the reterinary officer.

\section{II. - HOW TO PREPARE THE FOOT AND FIT THE SHOE.}

When preparing the foot for the shoe, the ground surface of the wall will be lowered to a sufficient extent with the rasp. The drawing knife will not be used. The sole will be left uncut. The frog must not be 
tonched if it is sound and firm. If, however, it is ragged and soft, and inclined to thrush, it should be attended to and dressed. When necessary. the toes of the feet will be shortened by rasping the ground surface of the fore part of the hoof. The toes will not be shortened after the hoofs are shod.

The shoes made by farriers will not be fitted when too hot. The shoes will be made to fit accurately the outer edge of the crust round to, and including, the heels. It will not project beyond the wall at any point except a little at the heels. The outer edge of the wall will be well rounded with the rasp before the shoe is fitted or affixed, but no rasping of any kind will be permitted after the shoe is on. The nails will not be driven too high up in the wall, and the clenches are to be evenly laid.

Every horse is to be shod with new shoes when necessary. When the shoes are not worn out, removes are allowed at the discretion of the commanding officer or veterinary officers.

The practice of using grease, tar, or other dressings, to the horse's feet generally, will not be allowed.

Instructions with regard to the preparation and keeping up of shoeing books by farrier sergeants will be found in queen's regulations.

\section{ili.-INSPECTION OF SHOEING AT OUT STATIONS BY OFFICERS.}

At out stations, the officer in veterinary charge will supervise the shoeing. His attention is directed to the following points:

1. That the horses are kept well shod.

2. That the farriers make a daily inspection to see that no clenches are left up, that all broken nails are replaced and that unsound frogs are properly attended to.

3. That the sole and frog are unent with the drawing knife.

4. That the outside of the wall has not been rasped.

5. That the nails are not driven too high up.

6. That the toes are properly shortened in the way described.

Special facilities exist at out stations for training men to become shoeing-smiths and "cold-shoers." Officers commanding should, therefore, encourage men to attend the forge for instruction.

\section{IV.-DIMENSIONS OF HORSESHOES BY SIZES.}

For convenience of reference, the sizes of shoes, fore and hind, are divided and numbered 1 to 8 . The following tables give the approximate dimensions of the several shoes:

Fore shoes for riding, draft, and wheel horses.

\begin{tabular}{|c|c|c|c|c|c|c|}
\hline Size & Width. & Length. & $\begin{array}{l}\text { Wilth } \\
\text { of web. }\end{array}$ & $\begin{array}{l}\text { Average } \\
\text { weight. }\end{array}$ & $\begin{array}{l}\text { Number of } \\
\text { nail holes on } \\
\text { each side. }\end{array}$ & $\begin{array}{c}\text { Designation } \\
\text { number } \\
\text { of nails. }\end{array}$ \\
\hline $\begin{array}{l}\text { No. } 1 \\
\text { No. } 2 \\
\text { No. } 3 \\
\text { No. } 4 \\
\text { No. } 5 \\
\text { No. } 6 \\
\text { No. } 7 \\
\text { No. } 8\end{array}$ & $\begin{array}{l}\text { lurlies. } \\
4 \\
43 / 8 \\
43 / 4 \\
5 \\
51 / \frac{1}{3} \\
51 / 2 \\
53 / 4 \\
6\end{array}$ & $\begin{array}{l}\text { Inchex. } \\
41 / 4 \\
43 / 8 \\
5 \\
51 / 4 \\
51 / 2 \\
53 / 4 \\
6 \\
61 / 4\end{array}$ & 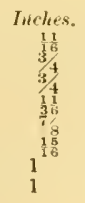 & $\begin{array}{l}\text { Ounces. } \\
8 \\
121 / 2 \\
14 \\
16 \\
171 / 2 \\
221 / 2 \\
25 \\
281 / 2\end{array}$ & $\begin{array}{l}3 \\
3 \\
3 \\
3 \\
3 \\
4 \\
4 \\
4\end{array}$ & $\begin{array}{c}3 \text { or } 4 \\
6 \\
6 \\
7 \\
8 \\
8 \\
9 \\
9\end{array}$ \\
\hline
\end{tabular}


Hind shoes for riding and lead horses.

\begin{tabular}{|c|c|c|c|c|c|c|}
\hline Size. & Wiath. & Length. & $\begin{array}{l}\text { Width } \\
\text { of web. }\end{array}$ & $\begin{array}{l}\text { A verage } \\
\text { weight. }\end{array}$ & $\begin{array}{l}\text { Number of } \\
\text { nail looles on } \\
\text { each sille. }\end{array}$ & $\begin{array}{c}\text { Designation } \\
\text { number } \\
\text { of nails. }\end{array}$ \\
\hline $\begin{array}{l}\text { No. } 1 \ldots \\
\text { No. }{ }^{2} \\
\text { No. } 3 \\
\text { No. } 4 \\
\text { No. } 5 \\
\text { No. } 6 \\
\text { No. } 7 \\
\text { No. } 8\end{array}$ & 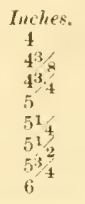 & $\begin{array}{l}\text { Inches. } \\
4^{1 / 2} \\
4^{7} \% 8 \\
51 / 4 \\
51 / 2 \\
53 / 4 \\
6 \\
61 \\
60^{1}, 4\end{array}$ & $\begin{array}{l}\text { Inches. } \\
\frac{12}{16} \\
3 / 4 \\
3 / 4 \\
3 / 4 \\
\frac{1}{3} \\
76 \\
7 / 8 \\
\frac{15}{16} \\
1 \\
1\end{array}$ & $\begin{array}{l}\text { Onueres. } \\
8 \\
13 \\
141 / 2 \\
161 \% \\
191 \% \\
24 \\
26 \\
29\end{array}$ & $\begin{array}{l}3 \\
3 \\
3 \\
3 \\
3 \\
4 \\
4 \\
4\end{array}$ & $\begin{array}{c}3 \text { or } 1 \\
6 \\
6 \\
7 \\
8 \text { or } 9 \\
8 \text { or } 9 \\
9 \\
9\end{array}$ \\
\hline
\end{tabular}

Hind shoes with calks for wheel horses.

\begin{tabular}{|c|c|c|c|c|c|c|}
\hline No. 5 & $51 / 4$ & $53 / 1$ & $7 / 8$ & 22 & 4 & $\begin{array}{l}8 \text { or } 9 \text { heel } \\
\text { holes, } 10 \\
\text { toe holes. }\end{array}$ \\
\hline No. $\mathrm{G}_{-} \ldots$ & $51 / 2$ & 6 & 15 & 24 & 4 & 8 or 9 heel \\
\hline $\begin{array}{l}\text { No. } 7 \ldots \ldots \ldots \\
\text { No. } 8 \ldots \ldots \ldots\end{array}$ & $53 / 4$ & $\begin{array}{l}61 / 4 \\
61 / 2\end{array}$ & 1 & $\begin{array}{l}261 / 2 \\
33\end{array}$ & 4 & $\begin{array}{l}9 \text { heel holes, } \\
11 \text { to } \\
\text { holes. } \\
9 \text { heel holes, } \\
11 \text { t o e } \\
\text { holes. }\end{array}$ \\
\hline
\end{tabular}

\section{V.-COLD-SHOEING.}

Veterinary officers are to make themselves acquainted with the details necessary to render the system of cold-shoeing as perfect as possible, and especially with regard to the requirements of field service. They should be able to recognize the different sizes of shoes and nails, and know the proportion of sizes required in the units to which they are attached, so that provision may be made for an ample supply in barracks, on the line of march, or in the field.

In working the system, commanding officers should give veterinary officers every support, as the latter will have to see that the shoeing is carried on with the utmost care and economy, and at the same time efficiently; that the instruction afforded by the farrier staff sergeant and sergeants to the shoeing-smith, acting shoeing-smiths, and learners, is carried out properly and thoroughly, and that as many men from the ranks as possible are trained to shoe. Attention is directed to the regulations issued with regard to keeping men already instructed in practice by having them in the forge at intervals, and for as long a time as may be necessary or convenient.

The chief feature in the system, and the one npon which the scheme is mainly based, is the adoption to a large extent of the practice of what is generally known as "cold-shoeing," i. e., the cold fitting of shoes issned ready for immediate use, and nails requiring no preparation, both being provided from store.

One-half of the shoes and nails required for units will be so supplied, the object in view being to main tain the practice of sloeing exactly as it would have to be performed in the field-quickly, simply, and efficiently; and to 
allow of the training of large numbers of men in the ranks as shoers, while also making provision for a supply of veterinary assistants for war service from the farrier staff sergeants and sergeants and shoeing-smiths who have successfully passed through the Aldershot or other recognized military veterinary school.

The remaining half of the shoes will be made from old shoes, and the remaining half of the nails from nail rod supplied on requisition, in order to instruct and keep the shoers in practice, so that in cases of emergency, as when the supply of shoes or nails fails, but the materials for making them are available, there may be no interruption to the shoeing. It is estimated that one and a half or two old shoes will suffice to make a new one.

Fuel, tools, aprons, and other materials necessary for shoeing, as laid down in the equipment regulations, will be supplied from store at regular intervals, or on application when required.

The maximum requirement of shoes should not exceed 18 sets a year per horse, and with care it may, under favorable conditions, be considerably reduced. The supply of nails is more than is necessary for new shoes; indeed, in the smaller sizes of shoes, and particularly the fore ones, all the nail holes need not be filled, five nails being generally sufficient for each shoe, if well placed and driven in the hoof; the surplus can therefore be utilized in removing shoes or replacing lost ones. Loss or waste of shoes and nails is to be carefully guarded against, and when it can be clearly proved that this is due to negligence on the part of the farriers, or others, they should be required to replace them at their own expense.

A new rasp should last, when supplemented by an old one, from six weeks to two months, or longer. This is the tool which must be replaced most frequently. The wear of the other tools is indefinite, but they will not be replaced at the public expense unless certified that they are fairly worn ont, or broken or lost through no fault of the farriers.

It is necessary that the training of farrier staff sergeants and sergeants and shoeing-smiths, to act as hospital assistants on active service, be kept up in regiments, even when they have passed a course of instruction at the Aldershot or other recognized military veterinary school; and veterinary officers are to afford them every opportunity in this direction.

The squadron shoeing-smiths are to be trained so as to be in readiness for promotion to the rank of farrier sergeant; and those who are to be made shoeing-smiths should be selected from the best men for the purpose.

It is incumbent upon commanding officers to watch carefully the working of the system, in order to prevent waste, and they will hold the veterinary officers in charge responsible that the horses are not shod oftener than is actually necessary, and that all shoes, nails, iron, and coals issued to the farriers are appropriated solely to the uses for which they are supplied.

\section{VI. -INSTRUCTION OF SOLDIERS IN COLD-SHOEING.}

With the view of insuring thoroughness and uniformity in the instruction of soldiers in shoeing horses, in the manner required to be followed on active service, directions for instruction are laid down in Appendix VIII. Shoes are provided ready for immediate application to the hoofs, or needing only trifling alteration in shape in special cases; and nails are also 
issued, "pointed" and finished in such a way as also to be ready for use without further preparation.

The different steps in the operation of shoeing are to be adopted methodically and progressively, and taught thoroughly.

For instruction, men are to be preferred who have been accustomed to work in a forge, to handle a liammer, or to manipulate horses' legs and feet.

No man is to be dismissed as proficient who can not shoe a horse, serviceably well, within an hour.

Level, even fitting of the shoe to the foot and careful and solid nailing on are the chief objects to be attained in this system of shoeing.

\section{VII. - WINTER SHOEING BY THE INSERTION OF FROST NAILS.}

These nails are intended for "roughing" horses in frosty or slippery weather, and are made of mild steel, having chisel-shaped heads. The heads are hardened, but the shanks are not.

The "small" size is similar in shape in the shank to the ordinary horseshoe iron nails, and is suitable for use by medium or light cavalry and other riding horses. The shoes for such liorses will range from No. 2 to No. 4 or 5 sizes.

The "large" size nails are suitable for mounted services otler than those mentioned above, the shoes for which range from No. 5 to 8.

The average weight per 1,000 is: large, $35 \frac{1}{2}$ pounds; small, 24 pounds.

The following general instructions for the use of these frost nails are published for the information of all those concerned:

One should be inserted in each heel of each fore shoe, and one in the onter heel of each hind shoe, where there are no calks or wedge heels; or, should it be considered expedient, in the case of draft or other heary horses one nail would be inserted in each heel, and in the toes when considered requisite. For this purpose the "small" nail will do, as the shank will, if necessary, penetrate the hoof.

For draft horses an oblique hole similar to those in the heels should be stamped between the first and second toe nail holes, so that frost nails can be readily inserted in the same manner when required.

These holes would take the small or large frost nails at discretion.

It is a good plan to have the head of the ontside nail across the shoe, and the inside one in the same line as the shoe, so as to prevent injury to the opposite leg of the horse.

The success of these nails entirely depends on the accuracy with which they are fitted to the nail holes. The conntersunk portion of the nail head should be completely embedded therein, only allowing the "chisel" head or sharp portion to remain above the shoe, otherwise an undue strain is caused on the neck of the nail, which breaks or wears loose, or bends over. Too much attention can not be paid to this, as a neglect of it often leads to failure.

The horses must be shod a little wider at the heels than usual, to allow of exit of nails without penetrating the horn, and the nail hole must be punched exactly on the wearing surface, from whence it should pass obliquely upward and ontward to the npper surface of the shoe. The nail should fit tightly; to insure this, it is a good plan, after the nail is 
turned ontward from the shoe to let the horse put his full weight on it, and then to fasten it.

A groove may be made in the shoe where the nail turns over at the side of, and under, the shoe. This would protect the shank and also prevent its striking the opposite leg.

It is not necessary to remove the nails when the horses return to stables, but it may be done at discretion. No special tools are needed for the use of these nails; the ordinary stamp and pritchel are suitable, and the nails are readily removed with pincers.

Sample shoes, showing the exact way of making the holes and securing the nails, will be supplied on demand for the guidance of farriers.

To avoid waste and loss, all unused frost nails at the end of winter are to be returned by commanding officers to the chief ordnance officer of the district.

At the discretion of the veterinary officer the shank of the nail may be pinched off abont half an inch from the foot surface of the shoe; this can be done by making a nick in the nail with the edge of the rasp; a twist or two of the pincers will then break the nail. The part of the shank remaining should be firmly fastened by being hammered down.

26. Shoeing is carried out in all units by the farriers under the orders of the commanding officers, and supervised by the veterinary surgeons in the forges.

2\%. Horses are groomed twice a day in winter, i. e., morning and midday, but when they do not come in from work before the dinner hour, they are groomed in the afternoon. At the evening stable hour little grooming is done, but horses are rubbed down and wisped.

28. Forage.-The following is taken from the Regulations for the Allowances of the Army:

SCALE OF ISSUES IN KIND AT HOME.

The following are the daily issnes of forage for horses in the United Kingdom:

\begin{tabular}{|c|c|c|c|}
\hline & Oats. & IIty: & Straw. \\
\hline If in quarters & $\begin{array}{c}\text { Poumils. } \\
10\end{array}$ & $\begin{array}{c}\text { Poncels: } \\
12\end{array}$ & Pounds. \\
\hline $\begin{array}{l}\text { If in camp, or in other circumstances which are, in the opinion of the gen- } \\
\text { eral officer commanding, equivalent to being in camp. ( } A \text { special report } \\
\text { should, in the latter case, be made to the war office) }\end{array}$ & 12 & 12 & Nil. \\
\hline
\end{tabular}

For cobs the daily issues will be 2 pounds of oats less than the above.

The ration of forage counts from the midday feed of the day for which it is drawn, and therefore includes the morning feed of the next day.

An extra issue of 2 pounds of oats may be made as follows:

(a) For horses of the army service corps throughont the year when drawing wagons at a trot.

(b) For all horses-other than those drawing under (a)-employed at draft work for at least five hours a day during the period from October to April, inclusive. 
(c) For horses employed on special work which, in the opinion of the general officer commanding, renders the issue necessary, a special report being made to the war office.

(d) For draft horses, of the army service corps, of 16 hands and over in addition to the ration they are otherwise entitled to whether in quarters or in camp.

The ration for mules at home will be as follows:

Mules of 15 hands and upwarl emj hyed on heary draft work The same if in encampments

smailer mules

The same if in encimpments

\begin{tabular}{|c|c|c|}
\hline Oats. & Hity. & Straw. \\
\hline $\begin{array}{r}\text { Poninils. } \\
\text { fo }\end{array}$ & $\begin{array}{c}\text { Poumels. } \\
12\end{array}$ & lonnerls. \\
\hline 12 & 12 & Nil. \\
\hline 5 & 10 & 13 \\
\hline 6 & 12 & Sil. \\
\hline
\end{tabular}

The ration for registered horses employed for mobilization purposes will be as follows:

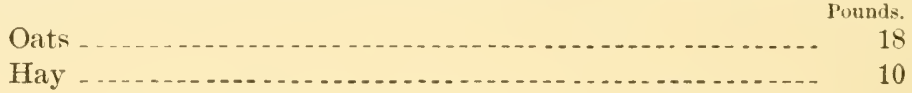

The authorized ration is laid down as being sufficient for the average requirements of horses. Officers commanding mounted units will nse their discretion, as a matter of regimental arrangement, in directing the distribution of the proportions of the full ration. Power is also given in the conditions of contract which will further enable the officer commanding to vary the food of the horses of the unit by giving equivalents in lien of a portion of the ordinary ration.

The following scale of equivalents shows the substitutes which are allowed to be drawn where necessary (all equivalents of each other):

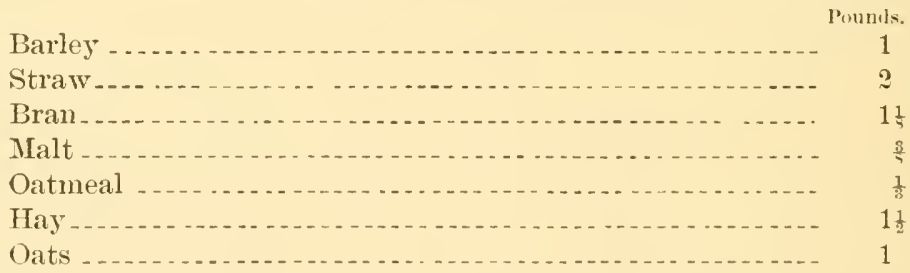

Carrots, green fodder, linseed, and mangelwurzel, and other articles, are in lieu of oats or hay, the issues to be regulated according to their average market value as comprared with the contract rates for the oats or hay for which they are substituted.

Deriations from this scale may be made in special cases at the discretion of the general officer commanding, provided the variations sanctioned do not give rise to increased cost.

29. No compressed forage is issued except foreign and colonial hay (and there is no rule to regulate this) which is sometimes bought in place of the home-grown supply.

30. Officers of cavalry, horse artillery, staff, and infantry supply their own horses at their own expense. In the field artillery the goverument supplies ofticers free of charge. 
The regulations permit all officers to hire horses for $£ 10$ per annum, and officers under the rank of lieutenant colonel to purchase remounts, under certain conditions, but the revision of these rules is now under consideration.

\section{COURSE OF INSTRLCTION OF SOLDIERS IN SHOEING.}

[Regulations for Army Veterinary Service, Appendix VIII.]

InstrLCTION 1.-The easiest and safest method of seizing, lifting, and holding the horses' front and hind feet, as in the operation of shoeing.

Note.-This instruction should be carried ont on old steady horses, and particnlar care shonld be observed in showing how the shoer is to manage a restless or vicions horse, and the precautions to be adopted to gnard himself from injury. Patient and gentle treatment should be inculeated.

How to shoe tronblesome horses with the side line on the hind leg is also to be taught.

IxSTRtetion 2.-The best and most expeditions way to take off fore and hind shoes.

Note-Completely cut off all the clinches, insert pincers between shoe and hoof, toward the extremity of inside heel, pry steadily and firmly downward and across the foot to start heel nails, and withdraw these; then apply pincers to ontside heel in the same mamner, withdrawing nails, and so on mintil the shoe is off.

Show how to remove broken nails from the hoof when the shoe is off; and also how to take off shoe from a painful foot, by driving the nails down ward from the front of the hoof and withdrawing them one by one.

Ixstruction 3.-How to handle the rasp, and reduce the wall of the hoof properly to its normal dimensions.

Note.-The proper length and natural slope of the wall are to be shown, and the method of obtaining these in an overgrown hoof demonstrated. This is important. Hoof to be made quite level on the gromnd surface, which shonld have a wide and solid bearing for the shoe to rest upon. The sides of the hoof should be equal in height, so as to keep leg and foot in a straight direction. Toe of hoof well shortened; heels not too much lowered. Sole and frog to remain strong and mmpared, loose fragments only being removed. Edge of the wall to be ronnded.

Ixstrection 4.-How to fit a shoe properly and quickly.

Note.-As it is not possible to provide shoes to fit all hoofs exactlythese varying greatly in size and form-the number of the size required should be explained, and if alteration in length or shape is needed how this should be effected-making the shoe narrower or wider, more elongated or more circular, as the shape of the hoof may demand. The shoe should fit the full ontline of the hoof. A sinall portion of the horn must be removed at the toe of the fore foot, sides of toe of hind foot, to effect this and to lodge the clip. If the alteration is made on the anvil, it should be by a series of firm, steady, and not too heavy blows of the hammer. When altered to the proper shape, the shoe shonld be made perfectly level by hammering it lightly on the surface; this also makes it wear better.

Instruct how to alter shoes withont an anvil, as on the tire or nave of a cart wheel, stone, ete.

Nail holes to be easy for the neck of nails; if too tight widen from the fuller surface, not the back of the shoe. With holes too tight, the nails break at the neck. Show how to narrow or close fuller, so as to allow smaller nails to be used in case of necessity.

There should be solid and close coadaptation between the surface of hoof and shoe, to insure the latter being well retained. Shoe to rest on 
the entire width of the wall and margin of sole. All but the heavy hind shoes with calks can be altered in a cold state, as a rule; and these can be also altered to some extent without heating them, when alteration is necessary.

INSTRUCTION 5.-How to nail on a shoe safely and securely.

Note.-The shape of the nail is to be explained and the reasons for the bevel at the point insisted upon, in order to prevent the nail from entering the sensitive parts of the foot. The mode of driving the nails; height to which they should be driven in the horn; their direction-toe nails lightly forward, so as to include more of the fibers of the wall; when all are inserted, how they shonld be driven home and drawn up at ends (with the fore feet toe nails first, and firmly; heel nails last, and lightly).

INSTRUCTION 6.-How to finish shoeing.

Note.-Laying down and embedding the ends of the nails, or "clinching," to be taught; and the necessity for the clinches being strong, and projecting as little as possible beyond the wall, especially on the inside of the hoofs.

The surface of the wall not to be rasped except round the edges between it and the shoe.

It is desirable, if possible, to acquaint the men under instruction with the structure of the horse's foot, even should the instruction be very elementary, the hoof being the chief subject for consideration.

How to fasten a loose shoe; how to make a hind shoe fit a front foot, and vice versa, on an emergency; how to remedy too fine or too coarse nail holes; and how to act when a nail has been accidently driven into or too near the quick, should also be taught.

HORSES, COBS, AND MULES PURCHASED BY GREAT BRITAIN BETWEEN OCTOBER 1, 1899, AND MAY 31, 1901.

\begin{tabular}{|c|c|c|c|c|}
\hline Country. & Horses. & Cobs. & Total. & Mules. \\
\hline Great Britain & 35,197 & 3,149 & in, 346 & \\
\hline Ireland & 7,372 & 4,147 & 11,519 & 166 \\
\hline Argentina & 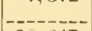 & 25,872 & 25,872 & \\
\hline Inited states of America & 10,647 & 30,412 & 41,059 & 56,987 \\
\hline Canada & 3,664 & 824 & $4,4 \times 8$ & -.---n- \\
\hline Australia & 7,118 & 3,083 & 10,201 & 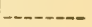 \\
\hline Hungary - - & $6,9.45$ & 5,400 & 12,345 & $-1--1$ \\
\hline Italy & 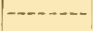 & $-\infty-\infty-\infty$ & $---1--1$ & $\because, 004$ \\
\hline $\begin{array}{l}\text { Spain } \\
\text { Cyprus }\end{array}$ & -- & - & & 15,229 \\
\hline 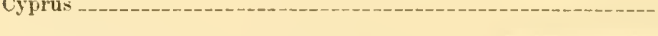 & & & & 128 \\
\hline
\end{tabular}

The official returns give the number of remounts purchased abroad for the South-African campaign as $6 \%, 958$ for 1900 and 91,983 for 1901. The total number of horses sent to South Africa from the British Isles, India, the colonies, and from abroad, in 1900 and 1901, is $242,311$.

\section{BRITISH COLONIES.}

[From "Zucht und Remontirung der Militär-1'ferde aller Staaten," by Dr. Puul Goldbeck, Berlin, I901.]

INDIA.

It is natural to suppose that England would take energetic measures to promote raising in this, her most important colony, but horse raising, as well as agriculture, in India 
depends in a great measure on the timely arrival of the monsoon, and, as droughts are prevalent, horse breeding suffers as a consequence. Until $18 \% 6$ the government kept its own studs, but the results were so poor that this method was abandoned and an entirely new system introduced. At present rural studs and government stallions are maintained, the latter being sent to depots. The purpose of these measures was to obtain good cavalry remounts. The mares are inspected and if declared fit for breeding are branded "V I" (veterinary inspection) on one shoulder and are served by the government stallions free of charge. Not all parts of India are by any means adapted to horse breeding, the famine districts being in this respect absolutely excluded. Breeding flourishes most in the northwestern provinces of Punjab, Beluchistan, and Sind, and in Deccan, of the Bombay presidency.

Table showing number of stallions kept by the government, together with the number of mares served by them in 1898-99:

Full-sized types:

Thoroughbreds and three-fourth breds_......... 103

English half-breds and Norfolks . . . . . . . . . . . . . 58

Hackney ... ............................ 44

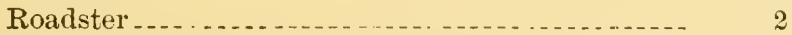

Australian ..................... 47

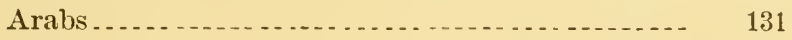

Local breeds ... . . .

Total stallions .

Ponies:

Arab ............ 18

Local breeds .............................. 1

Total pony stallions . . . . . . . . 18

Total stallions, including pony stallions........... 408

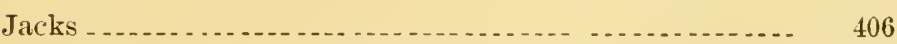

Number of mares .

The English thoroughbred has done good work in the improvement of the races in India wherever good specimens were employed, but it has become unpopular owing to the poor specimens, so that Australian thoroughbreds are now preferred. Hackneys have been utilized to increase the size of the native breeds, but the products soon become too bulky 
for cavalry purposes. Arab stock is very popular, as it perpetuates its traits and eliminates many weak points inherent in the native mares.

Besides the government stallions mentioned, numerous provincial governments and private parties keep breeding stallions, these amounting in 1898-99 to 198 animals, among which the Arab blood predominated.

The best known of the native races of nearer India are the Punjabs. In general the horse bred here is a small animal $1 t^{\frac{1}{2}}$ hands high, resembling the Afghan; there are, however, also larger horses called "Turki" or "Irani."

In Bengal the native horse is a pony 12 to 13 hands high.

In farther India an excellent pony is found in Burma, but neither mares nor stallions of this race are exported.

Mule breeding is given, in India, considerable attention, the number of jacks used for this service in 1899 having been 406.

There were in India in 1897 a total of 1,120,194 horses, $1,116,072$ mules and asses, and 233,477 camels. These were distributed as follows: Northwest provinces and Oudh, 493,000 horses and 309,000 mules and asses; Punjab, 271,000 horses and 55\%,000 mules and asses; Bombay, 152,000 horses and 67,000 mules and asses.

It is the aim of the Indian government to supply the troops exclusively with horses bred at home. This plan, however, is not yet entirely feasible, although energetic measures have been taken to promote horse breeding.

The native cavalry consists of 19 regiments of Bengal lancers, 5 of Punjab cavalry, 1 queen's own corps of guides in Mardan, 1 detachment of police in the Northwest Province and Oudh, 2 in Punjab, 1 detachment imperial serrice corps troops, 2 regiments central India horse, and 1 remount depot. The number of horses in a native regiment is abont 600. Of the English imperial troops only three regiments obtain their remounts in India, all the artillery and the remainder of the cavalry purchasing Australian horses. The native cavalry troops, on the contrary, are supplied almost entirely with home-bred horses. The remounts for native troops are purchased full-grown, and the number bought in 1899 was 1,763 . There were also purchased 1,571 mules for the English troops and 1,281 for the natives, mainly for purposes of transportation. Special committees are sent to Australia for the 
purchase of remounts for the artillery and part of the cavalry. The Indian cavalry received a valuable addition in 1890 in the shape of a camel corps which by 1833 had 500 camels. The animals are bred in a government establishment.

CANADA.

In Canada hardly any beginning has been made in systematic horse breeding. Manitoba, however, has a stallion register in which some 250 stallions have been entered, and a studbook is also kept for the foals produced. The eastern provinces have little or no importance as horse-breeding districts, while the western territories in some localities produce a considerable number of horses. The province of Alberta, especially, may be regarded as the center of the horse-breeding industry, the winters there being short and the pastures suited for the purposes. The breerling of heary horses is scarcely sufficient for the needs of the mining districts. The number of saddle horses produced is, on the contrary, quite large, being estimated at 30,000 head. In 1892 a number of breeders in the region of Alberta sent a petition to the governor general of Canada, stating that a large percentage of the thousands of light saddle horses raised at Alberta would be very suitable for remounts for the English army; that much English thoroughbred blood had been introduced of late, and that, as a consequence, the breed had been materially improved. The only thing stated to be lacking was a market. Furthermore it was claimed that the Canadian Pacific Railroad facilitated transportation and warranted the establishment of a remount depot at Calgary. Finally, it was asserted that the price of the horses was very low. The plan, although at first regarded favorably, was never carried out. A tour of inspection of the horses was made by two remount officers, who decided that the majority of the horses were unsuited for military use. This opinion was coincided in by the inspector general of remounts. A German horseman by the name of Hofaker, on the other hand, gave, after a visit to a ranch at Calgary, a much more favorable opinion of these horses.

In the provinces of Ontario and Manitoba there were in $189 \%, 613,670$ and 100,274 horses, respectively. For the other provinces statistics are lacking. 
CAPE COLONY.

The number of horses in 1897 was 357,960 .

In Cape Colony and Natal together there were, before the Boer war, four cavalry detachments with about 1,200 horses, all from Cape Colony.

\section{AUstralia.}

The total number of horses in Australia (inclnding New Zealand and Fiji) in 1897 was about 1,935,000, distributed as follows: New South Wales, 498,034; Queensland, 479,280; South Australia, 164,820; Victoria, 431,547 (in 1895); West Australia, 62,222; Tasmania, 29,898; New Zealand, 252,834.

In the most important colony, New South Wales, there were in 1898 :

\begin{tabular}{|c|c|c|}
\hline & Thoroughbret. & Ordinary. \\
\hline $\begin{array}{l}\text { Heavy draft horses } \\
\text { Light draft horses }\end{array}$ & \multirow{2}{*}{$\begin{array}{l}18,473 \\
13,758 \\
26,338\end{array}$} & \multirow{2}{*}{$\begin{array}{l}125,234 \\
108,308 \\
174,702\end{array}$} \\
\hline $\begin{array}{l}\text { Light draft horses - } \\
\text { Saddle horses - }\end{array}$ & & \\
\hline
\end{tabular}

The prices are very low. Heavy draft horses bring only $\$ 4 \% .60$ at auction in New South Wales; in West Australia from $\$ 4.75$ to $\$ 9.50$ more. Saddle horses cost about $\$ 28.60$, only the best (the Indian remounts) coming to \$r1.40. The exports are inconsiderable, amounting to 1,865 horses in $189 \%$, of which 1,189 went to India. As England has been purchasing a great number of remounts every year in Australia, interest has been awakened in the breeding of a stronger saddle horse than formerly.

As there is no standing army there is no remount service. Each colony, however, has a few batteries of permanent artillery, for which the necessary horses are bought in open market. There are also a few regiments of volunteer cavalry, partly lancers and partly mounted infantry-a sort of militia. Each volunteer has to secure his own remount. Australia is an important source for remounts, not only for the British colonial forces, but also, to an extent not yet appreciable, for mounted troops of other powers, particularly those in East Asia. Good thoroughbreds are imported to a great extent from England to improve the Australian breeds. An excellent half-bred saddle horse is raised in New South Wales and Victoria. 
NEW ZEALAND.

In New Zealand the method of breeding is in general the same as in Australia, but the industry has reached a higher stage than in the latter country. The number of horses in 1898-99 was 258, 649 , having increased by 5,442 since $1897-98$. The breeding stallions in service in 1898-99 were as follows: Thoroughbreds, 509; hunters and hackneys, 134; trotters, $23 \%$; light draft stallions, 409 ; pack horses, 780 ; ponies, 169 ; asses, 26. The total number of mares used for breeding purposes in the same year was $1 \%, 835$. No government aid is afforded to the horse-breeding industry. Draft horses cost $\$ 18$ to $\$ 30$ each, saddle horses and coach horses, \$7 to $\$ 25$ each. In 1898 there were exported 3,210 horses, of which 2,639 went to New South Wales and 116 to Bengal. 



\section{VIII.-I'TALY.}

[Reported by Capt. T. Bentley Mott, Artillery Cor]'s, United] States Military Attuché at Paris.]

What follows applies to horses in Italy. The few that are required for service in the Italian-African colonies are bought in Africa.

HORSE AND MULE CENSUS.

The latest figures are the following:

\begin{tabular}{|c|c|c|c|}
\hline & IIorses. & Mules. & $\begin{array}{c}\text { Horses aud } \\
\text { mules. }\end{array}$ \\
\hline Total in Italy - . & \multirow{2}{*}{750,1000} & \multirow[t]{2}{*}{330,000} & \multirow{5}{*}{$\begin{array}{r}1,080,000 \\
47,347 \\
21,251 \\
14,74 \\
11,350\end{array}$} \\
\hline Total in the army, including othicers' horses.-.-.-- & & & \\
\hline Total in the cavalry, incluling officers' horses & & & \\
\hline Total in the artillery and engineers, including ofticers' horses & & & \\
\hline Otber services. & $--2 .-2$ & & \\
\hline $\begin{array}{l}\text { Additional number required in case of mobilization for war, to } \\
\text { be brought or requisitionerl in Italy }\end{array}$ & & & 217,00 \\
\hline
\end{tabular}

\section{IMPORT AND EXPORT DUTIES.}

These duties are so insignificant that it may be said that practically there are no import or export duties on horses in Italy.

\section{YEARLY PURCHASES.}

The average number of horses bought each year by the remount depots is 3,680 . About 600 more are bought directly by the regiments. The cavalry takes about 2,600 , the artillery about 1,200 .

\section{PRICES.}

Cavalry, from $\$ 96.50$ to $\$ 193$ for troop horses; artillery, $\$ 193$ for wheel and $\$ 164.05$ for lead horses; mules an average of $\$ 173 . \% 0$. These prices include the cost of transportation to the destination

\section{PERCENTAGE OF LOST AND CONDEMNED ANNUALLY.}

In the artillery this loss is estimated at 10 per cent; in the cavalry it is somewhat greater. In the cavalry, horses adjudged unfit for active service, but still capable of doing less 
exacting work, are transferred to the train or sold to infantry officers at low rates.

The average number of years that horses are retained in service is: cavalry, 12; artillery, 13; mules and draft horses, 15 years.

\section{METHOD OF SUPPLY AND SPECIFICATIONS.}

All animals are bought in the market, none are raised on government farms.

\section{CAVALRY.}

Horses are bought for the remonnt service of the cavalry by boards sent ont in the spring from the different remount depots. The regiments are also authorized to buy horses between 4 and 8 years directly, provided it is established that they are raised in Italy.

The cavalry remount depots are under the direction of a colonel in the cabinet of the minister of war.

In the matter of getting suitable horses much is left to the judgment of the horse board, and the specifications are very general in their nature. Horses bought for the cavalry may be mares or geldings, of any color, between 2 and 3 years old, showing the requisite breeding and conformation. Lancers' horses should be from $15^{\frac{1}{4}}$ to 16 hands high; lightcavalry horses from $14 \frac{1}{4}$ to $15 \frac{1}{4}$ hands and weigh about 880 pounds.

These horses as soon as bought are sent to the raising depots, where they are kept until $4 \frac{1}{2}$ years old, when they are sent to the regiments. At these depots they are not seriously trained, but only handled and given sufficient exercise to keep them in good health. The training is all done in the regiments. There are six of these raising depots, four on the peninsula and two in the islands.

A good number of English thoroughbred stock is bought. In the islands they get a strain of Arabian blood that has come down from ancient times.

\section{ARTILLERY.}

Horses and mules for the artillery must be mares or geldings, of any color except gray, between $4_{2}^{\frac{1}{2}}$ and 8 years old, must weigh about 1,100 pounds, and must have a good disposition, and the breeding and conformation necessary for the service in view. Horses for field batteries and horse batteries 
should all have generally the same qualities as those demanded of wheelers. Mules must be good for the pack service of mountain artillery.

Horses of any blood are procured by purchase, the chief foreign races being American, French, or German; some French mules are also bought. The proportion of males and females should be about equal. Horses should be from $14_{4}^{3}$ to $16 \frac{1}{2}$ hands high; mules from $14_{4}^{\frac{1}{4}}$ to $15^{3}$.

Boards of artillery officers with a veterinarian buy all the horses and mules for the artillery and engineers.

\section{BRANDING.}

Horses and mules are branded with hot iron on the left hip. The mark is a cross and the number of the regiment.

\section{VACCINATION.}

Rarely practiced; against anthrax the Pasteur virus is occasio tally used.

\section{SHOEING.}

The method known as hot-shoeing is practiced, the hot shoe being applied to the hoof before being quenched and set. The Italian model of hand-forged shoe is used exclusively.

\section{FORAGE.}

The composition of the forage allowance is as follows:

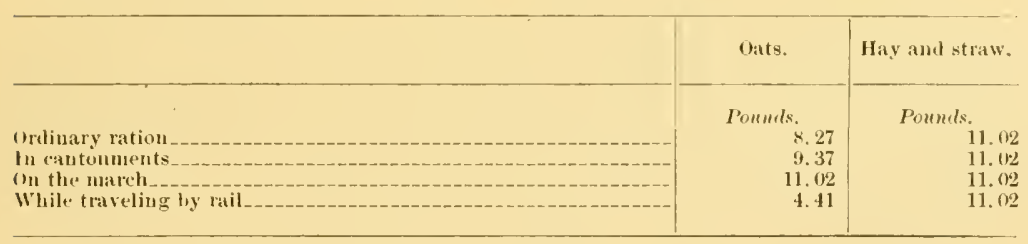

Compressed hay is very rarely used.

STUDS.

The army has at Persamo one small breeding establishment intended to distribute amung raisers brood mares of good blocd. This has been established very recently.

However, separate from the army, seven stallion depots are kept by the state for the purpose of encouraging, throughout 
the country, the raising of well-bred horses. These establishments have 600 stallions. Private stallions, before they are permitted to serve, have to be submitted to inspection and approval of a government board. The services of the government stallions cost generally from $\$ 2.31$ to $\$ 2.2 .2$ per mare served, though there are a few unusually fine animals for whose services $\$ 38.60$ to $\$ 115.80$ or more is paid. Thus the Italian government bought Melton, the winner of the Epsom Derby of 1885 , and his services cost $\$ 193$ per mare.

The majority of these state stallions are full or half blood English or Arabian and some hackneys, Clydestales, and Brabants.

\section{OFFICERS HORSES.}

In order to assist mounted officers in the acquisition of good service horses, a certain number of mounts are distributed each year, or advances of money made for the purchase of mounts. Such horses are denominated "cavalli de agevolezza." They are divided into the following categories:

\section{SPECIAL.}

CATEgORY A.-Horses for general officers.

CAtegory B.-Horses for general officers, for general staff officers, for cavalry officers, and for artillery officers entitled to the horse allowance of $\$ 54.60$.

\section{ORDINARY.}

Category 1.-Horses for general staff officers; cavalry officers; artillery officers; colonels and lientenant colonels commanding corps: and chiefs of service of infantry, engineers, the sanitary corps, the commissariat, and the military veterinary; but not for infantry staff oflicers.

CATEgORIES 2 AND 3.- Horses for officers of any grade in the infantry, engineers, the sanitary corps, the commissariat, and the military reterinary service.

The greatest debt which an officer may incur for a horse furnished by the state, or for advances made, may not excred $\$ 390$ for a general ofticer or a colonel holding the post of a major general, \$292.50 for an officer entitled to a horse allowance of $\$$ is and more, $\$ 224$ for an officer entitled to a horse allowance of $\$ 66.30, \$ 195$ for an officer entitled to a horse allowance of $\$ 54.60$. 
In special cases the minister may authorize an officer to exceed the maximum limits mentioned above. In such a case an officer, in addition to the horse allowance, must have delucted from his pay each month $\$ 1.04$ for each $\$ 48.75 \mathrm{or}$ fraction thereof until the debt has come within the limits mentioned. These horses, to whatever category they may belong, must be paid for within three years. After the last payment the horse becomes the property of the officer. When such a horse becomes unfit for service on account of physical defects, infirmities, or vices, the permanent conncil of administration, as well as that of the regiment to which the officer belongs, assisted by a veterinarian, examines the horse and gives authorization for its sale, the proceeds to be paid to the remount service if the debt has not yet been liquidated.

Horses belonging to the special category A are drawn from those of the cavalry school, recognized to be in sound condition, of good disposition, well broken, and from : to 12 years old, and are selected by a commission composed of two general officers, and one superior veterinary officer. This commission fixes the prices, which must not exceed $\$ 39 \% .50$ per horse.

Special category B horses are between $4 \frac{1}{2}$ and $\%$ years old, and are acquired either abroal or from the studs. In the former case their price does not exceed $\$ 39 \% .50$ each. In the latter case they have, according to the price established by the depot council of administration, a value of from $\$ 2.4$ to $\$ 292.50$ each.

Horses of the ordinary categories are selected in the caralry regiments by commissions nominated and presided over by the commander of the brigade and composed of one field officer, two subaltern officers, and one veterinary officer for each regiment.

The horses are classed as follows:

First category, those from 5 to 9 years of age.

Second category, those from 9 to 12 years of age.

Third eategory, those of 12 years of age and more.

The minimum height of the horses is:

For the first category, $14 \frac{3}{4}$ liands.

For the second and third categories, $14_{\ddagger}^{1}$ hands.

The cost is as follows:

First category, between $\$ 22 t$ and $\$ 175.50$.

Second category, between $\$ 165.15$ and $\$ 96.50$.

Third category, $\$ 8 \% .55$ and lower. 
The horses procured on the market for money advanced are entered in the proper category and are assigned as follows:

First category, t-year-olds (thoroughbreds may be 3 -yearolds) to 9-vear-olds and of a value not under $\$ 175.50$. second category, from 5 to 12 years and of a value not under $\$ 96.50$.

Third category, from 5 to 14 years and of a value not under $\$ 58.50$.

The height must be between $14 \frac{1}{4}$ and $15 \frac{1}{2}$ hands for officers entitled to second-grade rations, exception being made for officers over 5 feet 9 inches in height who may procure horses $15^{3}$ hands high. Officers entitled to forage of the first grade have mounts between $15 \frac{1}{4}$ and $15 \frac{3}{4}$ hands high.

The horses procured on the market by general officers for money advanced are entered into one of the two abovementioned categories, according to age, value, and height.

The advances of money for the acquisition of lorses come generally from the treasury of the corps to which the officers belong or from the mits in which they serve.

ASSITNMENT OF HORSES TO SEBALTERN CAVALRT OFFICERS.

Thirty-four horses in each cavalry regiment are assigned to subaltern cavalry officers. These mounts are selected from among the best received by the regiment from the studs or from the cavalry remount service. These horses, called chargers, are entered on a special roll (the roll of chargers) and are distributed among the squadrons. The chargers are not branded, and are not subject to the regulations for troop horses with regard to uniformity of dimensions and cut of the tail. Chargers are obligatory for subaltern officers but optional for captains and field officers.

A corps commander may permit a lieutenant, applying for such permission, to turn in the charger received from the state and substitute for it one of his own.

A newly appointed second lieutenant who has graduated from a military school must, before entering the cavalry school, join the regiment to which he has been assigned, and there the commander, taking into account the build, the aptitude, and even the wishes of the officer, assigns him a horse from among the available chargers of the regiment.

The charger is nsed only in the service and on such occasions outside the service which the commander believes 
convenient. It may be kept in the stable of the officer to whom it has been assigned.

The expenditure for bedding and shoeing for officers' mounts is charged to the fund assigned for those purposes for troop horses.

A corps commander, for the good of the service or on request of the interested parties, may anthorize officer's to turn in horses assigned them and take others from those available in the regiment.

The chargers are dropped from the roll of officers' horses after six years, and are then carried as troop horses and may be selected for sale on installments of the second and third categories. If, however, a horse, in the judgment of the officer to whom assigned, shows special aptitude for continuation in the service as a charger, the commander may leave him on the roll for another term. The commander may have the horse dropped from the roll before the expiration of the six years if the animal is found unfit for service as an officer's horse. Reports of such cases are sent to the minister. If unfitness results from carelessness of the officer to whom the horse has been assigned, the comncil of administration of the corps derlucts from the remount allowance of the responsible officer the sum representing the depreciation of the horse.

The annual supply of chargers to the corps is at the most one-sixth.

ASSIGNMENT OF HORSES TO SUBALTERN OFFICERS OF THE FIELD ARTILLERY AND HORSE ARTILLERY.

In field artillery and horse artillery regiments there are a number of horses called chargers, taken from the best horses coming from the studs, the ordinary remount service, or the special remount service ordered by the minister for this purpose. These horses are distributed among the batteries of these regiments, to be assignerl to subaltern officers of these regiments, with the exception of the train. Some of these horses are assigned also to the staffs of these regiments.

The chargers are entered on the rolls like battery horses with, in each case, the special note as charger, to which is added, "Assigned to - on —_," if for an officer. A report is made to the minister each time a horse is entered upon the roll or assigned to an officer. The chargers are not branded and are not subject to the dispositions in force with regard to battery horses referring to dimensions and cut of the tail, 
but, when not assigned to some officer, these horses seıve as saddle horses on the same footing as the battery horses.

The use of these horses is optional to captains of field artillery and horse artillery regiments, but obligatory for subaltern officers. The commanders of corps may, however, authorize subalterns, requesting permission, to substitute private horses for the chargers. The charger is used only in the service and in such cases outside the service in which the commander sees fit to permit its use. It may be kept in the stable of the officer to whom it has been assigned. Expenses for bedding and shoeing for officers' mounts fall to the sum allotted for those purposes for battery horses. The forage rations are the same as for battery horses. The care of the horse is provided by the officer. The corps commander, for the good of the service or on request of the interested parties, may authorize officers to change chargers for others from among the available horses of the same category.

When a charger is found unfit for the service as an officers' horse, he is carried on the roll as a battery horse, the term "charger" being effacerl. A report to the minister is made of such cases. If the unfitness of a horse for service is proluced by the carelessness of the officer to whom he has been assigned, the council of administration derlucts from the remount allowance of this officer the sum representing the depreciation of the horse. 


\section{IX.- JAPAN.}

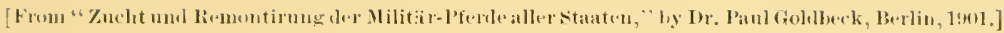

Japan has over $2,000,000$ horses, the number in 1895 having been 1,530,603, exclusive of the military horses used in the Chino-Japanese war.

Although Japan is by no means poor in horses, their quality leaves much to be desired. The animals are strong enough in the fore quarters, but weak in the hind quarters; their shoulders are short and abrupt, their chests narrow, and their size ranges only from $13 \frac{1}{2}$ to $14 \frac{1}{2}$ hands; they are, however, tough and enduring, and need little care.

Of recent years the govermment has endeavored to improve the breed by introducing American, Hungarian, French, and Persian stallions. As, however, the crossing was done at first without any definite aim, no success was attained, but for the last three years the earnest purpose of securing a medium-size sadkle horse has been followed. The best horses come from Yesso. There are at present four studs.

The obligation has been placed upon officers of the army to keep the number of horses corresponding to their rank. All higher civil officials must, moreover, possess two horses each.

The Japanese army was increased in 1896 , so that by the end of 1899 there were 13 cavalry regiments with 65 squadrons, and 13 field artillery regiments with 79 batteries (in 1900 $11 \%$ batteries). Great difficnlty was experienced in procuring suitable remounts for the increased organization. A horse board is sent yearly to all horse-breeding sections of the country, and also frequently abroad, especially to Australia. Principally 4 -year-olds were purchased, at a maximum price of $\$ 25$ each. The greatest difficulty consists in securing strong pack animals for the train service, for which purpose the government has recently been making purchases in Australia. Thoroughbreds are now, however, being imported from France in order to improve the home breed. Animals purchased are placed in a remount depot at Tokyo. 



\section{X.--LATIN AMERICA.}

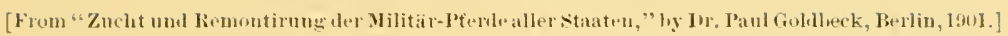

\section{ARGENTINA.}

The number of horses in 1894 was $4,44 \%, 000$, and the number of mules 483,000 .

The immense herds of wild, half-will, and broken horses which roam over the pampas of Argentina are the lescendants of original Spanish breeds, chief among which was the Andalusian. The Argentine horse has a reputation for great endurance and for requiring little care. He has been recommended as a good animal for light cavalry, and is said to have been imported for this purpose even into France. The price is very low, ranging from $\$ 24$ to $\$ 48$. Importerl stock is crossed with the native stock, principally for the production of carriage horses. However, the majority of the imported horses are bred among themselves. They consist of Arabs, English thoroughbreds, hunters, hackneys, Auglo-Normans, Morgans from the United States, Trakehnens, Oldenburgs, Hannoverians, Orlofs, Percherons, Clydesdales, Shires, Clevelands, and Suffolk Punch. Of late the most popular have been the Anglo-Normans, Trakehnens, and Clydesdales.

At present the ratio of native stock to crossed breeds is about $4,000,000$ of the former to 415,000 of the latter. The number of pure breeds in 1895 was $15,5 \%$. The numbers exported, in $189 \%$, were 13,615 horses, 16,390 asses, and $16,31 \%$ mules.

In November, 1899, there were 11 cavalry regiments of 4 squidrons each, 1 squadron of escorts of the president, 4 field artillery regiments, and 2 mountain artillery regiments, with a total of about 4,000 horses and 1,500 mules. In view of the above-mentioned figures it is evirlent that the remounts required are easily secured at home. A horse trained for riding costs only about $\$ \% .14$.

Argentina serves as a source of remounts for many European countries. England purchased a very considerable 
number of horses in Argentina for the South African war, and for some years has had a permanent remount-purchase commission there, which as early as 1898 purchased 1,500 horses for South African troops. By Angust, 1900, a total of 24,000 horses had been delivered for England. The prices are from $\$ 100$ to $\$ 250$ for cavalry horses, $\$ 100$ to $\$ 200$ for artillery horses, and $\$ .0$ to $\$ 80$ for cobs. According to recent reports, Italy contemplates sending to Argentina a similar commission, General Talpini having been sent thither in 1899 to study matters relating to horse breeding.

\section{BRAZIL.}

The principal horse-breeding localities are in southern Brazil, the portion inhabited by Germans. There is practically no horse breeding in the north. The small native horses are raiserl by a few landowners for private use, but mules are generally preferred and are imported in considerable numbers. The regions where mules are bred are in the states of Minas Geraes and the southern states. There is a lack of good military horses. A movement is on foot looking toward the establishment of government studs in Parana and Rio Grande do Sul. There are "i regiments of field artillery $(?, 562$ horses), 6 battalions fortress artillery ( 2,100 horses), and 14 regiments of cavalry (6,020 horses), making a total for the army of 10,682 horses. The supply of remounts is now derived from the herds that run wild on the prairies. Garrisons in Brazil are so far apart that when caralry is transferred from one to another the horses are not taken along, but new remounts are securerl from the plains nearest the new station.

\section{CHILE.}

This country had, according to a census taken in 18:\%, $44 \%, 000$ horses. According to statistics of 1885 the number of horses foaled per year, exclusive of Santiago, is 54,000 , and it is estimated that, including Santiago, this number would be 60,000. The breeds, like those in Argentina, are of clegenerate Spanish stock. Few horses are bred for sale.

When well-bred stock was introduced into Chile it was rather with the object of breeding it pure than crossing with the native breeds. With the exception of a few English thoroughbreds, the Cleveland bay is the horse that has been 
bred for the last thirty years for driving purposes. The few Anglo-Normans, Norfolk trotters, and North American breeds that have been introduced have not attained much importance. The government neither owns nor assists any stud or other establishment of the kind. On the other hand, private owners readily offer the services of their valuable stallions, the fees ranging from $\$ 5.80$ up to $\$ 28.95$.

The number of mules and asses raised is considerable, though scarcely sufficient for home needs.

Chile has $\%$ cavalry regiments with 4 squadrons each, and each regiment has at present $3 \% 0$ horses. There is an escort squadron with 250 horses, 1 regiment field artillery with 500 horses, and 5 regiments mountain artillery with so horses and $: 00$ mules each. As general-service liability was introduced in 1900, a considerable increase in the establishment will probably take place. Henceforth 12 per cent of the horses are to be replaced yearly. The purchases will be made by the adjutants of the remount section of the great general staff, in which about $i$ or $\delta$ adjutants and 30 men are on duty. The chief of the remount service has under him also the veterinary department. There is a kind of remount depot established. The age at purchase is between 3 and 4 years, but after purchase the horses, before distribution to the troops, remain in remount stations for one year. The yearly requirement of remounts is about 400 , and the average price paid is $\$ 24.38$. Mounted officers may purchase horses from the remount depot for $\$ 36.50$ each, and may sell them in case they become unfit for service. A new set of regulations is being prepared after the model of the German "charger" system.

MEXICO.

The principal horse-breeding region in Mexico is on the plateaus, where some of the large studs have as many as 8,000 or 10,000 horses and mules each. No special race is bred.

The Mexican cavalry consists, since $189 \%$, of 14 line regiments of 4 squadrons each, 8 skeleton regiments of 2 squadrons each, : regional squadrons, and 1 squadron of army gendarmerie, with $9,25 \%$ horses. There are 4 battalions of field artillery. The total number of horses in the army is 13,059. It is manifest that the purchase of the necessary remounts is an easy matter. 



\section{THE NETHERLANIDS.}

[From "\%ucht und Remoutiruug der Militär-Pferde aller stataten," hy Ir. Paul foldheck, Berlin, 1901.]

The number of horses in the Netherlands in 1896 was 269,000 .

The Dutch army has 3 regiments of cavalry, of 5 field squadrons and 1 depot squadron each, 1 orderly squadron, :3 regiments of field artillery, and a remount depot. The total number of horses is 5,259 , the number of remounts needed yearly being 420. All purchased horses, before being turned over to the troops, are kept in a remount depot for at least a year. The horses for the cavalry are purchased by a commission in Ireland, where the artillery horses formerly were purchased. Of late, however, some of the artillery horses have been secured at home-in $189 \mathrm{~s}$ about one-half. The average size of remounts is $15 \frac{1}{\ddagger}$ hands, the age, at purchase, between 3 and 4 years, and the arerage price about \$225.12. Although officer's are allowed to purchase their horses from the remount depots at the average price, and subject to certain conditions regarding disposal, they usually prefer to buy their mounts of dealers.

\section{DUTCH COLONIES.}

Although the climate of the East Indian archipelago is by no means adapted to horse breeding, still these regions have a large number of horses, especially of the races suitable for draft purposes in a warm, damp, and tropical climate.

Java had, according to the last census, 485,131 horses. The Java horse is a small animal, 12 to $12 \frac{1}{2}$ hands high, and thrives best in a mountainous country. There is also a saddle horse. Most of the horses in Java are imported from the other islands.

The Dutch troops in the islands have 1 cavalry regiment with 700 horses; 4 field batteries with 75 horses each, or 300 horses in all, and 4 mountain batteries with a total of 105 horses and 160 mules. The yearly requirement for remounts 
is 250 horses and 15 mules. Horses for the remount depot are bought from $1 \frac{1}{2}$ to 4 years old; for the direct supply of the artillery and the cavalry they are bought full-aged, but not over $r$ years old. The size with trimmed hoof must be as follows: $1 \frac{1}{2}$ to 4 years old, $12 \frac{1}{4}$ hands $: 4$ to $\%$ years, $12 \frac{1}{2}$ hands. Horses from Sumatra may measure as low as 12 hands. Mules for the mountain artillery are bought in China. Owing to the hard usage to which the natives put young horses, the government decided to establish a remount depot in 1858 in Java. The horses are kept there till they reach the age of 5 years, when they are turned over to the cavalry or artillery. 


\section{XII.-NORWAY.}

[Reportel by Lieut. Col. W. R. Livermore, Corjs of Engineers, Inited States Military Attache at Copenhagen and stockholm.]

The Norwegian government, not contemplating the invasion of any foreign country, has organized its army purely for purposes of defense. In case of war only the line is liable to duty abroad.

Horses for the army are supplied in three different ways:

(a) By purchase abroad, "original horses" (stamheste) 250 in all;

(b) The rest of the horses in time of peace, the so-called "quarter horses" (kvarterheste), about 3,400 in all, are obtained at home by the supply establishment;

(c) The horses required in the field in excess of those available in time of peace are obtained by conscription.

\section{(a) STAHHESTE.}

The stamheste are purchased in Sweden and in England by the remount commissioners. The prices vary from $\$ 134$ to $\$ 268$.

Special orders about inspections are issued at every purchase.

The cavalry requires about 182 , of which about 10 per cent, namely, 1s, are acquired annually. The horses are generally half-blood English. They are mares or geldings. The color is indifferent. The artillery requires 39 stamheste at the rate of about 4 a year; the requirements are similar to those of the cavalry. During the past few years about 25 horses have been bought annually, but in 1899 , at a single purchase, 80 were bought for the orderly squadron.

There is no government breeding establishment in Norway. The Norwegian Government is making investigations with a riew to finding an economical remount system based upon the stock now in Norway. One of the three stallions now used is a hackney, the two others are Norwegian. The stallions are lent to civilian horse raisers with the condition that 
should the foals be deemed suitable they can be bought at a stipulated price when they reach the proper age.

The import duty is $\$ 13.40$ per horse.

\section{(b) KVARTERHESTE.}

There are about 150,000 horses in the country.

There are in the army 3,400 kvarterheste, 200 ofticers' horses, and 250 various, outside those obtained by conscription. The kvarterheste are distributed as follows: cavalry, 1,600; artillery, 1,300; other branches, 250 ; draft horses and pack horses, 250 .

In case of mobilization for war about 14,000 more would be required. These they expect to raise by conscription.

The annual loss is about 10 per cent.

Cavalry horses and artillery horses are retained in the service about ten years. About 10 per cent are required annually. Draft horses and pack l. orses are retained about twelve years. Horses for cavalry are kept at the remount school about ninety days; those for artillery, engineers, and train, about forty-five days. Men to look after them there are detailed from the organizations to which the horses belong. The horses are not branded and are never vaccinated. They are shod with ordinary horseshoes with calks. The number of times they are groomed varies with circumstances.

In the field the forage allowance is 14.33 pounds of oats or barley, 9.92 pounds of hay or 13.23 pounds straw. Compressed forage is used.

The native Norwegian horses are small and stout. They are well formed for artillery uses, and are very nimble in climbing. There is some difference of opinion among Norwegian officers with regard to their fitness for cavalry. The opposition to them comes in part from those having a fondness for shock tactics. 


\section{XII.-PERSIA.}

[From "Zucht und lemontirungder Militir-Pferde aller Staten," by Dr. Paul Goldueck, Berlin, 1901.]

Persia, renowned from time immemorial for her horses, still possesses an excellent supply of them. The shah and noblemen of the country each keep a number of studs, in which, however, only the horses needed by the court are bred. The principal wealth of horses lies with the tribes of nomads, who follow the same methods of horse breeding as the Arabs. The Persian thoroughbred is very nearly related to the Arab, but is more slender in build.

The Persian cavalry, excluding the three Cossack regiments under Russian command, stationed in Teheran, and the bodyguard of the shah (about $1,: 00$ cavalrymen), consists of irregular troops. There are said to be 125 squadrons of cavalry. The artillery is said to consist of 20 batteries. In the cavalry each trooper is obliged to furmish his own horse and equipment. Russian horses have been introduced experimentally for artillery purposes, but balk on long grades. It is very difficult to find suitable draft horses in the country. Horses become mnserviceable usually at the age of 12 years, though Arabian horses attain ages of 18 to 20 years in spite of their rough usage. The ration consists of 6.61 pounds of barley for saddle horses, 8.82 to 11.02 pounds of barley for draft horses, and for each also 13.23 pounds of straw and 5.61 pounds of hay. The barley is fed half in the morning and half in the evening. In May all dry feed is withheld from the animals, and they are given grass and hay without limit. During the last days of May a little barley is added and then dry forage is resumed.

$23555-21$ 



\section{XIV.P()RTUGAL.}

[From "Zncht und Remontirung der Militiar-Pferdealler staaten," by Pr. Paul Grohbeck, Berlin, h:M1.]

As horse breeding receives no support from the Government, it has reached a very low stage, and no exact census of the number of horses and mules exists.

Portugal has 8 regiments of cavalry (3\% squadrons), 3: batteries of field artillery, 2 batteries of horse artillery, and 2 of mountain artillery; and in the reserve, 8 groups of cavalry (16 squadrons) and $t$ sections of artillery ( 16 batteries). In the standing army there are $6,39+$ horses and 4,342 mules, and in the reserve 3,121 horses and 1,992 mules; total 9,515 horses and 6,334 mules.

Remounts are purchased for the army by a general remount commission, consisting of a colonel of cavalry as president, a captain of cavalry, a lieutenant, and two veterinarians. The amount to be expended each year on remounts is fixed by the war minister. The prices have ranged for the last few years between $\$ 130.6$ and $\$ 138.38$; for officers' mounts from $\$ 181.20$ to $\$ 214.42$ are paid. The age limits are between 3 and 7 years. The average length of service of a horse is calculated at ten years. The following are the rules with regard to size: Horses 3 to $3 \frac{1}{2}$ years old, $14 \frac{1}{4}$ hands; 4 years old, $14 \frac{1}{2}$ hands; 4 to 2 years, $1+\frac{3}{4}$ hands; for horses of generals, and general staff, cavalry, and lancer officers, $14^{\frac{3}{4}}$ hanils; for all others, $14^{\frac{1}{2}}$ hands; mules must measure $14_{4}^{1}$ to $14^{\frac{3}{4}}$ hands, according to the service for which they are intended. Seventy per cent of the horses purchased are of Spanish origin, the remainder of Portuguese. 



\section{NT.RLSIA.}

[From "'zucht mul lienontirung der Militär-Pferde aller staaten," by Ir. Pau] Goldheck, Berlin, 1901, and repert of Capt. S. L'II. Nlocum, Eighth Cavalry, United states Military Attaché at st. Petersburg.]

Russia is the greatest horse-producing country in the world, although she stands behind many other countries if the number of horses produced is considered in proportion to her area. The total number is about $25,100,162$, of which over $21,000,000$ are in European Russia.

The liorses of Russia are for the greater part steppe horses, i. e., wholly or half-wild horses, ranging in bands of 20 to 30 each. To these belong the horses of the Kirghizes and Kalmuks, those of the Don and the Cancasus, and a part of the peasants' hor'ses.

The horses of the studs have been produced by crossing with English and other breeds.

Breeding stallions are placed at the disposal of the rural proprietors: (1) Those stationed in the government studs are occasionally allowed to serve mares of private parties (2) There are established so-called breeding stables (rural studs), from which stallions are sent to the rarions stations during the covering period. The total number of these studs in 1893 was 33 , the majority of which had their chief seat in the capitals of the respective govermments. (3) Government stallions may be assigned to so-called "permanent covering stations," thit is, into private liands, where they remain throughout the year and are allowed to serve free of charge (or for a nominal fee). They are not allowed to be used for work. The keeper must bear the expense of maintaining them and may have 15 mares of his own serred.

Corresponding to the generally low stage of the breeding service, the number of mares served is rery small. In 1899 the number of stallions in the depots was 3,939 and the number of mares served only 89,219 . Of the stallions, 2,480 were in the agricultural zone of Russia, and 1,459 in the Cancasus, steppe, and Tomsk depots. The number of stallions is not nearly sufficient. Eighty-nine private stallions were approved in 1889 . It is also proposed to increase the number of government stallions and establish more depots in 1901. Special 
attention will be paid to the Poltava and the Yelizavetgrad depots, as they are the principal somrces of production for cavalry remounts.

The best-known government stud is that of Khrenovoye on the Don. There are three breeds, namely, trotters (on January 1, 1900, 12 breeding stallions, 119 brood mares, and $20: 2$ foals); hunters ( 6 breeding stallions, 28 brood mares, and 24 foals); and draft horses of foreign races (18 breeding stallions, 166 brood mares, and 186 foals). The remaining government studs are all in the district of Kharkof, as follows:

STRELETz.- The stock was originally Arab, but later some Orlof blood was added. The aim was the production of a light-cavalry horse. Owing to the difficulty of procuring suitable Arab stock, English thoroughbreds were eventually introduced (in 1890), but it is now proposed to discontinue them. On January 1, 1900, there were 15 breeding stallions, 152 brood mares, and 334 foals. The area of the stud is $2 \%, 181$ acres.

LIMARESK.-The original aim was to produce a light-cavalry horse, and Arab stock was first bred. In 1885-86 English thoroughbred blood was introducerl, and the object was changed to the breeding of a heavy cavalry horse. It is now intended, howerer, to discontinue the English thoroughbred stock and breed the pure Orlof-Rostopchin saddle horse. The status on January 1, 1900, was $1+$ breeding stallions, $1 \% 4$ brood mares, and 411 foals. The area is 27,181 acres.

DerkuL.-English thoroughbred stock is bred here, the number of thoroughbreds being 8 breeding stallions, 45 brood mares, and 64 foals. The number of private mares server yearly at Derkul is 100 , at a fee each of ahout $\$ \% t$ and under. There is also an Arabian (steppe) section which, on January 1, 1900, had 6 breeding stallions, 39 brood mares, and 38 foals.

Novo Alexandrovsk. - The mission of this stud in 183:3 was the production of a cuirassier horse, and much English thoroughbred blood was introduced. Heavy carriage horses and saddle horses are produced. The status is 10 breeding stallions, $1 \% 1$ brood mares, and 302 foals. The area is 30,887 acres.

JANow.-This is the only government stud in Poland. English thoroughbred stock is bred, and the numbers on hand are 12 stallions, 12 thoroughbred mares, and 49 halfbred mares. The foals number 25 thoroughbreds and 93 half-breds. 
The numerous private studs follow for the most part, as far as breed is concerned, the tendencies of the government studs of their respective regions.

The number of animals in the government studs was as follows on January 1, 1900: One hundred and three breeding stallions, 955 brood mares, 1,780 foals, 151 draft horses and others; total, $3,00:$ head.

The total receipts from government studs were $\$ 141,371.10$, and the expenditures $\$ 1,115,142.3 \%$.

There were exported in 1899 from Russia 59,448 horses. 5\%,100 going beyond the European boundary, 436 to Finland, and 1,91: beyond the Asiatic boundary.

The following table shows the number of regiments, etc., including Cossacks:

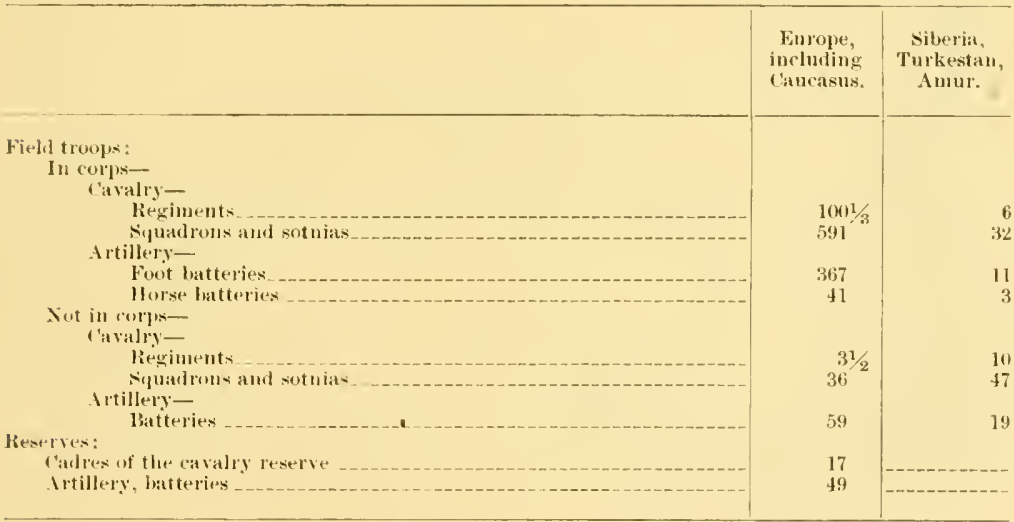

The total number of Cossack sotnias is 311, which number can be increased in war to 1,000 . The peace establishment of cavalry horses is 140,000 ; in the war establishment this number is increased to 350,000 . There are special remount services for each branch; that is, one for the regular cavalry, one for the artillery, and one for the Cossacks. The total number of horses in the army is 175,000 . The number required annually is $1 \%, 500$. In case of mobilization 350,000 more would be required.

The cavalry troops of European Russia formerly received their mounts entirely througl remount officers, who, in consideration of a sum, varying from $\$ 108.15$ to $\$ 154.50$ for each horse, harl to purchase remounts at their own expense and their own risk and deliver them in a serviceable condition. They were really to a certain extent wholesale horse dealer's. 
There were at first no oflicial remount depots, but the remount ofticers had private depots of their own where they kept the horses bought by them until fit for service.

The age limits prescribed are from $3 \frac{1}{2}$ to $:$ years. The heights are as follows: For guard cuirassiers, $15 \frac{1}{4}$ to 16 hands; light guard cavalry, 15 to $15 \frac{1}{4}$ hands; line carilly, 15 to $15 \frac{1}{4}$ hands: gruard artillery. 15 to $1.5 \frac{1}{4}$ hands; field battery saddle horses, 15 to $15 \frac{1}{4}$ hands: grm horses, 14 to $15 \frac{1}{4}$ hands: horse battery saddle horses and draft horses, 15 hands. Stallions, geldings, or mares may be taken.

The abore-mentioned remount system was found rery defective. so that the govermment was finally compelled to take charge of the service, the German method of private purchase and remount depots being introluced as a tentative measure. At first the positions of remount ofheer were discontinned in Moscow and Kief, those in other places being continued. Since January 1. 1901, the new method has been definitely adopted. Tro kinds of remount commissions, permanent and temporary, have been established. The former are appointed by the supreme military council and the latter by the inspector general of cavalry. There are at present seren permanent and two temporary commissions. Every commission consists of a general officer as president, a field officer, a reterinarian, and assistants. Horses bought in the fall must be $3 \frac{1}{2}$ to $5 \frac{1}{2}$ years old, and those bought in the spring from 4 to 6 years. The following prices are fixed from 1901 to 1903:

\begin{tabular}{|c|c|c|c|c|}
\hline & & ciate & yory. & \\
\hline & $\begin{array}{c}\text { I. } \\
\text { Thorugsh- } \\
\text { bret } \\
\text { without } \\
\text { blemioloes. }\end{array}$ & $\begin{array}{l}\text { II. } \\
\text { Thoroush- } \\
\text { bret with } \\
\text {-light } \\
\text { blewishes. }\end{array}$ & $\begin{array}{c}\text { IlI. } \\
\text { Partially } \\
\text { thorough- } \\
\text { lurtel } \\
\text { without } \\
\text { blemi-hes. }\end{array}$ & $\begin{array}{c}1 \mathrm{i} \\
\text { Partially } \\
\text { thoroush- } \\
\text { brel with } \\
\text {-lizht } \\
\text { blemi-lies. }\end{array}$ \\
\hline 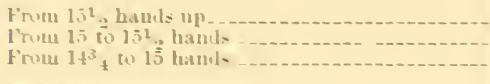 & $\begin{array}{l}5.231 .75 \\
27+1.141 \\
1 \times 1) .25\end{array}$ & $\begin{array}{l}5193,12 \\
16 \div, 3 \% \\
1+1.62\end{array}$ & $\begin{array}{l}51+i, 37 \\
141.62 \\
103,100\end{array}$ & 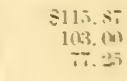 \\
\hline
\end{tabular}

Artillery remomints were formerly supplied by permanent remount officers each buying for the artillery in his own district. It was only in certain districts-Finland. Moscow, Don territory, ete. - that the artillery was permitted to purchase remounts independently. In these an oflicer of each brigade was charged with making the purchases. and a commission detailed to approre them. Since 1891 all permanent 
frot batteries and horse batteries have been allowed to purchase their remounts independently. The amounts they are allowerl to expend for this purpose per holse are as follows: Guarl hatteries, \$14t.20; field batteries in St. Petersburg military district, $\$ 103$; in military districts of Kief and Odessa, s\$10.12, including all expenses.

Heretofore all the Cossacks have been required to procure their own mounts. These troops are divided into three bans, each of which has a very different class of horse. The following arrangement has been made to improve the mounts of the Cossacks of the first ban, who are gradually acquiring a standing with the regular caralry. Upon the discharge of the Cossacks who are to be transferred to the second ban in the fall, the regiments of the first ban may exchange their unserviceable horses for serviceable ones by paying a small sum of money.

Up to 1884 all the cavalry officers, as well as most other officers, were required to purchase their own mounts. This rule is still in force for the guard officers, but the officers of the regular cavalry and horse artillery receive so-called "crown horses" from among the service horses. A second horse ration is allowed so that officers, if they so desire, may keep a private mount besides. Every officer of mounted troops may purchase a service horse from his regiment, but no more than six horses per regiment may be sold each year. "Crown horses" remain the property of the government and may be used only in the service. Since October, 1899, the obligation to keep a private service mount has been extenled to officers of the horse artillery, including the mountain artillery. Officers of foot troops are allowed to select suitable horses from among the condemned cavalry horses, for which moderate prices are charger.

The forage ration is as follows: For the guard cavalry (cuirassiers), drait horses of the guard artillery, of the officers' leser've school, and of cadre 1 of the guard caralry reserve: $13 \frac{1}{2}$ pounds oats, 10 pounds hay, and 4 pounds straw. For the horses condemned from the guard and caralry regiments: 10 pounds $t \frac{1}{2}$ ounces oats, 10 pounds hay, and 4 pounds straw. All other sarldle horses of the guard cavalry and artillery, of guard cadres Nos. 2 and 3 , and of the officer's' schools: 12 pounds oats, 10 pounds hay, and 4 pounds straw.

Cavalry horses undergo one year's training before being turned over to the troops. Each regiment has a depot for this purpose. 



\section{XVI.-SPAIN.}

[From "Zucht und Remontirung der Militiir-l'ferde aller Staaten," luy Ir. Paul Goldbeck, Berlin, 1901.]

The number of horses in 1897 was $39 \%, 1 \%$. Spain raises a great number of asses and mules. An English commission purchased there for the Boer war a total of 12,000 . They are reported to have proved admirably adapted to the transportation of light artillery in hilly regions. The usual price of mules reaches as high as $\$ 193$.

In order to assist horse breeding the Spanish goverument maintains four stallion depots of 100 animals each, and three annexes with 25 stallions each. The stallions kept at these depots are mostly of the Spanish race, but there are also Arabian and English thoroughbreds, the latter very few in number and poor in quality. There are also some Noriolk, Percheron, Anglo-Norman, and even Anglo-Hispano-Arabs in use. In order to aid breeder's the covering fee is made as low as \$4.\$2, and in some regions where the breeding industry is in a backward state no fee is charged. The number of thoroughbred stallions in Spain in 1896-9\%, according to the Spanish studbook, was 155 English, 19 Arab, and 19 AngloArab stallions. There has been a considerable decrease since $1894-95$.

A military stud has been established, as a sort of experiment, in the province of Cordoba. It has 80 mares of the Spanish, Anglo-Arab, Anglo-Norman, and Percheron races, as well as 4 breeding stallions-2 Spanish, 1 English thoroughbred, and 1 Norfolk. It is intended to raise not only sires for the stallion depots, but also stallions to be sold at cost price to breeders.

Spain has 28 regiments of cavalry and 14 regiments of reserve cavalry, 9 remount depots, establishments, etc., gendarmerie, and 16 regiments of field artillery and mountain artillery, having a total, including other branches of the service, of 14,300 horses and mules.

There are three remount purchase commissions for cavalry, each with a remount depot under its supervision. In these 
depots the colts are kept until 4 year's old before being turned over to the regiments. The general staff, infantry, artillery, engineers, carbineers, administrative troops, and medical corps purchase their horses and mules rearly for service. The artillery has a remount commission consisting of a colonel, heutenant colonel, major, and two administrative officers, with headquarters at Madrid. The civil guard also has a remount commission of its own. To purchase the necessary remounts the commission makes tours through the country. Some remounts are bought abroad. All draft horses for the artillery are purchased abroad, principally in Belgium. The requirements of remounts are as follows: Cavalry-age, 2 to 4 years; size, 14 to $15^{\frac{8}{4}}$ hands, according to age. Artilleryage, $t$ to 7 years; size, 15 to $15 \frac{1}{2}$ hands for saddle animals, $15 \frac{1}{2}$ to $15^{\frac{3}{4}}$ hands for draft animals, and $14 \frac{3}{4}$ to $15 \frac{1}{4}$ for officers' mounts. Other troops-age, $t$ to 7 years; size, $14 \frac{3}{4}$ to $15 \frac{3}{4}$ hands (in the civil guard, $15 \frac{1}{4}$ to $15 \frac{3}{4}$ hands). The length of service of a horse is reckoned at 10 years.

The arerage price paid for horses by the army is $\$ 106.15$ for 2-year-olds, $\$ 168.87$ for 3-year-olds, $\$ 193$ for 4 -year-olds, and $\$ 173.70$ to $\$ 386$ for trained animals. The average value of an Andalusian saddle hor'se is $\$ 289.50$, especially valuable specimens being $\$ 400, \$ 600$, and even $\$ 800$. Light draft horses are sold at $\$ 7 \% 2$ to $\$ 1,158$ per team; heavy horses, which are rare, from $\$ 289.50$ to $\$ 386$ each.

General officers may select and buy their horses from among the cavalry remounts, at cost, but never for less than $\$ 241.25$ each. Field and company officers who are required to have mounts receive them from their regiments, but must pay for them a certain sum, varying according to the grade of the officer, from $\$ 38.60$ to $\$ 135.10$. 


\section{XVII.-SWEDEN.}

[From "Zucht und Remontirung der Militï-Pferle allerstaiaten," by Dr. Paul Goldbeck, Berlin, 1901.]

The number of horses in Swerlen in 1897 was $512,406$.

The Swedish Goverument favors the horse-breeding industry in every respect. Great attention is paid to the raising of military horses. The successes are such that the peasantry not only furnishes all the army remounts and all the breeding stallions needed for service throughout the country (except those imported to keep up the stock), but also many excellent remounts for Norway. Formerly the government maintained studs of its own, but this is now no longer necessary. These studs were situated as follows: At Stromsholm, until 18;2; at Flyinge, until 188\% (English thoroughbred and half-bred stock); and at Ottenby, in Öland, until 1892 (English halfbred stock). The first and second mentioned are now stallion depots. The number of stallions at Stromsholm in 1899 was 74 and at Flyinge 89 , besides 62 young stallions at the latter place. Most of the stallions stationed at Stromsholm and Flyinge were purchased abroad-partly in England and partly in Hannover. Stallions subsidized by the government are kept by a great many private owners.

The Swedish permanent troops include 8 cavalry regiments (5,300 horses), and 11 batteries of field artillery and mountain artillery. The total number of horses in the army in 1900 was 6,742 . In case of mobilization the number is increased to 28,319 , which are all at hand. The yearly number of remounts is about 540. All remounts, except those of the indelta cavalry, are purchased through a remount commission, consisting of a chief, a veterinarian, and another member. The average price paid is $\$ 18 \% .60$, but it is intended to raise this price. The remounts must be between 3 and $r$ years of age, and must not be under $14_{4}^{\frac{1}{4}}$ hands high measured behind the saddle. A peculiar system, similar to that in vogue in Norway, exists for the indelta cavalry, for which certain landho'ders are required to maintain remounts. 



\section{XVIII.-SWIT\%ERLAND.}

[Reported by Maj. G. K. Cecil, Third Infantry, Initel stutes Military Attacbé at Bern.]

The Swiss system of supplying horses for military purposes, like the entire Swiss militia system, is unique. In the first place, no recruit is assigned to the mounted service until he has produced conclusive evidence of his ability to own and care for a horse. The horses are bought by the government and trained. The recruit is permitted to select one at the appraised value, and pays to the government, at the time the horse is assigned to him, one-half the amount. He takes the horse to his home and uses him as his private property, but must keep him in good condition and ready for inspection. The recruit must report with this mount every time he is called to service. The government, at the end of each year, refunds to him ten per cent of the amount he has paid; that is, ten per cent of half the appraised value of the horse, so that at the end of his ten years' service in the élite, all his money has been returned to him, he has had the use of the horse for ten years, and the animal now becomes his private properiy, which he may sell or otherwise dispose of.

The recruit may furnish his own mount, which is inspected and appraised, after which the government pays the soldier half the appraised value of his horse, and thereafter ten per cent of the other half annually for ten years. If the horse dies in the meantime, or becomes unfit for service, the balance is refunded to the soldier, who then selects another horse from the depot on the same conditions, except that, when the soldier is transferred to the landwehr, the horse does not become his private property, but must be returned to the depot. On returning his mount to the depot the soldier receives the balance of the amount paid by him. The same rule applies to the horses for both officers and enlisted men, though the officers, in selecting, are not limited to the cavalry remount depot, as there is a horse régie at Thun supplying a higher grade of horses, especially for officers. This régie 
also trains and supplies horses for the field artillery. These horses are purchased during the first months of the year, and are used during that year at the recruit schools for light artillery. In the autumn they are appraised and sold at auction, to natives only, on condition that they be well cared for and returned to the recruit stations, for use in a recruit school, at such times as called for each year, for the three following years. After that they become the absolute property of the purchaser. If the bids on any horse are less than his appraised value he is not sold, but is held for a future auction. For the use of his horse at recruit schools, etc., a purchaser is paid, while the animal is in service, from two to four francs per day. In this way the government has, for use in the instruction of the light-artillery recruits, and for service during the cours de répétition, as well as at other times, a supply of fairly well trained horses. All horses for the artillery and trains, whenever required, are hired from civilians. The owners are paid the rates established by the government. The horses are examined by a board of veterinary surgeons three times, namely, upon delivery, then two days after delivery, and, finally, upon being returned to the owners. Upon the reports of this board damages are paid by the government. Besides the 100 horses bought each year for the régie and intended for the artillery, and for officers, there are purchased about $\$ 00$ horses every year for the cavaliy.

Last year there were bought for the cavalry:

Foreign horses 798

Swiss horses

Horses furnished by soldiers _........................... .)

Horses furnished by soldiers to replace their lost horses .... 2 2

Total 804

The foreign horses are bought and inspected by a board, which is composed of the chef darme, chief veterinarian, and usually also the commandant of the depot, and which, to make the purchases, is sent abroad. Of late years the horses have been bought in Ireland, northern Germany, or Hungary, as the markets have seemed most favorable.

SPECIFICATIONs FOR Horses.-Active temperament; neck shapely and of medium length; withers prominent; barrel 
short; back straight; loins arched and muscled; the croup substantial and approaching the horizontal; chest large and deep; the legs and fetlocks strong; unbound tendons; good feet. White horses of too striking appearance are rejected, unless the purchase is justified by excellent qualities. The height should be not less than 15 hands nor more than $15 \frac{3}{4}$ hands; age not less than 4 years nor more than 6 years. Mares and geldings are accepted.

The horses are shipped to the depot at Bern, where they become acclimatized before they are given any hard work. They are then given a course of training involving about four months' time, in which they are exercised at the walk, trot, gallop, and in jumping hurdles. They are trained also to work in harness, that they may be useful to the owner in agricultural labor. For this purpose the necessary number of trainers is employed. When the training is completed the horses are inspected by the chef d'arme, the chief instructor, and the chief veterinarian. Any that are found fractious, near-sighted, blind, wind-broken, stiff, or incurably diseased are returned to the depot either for treatment, or, if found permanently disqualified for service, for sale. Horses when first purchased are branded on the near fore foot; those accepted for assignment to recruits are branded also with the year and the federal cross on the off side of the neck and with the number on the near side of the neck. Horses condemned to be sold are branded on the left ear.

The horses intended for enlisted men are arranged, according to appraised values, into four classes. The classes correspond to four values, $\$ 312, \$ 2 \% 3, \$ 234$, and $\$ 195$. The horses intended for officers are appraised at $\$ 351$. These values are calculated to cover the first cost of the horses, the transportation, acclimatization, and training, in other words, to cover the expenses of the remount depot.

A descriptive book accompanies each mount issued. This book must be presented at all subsequent inspections of the horse. The inspector notes therein the horse's condition and any other pertinent remarks.

Provision is made for returning horses to the depot for further training or for exchange when, after reasonable trial, they are found unsound, vicious, or in any other way unfit 
for the military or home use of the holder. When a soldier is unable to keep his horse he is permitted to transfer him to some responsible party, who assumes the care of the animal under the conditions prescribed for the soldier. After ten years this party becomes the absolute owner of the horse.

No figures are obtainable at the military department as to the percentage of annual loss, but it is believed that this percentage is very small, and that a very large proportion of the horses assigned to recruits are serviceable during the entire 10-year term of service in the élite, as well as useful a number of years thereafter. The Swiss are very kindly disposed toward animals and take elegant care of their horses and cattle. The system for the purchase and treatment of horses for the régie at Thun is approximately the same as for the cavalry remount depot at Bern. Greater latitude is allowed in procuring fine horses for officers. Those horses intended for the light artillery are given less training under the saddle. The receipts from the régie about balance the expenditures.

As it owns few horses and keeps those of the army largely in the hands of private citizens, the government has no adopted method as to shoeing. So far as my observation goes the shoes are similar to those in our service.

There is no government stud under the military department, but there is one at Avenches under the agricultural department. The purpose of this stud is the improvement of the breed of Swiss horses. Ninety-three fine stallions are kept in the establishment. No mares are kept. The stallions are distributed among the different cantons. The charge for the stallions' services is $\$ 1.1 \%$ each.

The government charges to private individuals a nominal duty on imports, amounting to 59 cents per horse and 20 cents per colt.

When employed in government service, the horses, whether owned by the government or hired from citizens, are each allowed the following ration: 9.9 pounds oats, 9.9 pounds hay, and 6.6 pounds straw. The commanding officers of the cavalry remount depot and of the regie are allowed to vary this ration for sick horses and those undergoing acclimatization, provided the appropriation be not exceeded. When necessary, bran and molasses may be fed. Compressed forage is seldom, if ever, used. The horses are habitually groomed twice a day. 
In 1900 a census of all horses, with a view to their employment for military purposes, was made in Switzerland, with the following result:

\begin{tabular}{|c|c|c|}
\hline & 19010. & 1890. \\
\hline \multicolumn{3}{|l|}{$\begin{array}{l}\text { Type: } \\
\text { Common- }\end{array}$} \\
\hline 11 eary & 23,804 & \\
\hline Light & $49,3 \times 6$ & 61,896 \\
\hline $\begin{array}{l}\text { Improved } \\
\text { Pure blood_- }\end{array}$ & 21,277 & $\begin{array}{r}15,0103 \\
4,490\end{array}$ \\
\hline Half blood & 117 & 161 \\
\hline \multirow{2}{*}{\multicolumn{3}{|c|}{$\begin{array}{l}\text { Saddle horses: } \\
\text { utticers- }\end{array}$}} \\
\hline & & \\
\hline Otticers incorporated _...-.-_..... & 972 & 862 \\
\hline Trained --1- & 3,525 & 2,434 \\
\hline Suitable for training & 1,617 & 1,374 \\
\hline Noncommissioned ufticers- & & \\
\hline Trained - & 1,837 & 1,423 \\
\hline \multirow{2}{*}{\multicolumn{3}{|c|}{ Draft horses: }} \\
\hline & & \\
\hline For light artillery-1-1 & 23,897 & 22,654 \\
\hline $\begin{array}{l}\text { For train } \\
\text { Total arlapted for military services }\end{array}$ & 29,719 & $\begin{array}{l}25,619 \\
57,405\end{array}$ \\
\hline $\begin{array}{l}\text { Total arlapted for military services } \\
\text { Horses that may be used in emergency }\end{array}$ & 18,457 & 10,140 \\
\hline Infit for militury services & 18,314 & 14,005 \\
\hline 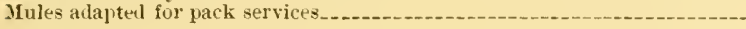 & 1,613 & 1,544 \\
\hline
\end{tabular}

The chief of the military department says, with reference to the showing made, that in point of view of numbers and quality of the horses adapted for military services, this census has been favorable. There appears to be in the comntry an ample supply of horses for a mobilization of the entire military force. All the animals may be taken when needed in defense of the country. The report shows a decided increase during the preceding decade.

On January 1, 1901, the élite cavalry possessed 4,641 horses and the landwehr cavalry 3,433 horses. 



\section{XIX.TURKEY.}

[From "Zucht umd Fiemontirmng der Militär-Pferde aller staaten," Wy In, Panl Goldbeck, Berlin, 1901$.

According to the reports of the tax officials, which for various reasons can hardly be regarded as entirely trustworthy, Turkey has over 2,000,000 horses; nevertheless, she is unable to supply her own remounts at home, probably because the amounts offered are too small. The peasants are unwilling to sell as low as those of other comntries.

There are four military studs in Turkey, all under the supervision of an inspector general, who is directly subordinate to the war ministry. They are as follows:

Chifteler, the largest, is 22 miles long by 16 broad. The number of horses is as follows: 52 stallions (15 Hungarian and Russian, 6 native, 31 Arab) ; $30 \%$ brood mares (119 Hungarian and Russian, 180 native, $\delta$ original Arab); 686 foals (382 of foreign blood, 164 native, 140 Arab); 7 working horses; total, 1,05: horses.

Malatia (IN ARMenia).-The number of horses is 460 . The breeding tendency is the same as for the preceding stud, but it is sought here also to refine the Kurd breed of horse.

ADANa, with 250 horses at present. The mares are Arabs.

BAGDAD. - This stud consisted in 1899 of 1,300 hor'ses of pure Arab stock and 20 Hungarian mares.

There are no private studs in the real sense of the word.

Beyond the free use of stallions from the above-mentioned studs, horse raising receives no support from the government.

The export of Arab mares is strictly forbidden, and that of stallions is subject to an export duty of $\$ 23.16$ each. There are really no horses exported, except a few of Arab stock, and imports are made principally for the army.

The Turkish army contains, on a peace footing, $40 \frac{1}{2}$ cavalry regiments with 880 horses each (202 squadrons), 15 batteries of horse artillery, 169 batteries of field artillery, 38 batteries of mountain artillery, and 13 train companies with mules and a few horses. In war there wonld be 115 cavalry regiments 
with 543 squadrons, each squadron with 150 horses, and 18 field-artillery regiments with 216 field batteries, and 36 horse batteries of 6 guns each, the field batteries having 150 and the horse batteries 230 horses each.

The irregular Kurd cavalry, which was recently increased from 36 to 45 regiments-the so-called hamadich-procures its own remounts. The military horses of the remaining troops are purchased abroad, partly in Russia but principally (and of late almost entirely) in Hungary. The number purchased each year depends solely on the financial means available. The yearly percentage of remounts required is officially fixed at 11 for the cavalry and 9 for the artillery. For 1898 1,100 artillery horses were bought in Russia, and 400 artillery and 700 cavalry horses in Hungary. The requirements made of remounts are the same as those in Germany, after' which they are copied, but in reality any healthy 5-yearold is accepted. There are several remount depots in Turkey in Asia, but none in Turkey proper. The length of service of a horse is said to be officially calculated at seven years. Mules are used for the mountain artillery and for hauling forage and provision wagons, etc. 


\section{APPENDIX A.}

The following report was not received until after the other manuscript had gone to press :

\section{INFANTRY TARGET PRACTICE REGLLATIONS OF JAPAN.}

[Reported by Maj. 0. E. W゙ool, Artillery Corps, Lnited States Military Attaché at Tokyo.]

The following extract from a recent translation made under my direction of "Infantry Target Practice Regulations of the Japanese Army" will give an idea of the plan and scope of instruction which is carried out in each infantry regiment:

PART I. - THE THEORY OF TARGET PRACTICE.

The two chapters devoted to Part I contain a brief discussion of the trajectory-its form and elements, the influence of the force of gravity, the weather, light, wind, etc., on the firing; a discussion of the front and rear sights, line of sight, etc., velocity, penetration, danger space, angles of elevation and angles of fall.

As an illustration of the difficulties experienced in using the translation for the purposes of this paper, the following quotations are made:

"The weight is that which to fall down the flying bullet and its degree is to increase with the time elapsed."

"The gravity is that which to drop the bullet to ground according to the time of the flight and the resistance of air constantly reduced the velocity of bullet, therefore the trajectory forms the curve, and degree of it increased as much as the bullet apart from the muzzle."

PART II. -FIRING INSTRUCTIONS.

Chapter 1 discusses the duties of officers-regimental, battalion, and company commanders, company officers, and noncommissioned officers. 
With reference to the duties of the company officers, the translation reads:

"These officers and noncommissioned officers are not only to be well acquainted with theory of firing, but to be well furnished with skill to correct the bad rifle."

Chapter 2 takes up the modes of instruction-a general outline-elementary drills for recruits, sighting drill, position and aiming drills. One quotation is very pat and well expressed :

"In all firings, the selection of a proper position, accuracy in estimating distances, quickness of loading, correctness of sighting, quickness of aiming, and the presence of mind, are the necessary conditions of a soldier, and one who lacks them can not be called a skilled marksman."

Chapter 3-preliminary drills-goes into the details of aiming drills, a complete discussion of the sights, use of tripods and sand bags for proper instruction in aiming, methods of correcting errors, tests by means of the triangle, and describes the proper standing, kneeling, and prone positions.

With regard to the use of the trigger and hammer, paragraph 55 of the translation reads:

"The use of trigger has great influences upon the firing, therefore, it must be minutely instructed and it needs constant attention."

Chapter 4-estimating distances-is very full and complete. It provides that every officer, noncommissioned officer, and soldier must become skillful in estimating distances for short range (up to 600 meters), for middle range (between 600 and 1,000 meters), and become accustomed to estimate distances for long range (over 1,000 meters).

Three methocks are provided:

First, estimating by sight by the use of soldiers either mounted or dismounted in various positions. After the distance is estimated by sight it will be actually measured by the step or by the surveyor's chain, except for the longer ranges, when maps and instruments are used.

Second, by sound. The velocity with which sound travels being given as a guide.

Third, by pacing.

(The above methors are very similar to those used in the United States army.) 
Chapter 5 gives the divisions of target practice and the allowance of ammunition. Three divisions are mentioned: drill practice, battle practice, and testing practice. These divisions are explained with great minuteness, and are very complete.

Each officer, noncommissioned officer, and soldier is allowed annually 25 rounds of ball cartridges in drill practice, 45 rounds of ball cartridges in battle practice, and 100 rounds of blank cartridges for preliminary practice and in field service.

Each company is annually allowed in addition 1,200 rounds of ball cartridges for rifle tests, inspectior. practice, and for the honor firing.

Chapter 6 takes up details of drill practice, covers all instruction concerning the firing, the ranges, the dress, the duties of markers, the superintendence by commissioned officers, the various details required, the methods of marking and scoring, the records, the different classes of marksmen, the care and distribution of ammunition, and the police of the range.

Among other rules the translation reads:

"The aiming is not exercised licentiously on the range." Chapter 8 speaks of the battle practice. The object is to practice firing under battle conditions, the troops being in heavy marching order. This practice is divided into file firing, and party battle practice.

In file firing, a preparatory drill is had under the regulations for skirmish drill in Part I of the infantry drill regulations.

The file firing is conducted in the company, man targets in different positions being used at unknown distances. As the men become more proficient, disappearing and moving targets are used.

The result of the shooting is reported by signal markers after the firing has ceased.

Party battle practice is conducted at unknown distances in short range, middle range, and long range. Fire control and discipline conform to the requilements of infantry drill regulations.

Battle practice is either by squad, section, or company and is always practiced at unknown distances in various localities.

Chapter $S$ is devoted to testing practice. This is for the purpose of testing for accuracy by means of the rifle securely 
fixed on a tripod or stand, at known distances, in good weather. Every soldier in turn is required to fire nine shots at 300 meters' distance with his own rifle in the usual positions for that range. The results are compared with the standard rifle, and all deficiencies or inaccuracies are colrected by skilled workmen.

Night practice is had occasionally at targets posted at from 200 to 800 meters, using a search light or fire light, and resting the rifle on top of the breastworks. This is for the purpose of trying the men under unusual conditions.

Chapter 9 gives the different classes of marksmen.

'The third class consists of recruits and men in their first year of service; in preliminary practice at 100,150 , and 200 meters, and in the regular practice at 200,300,400,500, and 600 meters.

After completing the course of practice laid down, the third-class man is promoted to the second class, and after completing a somewhat similar course in that class, he becomes a first-class marksman and practices at all ranges under varying conditions.

Officers and noncommissioned officers who have fulfilled the requirements of the first class for two successive years become special marksmen.

Chapter 10 is devoted to inspection practice. Once in each year the division or brigade commander inspects each regiment in battle practice, simulated so far as practicable to actual battle conditions, thus testing the skill of ofticers and men. A copy of the report of this inspection is preserved in the regiment.

Chapter 11 speaks of marksmen's badges. Four badges or medals are given each year as a reward of good shooting.

The special marksmen's badge is given to the three best shots in a regiment.

The first-class marksmen's badge is given to the two best shots among the commissioned officer's of each battalion, and to the two best shots among the soldiers of each battalion.

The second-class marksmen's badge is given to the two best shots among the soldiers of each company.

The third-class marksmen's barge is given to the best shot among the soldiers of each company.

These badges are presented with due ceremony with the whole command drawn up under arms, and may be worn on the uniform during the individual's service in the army. 
PART III.-MATERIALS FOR TARGET PRACTICE, AND THE RIFLE RANGE.

Chapter 1-Targets and Markisg Instruments. - The targets are made of wood and bamboo frames, covered with cloth and paper.

1. Ordinary target, a white rectangle 1.65 meters long and 1 meter in width, on which ten black concentric circles are painted; the intervening spaces or zones between the circles counting from 1 (outer) to 10 (bull's-eye). The eighth and ninth zones and bull's-eye are all in black, the eighth and ninth circle painted in white. The diameter of the central zone is 10 centimeters.

2. Ordinary target with head figure covering eighth, ninth, and tenth zone, the black figure showing the head and shoulders of a soldier.

3. The figure target, complete figure of an infantry soldier in black, widest part of figure being 40 centimeters.

There are four kinds of figure targets:

(a) Whole body figure standing, 1.65 meters high.

(b) Kneeling figure, 1 meter high.

(c) Breast figure, 50 centimeters high.

(d) Head figure, 35 centimeters high.

4. Figure target of several figures; the figures are in black on a white rectangle, 1.65 by 1 meter in size.

Targets are of three kinds, fixed, disappearing, and morable. The tixed (ordinary) target is on a double revolring frame, similar to those in the United States in manner of construction. The disappearing target is handled by a syrstem of ropes and pulleys, appearing and disappearing from a fixed location. The movable target is arranged so that it can be moved (within certain limits) in any direction-up, down, right, and left.

Signal flags and markers are constructed and used generally in a similar manner to those in the American army.

Chapter 2-The Ranges. - The ordinary ranges for drill practice are exceedingly well planned, constructed, and arranged for the different firing stands from 100 up to 600 meters. They are well protected by traverses, so that every range can be used at the same time; a long bricked-up gallery leading from the longest range (at the side) to the long continuous line of pits where the targets are placed, 16 targets on each side. 
These target ranges are located in several places in the suburbs of Tokyo, and also adjacent to the stations of infantry troops of the different divisions throughout the empire.

Temporary ranges are used for battle practice in such localities as may be deemed suitable.

PART IV.- PRACTICE RECORDS AND REPORTS.

The usual and customary record books for the different battalions and companies are kept; also, each soldier has a target practice record book which he keeps, similar to ours.

Company practice records are completed every year and reports sent in to the battalion commander. Each battalion commander is responsible that full reports are sent to regimental headquarters.

The regimental reports are sent to brigade commanders, and brigade reports to division commanders, where they are consolidated and forwarded to the war department.

ADDENDUM.

Regulations for gallery practice are given, the range generally being about 15 meters, small targets, and reduced charges.

Target practice for the "kobi" (landwehr) reserve, depot troops, and the six weeks' active service soldiers is also provided for, regular tables of instruction being given.

Honor firing or competitive tomrnaments are executed in each regiment annually under the supervision of the division commander, according to special regulations from the war minister.

The time and details of the event are prepared and notificution of the place selected, etc., are all sent through the division.

A special badge is given to that company in the division which makes the highest percentage, and three days' furlough is given to each member of the entire company.

This barlge is preserved by the company until the honor firing of the succeeding year.

A special report is made and forwarderl by the division commander to the war minister. 


\section{INFAN'TRY TARGE'T PRAC'TICT.}

REPORT OF THE TARGET PRACTICE OF THE FIRST REGINENT OF INFANTRY OF THE IMPERLAL GUARD DIVISION.

On April 25, by permission of the war department, I witnessed the target practice of the first battalion of the first regiment of infantry of the imperial guard division on the "shatekiba" (target range) at Okubo in the suburbs of Tokyo.

The firing was at 300 meters, the position taken was prone. The accuracy of the shooting was not very good; the explanation given being that they were only first-year men.

The Murata rifle, caliber 0.256 , is similar to the Mauser rifle.

Cartridges inserted by a clip (of five cartridges); the bolt action of breechblock simple and easy to manipulate.

The targets (at that range) seemed to be smaller than our own, and were certainly difficult to hit, for it took me three shots to get on the target.

All the conduct of the firing was excellent, no confusion whatever, no talking; and the officers appeared much interested in the practice of their men, taking frequent occasion to remedy faults in elevation, windage, holding, sighting, etc.

In the pits which I visited, everything was conducted quietly and uniformly, there were three markers to each target. When a shot was fired at a target, the target was revolved, the shot hole (if there was one) discovered and pasted over by one man, the flag raised by another man, while the third man indicated on the visible target, by means of a disk at the end of a long pole, the exact position of the hit. The work of each group of men was superintended and controlled by a sergeant, while a commissioned officer overlooked and controlled all the targets which were being used by each particular company.

In all my experience I can suggest no improvement in the manner of conducting target practice; it seemed to be complete.

The target range at Okubo is said to be the finest in the vicinity of Tokyo; it covers an unusually wide area, there being arrangements for 32 targets which can be used at the same time, at the same range, or at different ranges.

When firing is conducted for battle practice, the troops are marched out in the conntry as if for a regular campaign against the enemy, and firing up to 1,:000 meters is practiced. 
AMUUNition ALLOWANCE.

Note.-Information just received that the annual allowance of ammunition is as follows: For each infantry soldier, 125 ball and 100 blank cartridges; for each cavalry soldier, 98 ball and 30 blank cartridges. For revolver practice-for each infantry noncommissioned officer, so ball cartridges; for each cavalry noncommissioned officer, 20 ball cartridges.

\section{FIELD ARTILCERY TARGET PRACTICE.}

The field artillery application school is located at Yotsukaido, about 30 miles southeast from Tokyo, under the superintendence of Colonel Noma of the artillery, with a staff of about ten instructors. The students number about 30 ; there being one lieutenant from each of the regiments of artillery of the twelve divisions and the imperial guard, and one lieutenant from each of the six additional regiments of artillery which constitute the two brigarles of artillery, together with extra officers and supernumeraries.

The course of instruction is essentially a practical one, consisting of instruction and practice in field and mountain artillery, and the care of ammunition, signaling, and equitation, and extends over a period of six months-from December 1 to June 10-divided into two courses of three months each.

There are two batteries of artillery at the school, fully equipped with both field and mountain guns, so that each may be used as occasion requires.

The eighteenth regiment of artillery, composed of six batteries of six guns each (which belongs to the second brigade of artillery), is also quartered here in barracks and stables adjoining the inclosure which comprises the school of instruction.

The ground in the vicinity of the school extends for several miles, giving an area rectangular in shape, with but few clumps of trees, and fairly level; small hummocks and shallow depressions here and there not interfering with the maneuvers of artillery in any direction, presented an ideal terrain for practice.

The extreme ends of this range of open country is bounded by thick groves or small forests of trees behind which, to the north and south, have been constructed high artificial embankments of earth for the better protection of the surrounding country from the effects of artillery fire, but which are not visible. 
On the occasion of my visit on April 28 , the varions batteries of the eighteenth regiment were having drills of various linds; other detachments were being drilled in signaling, and while one of the school batteries was being drilled as a mountain battery, the other battery had proceeded to the plain of maneuver preparatory to the artillery practice which was to take place.

At the extreme end of the range to the south could be seen (with glasses) the target, supposedly the enemy's artillery, there being eight groups at proper intervals representing the guns with their detachments.

The battery (of six guns and three caissons) moved out from their temporary resting place in column of sections-took up the trot, and came "right front into battery" into their first position (about 3,000 meters), obtained an approximate range by use of a range-finder, and fired two or three shells; then rapid fire of shell and shrapnel for about two minutes (as near as could be judged while watching the effect through glasses). The range seemed to be very accurate, as the shrapnel burst apparently a short distance in front and over the line of targets.

The actual result in hits had not been ascertained when I left the field.

A certain peculiarity in the ground must here be noted in order to make intelligible what is to follow. There were places across the plain of fire where the ground seemed to break into parallel lines.

Suddenly there was a sharp yell from someone, the guns, which had ceased firing, were run by hand rapidly to the front some 50 meters, and looking toward the gun targets I saw what appeared to be the head of a column of infantry in company column a short distance to the right of the gun targets and some 300 meters nearer; and I was informed by one of the officers that the yell meant, "There comes the infantry in column."

In an incredibly short time the new range of the infantry column target had been found by one or two shells; and then rapid fire with shrapnel (timed at the rate of one shot every three seconds) filled the vicinity of the target with bursting shrapnel for about one and one-half minutes.

Then another sharp yell, and we could see suddenly a line of soldiers' heads which appeared to spring out of the ground 
at a distance of some 700 meters nearer, and extending almost across the whole plain of fire. (I was afterwards told that there were 1,000 of them-there certainly were several hundred.)

Again the range was quickly obtained, and the shrapnel seemed to cover the entire line-the little puffs of smoke of the bursting shrapnel seeming to be at the right distance in front, and just high enough to do effective work. There were of course some wild shots, and some few short fuzes; but I did not notice a single failure to explode in the air. It was wonderful shooting, but I would have been better satisfied if I could have found out the percentage of hits.

These infantry targets were so arranged that by moving a long lever, away off at one side out of sight and out of range, the rows of figures could be made to show up above the slight depressions referred to, and by a reverse motion could be made to disappear.

It certainly was a very ingenious and novel idea, and very effective; and as there were a number of these depressions, where the infantry column or line target could be used, it was not known in advance where they were to appear, and in each mstance the range had to be found in order to do effective work.

The effect of these heads showing up as they did was uncanny, and one could not resist the impression that they were human beings.

The battery limbered up and withdrew out of sight until after lunch was disposed of by officer's and men, when the firing was resumed under similar conditions but at different ranges. I was much impressed by the rapid and orderly manner in which they all worked together with apparently good results.

After the practice was completed, all the student officers and the battery officers who conducted the firing were gathered together, and an exhaustive criticism was made by Colonel Noma and the field officers present, in which every point was carefully discussed, the officers all making notes in their field books for future reference and guidance.

On returning to the parade ground of the school, the drill with the mountain guns was witnessed.

Five horses (no mules are used) were packed with one gun and its equipment. While marching in column the command 
"Halt! In Battery" was giren, and in one minute and thirty seconds (timed) the gun was in position, loaded, and rearly for action, and the horses to the rear out of the way.

These Japanese soldiers seem to be human machines; they work quickly and silently, each doing his own part exactly as he has been instructed, and the officers seem imbued with a pride in their profession which is most commendable.

Annual Allowance of Ammunition.--Shell and shrapnel: To each battery, 426 rounds; Blank cartridges: To each battery, 600 rounds.

$23555-23$ 



\section{INDEX}

To

TARGET PRACTICE AND REMOUNT SYSTEIS.

(355) 



\section{INDEX 'TO TARGET PRACTICE.}

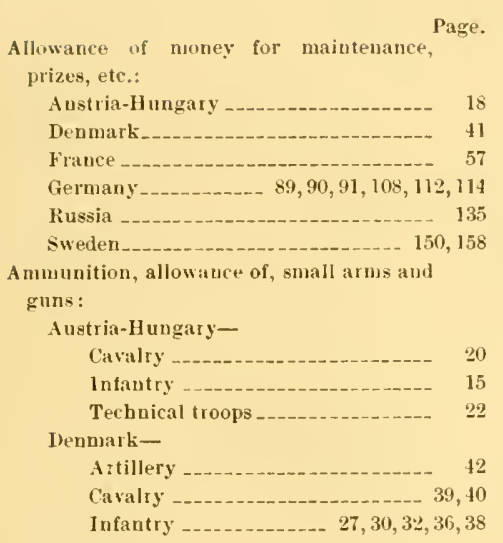
France-

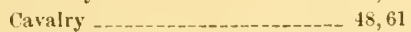

Iufantry _._. 47,50

Germany-

Artillery -_-_-_- 112

Cavalry _._._._._. 107

Infantry _._._........ $81,84,90$

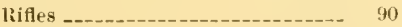

Technical troops

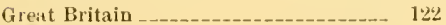

Russia-

Artillery -

Cavalry _-_-_-_-_-_-_-_-_-_ 136

Infantry -..._-_. 133

Sweden-

Artillery _-______ 167, 169,170

Cavalry _._-______________ 151, 152

Infantry _.___._._._._._. 147-149 switzerland-

Artillery - -

Infautry and cavalry _. 193, 197, 199, 201

Machine gun ________________ 202

Aıtillery target practice:

Denmark_...___._._._._. 11

France _._._._. $48,64,66,72,73$

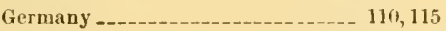

Russia _..-...-

Sweden_-_-_-_-_-_-_-_-_-_ 159

Switzerland -......-- 200, 202

Badges. (See Insiguia.)

Camps of instruction :

Denmark

France 60,69
Page.

Camps of instruction-Continued. Gernany _... Great Britain _._._. 122

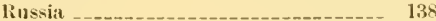

Sweden _........ 150,14 i6

Swityerlitul _._. 2013

Classificatiou of men firing :

Austria-Hungary _._._____......... 8,1 ,

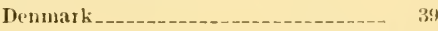

France _-_ $50,63,34,71$

Gerwany _-_-_-_-_-_-__-_-_ 79, 85,91, 108

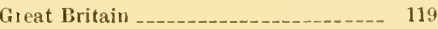

Russia -

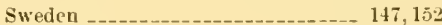

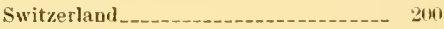

Collective fire:

Austria-Hungary -

Denmark__..._. 32

France _._._._._._._._._. $4 \overline{7}, 54,56$

Germany _.........._-_._- 106

Great Britain _-__-_- 121

Russia - -

Sweden____... 146, 148

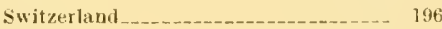

Competitions :

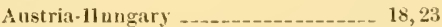

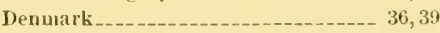

Fratre -

Germany _-__-___-_ 88, $89,93,108,114$

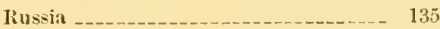

Sweden _-______ $149,153,158,159,164$

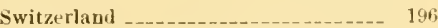

Demonstration firing, testing rifles, etc.:

Austria-Hungary ____________ 7, 16

France ....

Germany _-

Estinating distances:

Austria-11ungary -_-_-_-_-

Denmark _..._-_._-_._- 28, 29, 34

France

Germany -_- 79

Riussia -

Swerlen _- 145

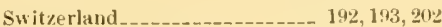

Examination or test firingl:

Denmark--- 29,34

Germany _.___._. 77,13

Field firing:

Austria-Hungary _.__________._. 16,21

Denmark__._.

Frauce _.__ _ 55,69

Germituy - $93,145,111$ 
Field firing-Continued.

Great Britain

Russia

Swedell_______ 146

Switzrland___________ 196

Figure targets. (Nive Targets.)

Firing schools :

Denmark

France-

Artillery

Infantry

Regimental__._................... 63

Frenuany _-_____ 110, 115, 116

freat Britain _. 121

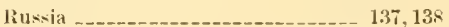

sweden-

Artillery --_-- 160, 165, 166, 168, 170, 188

Cavalry _..__._. 152

Infantry _______ $142,147,149$

Switzerlaud _._._._._._._. 191, 201, 202

Gallery practice:

Austria-Hungary _...... o

Denmark _........................ 27

France _..._.

Germany _._. 68

Russia _._. 136

Swerlen____ $140,141,147$

Switzerlaud _._____________._. 194

Individual practice, range and field:

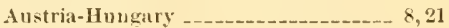

Denmark_._. 38

France ___ 47,56

Gernany -___- 77-81, 104

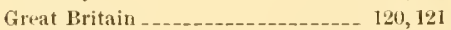

Russia _. _ _ _ _ 134, 136

swerlen___ 146,148

Switzerland_________ 194

lusignia anel rewards for good shots :

A ustria-H ungary _._. 13

Denmark___ 27,36

France _-

Gernany ___.___ $87,88,90,114$

Russia - 135

Sweden _._____ $150,158,164,165$

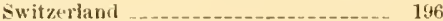

Instruction, course of :

Anstria-Ilungary-

Cuvalry _..._-_._._..... 19, 20

Infantry $\quad 7,11,12$

Ufficers' - . - 22

Technical aud train troops_......... 22, 23

Denmark-

Artillery -__ 41

('itvalry _-_._.

1ufantry _._.

France-

Artillery -

Cavalry ___

1nfantry _...... $49,54,5.5,60$

Germauy-

Artillery _-___

cavalry

107
-107
Instruction, course of-Continued.

Page.

frermany-Continued.

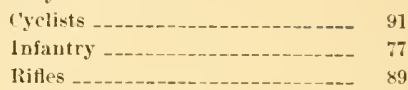

Technical troops - -

Great Britain _-_._- 119-121

Russia-

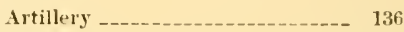

Cavalry _-___

Infautry -_-____ 133, 134

sweden-

Artillery _-______ 159, 161, 166

Cavalry _..__. 151

Infautry _...___ 139,142

switzerland-

Artillery -_-__-_-_-_-_-_ 199, 20.3

I.avalry _._. 201

Iufautry - ___________ 191, 197

Hachine-gun practice:

France -

Germany _-_ 116

Switzerland _......... 202

Mlarking, scoring, signaliug:

Austrit-11ungary _ _ _ _ _-_._._._. 13

Denmark _................ 33

Germany _._._._._._._. $84,86,113$

Great Britail ____ _ _ _ _ _ 120, 121

Russia …............ 135

Sweden _._._...... 145, 146, 16it

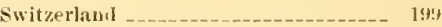

Matches. (See Competitions.)

Officers, practice :

Austria-Hungary _.___________. 19, 2:2

Denmark__._._. 37

France -

Germany ___ 84, 89, 109

Russia _..._. 134

Sweden $\quad 153,167$

Switzerland ___ 191, 192, 198, 201

Officers, range; duties_._._._._._._._. 50,51

pistol firing. (See Revolver and pistol

practice.)

Position aul aining drills, (See lustruc-

tion, conrse of.)

Practice, additional, Denmark -

Practice, fielll firing. (Ste Field firing.)

Practice, known distances:

Austria-Ilungary _..._.

Denmark

France - 54

Germany ________ $85,86,89,107,110$

Great Britain ___

liussia _...

Sweden $147,148,149,15$

Switzerlaud _._.______ 192, 194, 197, 198

l'ractice, preliminary or preparatory :

A ustria-llungary -

I lenmark _._.

France _...._............. $47,4 \curlyvee, 51,66$

Germany _.________ $77,80,85,104$

Swedel_____ 139, 153, 162

Switzerlaud _._._._._._-_______ 192 
Practice, revolver. (Siee lievolver and pistol practice.)

Puctice, s]weial contitions, Germany _._._. 42,93 Practice, rolley firing. (See Collectire fire.)

Prizes. (See Compretitions.)

Qualifying scores:

Austria-llungary

German! $80,81,85$

sweden $147,15 \%$

Switzerlaud _-________ 192, 194, 197, 198

Range practice. (See Practice, known thistances.)

Range practiee, time and weather.

Ranges. (See (ampls of instruction.)

Revolver and yistol practice:

Austria-Hungary -

Denmark

France - 49,64

Germany 109

Russia 136,137 lievolver and pistol praction-chutionat.

Sweden__53-157
Switzerland

Schools for instruction in firing. (Sice Firing scliools.)

Scores to yualify. (See Qualifying seores.)

Scoring. (Siee Matking, scoring, signaling.)

Signaling. (See Marking, scoring, signaling.)

Tiargets:

Anstria-11ungary
Denmark
France
Germany
Great Britain $9,10,11$
Russia
Sweden
Switzerland
forms worn in practice
ley fire. (See ('ollective fire.)





\section{INDEX TO REMOUNT SYSTEMS.}

Acclimatization of horses:

A ustria-Hungary -

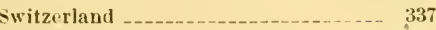

Atlana stul, Turkey.___.__ 341

Alvances for vurchase of officers' remounts :

Frauce - 238

Germany _..._._.

Italy _..... 306

Afgban type of horses, India_._______ 298

Ages of horses and mules:

Algeria__- 249,262
Austria-llungary - 208,209
Chile__

Denmark _

Dutelı East Indies ________ 318

Fratree _._. $244,24+i, 249,255$

Germatny _.__ $271,275,276$

Great Britain _...

Italy _._._.

l:1рan _... _ _ 311

Netherlands ___________._. 317

Portugal _........... 323

Russia _._. 328

Spain _- 3332

sweden__-__- 333

Switzerland_____ 337

Tunis _-_._.

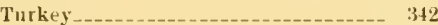

Agram stallion dejoot, llungary _ 218

Allerta borse breerling, Canalia _-______ 299

Algerian remounts _._.

Allelik. (siee L'Allelik.)

Allowances for remounts to officers:

Austriat-IInurary

France

255,256

Germany -_._____________ 273, 274, 279

1taly

306

American stallions in Jajan _._._....... 311

Andalusian saddle horst-____________ 332

Auglo-Hisjano-A rab stallions___________ 331

Anglo-Xorman stallions:

$\begin{array}{ll}\text { Argentina _- } & 313 \\ \text { Austria-Hungary } & 220 \\ \text { Chile } & 315 \\ \text { Spain } & 331\end{array}$

Antual luss of horses. (Siee Fearly requmrements of horses.)

Annual requirement of remounts. (Siep Yearly requirements of horsin.

Autirax:

France

Italy
Page.

Antistreptococique serum, France _._._._- 260

Apponyi's (Count Albert) breeding estab-

lishmeut, Austriat-1lungary _________ 221

Apportionment of horses on mobilization:

Anstria-1lungary _.___._... 215, 216

Denmark_-_-___._. 230

Appraisement of mobilized borses:

Austria-11ungary .......... 21ti, 217

Denmark__._. 231

Germany _. 281

Arab-Barbary horses, Algeria and Tunis .. 249 , 260,261

A rab-Barbary thoroughtred stallions, num-

ber of, Algeria _... 260

Arab lorses, Algeria and Tunis_.__ 249,260,261

Arab lorses, importel into Argentina ....- 249 Arab nitres:

Germany _.

Turkey _._. 341

A rab nares, export forbidden, Turkey _._. 341

Aralo stallions:

Algeriat_.

Argentina .

Austria-llungary _________ 221

France _. 260,261

Germauy _...... 282

India _ _.

I taly - 306

Siritin -

Turliey-_ 341

Ardeunes horse, Belgium_._.___._._. 225

Argentina as a source for remonnts for

Europe____ 313,314

Argentine horses:___________ 296,313,314

Argentine Iorses in Fratice._._._. 313

Army breeding farms. (Fee Breeding es-

tablishments.)

Army horses with private keepers. (se

Civiliaus' use of army horses.)

Army studs. (Siee studs.)

Artillery batteries, number of. (See Xum-

ber of artillery hatteries.)

Artillery horses:

Argentina ___ 313,314

Austria-11ungary _________ 215, 217

Delgium _... $\quad 225$

Britail _._._. 314

Chile. $\quad 315$

Denumark _2:21, 2:30

Dutch Eist I udies _.________ 317

Frince -

Germany - 
Artillery borses-Continued.

Page.

Great Britain _-___________ $285,2 \times 6$

It taly_____ $303,304,305,306,309,310$

Mexico____.___._. 315

Netleerlauds _._. 317

Norway _-_ 320

Persia _._._._. 321

Ru:siit _._____ 328,329

Spain _... 332

Switzerlabd ______________ 336,339

Turkey _.__________ 341, 342

Artillery regiments, numler of. (See Num-

ber of artillery regineuts.)

Asers:

Argentina_ _-

Bonilay _.__ 298

('hile-_-_-_-_- 315

China $22 \%$

Gernan colonies -..-_...-284

Germaty _-_. 274

Indiat ... _. 2997,298

New Zealand _... 301

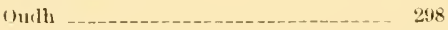

Puijab

spain _.._- 331

Assigmment of horses to officers. (Sive lissue

of Jorsen to oflicers.)

Assigument of horses to the varions units.

(see Issue of horses to various units.)

Australia as a source for remounts _____ 300

Australian horses _.____ $27 \times, 284,296,247,310$

Australian stallions, India__________ 297

Anstralian type of loores, Imlia_____.__ 297

Anstro-Ilungarian horses exported into Ger-

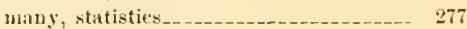

Avenclues stud, Switzerland__._______ 338

Babolna breeding establislment, Hungary,

$218, \geq 21$

Baerenklan remomnt dejot, Germany ___. 275

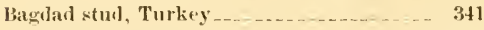

Bales of hay, weight of, France-_____ 263

Barbary stallions, Inumber of, Algeria_ 2601, 261 Barlary tyje, lreeding of, Algevia _ 259, 260, 261 Barley meal, rations:

Algeria _._. $26^{\circ}$

France

Barley ration :

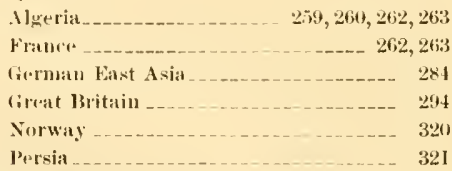

Bavaria remonut dejots. 271

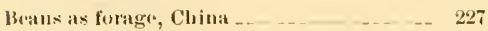

Beans, forage ration :

$$
\text { Algeria }
$$

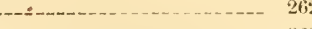

Botherbeck, Prussia _ol

Hecker's (Johu) private hreeding estalılishuents, Anstria-IIungary
France --

Bedding for officers' horses, Italy _......... 3n:

Belgian horses:

Germany -

Spain _._. 332

Beluehisian, horse breeding _.____._. 207

Bengal type of borses, India ______ 2:13

Bern remount depot, Swit\%erlabi ______ 337

Bilak remount dejot, Anxtria-Hungary _ 209, 210 Blaskovics's (Stephen) private breeding es-

tahlishment, Austria-IIungary ___ 2.21

13lidah remount depot and stud, Algeria _.. 257

Board* for mobilized horses, Denmark__._. 231

Bumbay horse brealing___________. 297

Brabauts stallions, ltaly____________ $36 \%$

Bran ration :

Algeria _ $20+2$

France _.

German East Asia_._._.......... 284

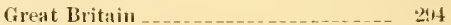

Switzerland ___ _ $39 \mathrm{~s}$

Branding:

Algerin _..._.

Austria-Hungary _. _ _ _ 209, 220

Demmark______ 230

France __ _ 245,247

Germany _.__ $\quad 276$

Great Britain _._. 287

IIungaty _ _. . . . .

Italy _.._ _ _ _ _ _ _ 305,309

Norwiy _ _ $3: 0$

Switzrlaud____._. 333

Tunis _.__ 251

Brazilian remounts____________._. 314

Breeling associations, Denmark ..___._. 229

Breeding establishments:

Algeria_-_._-_._- 257, 261

Sustria-Hlungary _.___._______ 217,218

Bavaria _.._.

Brazil _____ 314

Demmark - 229

France _... _. _ _ _ _ _56,257

German colonic's _.._.

Germany - _..._. $271,281,2 \times 2,2 \times 3$

Great Britain _._. 287

II ungary. ___ _ _ _ _ _ _ _ 219

India …….....

Italy _... 305,306

Japan _ _ 311

Mexicy _._._. 315

Norway ___________ 319

Persia

Prusmia _._____._. 281

Jiussia _ _ _ _ _ 325, 326.327

Saxony -

Spain _.__ 331

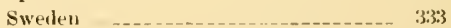

Tunis _._. 257

Turkey _._._._. 341

Wurttrulserg _ 283

breeding farms. (See Brceding potablishments.) 
Breeding of horses:

Algerii_

\section{Argentina}

Australia _.

Austria-llungary -__________ 217-222

Bavaria _..._.... 283

Belginm _. 225

Beluchistan ….......... 297

Bombay _-_ 297

Brazil _.. 314

Canala_______ _ _ _ 299

Chile_...___ 314

China__-__- 227

Dece:

Demmatk

France _ _ $256-262,268,269$

German colonies ......._._._._. 284

Germatty _-_._........... 281, 282, 283

Great Britain__.___ 2N7, 296-301

Hungary -_._-

India - _.__ $296,297,2908$

Italy _-_ 305,306

Japan _..._______ 311

Maneluria _................... 227

Manitohit_-___- 299

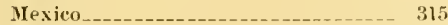

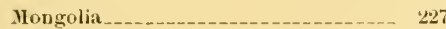

New South Wales _.____ 300

New Zealand _.__ 30I

Norway _-___._.

Persia____________ 321

Portugal _... _. 323

Prussia______ 281, 282

Punjab_ _._.

Russia ___________ $325,326,327$

Saxony _._.

Sind, Indial _ _ _ _ 29!7

Spaitı _... 331

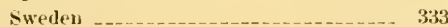

Swit\%erland _..... 338

Turis _._. 257

Turkey _-_

Vietoria, Australia -_-_-__-________ 301

Wurttemberg _._._. 283

Breeding of mules:

Argentina - -

irazil___________ 314

Chile

China _..._- 228

Germatn Africit_-_-_-_- 284

India _..__

Jexico____ 315

New Zealand ___ 301

Spain _.._ 331

Breeding stables. (see Breeding establishments.)

Breibolen, remount depot, Wurtteminer.y-_- 272

British colonies, remounts ..... 28.5, $287,296-301$ Brood mares:

Algeria

261,262

Austria-Hungary

218,219
Brood mares-c'ontinued.

Page.

Frince - Germauy -

1lungary _. 218,219

Indial _.

Italy _._ _ 305,306

New Zealand _ _ _ _ _ 301

Prussia _..._-_...- 282

liussia _ _. _ _ _ 326,327

Spitin -

Turkey _._. 341

Buccaneer, eelebrated stallion, Kis-Ber,

If ungary . _.

Budajest remonnt purchasing commission,

Austria-Hungary _.__ 208

Budgetary effective of horses. (See Number of horses, army.)

Burma pony, Intlia _..._._. 298

Calgary, remount dejot, Cunada _______- 299

Camel corps, India __________ 299

Camels, army:

Algeriat_____ 239

Inlia - 298

Tunis _.__ _ _... 239

Canadian hors's jurchased by Great Britain, statisties ….......

Canadian remounts _.

Cantinière, France-_. 264

Cape Colony remounts _.__ 300

Carbuncle fever. (See Authrax.)

Carrots used as forage:

Algeria

France - 262

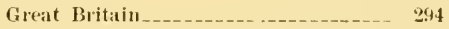

Castration followed by tetanus, France___ 266

Citucasus stallions._________ 325

Cavalli de agevolezza, (officers' looress)

Italy - $314 \mathrm{j}$

Cavalry horses on mobilization. (sie Nobilization of horses.)

Cavalry horses, supply of. (See Supply of horses.)

Cavalry, (Sire Hounterl troops.)

Cavalry regiments, number of, (See Num-

ber of cavaly regiments.)

Census of borses. (See Number of borses.)

Chamont stallion, Gemany -__._-_._. $28: 2$

Change of horses by officers, Italy _._- 309,310

Chargers:

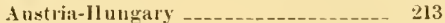

Chile_.-_-_-_._- 315

Germany -________ $273,274,276$

ltaly______ 318, 3169, 310

Cheval de carrière, france _.___. 239, 254, 250

Cheval de manège, France _______ 239, 254, 256

Chief farriers, Frauce -....... 2 $\{1\}$

Chifteler stud, Turkey _.___________ 341

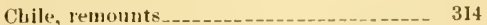

Chilean breed_-_______- 314

Chinese mules for East Indian artillery __. 318

Civil ofticials' horses, Japan _.......... 311 
Civilians' use of atumy horses:

Page.

Austria-Hungary

215

Denmark

$232,233,234$

Switzerland

Classification of hotses

Austria-Iluugary

212, 216

France

216,255

Germany

$273,274,275$

Italy

$306,307,30$

Russia

328

Switzerland

Cleveland lay, Chile 337

Clevelauds:

Argentina

thile

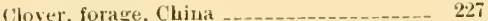

Clydesiales, imprterl into Argentina _..._. 313

Clydestales, stallions:

Argeutina _... 313

Italy _.. 306

Cobs, statistics of purchase, Great Britain 296

Colıl shoeing, Great Blitan ____.____ 296, 291

Colic, Prussia____._. 283

Colonies, remonuts:

France

$23 ! 9,251$

Germany

$277,278,284$

Great Britain_________ 285, 287, 296-301

Italy _._. 303

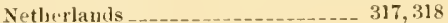

cilor, army horses:

France _-_

Great Britain______._. 286

Italy _. _ _ _

Norway _._.

cults, thoroughbred, Hungary___.____._ 221

Commutation of forage:

Algeria - _. 250

Austria-Hungary _._._._._._._._._. 214

Germany - - 279

Compensation for molvilized horses:

Austria-Hungary -_..._-_._._. 216

Denmark -

Compensation for stationed-out horses (witl mivate bcepers):

A ustriat-Hungary _._._.

Denmatk____._. 234

fondemuation of huars:

Austria-1Iungary _._._._._. 209,210, 11$]$

Belginu____.

(liilu-

Deumark______ 230,234

Fince. $23 \times, 246,254$

Germany _. _..._. $273,27(\mathrm{t}, 2 \times 0,2 \times 3$

Great Britain_____... 287

1 taly__._. $303,304,309,310$

Norway _._. 320

Prussia _._._._. $28: 3$

Ri1s:19 _327,329

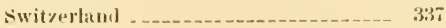

Tutkey -... l'age,

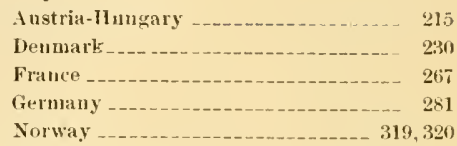

Constantine remount depot and stud, Algeriat

Cordoba province, military stum, Siain

Corn, forage ration, France

Cossak renounts, Russia _.________ 327,329

Covering:

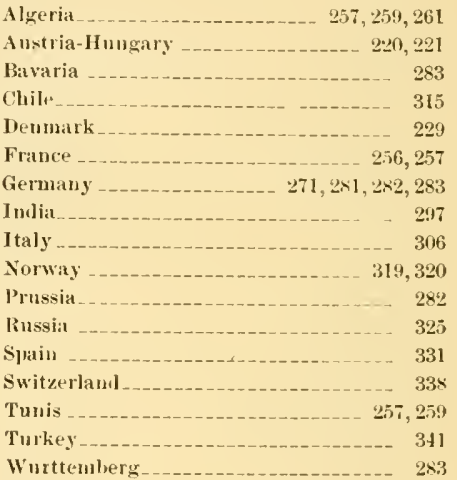

Covering fees:

Algeria

Austria-Hungary -._.

Chile $\quad 315$

Denmark__... 229

Fuance - $25 \%$

Germany - 28.

Intia_____ 297

Italy-_ 306

Prussiat_._. . $28^{\circ}$

liussia _...

spain … 331

Switzerlabel

Tunis _- 25 !

Turkey _.__ _......_._. 34

Cross-contutry hors', France _.... 251;

Crown horses, Russiil _._._. 32!

Cyprian mules jurchased ly Great Britain_ 296

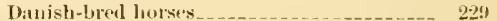

Danish hor ses imported into Germany, statistics _. _ 277

Debrecain stallion depot, llumgary _ 218

Debts incurred by ofticers in purclasing res-

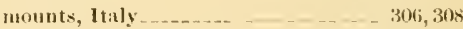

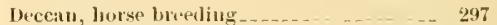

Decentralization of remonut service, fier-

mat11 _ _ _ _ _

bepots for traning temounts. (sice Train-

ing school for horses.)

lerkul stuul, lausia_____._. 32ti

l)escriptive hook of horses, Fiance _...- 246,247 
Distists of lurses:

Iustriatllungary

r'ag".

Denmark

$211,212,219$

France.

230,235

Grent Britain -

1 t:tly _ _ _ _

Prussia_____-_ 283

switzerlitud____ 337,338

Draft animals, other than horses, German

Suuthwest Africa - _-_-_-_-_-_-_-_-_-_-_ 284

Draft horses:

Australia _-______ 300

Austria-Hungary _..___.__ 209, 216, 219, 220

Belgium _._.

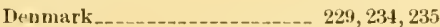

France _-_-_._-_._ 239, $240,246,247,248,267$

Germany -_-__-_-___... 271, 277, 280, 281

1 taly _._ 303, 304, 305

New South Wales ___ 300

New Zealant _.___________________ 301

Norway _... 320

Persia _..__ 321

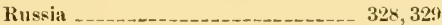

Spaill -..- 332

Switzerland _-_.-_- 339

West Australia ........ 300

Irift mules :

Algeria_-..-_-_-_._._. 239, 240, 246, 249

France --_-_-_-_-_-_-_-_ 239, 240, 246, 249

German colonies -

Tunis _________ 239, 240, 246, 249

Turkey _-_-_-_-_-_-_-_-_-_-_-___._ 342

Wrohowyze stallion depot, Austria ....... 218

Dropsy, Frauce __.

Dullin, remount depot, Ireland_-___._._. 287

Dutch colonies.

Ditch horses inuported into Germany, statistics

Duty on Arab stallions, Turkey _________ 341

Duty on horses, mules, asses, and foals :

Austria-Hungary _._._._._._._. 209

Denmark____. 229

France _._._. 237

Germany _._..... 277

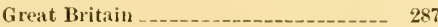

I taly _._._.

Norway -------1- 320

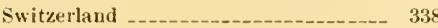

Turkey _...._._. 341

East Prussian remounts ____________- 272

Elephant batteries, India_________ 285

Élite, Switzerlaud _._.

Eugineer's' horses:

Belgium

225

France

$239,240,255$

Great Britain

$-286$

Italy 303,306

Spain 332
English stillions:

Pare.

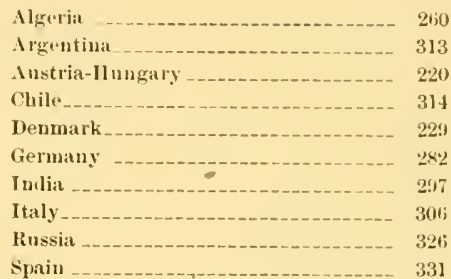

English thoroughbrets imported into

Argentina _..._... 313

Erysipelas, France $\ldots$

Expenditures of lreeding estat,ishments:

Algeria _._._._._. 262

Russia __. 327

Expenditures, purchase of boree:

Algeria -

Austria-llungary _._._._._._____ 209

Denwark -..-_-_. 229

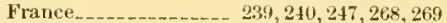

Germany _._._._._._._._._._._._. 271, 274

Italy _._._._.

Portugal .......... 323

Tunis _ 239,240

Expenditures, remount depots, Germany_._ 271

Export duty on Arab stallious, Turkey _.__ $3 \$ 1$

Export duty on horses. (See Duty on

horses, mules, and asses.)

Exports of horses, mules, and asses:

Algeria -

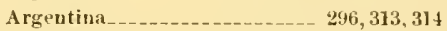

A ustraliat _-_____ 278, 284, 296, 300, 31 ]

Austria-Hungary _._._._._._._._._. 277

Belgium … 332

Canada _.......

China _- 329

Cyprus _-

Denuark_........ 277

France

Germany-_-_-_-_-_ 229. 277, 305, 313,336

Great Britain___________ 229, 246, 313, 333

llanover _................... 333

Hungary _.___________ 296, 33t;

I reland _._____

I taly _._.

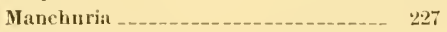

Netherlinds_._.

New Zealind _..._..... 301

Persia -

Russia _..._...... 321,327

Spain _._._. 296, 323,331

Turkey ______________ 219,3\&1

Cuited States _.____ 2688 ,

$277,278,284,296,305,313,315$

Extrit pay for remounts of othicers. (Siee

Allowances for remounts to officers.)

Farriers :

France Great Britain _._._..._._._. 2894, 291, 293 
Farriers' school:

Denmark

Frauce

Great Britain

Faults of purcinated horses ghatanteed against. (Sep Guarantee of horse keller required.)

Fees for covering. (See loveriug fees.)

F'es of farriers, France

Feed. (See Forage.)

Fielll-ofticers' horses:

Anstria-IJungary

213,214

France

$237,238,25$

Italy _. 308

Fiji, remounts _._

Fines for disabling a horse:

France

Italy _.....

Fines for disobeying mobilization orders:

Iustria-lluugary ___ 215

Dennark__._.

Fines for violation of regulations for stationet lout horses, Denmark ______ 234

Flemish horses, Belginm___ 225

Fogaras, breeding establishment, Hungary,

Fontaineblean artillery-school horses,

France _.....

Forage:

Algeria _-_ 250,259, 260, 262

Austria-llungary

211,214

China

Jenmark-1 230

France _..___ $255,262,263$

German Fant Asia _..._._. 284

Germany -

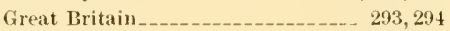

Italy_____ $305,308,310$

Norway _-___- 320

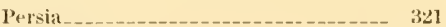

Rinssia _-__-_- 329

Switzerland _- 338

Forage allowance :

Algeria ___ $250,259,262$

Austria-11ungary -________... 211,214

lentmark - 230

France ________ $25 \%, 255,262,263$

Germany _..._... 2T5,277, 278,279

Great britain _._._. 293,244

Itaiy _ $3015,308,310$

Norway _.

P'rria _a_ 321

Russia _ _ _ _ _ _ 329

Switmerlitul _. 338

Forage commutation. (See Commutation of forige.

Forage furnished tospahis, Ilgeria_..__. 250

Forage storelionses, Instria-IJungary _._ 214

Forster (Wheck), prirate lreesling establish-

ment, Austria-11 ungary._____ 21

Freme horses imported into Germany_._. 277

French horses and mules for 3 talian attiliery 305
Page

French stallions in Japan _ _ 311

Frost nails, shoeing, Great Britain _._. 292

Funds, remonnt service:

France _._- 247

Germany _._.

Fyen remonnt depot, Denmark _._______ 229

Galician sallle horses, A ustria-Hungary -- 222 Gendarmerie:

Belgium _..._- 225

France_-__ 239, 240, 255

Mexico - 315

Spain _._. 33 ]

Generals' horses:

Fance - 238, 255

Germany _._._._. 279

Italy _..._.

Syain _-_._. 332

General staff oflicers' horse's:

France -

Italy 306

Gernan "charger" system in Chile_____ 315

German colonies, remounts _._._._._._. 284

Germatu horses for Italian artillery ___ 305

German horses for Swiss army _..__... 336

German stallions _._._.

Gidran stallions, Austria-13ungary _.____ 220

Glanders:

Frame

Prussia - $2>3$

Giidling stallion depot, Austria _____ 218

Goverument stallions. (Sie Stallions.)

Goverument sturls. (See Studs.)

Gradit/ breeding stable, Prussia _- 281

Graditz stallions, Germany ________ 282

Gratuitous remounts. (See Officers' horse's, gratuitous.)

Graz stallion depot, Austria

Green fotlecr:

China

France _..._-

Germany

Great Britain

Persia_

Grooming :

Algeria -_._._. 259

I ustria-llungary _._..._........ 212

Jeumark .......

Frauce _ 24s,25,4,26i3

Grmany____... $2 \times 0$

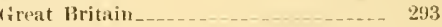

Norway - _. 320

Switzerland _.- 338

Ginirantee of horse selier required:

lle'נmark _ 235

France 245

Hackuey stallions:

Argentina _ 313

I ndia - 2997

1 taly_ _.

New Zealanul _.__ 301

Norway _. _ _ _ _.

llanover remounts, ficrmany 
Hanoverians imported into-

Aruentina

swellen - 333

IIay ration:

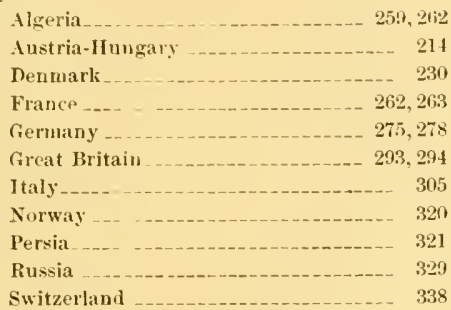

Hódmezio-Vásárhely, city breeding stables,

$$
\text { Hungary }
$$

Holics hunts serving as tests for stallions,

Austria-IIungary 222,223

Holics hunts, training of horses, Austria-

Hungary -.... -

Horse boards. (See Remount commissions.)

Horse descriptive book, France _..._... 246, 247

IIorseshoes:

Austria-Hungary -

Denmark_.._............... 230

France _-_._- 265

fiermany _._._. 280

Great Britain_______ 288-293, 295, 296

Italy_-_ 305

Norway

Switzerland _.__ 338

Hungarian horses:

Great Britain _._. 296

Japan _. _. 311

Switzerland _..._- 336

Turkey- 342

Hungarian mares, Turkey-_-_-_-_-___-_ 311

Hungarian sadlle horses _._._._._._._._. $\quad 222$

Hungarian stallions:

Japin

Hunter stallions, New Z vand_..... 301

Hunters imported into Argentina____ 311

Ihaszi Marczalto remount depot, Austria-

II ungary

Import duty on horses. (See Duty on horses, mules, asses, and foals.)

Imports of horses, mules, and asses:

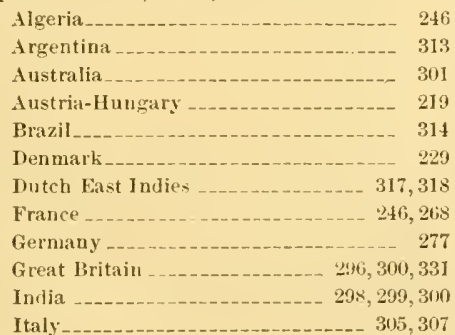

Imunrts of horses, mules, and asses-c'unt'd.

Jaрitu_...

Netherlands _ 31 i

New Sonth Wales_________ 301

Norway _.. 319

Persit _ _ 32$]$

Portugal _. 32

South Africa_. _..

Spain _..._-_. 332

Sweden _- 333

Switzerland _.___._._._. 336

Tunis _ _ _

Turkey_________ 341,342

Indelta cavalry borses, Sweden_..__._._. 333

I udian remounts_._.

Infantry lorses:

Austria-Hungary _._._._. 217

Belgium_........ 225

France _-_ 239, 240, 25.5

Italy _ _ _

Russia _ 329

Influenza, Germany _.______._._. 275, 2800

Inspectors general and inspectors of remount service:

Algeria

Anstria-Hungary - _._-

Deumark_-___ 232, 234

France - 241

Germany _-_._-_._. 274

Great Britain _._._. 285

Rus i: _... 328

Switzerland _...__ 337

Tunis _ 258

Installment plan of purchase of horses by

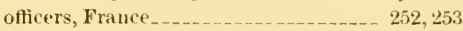

Instruction in loorseshoeing:

France _..._. 263, 264

Great Britain______ 291, 292, 295, 2966

Instructions for the mustering boards, Den-

mark _..._.

Irani type of horses, India .......... 29

Irish horses purchased by :

Belgium

.reat Brititin-_-_-_-_-________- 29i

Ne iherlands _._. 317

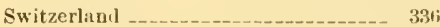

Irish hunters, France___.____ 251;

Irish mules purchased by Great Britain _._. 29:4

lssue of horses of homogeneoustype in each unit:

Algeria_.

Austria-Hungary _._._._._._._. 211, 212

France

Tunis _...... 249

1ssue of lorses to officers:

Austria-Hungary -_____- 2II, 2I2, 213,211

Belgium _.

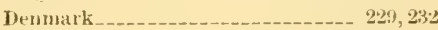

France 252

Germany - _...-...- 273, 274

Great Britain___-_._- 294, 295 
Issue of horses to officers-Continued.

Itaiy.

Netherlands

317

Russia _. 329

Spain $\quad 332$

Switzerland _._._._. 3335

Issue of horses to Iirivate keepers. (Sep

rivilians' use of army horses.)

Issue of horses to various units:

Algeria............. $249,250,251$

Austria-Ifungary _.________. 210,212

Belgium _._. 226

Denwark__._... 232

France_______ 244, 245, 246, 247, 248

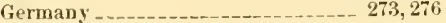

Great Britain _._._._. 287

Italy__....

Netherlands _ 317

Russia _..-_- $327-329$

Spain _.

Sweden _- 333

Switzerland _._. 335,337

Italian colonies' remounts__..___..._._. 303

Italian mules purchased by Great Britain _- 296 Jacks :

India _

New Zealand ........... 301

Janow stud, Russian Poland _......_..... 326

Java _-_____ 317

Kalmuk horses, Russia_______._._._. 325

Karolyi, Count Alvis, private breeding stable, Austria-Hungary _..._..._._._. 221

Kattenau remount dejot, East Prussia _-_- 275

Kharkof district studs, Russia _____.______ 326

Khrenovoye goverument stud, Russia__-_- 326

Kirghiz horses, Russia _..._._._._._._. 325

Kis-Ber lreeding stable, Jungary -_-_- 218, 220

Klalriber breeding stable, Hungary _..._. 221

Klecza Dolna remount depot, Austria-IIungary

Gorses, Germany - 280

Kulkruth remonnt depot, Saxony____._. 271

Kurlish cavalry, Turkey_-_.___._... 342

Kurdish horkes, Turkey__.______ 342

Kvarterheste, Norway _._... 319

Labou remount depot, Austria-Jlungary, 20:, 210

Lack of good military horses, Brazil_._._. 314

1, Allelik brevling farm, Algeria_._..... 257

L'Allelik r.monnt annex, Algeria _...... 257

Laulhollers' horses for indelta cavalry, swecken

Landwehr, Switzerland _.________... 339

Lemberg remonnt purchasing commission,

Austria-llungary

length of service of horses:

A ustria-1lungary

Belgium

(')ille__-

Detumark

France -

Germany - _

Grent Britain
Page.

Length of service of horres-r'ontinued

Italy__._. 314,304

Norway _._._.

Persia ___ 321

Portuga] _..... 323

Russia _-_-_- 327

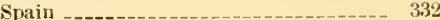

Switzerland _.. 335,338

Turkey _._._. 342

length of service of mules:

France --.-- 238

Italy _.. 304

Light-Iraft stallions, New Zealand _._._. 301

Limaresk stud, Russia__........_._._. 326

Linseed forage ration :

Frince

Great Britain _... 294

Lipitza breeding stable, lInngary _....... 221

Lockjaw. (See Tetanus.)

Loss of horses, annual pereentage. (see

Yearly requirement of horses.)

Lögstör, apportionment of mobilized horses. Denmark

Lung diseases of horses, Denmark _...... 230

Lusk remount depot, Ireland _._._._... 287

Lymph. (See Serum.)

Malatia stud, Turkey_._._._._._._. 341

Malt forage ration, Great Britain _._._._. 294

Nanchuria, horse breeding _._._._._. 227

Manchurian horses _._._._._._._._. 227

Mangelwurzel forage ration, Great Britain 2:44

Ifanitoha, horse breeding _._._. 299

Mares. (see Brood mares.)

Ileasurement behind saddle, sweden _....- 333

Jelton stallio:, ltaly _._. 306

Mexico, remounts___ 315

Mezöhegyes breeding establishuents, HunGary _-___- 218

Miliamah branch remount depot, Algeria _- 257

Militia system, Switzerland________._ 343

Minas Geraes, wule breeding, Brazil _..... 314

Miskolez remount purchasing commission,

Austria-Hungary -._._._._._. . . 2 13

Mohilization of hories:

Austria-Ilungary _..._._. 207, 215, 216,217

lenmark _._.

Finuce _._. 267

Germauy _...

Great Britain $\quad 287$

Italy _._.

Norway _........... 320

Russia _... 327

s'weden _._.

Switzerland _ 339

Nolasses as feed for horses, Switzerland _. 338

Moldavian stallions and mares imported

into Austria-IIungary __________._ 219

Mongolia, horse breeding

Morgans inported into Argentina_......._ 333

Mostaganem remount depot and stud, Alge-

rí. 
Mounted troops:

Algeria.

P:aye.

Argentinn -

239.240

Austria-Hungary _..__________ 215, 217

Belginm__.

Brazil__-_._- 314

British colonies

Chile-_- 315

China -

Denmark -

Dutch East Inlies _._._.________ 317,318

Eqypt_-

France - -

German colonies

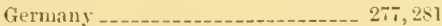

Great Britain _._._._________ 287

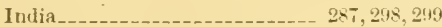

I taly - -

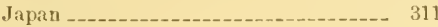

Malta _........ 287

Mexico _-

Netherlands _-_--_-_-_._. 317

Nortbwest provinces of Intlia________ 298

Norway -_._-_-_._- 320

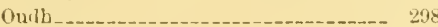

Persia __-_-_____- 321

Portugal …- 323

Punjab_-__- 998

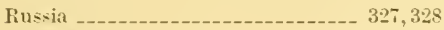

South Africa

Spain _-_ _

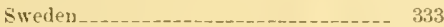

Switzerlaui _. _.___ 335, 337, 338, 339

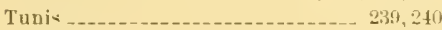

Turkey...._- _._.

Iule breeding. (see Breeding of mules.)

IIules:

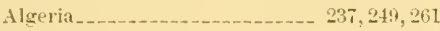

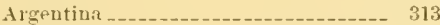

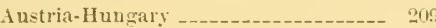

Bombay --_-----_-

Brazil _- 314

rhile-_-_-_-_-_-_ 315

CHina _-_-_2

Cурrา

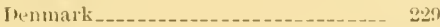

Inutch East Indies _._________ 317,318

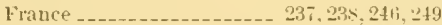

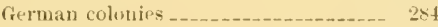

Germany -

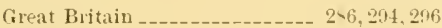

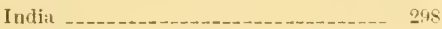

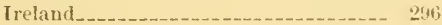

Italy _-__________ 296i, 3113,314, 305

Mexico _-_____________________ 315

Northwest provinces of Intlia _........- 298

Ouilh

Portugal _.

Punjab - 295

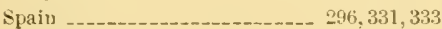

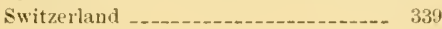

$23555-24$
Mules-Continuerl.

Page.

Tunis _-

Turkey-_-_-_- 342

[nited states of Anerica _._______ 26h;

Murrain, l'russia -.._- 203

Mustayba remount aumex, Algeria ____ 257

Mustering loatrls, Ihamark_______. 232

Nagy-Diat-Sari renount dejot, Austria-

II ungary - _._.

Sagy-Kaniza renount purchasing commission, Austria-IIungary-_-___-__-_- 208 Nagy-Körios stallion depot, Hungary___-_ 21S Nails, horseshoeing, Great Britain _-_._. 289, $291,292,293,299$

Natal, remounts

Netherlands, colonies. (see Dutch colouiles.)

New South Wales, remounts.

New Zealanil, remounts

Nonin stallions, Austria-Ilungary _._. ...- 220

Norfolk stallions:

rbile

India _..._- 297

Spain - -

Novo-dlexaudrorsk stud, liussia__._._____ 326

Number of animals in the government studs, Russia -_-_-_-_-_-_-_-_--- 325, 326, 327

Number of artillery batteries:

Dutch East Indies _-_._-_-_-_-_-_-_--- 317

Persia__._._.............. 321

Portugal _._.

Russia _-_... 32 -

sweden -

Turkey--

Number of artillery regiments :

Argentiua -...-_. 313

Belgitum - - 205

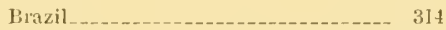

dapan -

Mexico (battalions) -

Netberlands_ --_-_-_-_-_-_-_-_-_-_-- 317

Spain_ _ _.

Number of asses:

Bombay - -

India -

New Zealanel _.

Punjab__.......... 298

Spaic _ _ _ _ 331

Number of asses exportecl, Argentiua_-___- 313

Nimuler of camels :

India -

Number of camels, army:

Algeria and Tunis_._.................. 239

India__-_._-_-_-_- 299

Number of cavalry regiments:

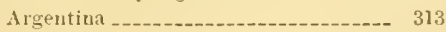

Belgium -..---.-- 225

Brazil _._- 314

Iutch bast Indies _._._._._._._._._._. 317

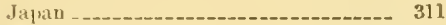

Mexico _-_- 315

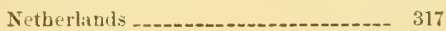


Number of cavalry regiments-Continued. Page. Persia (squadrons) -................-...-.-

Portugal _._.

Russia - 327

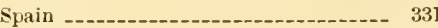

Sweden____._._._. 333

Turkey -

Number of horses:

Algeria -

Argentiua - 313

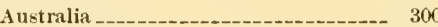

Austria-Hungary _._._._._._._._._._. 207

Belgium - 225

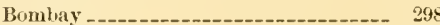

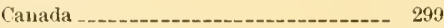

Cape Colony _._-

Chile

Denmark_...-_-_-_- 229

Fiji -

France _._. 237,267

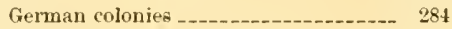

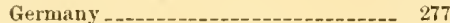

India_- 298

Italy _.._-_._- 303

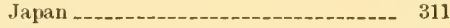

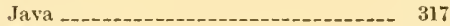

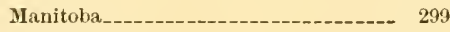

Natal _.-_-

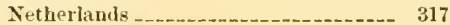

New South Wales _._-__-_-_-__-____-_ 300

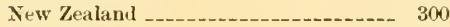

Northwest provinces, India_.........-. 298

Norway _-_-_-_._-_.

Ontario_..._. 299

Oudh, India _.............................. 298

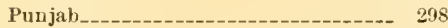

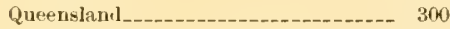

Russia -.--_. 325

South Australia ...................... 300

Spain -_-_-_-_- 331

Sweden

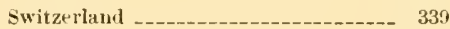

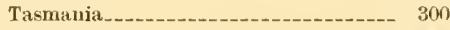

Turkey

Vietoria, Australia_.................... 300

West Australia _ _ 300

Number of horses, army :

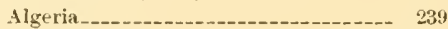

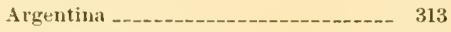

Austrit:-1lungary .........._-_.___. 215, 217

Belgium_._- 225

Brazil _._._._.

Chile_-_-_ 315

Derimark_-_-__________________-_ 229

Dutch East Indies _........._-_._- 317,318

Figyt - 287

France _..._-_._____ $247,237,239,240,267$

German Africin colonies ............. 284

German East Asiat_-__-_-_-_ 284

Germany -..-_-_-_-_-_-_-_-_-_._ 207, 277, 283

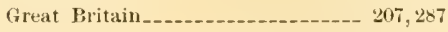

Number of horses, army-Continued.

Puge.

India -_-_-_._.

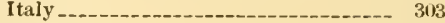

IIalta _-_._- 287

Mexico._-_-_-_-_-_-_-_-_-_-_-_-_-_-_ 315

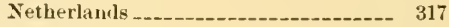

Norway _-_.

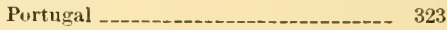

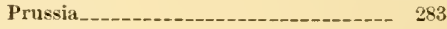

Russia _-_._-_._- 207,327

South African war, Great Britain _...- 207

Spain --_-_-_-_- 331

Sweden - -.....- 333

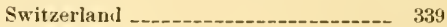

Tunis _-_-

Turkey _._._._._._............ 341,342

Number of horses, artillery :

Algeria - -

Austria-Hungary _..._._..._-_._-_ 215

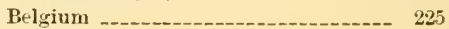

Brazil__.

Chile_-_-_-_-_-_-_ 315

Denmark-_-_-_-_-_- 229

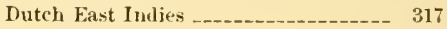

Eqypt_-_._._._. 287

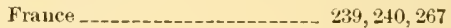

Germany -_-_-_-_-_-_-_-_-_-_-_-_-_-_- 277

Great Britain _....-_-_ $\quad 287$

India _-_-

Italy _._.

Malta _._._.

Norway _......... 320

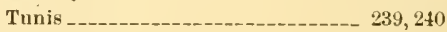

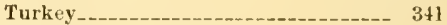

Number of horses, cavalry:

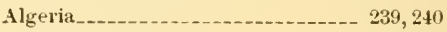

Austria-IIungary _-_-_-__-_-_-_-_ 215

Belgium-_-_-_-_- 225

Brazil _-_-_-_-_-_-_ 314

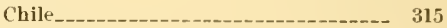

Deumark_-_--_- 229

Dutch East Inclies _..._-_______ 317

Egypt__..._._. 287

France -

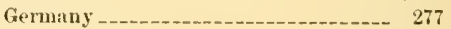

Great Britain _...__________._. 287

India _..... 287

Italy _...

Nlalta_-_-_- 287

Norway _._-_ 320

Russia _ _-_ 327

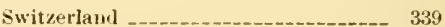

Tunis _....-.

Turkey _._._.

Number of horses, engineers:

Algeria_._._. 240

Belgium____.

France -

Italy _..._-

Tunis - -

Number of horses exported. (see Exports of horses, mules, aud asses.) 
Sumber of horses, gendarmerie:

Belgium

France

Number of horses imported. (See Imports of horses, mules, and asses.)

Number of borses, infantry:

Austria-1Iungary Belginm

Sumber of horses, mobilization. (See Mobilization of horse's.)

Number of horses, monnted infantry:

$\begin{array}{ll}\text { Egyit } & \\ \text { Great Britain } & \\ \text { India_-_. } & 287 \\ \text { Malta } \ldots \ldots & 287 \\ \end{array}$

Number of liorses pmrchased:

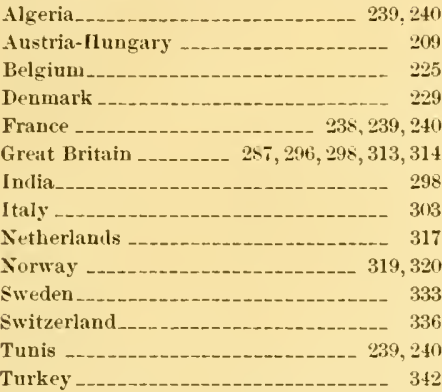

Turkey --_-_-_. 3

Sumber of horses, train. (See Train liorses.)

Number of borses, transport. (Sie Train horsers.) Number of mules: 237

Argentina --.--_-

Bombay _. 99

France _..-_-_-_-_ 237

India

Italy _._.

Northwest provinces and Oudh, India - 248

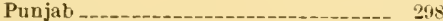

Spain - 331

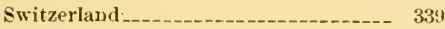

Number of mules, army :

Argentina_ _-________ 313

Chile -_-

Dntch East Indies______________ 317,318

France -... 238, 239, 240

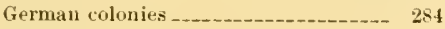

Germany _._.

Great Britain _-_- 296

India_..._............. 298

Italy -

Portugal _..-_-_- 323

Spain -

Number of mnles exported. (See Exprorts of horses, mules, and asses.)

Number of unles purchased, Great Britain_ $290^{\circ}$

Number of pack borses, army. (See Pack animals.)

Number of pure breeds, Argentina 313
Number of stallions. (See Stallions.)

l'age.

Oat ration :

Algeria_-_-_-_-_-_-_ 259, 262

Austria-llungary -....-_-_-_-_-_-_-_-_ 214

Denmark - 230

France _ 259, 262

Germany -..-_-_-_-_-_-_-_-_-_ 275, 278

Great Britain __ 293, 294

I taly _._.

Norway -_-_- 320

Russiar _- 329

Switzerland______ 338

Oatmeal, forage ration, Great Britain__._-_ 294

Oats, kinds of, France - 263

Officers' extra pay for purchase of lorses.

(Siee Allowances for remonnts to othicers.) Ofticers' horses :

Algeria _..._- 249

Austria-Hungary -_-_._-_-_-_212, 213, 214, 215

Belgium _......_. 226

Chile _..._-_______ 315

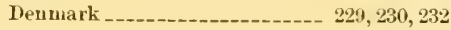

France -_._-_-_._- 237,

$238,239,240,249,252,253,254,255$

Germany -_.....-_-_-_-_-_-_-_..-- 273, 274

Great Britain _..._._._._._._._. 294, 295

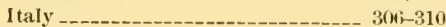

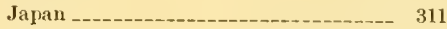

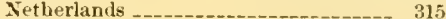

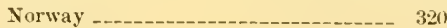

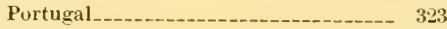

Russia_-_-_-_-_. 329

Spain___ 331

Switzerland__.._-_-_-_-_-_-_-_-_-_ 335, 337

'Tunis

Officers' horses condemned :

France -.--_-

Italy _._.

Officers' horses, forage ration, Germany - 278,279 Officer's' horses, gratuitous:

Austria-1I ungary -.._-_-_-_-_-_ 212, 213, 214

France --

Gernuany -...._-

Great Britain _..........-_.

Russia_-_- 329

Officers' horses, specifications:

Algeria - 249

Anstria-Hungary --_-_-_-_-_-_-_-_-_-_ 211

France -

Italy -

Portugal_-_-_-_-_-_-_-_-_-_-_-_-_-_-_-_ 323

Tunis _- 249

Olienbnrgs importel into Argentina _..._- 313

Oran remonnt branch depot and stud, Al-

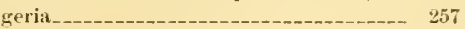

Orlof-Rostopehin breet _ _- 326;

Orlofs imported into Argentina _...____ 313

Oxen, breeding farms, Algeriat _..._._._._ 201

Oxen of Gernan Afriean colonial troopss_-- 284

Pack animals:

Austria-Hungary _._._-___._._. 207, 209, 216

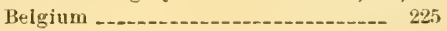


l'ack animuls-Continuerl.

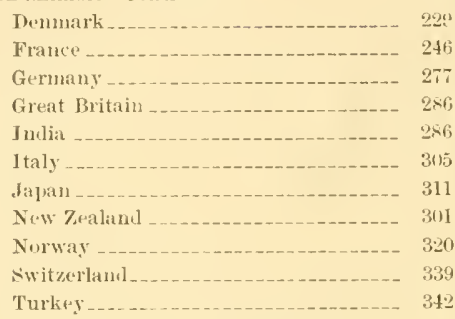

Pack horses. (Gep Park aniuals.)

Pack mules. (Sice Pack aninitlo)

Parana projecterl government stutl, Brazil: 314

Paris remount dejot, France _......... 254, 256

Parwips for forage, France.

Pay of farrier, France-_-_-_______._._. 264

Peare effertive of horses. (Sore Number of horses, army.)

Pease userl as forage, France-

Pidigree statement for jurclaised horses reipuiren :

Algeria

Germaly _-_..-- 273

Perceutage of anuual loss of horses. (Siee

Yearly requirenents of horses.)

Percheron stallious:

Arentina

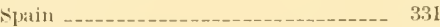

Percherons imported into Argentina _..._- 313

Persimo breerling estitllishment, 1tily _._- 305

Persitu stallions in Jajull ________ 311

Persian type of horees - _...

Personnel of remonnt service:

Frauce -.. _-_ _ 241, 257

Germauy 272,275

l'ilue breeling stahle, Austria _....... 218, 221

Pisek stullion dejot, Alustrit _.__...._._. 218

Poltava lurse dejot, husia _..._....... 32t

l'ony stallions, Julit_ _ 297

l'reniums for horke-raining

Algeria

France

Prenssiach-Mark remount lepet, East Prussil

Price, brool mares:

Algenili _- 23:

Frauco -

Frice, horses:

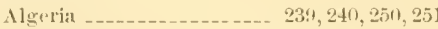

Argentina -..._.

Anstralia__

Austria-I] ungary ..._-_______. 2019, 212, 213

Bolgiuแ -

Cintuli__-_-_- 299

Chile_-_..-_-_- 315

Chin: $22^{-7}$

I

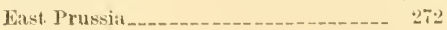

Price, horses-c'ontinued.

Page.

France -. 23a, 239, 240, 250, 251, 256, 26is, 269

Germany _._. 271,252

Great firitain _......

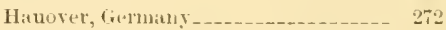

Italy _._._._. 303, 307,30

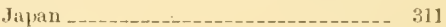

Netheriamls _ 317

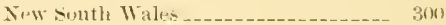

New Zealaul _.... 301

Norway _.__ _ 319,320

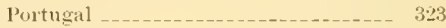

liussia _-

Slatiu _..._-

Sweil

switzerlitul _ 33 -

Tunis _ _ _ 239, 240, 250, 251

West Australi: _.__ 300

Price, Irish bunters, France-_... Price, mules:

Algeria -

France --

Italy _...

Sjain _._-_-__- 331

Price, stallious:

Algeria_-_-_._.
Germany - 230,250
11 ungary

Price, stallions raiserl at breeding establisit-

ments, llungary - _ 220

l'rice, thoroughlired colts, Ilungary_..... 221

private property, soliliers mounts, swither-

lawl_

Private stallious, alprorset, Rumia __.___. 325

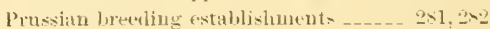

Prisialu remount ilepot

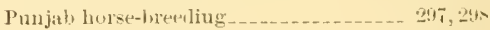

Punjal, ty] of horsen_._._.

Purchise of horses:

Algeriu______ 238, 239, 240, 249. 250, 251

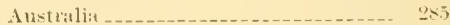

Ansti:i-1lungary _._. - 20i, 20s, 200, 210, 211

Belgium_-___._.

Thile__._. 31 .

Chila: _...

Demulark____ _._. 229, 231, 232. 234, 235

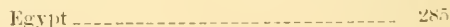

Fratue -

Geruan colonies _.....

Germany ........ 271,272, 273, 276, 2ख․, 254

Great Britain _.....

$2 \times 6,257,294,298,294,313,310$

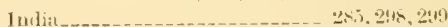

Itilly _._.

.1:1

vexico - $31: 5$

Netherlanl- _...... 317

Norway -...

Purtuial _... 323

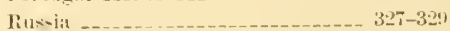

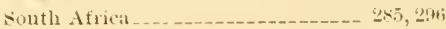


Purchise of horses-Continuer?

$$
\text { siain - }
$$

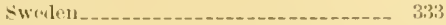
switzerland $33 \pi, 336,337$

Tunis $235,239,240,240,250$

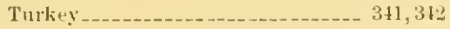

Purchase of horsts from the Government ly olticers, (see ufficers' horses.)

Purbase of horses in the market by ofticers, France

Purchase of horses for East Asiatic experli-

tionary forces, fermany _..._. 277, 275, 254

Purcluase of horses for South Africa _--- 285, 296

Purchase of horses, officers" extra pay for. (See Allowances for remounts to officers.)

Purchase comnissions. (See Remount conmissions.)

Purchasing season, Germany

Quality of borses and mules :

Algeria_-____ 249,250

Argentiua _._.

A ustralia _. 300

A ustria-11ungary _..._-_._._._._- 210, 211

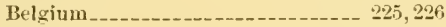

Brazil _... 314

Canada _._.

Chile _.___________ 314,315

China -

Denmark _._._._._. 229, 232, 234, 235

East Prussia _..._......... 272

France -_._._._. 244, 245, 246, 247, 248, 249

Germany _............. $272,273,275,2 \times 2$

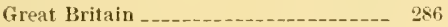

India__

Itaiy _...

Japian _... _. _ _ _ _

Java _-

New Zealanil _......._....... 301

Norway ...____________.. 319, 320

Per'sia . . . _ _. _ _. 321

Prussia_....._.

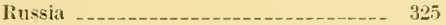

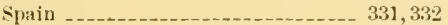

Sumatra _ _

Swerlen_.__________________- 393

Switzerlawl__ 339

Tunis _...

Turkey_.__________ 311,312

Queensland, remounts

Radantz lireeding establishment, Instria_- 221

Ratio of native stock to crossed breeds, . Irgentina

Peceipts and expenditures, gorernment studs, Russia _.____.............. 327

Receifits, remount depots, fiermany._._-- 271

Recruits' payment of horses, Switzerland 335, 337

Refuml of money to soldiers, Switzerland.- 335

Regristers, remount kervice, France _..- 246, 247

Regulations for the stationing-ont of army

borses with private keepers, Denmark _- $2: 33$

Remount annexes:
France.
241,243
Germany sious.)

Remonut conmissions:

Algr.riia__.

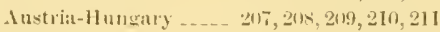

BeIgium_.._._. 226

Chile... 315

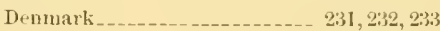

Frutce _..._.

Germany _..._._. _ _ 271, 272,27:3, 274

Great Britain _._.

I udia!'- - -

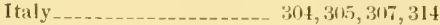

Jараи_..._._._._._._._._. 311

Netberlatuels _._.

Norway _._._._. 310

Portugal _..._.

Russia _- _. - 327-329

Spain _._. 331,332

Sweden _._.

Switzerlaurl _._.

Tunis _._.

Remount companies:

Algeria and Tunis _-_._____ 241, 243, 258

France _._._._._. 241, 243, 258

Remount deprots:

Algeria_______________ 249,257

Austria-11ungary _......_. 209, 210, 211,212

Bavaria _............... 2\%1

Belgium...._.

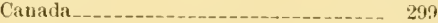

Chile_-_-_..... 315

Denmark_____ 229

Dutch East Indies _...___.____ 317,318

East Prussia__._._._._._. 272, 274, 275

France _._.

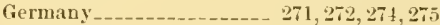

Great Britain_....._._.

Italy _-___.___-_ 304

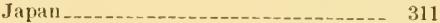

Java _

Netherlands _._.______________ 317

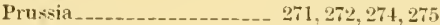

Russia _-.._-_._.

Saxony-_____________ 271

Syain _._.

Switzerland _. 337

Tunis _..._-_._. 249, 257

Turkey__._.

Wurttembere

Remount districts of Frawes..... 241

Remount establishments, ilirector of, Alge-

ria._.

Remount fumal of spabis, Algeria___._-_ 250

liemount markets, fiermitny _-_-_-_- 272,273

lenount jurchasing commision. (Fee Remount commissions, )

liemount service:

Alseria - 249-252

Austria-1lungary _..._.

Belgium_................... 260

Chile

Irentmark _... 
Remonnt service-Continued.

Dutch East Inılies.

France

241-248

German colonies _................... 284

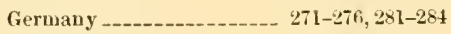

Great Britain_-_-_-_-_-___. 28,5-287,314

India _-_____________ 296, 298, 299

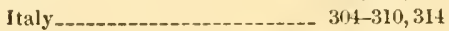

Japan__.___._._._. 311

Netherlands _._._._-_._- 317

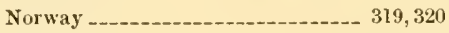

Portugal _..--_-_-_-_-_-_-_-_-_-_-_-_-_ 323

Russia _-_-_- 327-329

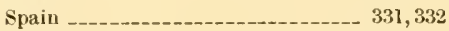

Sweden_-_- 333

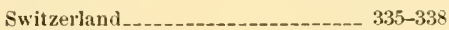

Tunis _.

Turkey_-_-_-_-_-_-_-_-_-_-_-_-_ 341,342

Renount service, inspectors general and itspectors. (See Inspectors general and inspectors of remount service.)

Remount service, personuel. (See Personnel of remount service.)

Remount service, funds. (See Funds, remount service.)

Remount stations. (See Remonnt depots.)

Remount training schools. (See Training schools for horses.)

Rental of private horses by troops, Switzer-

land

Requisition. (Sie Mobilization of borses.)

Reserve officers' horses, France__-_-_-_-_--- 252

Riding exercises at Holics bunts, Austria-

II ungary _...___._._. 220, 222, 223

Riding-halt horses, France _................. 256

Riding-school horses, Denmark-_-_-_----- 229

Riding sclrools :

Austria-Hungary -_.

Denmark

France -

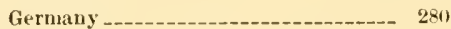

Rice as forage, China _._._-_._-_._-_-_-_ 227

Rio Grande do Sul, projected government stud, Brazil.

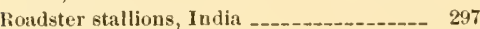

Russian mares, Turkey.-_-______._._. 341

Russian stallions, Turkey _-______._._._- 341

Rye, forage ration, France _..._-_._-_-_-_-_ 262

Rzeszow remount purcbasiug commission,

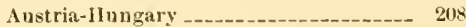

St. Cyr, riding-school horses, Fratice _-____- 256

Sale of government horses:

Austria-Llungary

France - 246, 247

Germany _-_-_-_-_-_-_-_-_-_-_-_-_-_ 273, 277

Italy _..._._._.

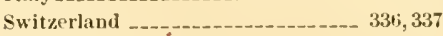

Sale of horses condeintiel:

France

246,247

Germany _....... 273, 277

Italy _...__ 307

Switzerland _ 337
Page.

Saumur, farriers' school, France -......... 264

Saumur, training school for horses, France_ 242 Saumur war-school horses, France, 242, 254, 256 Saxony, breeding establishments _._-_...-. 283

Saxony, remonnt deprots_._-_._-_._._._. 27 Sepsi-Szent-György, stallion depot, Hungary,

218,221

Serum :

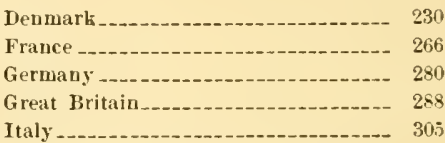

Service of horses, length of. (See Length of service of horses.)

Setif, remount branch depot and stud, Algeria

Sex of army horses:

Algeria__-_._- 246,249

France -..._- 214, 219

Germany--:- 273

Great Britain

Italy -

Norway _._._._._. 319

Russia - 328

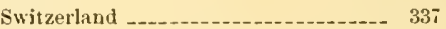

Tunis _._-

Shires, imported into Argentina _..._._._. 313

Shoeing:

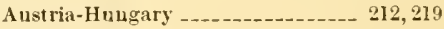

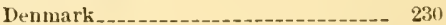

France -

Germany -_-_-_-_-_._-_-_-_-_ 275, 279,2 240

Great Britain _-_._-_-_.... 288-293, 295, 296

Italy _..._. $305,30 y$

Norway _..._-_._- 320

Switzerlaw1___- 338

Shoeing inspection, Great Britain _-_-_-_-- 289

shoeing instruction for soldiers, Great

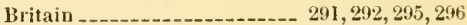

shoeing school. (See Farriers'school.)

Silladar regiments, India -............-- 28.5

Siud, India, horse breeling-_._-__._._- 297

Size of horses and mules:

Algeria-_-_-_-_-_-_-_-_-_-_-_-_-_._-_ 249

A ust rit-lJungary -.........-_- $208,209,216$

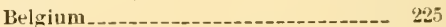

Brazil _._......_-_._. 314

Clinit -

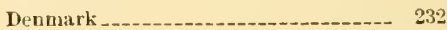

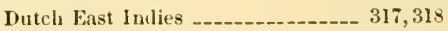

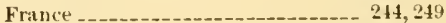

Germany -

Great Britain -_-_-_-_- 286

Indiit-_-_- 298

Italy _-___

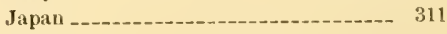

Java _- 317

Janchuriat -

Mongolia _-_._-_._-_ 227

Netberlauds _._._. 
Size of borses amd nutes-Continued Page.

Norway - -

Portugal - -

Russia - 328

Spain -._- 332

Sweden _-_- 333

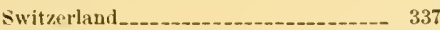

Tunis _...-.-.--_-

Skassa, remount depot, Saxony _..._._._- 271

South Australia, remounts _._._._._._. 300

Spahis, horses, Algeria _...-.--_-_-_-_- 250

Spahis, remount funds, Algeria

Spanish horses, Austria-Hungary _-_.--_-_ 221

Spauisu mules purchased by Great Britain_ 296 Specifications:

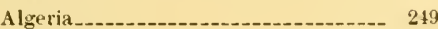

Austria-Hungary -..--...-...... 208, 209, 216

Belgium__............ 225

Dennark-_-_-_--_-_-_-_-_-_-_-_-_-_ 229, 232

Dutch East Indies_-_-_-_-_-_-_-_-_- 317,318

Frauce --_-_- 243, 244, 249

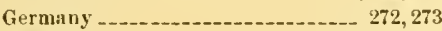

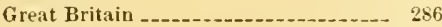

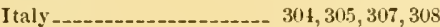

Netherlands _._._._._._._._._._. 317

Portugal -.---_-_-_-_- 323

Russia -

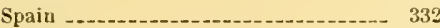

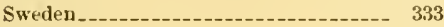

Switzerland_........ 336, 337

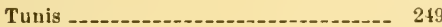

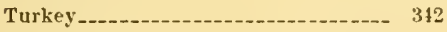

Specificalions, officers' borses. (See Officers'

horses, specifications.)

Stadl, stallion depot, Austria_-_-_-_._-_-_- 218

Stallion depots, stallion stations, etc.:

Algeria_-_-_-_-_-_._-_ 257, 259

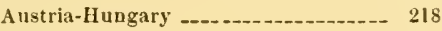

Bavaria -

Denmalk

France - -

Germany _..._-_._-_._-_._. 271, 281, 282, 283

Hungary _._._.

India____

Italy _._.

Prussia_._-_._._-_._-_._-_ 281, 282

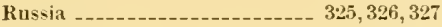

Spain -..._- 331

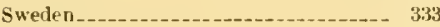

Switzerlaud__..........._._._._._._. 338

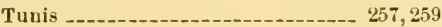

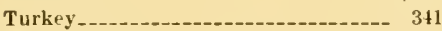

Wurttemberg_-_-_-_-_-_-_-_---_-_-- 283

Stallion fees. (See Covering fees.)

Stallion statious. (See Stallion depots, stal-

lion stations, etc.)

Stallions:

Algeria $257,259,260$

Argentina --- 313

Austria-Hnngary .............. 20i, 220, 221

Bavaria _._-_........... 283
Stalliens-Continued.

Page.

Belgium _._. 225

Chile-_- 315

Denmark

East Prussia .........

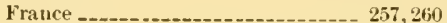

Germany --_-_._-...-_-_._-_-_271, 281, 282, 283

Great Britain _-_-_-_-_-_-_-_-_-_-_-_-- 297

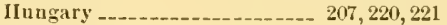

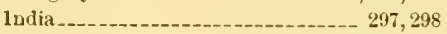

Italy _._-_-_._- 305, 306

Japau _._-_._. 311

New Zealand _._._._._. 301

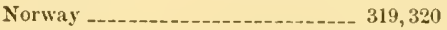

Prussia

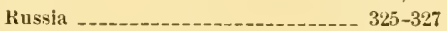

Spain -..-- 331

Sweden____- 333

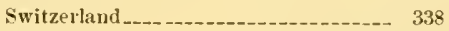

Tunis - - -

Turkey-_. 341

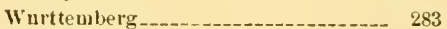

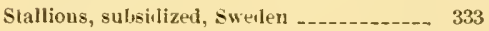

Stallions, various breels:

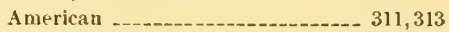

A nglo-11 ispano-A rab _._-_-_-_-_-_._. 331

Anglo-Norman _..._.......... 313,315, 331

Arab -

$260,261,282,297,306,313,326,331,341$

A rab-Barbary -.-_-_-_-_-_-_ 259, 260, 261

Australian _-_._-_._-_._-_ 297

Barbary--_-_-_-_-_-_-_-_-_--- 259, 260, 261

Bralant -.- 306

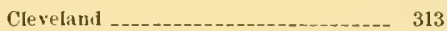

Clydesdales _-_._- 306,313

East-Prussian _........-_...- 282

Euglisu $260,282,297,306,313,325,326,331,333$

French__._. 311

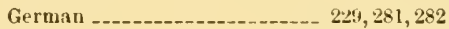

Gidran _-_---_-_-_-_-_-_-_-_-_-_._- 220

Hackney _-_-_-_-_-_-_-_._ 297, 301,306, 319

Hungarian --_-_-_-_-_-_-_ 220, 221,311,341

Hunters - - -

Nonin - 220

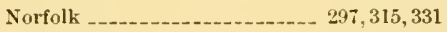

Norwegian _-_._- - 319

Oldenburg-- 313

Orlof _._.

Perclieron --_-_-_-_-_-_-_-_-_ 313,331

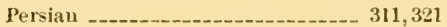

Pony-_-_-_-_-_-_-_-_-_-_-_-_-_-- 297,301

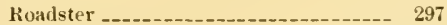

liussian _........._. 325-327, 341

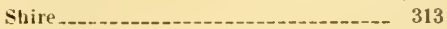

Suffolk Puncli _._-_._- 313

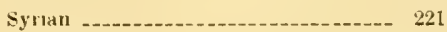

Trutonic - -

Trakehnen -...-_- 282,313

Trotter.--_-_-_-_-_-_-_-_-_-_-_-_-_ 301

Turkish _._._._-_. 219 
Page.

Stamlieste, Norway

Stationing-out of horses with private

keepers. (See Civilians' use of army Lorses.)

Statistics of exports of horses. (Nee Exports of horses, unles, ant asses.)

Statistics of horses. (Sice Number of horses.) Statistics of purchase. (See Number of horses purchiased.)

Stepue horses, Riussia

Storehouses, forage, Austria-Hungary--_Straw ration:

Algeria_._.

Austria-Hungary -_-_-_-_-_-_-_._-_. 214

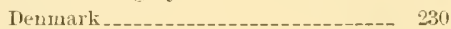

France _-_-_-_-_-_._._-_-_-_-_-_ 262, 263

Grrman colonies .............. 284

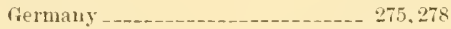

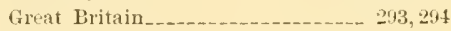

1tily -

Norway _._. 320

Persia_-_-_._-_-_-_-_-_-_-_-_-_-_-_-_-- 321

Riussia -

Switzerland _-__- 338

streletz sturl, liussia _-____._._.

Stullbook:

A]geria_......_-_- 259

Canada_- . . -

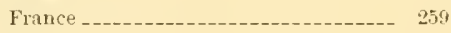

Sl:tin _... 331 Stuls :

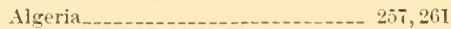

Austria-lfungaly _.___-______-_ 217,218

Bavitria -_-_-_._. 283

Brazil _-_-_-_-_-_-_-_ 314

I)

France _._._._._._._. 256, 257

German colonies _-_._-___-_______- 284

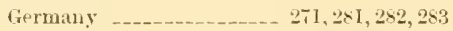

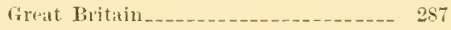

II ungary _..._. 218,219

India _._.

Italy ___ 305,314

Japan _-_ $31 \mathrm{I}$

Mexico___

Persia______ 321

Prussia - .

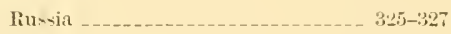

Saxony - $2 \times 3$

Spxin _... 33I

Sweqlen - _.

switzerlaul _-___ 338

Tuuis _._._. 257

Turkey-_-_-_-_-_- 341

Wurttemlx

stuhlweissenhurg stallion leput, llumgary- 218 sulaltern offices's horses:

Austria-IIungiry ____._._._._. 212

France - .

Italy ___ _ $30 \times, 349$ Sulsillizerl stallions, Swerlen_.._...___. 333 Suffolk P'unch stallions, Argentinat_____._. 313
Pace.

Suippes depot for young horses ---- 242, 245, 259

Suipes remount amex, France ------ 242, 254

Sumatra horses ___________________ 31 .

Superior mustering board, Lentuark --.-- 232

supply of horses.

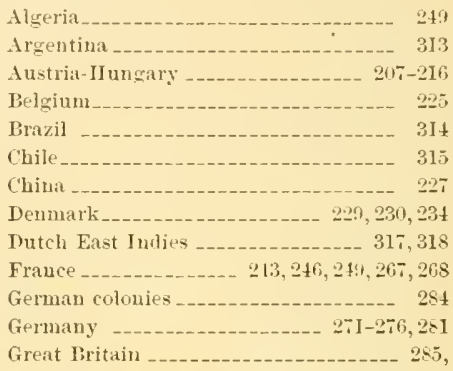

$286,287,298,299,300,301$

India _................. 298, 299

Italy - -

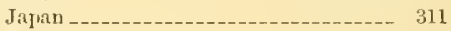

Mexico _-..- 315

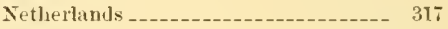

Norway - -

Persia -

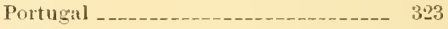

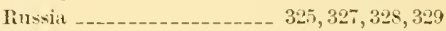

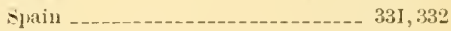

Sweden - 333

Switzerland --_-_--_--_ 335, 336, 337, 339

Tunis _-_-_-_. 219

Turkey -._-_-_-_-_-_-_-_-_- 341,342

Supply of motrilization hores. (Nee Mobili-

zation of horses.)

supily of mules:

Algeriil-_-_- 249

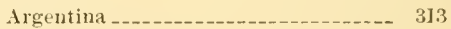

Austria-II ungary _..._......... $\quad 209$

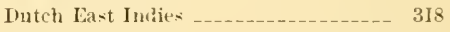

Frauce -

German colonies -

Julii _-

Spain _-_

Switzerlatul -

Tunis _._. _.

Syrian-Arah type of horses, Britisla folonies- 2-2.5

Syrian stallions and mares, Austria-Ilum-

gary _- _21

Szegenlin remount purchitsing commission,

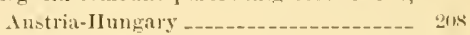

Tithle of army remomits, france__._._ 239, 240

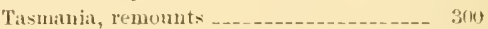

Tetanus, Frauce --

Tentonic lieed of lorses, firmuny____ 2az

Thoroughbrels for oflicers, Franci-_.. 241, 255

Theroughbrels jurchiased, Italy_-____- 314

Thun horse régie, Switzerbul________ 335

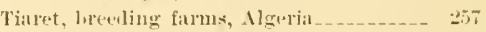

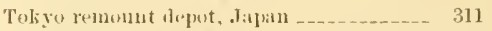

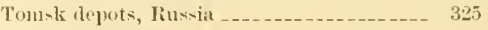

Twols for horwerhoring, freat Britain _- 291,293 
Train hores and mules:

Algeriat

Austria-Hungary

Belgiun

Denmark

Egypt

France

Germany

Great Britain

Iulia

Italy

Jарав

Malta

Tunis

Turkey

Training of farriers:

Denmark

France 213,264

Great Britain

Training of horses:

Austria-Ilungary

220, 222,223

Denmark

230

France

$-241,242$

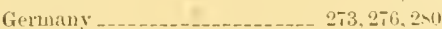

Great Britail _...___._. 287

Italy _._._._.

Norway -_-_-_-_-_- 390

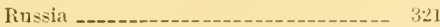

Switzerland ---------------- 337, 33:, 339

Training schools for horses:

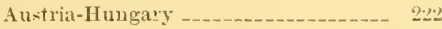

France --

Norway - _-_._. 320

Jussia --_-_-_-

Trakehnen breeding stable, Prussia_-_- 281, 2\$2

Trakehuen borses, Germany-_-_-_-_-_-_-. 282

Trakehnen horses imported into Argentiua 313

Transport horses. (see Train horses.)

Treatment of horses:

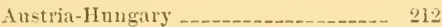

Denmark -

France - ......... 2615

Germany -

Great Brititin

Italy _._. 305

Norway -

Prnssia - 2n?

Troop horses usel at schools, France-____ 2251;

Trotter stallions _-_-_-_-_-_-_-_-_-_-_-_-_- 301

Tunis remount depot aurl stmil _._._._._. 257

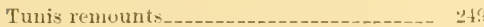

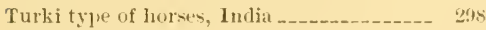

Turkish stallions and mares imported into

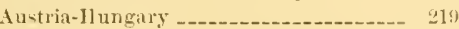

Lnited states horses exportetl_..__._._. 26s, $27 \pi, 278,244,296,315,315$

Lumerviceable horses:

Anstria-Hungary _......_._._... 211, 215, 216

Denmark _... 231, 23t

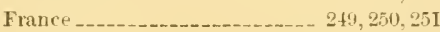

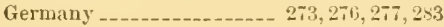

Inservicuable lorses-Contmued.

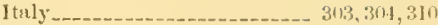

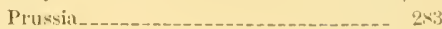

lusvia _ _

Switzerlaml

Vacciuation:

Austria-IInngary _...___._.

benmark-_-_-231

France _-__a $26 \mathrm{iti}$

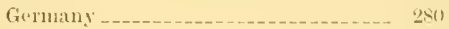

Great IBritain $28,20 \mathrm{~s}$

Italy _.___ 305

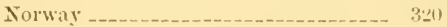

Vaccine. (See serum.)

Vaccinc institute at Aldershot, Great Brit-

ain _..._.

Viluation boards for mobilized horses:

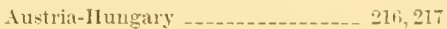

Denmark _......._-_._-_._- 231

Germany _.......

Versaille: artillery school horses, France _- 2iti

Teterinary medical report of the Prusian army

Veteriuary service:

Germany -

Great Britain__.____ 248, 289, 290, 295, 296

Prussia_-_.-- 283

Veterinary school, freat Britain_-_._-_-_- 291

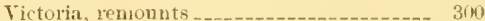

Virus. (See Varcination.)

War effective of horses. (See Mobilization of borses.)

Water ration:

Algeria__..._- 262

France $20 \%$

Weight of horses:

Trumark -.._- 229

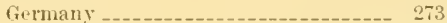

Great Britain _... 286

Italy _-

West 1 longolian horses._......... $2: 27$

Wheat its forage, France

Wild hures:

Argentina -

Pusiat_-_. 395

Winter shoeing, Grat Britin _._..._. 292

Woolwich remount depot, Great Britain_-_ 287

Winttrubery breeding estahli-hment:_..._. $2 \times 3$

Wurtteuberg remount depot _._-_-_-_-_ 27], 272

Wurttemberg stallion depots and stallion

stations - - -

Yearly requirements of Lorses:

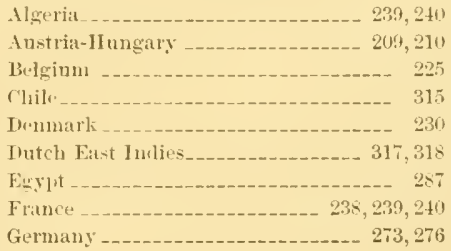


Yearly requirements of horses-Continued.

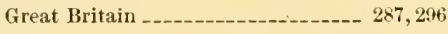

India

Italy -

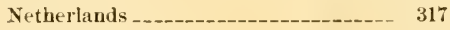

Norway _-_._-_-_ 319, 320

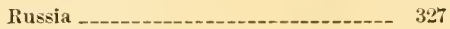

South Africau camyaign ..............-. 296
Yearly requirements of horses-Continued. Page. Sprain -

Sweden____. 333

Switzerland_-_-_-_-_-_-_-_-_-_-_._. 336, 338

Tuuis _...-...- 239, 240

Turkey -..-_-_.-- 342

Yelizavetgrad horse depot, Russia_-_-_-_-- 326

Yesso horses, Japan_...---_-_-.-_-_-_-_-_ 311 







Webster Family Library of Veterinary Medicine Cummings Schcol of Veterinary Medicine at Tufts University 200 Westooro Rnad Marh Grafion in n+5?-3 



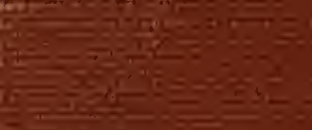

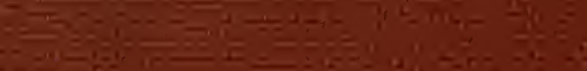

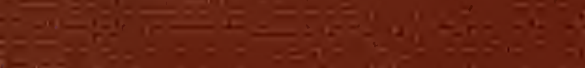

\section{$\underset{10}{-1}$}

$=-\frac{12}{20}$

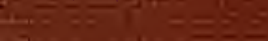

$5=\frac{1}{3}=$

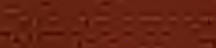

$=2 \frac{0}{20}=0$.

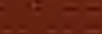

